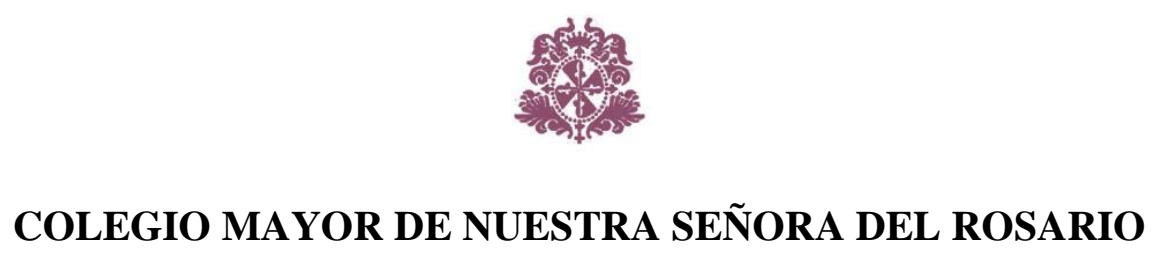

\author{
FACULTAD DE JURISPRUDENCIA \\ DOCTORADO EN DERECHO
}

\title{
LA RESPONSABILIDAD CIVIL MÉDICA FRENTE AL INCUMPLIMIENTO DEL CONSENTIMIENTO INFORMADO
}

\author{
Daniela Navarro Reyes
}

\section{Bogotá D.C.}

Mayo de 2019 


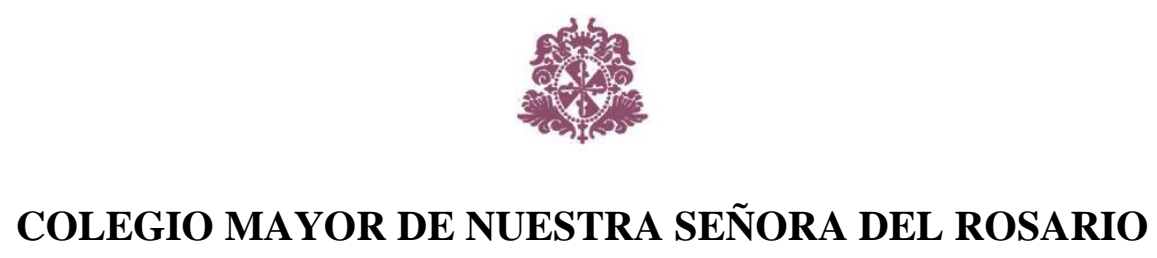

FACULTAD DE JURISPRUDENCIA DOCTORADO EN DERECHO

Tesis para optar al grado de doctora en derecho

\title{
LA RESPONSABILIDAD CIVIL MÉDICA FRENTE AL INCUMPLIMIENTO DEL CONSENTIMIENTO INFORMADO
}

\author{
Estudiante \\ Daniela Navarro Reyes
}

Director de tesis

Doctor Francisco Ternera Barrios

Bogotá D.C.

Mayo de 2019 
A Dios por ser mi luz y guía.

A mi padre por ser mi maestro.

A mi madre por su oración y voz de aliento.

A mi amado esposo por su amor y apoyo sin límites. 
"La experiencia es engañosa, la vida es breve, largo el arte de curar, fugitiva la ocasión y difícil el juicio” (Hipócrates). 


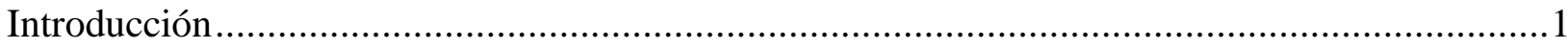

Capítulo I. El consentimiento informado como derecho humano, principio y deber ético-legal....7

1 Antecedentes trascendentales de la relación médico paciente en torno al manejo de la información y la toma del consentimiento ................................................................

1.1 Generalidades de la relación médico-paciente en la Grecia clásica .............................7

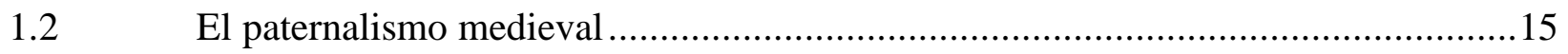

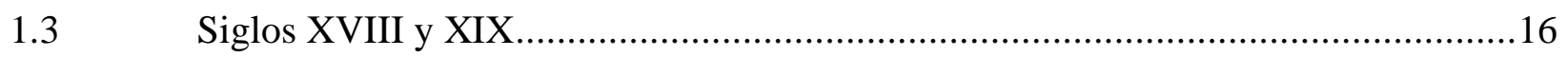

1.4 Siglo XX: de la oscuridad a la luz en la relación médico-paciente ............................19

1.4.1 La jurisprudencia norteamericana y sus contribuciones al reconocimiento del consentimiento informado en las relaciones sanitarias .............................................20

1.4.1.1 Caso Schloendorff vs. Society of New York Hospital - 1914 .................................22

1.4.1.2 Caso Salgo vs. Leland Stanford Jr. University Board of Trustees- 1957: el nacimiento de la doctrina del consentimiento informado .........................................................24

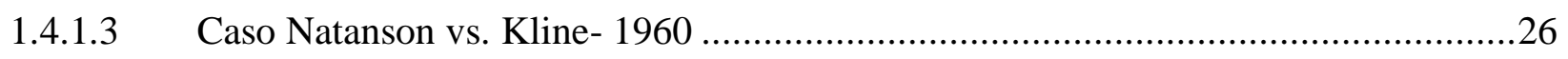

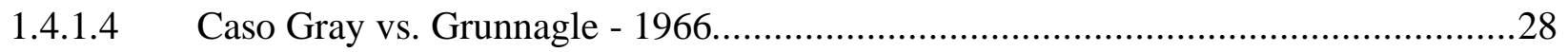

1.4.1.5 Caso Canterbury vs. Spence and Washington Hospital Center - 1972 _.....................29

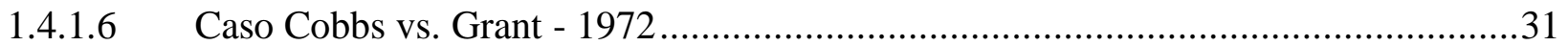

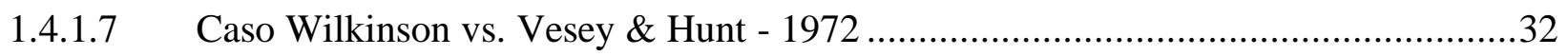

1.4.2 El auge del consentimiento informado desde la perspectiva ética y legal de alcance internacional ...........................................................................................

2 Marco ético-legal del consentimiento en Colombia ............................................42

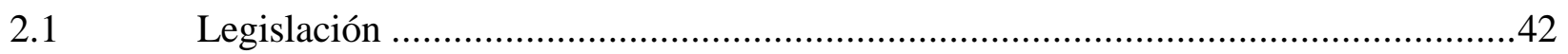

2.2 Resoluciones del Ministerio de Salud y Protección Social .......................................45

3 El consentimiento informado: perspectiva constitucional colombiana .....................49

$4 \quad$ Importancia del consentimiento informado en la praxis médica ................................54

5 El consentimiento informado en la globalización de la salud: del papel a la práctica

Capítulo II. Aspectos relevantes del consentimiento informado ...............................................67

1 El consentimiento y la información desde la teoría general de los contratos..............67

1.1 El consentimiento: elemento de la existencia del negocio jurídico ............................67

1.2 El deber de información precontractual: manifestación de la buena fe ......................69

2 El consentimiento informado en la relación médico-paciente ...................................74 


\section{Tabla de contenido continuación}

2.1 La relación médico-paciente como relación jurídica .........................................74

2.2 Modalidades de la relación jurídica médico-paciente.........................................77

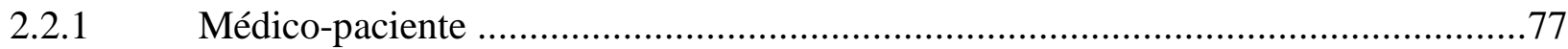

2.2.2 Médico - clínica o establecimiento privado - paciente .......................................80

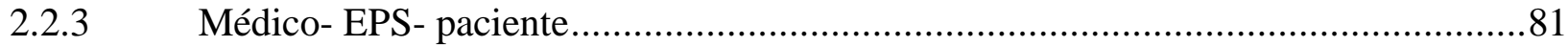

2.2.4 Médico - plan voluntario de salud - paciente ….........................................82

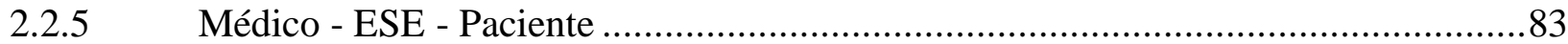

2.2.6 Médico - paciente - orden judicial o ley..........................................................85

2.3 El consentimiento para el contrato médico y el consentimiento al acto médico........86

2.3.1 Consentimiento contractual en el ámbito médico.............................................86

2.3.2 Consentimiento informado: legitimación del acto médico ..................................88

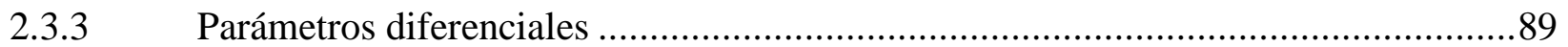

2.3.3.1 Ejercicio de derechos fundamentales ........................................................... 89

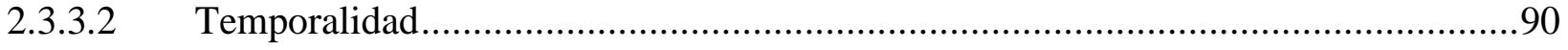

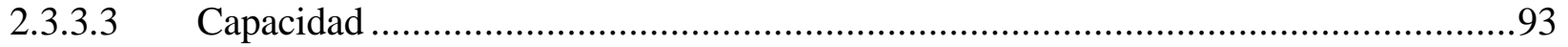

2.3.3.3.1 Cuestiones prácticas en torno a la capacidad para consentir ...............................98

2.3.3.3.1.1 Incapaces en razón de la edad..............................................................................98

2.3.3.3.1.2 Personas con discapacidad mental - esterilizaciones definitivas............................ 101

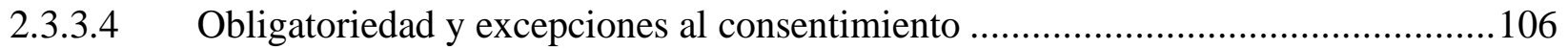

2.3.3.5 Fundamento y justificación de la obligación de información ...............................107

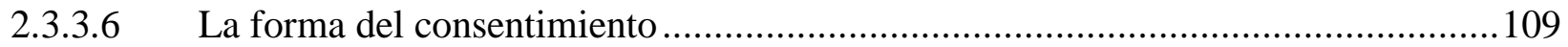

2.3.3.7 Reclamaciones frente al incumplimiento del consentimiento informado................111

3 Contenido del consentimiento informado .................................................. 113

3.1 Información para el consentimiento informado............................................113

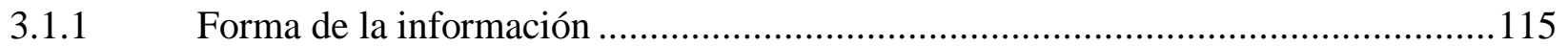

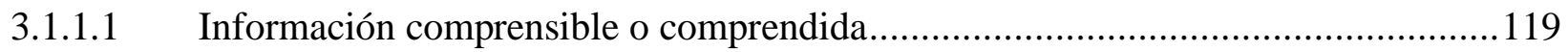

3.1.1.2 Contenido de la información: información adecuada .......................................122

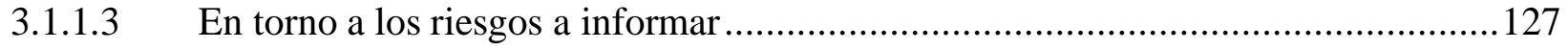

3.1.1.3.1 Diversidad de terminológica y de criterios ................................................ 128

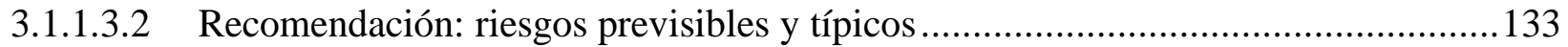

3.1.1.3.3 Información en medicina curativa o de voluntaria o satisfactiva ..........................139

3.1.1.3.4 Necesidad o privilegio terapéutico ............................................................ 140 


\section{Tabla de contenido continuación}

3.1.1.4 Deber de consejo .142

Capítulo III. De la responsabilidad civil por incumplimiento del consentimiento informado del paciente

1 Del enfoque patrimonialista al personalista de la responsabilidad civil 145

2 De la función reparadora de la responsabilidad civil. 150

3 Presupuestos de la responsabilidad médica por incumplimiento total o parcial del consentimiento informado del paciente 154

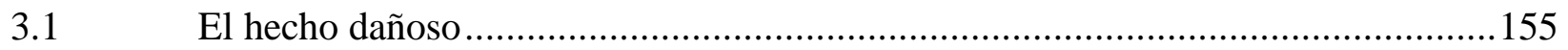

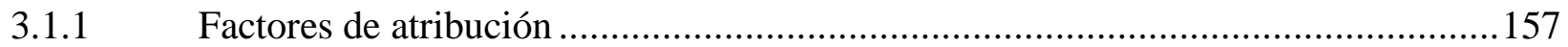

3.1.1.1 El consentimiento informado: entre obligación de medio y de resultado................161

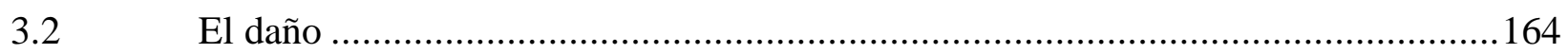

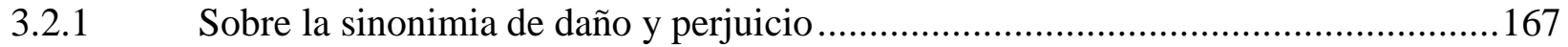

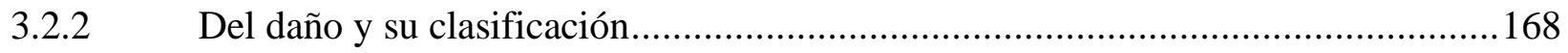

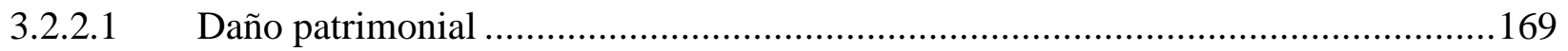

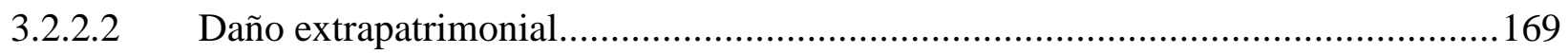

3.2.3 Análisis del daño al consentimiento informado con independencia de la corrección técnica del acto médico ........................................................................... 175

3.2.3.1 El consentimiento informado como daño moral autónomo .................................177

3.2.3.2 Las fronteras del daño moral por incumplimiento del consentimiento informado...188

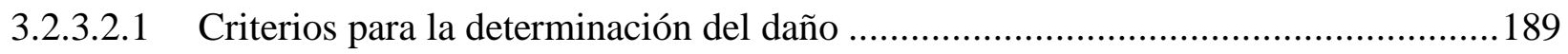

3.2.3.2.1.1 Actuación médica correcta, información defectuosa y materialización de un riesgo previsible.

3.2.3.2.1.2 Actuación médica correcta, defectuosa información y no se materializan riesgos ...190

3.2.3.2.1.3 Actuación médica correcta, información defectuosa de tratamientos alternativos y materialización de un riesgo previsible e informado

191

3.2.3.2.1.4 Actuación médicamente correcta y ausencia total del consentimiento informado...192

3.2.3.2.1.5 Mala praxis médica y ausencia total del consentimiento informado..................... 192

3.2.3.3 Función reparadora del daño moral por incumplimiento del consentimiento informado .193

3.2.3.4 El daño moral por incumplimiento del consentimiento informado no suprime los

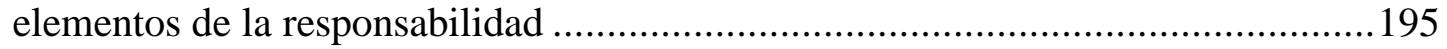

3.2.3.5 Otras posturas sobre el daño por incumplimiento del consentimiento informado ...195

3.2.3.5.1 Asunción de los riesgos y atribución del daño final ......................................... 196 
Tabla de contenido continuación

3.2.3.5.2 Conducta alternativa conforme a derecho/consentimiento hipotético: moderación de la

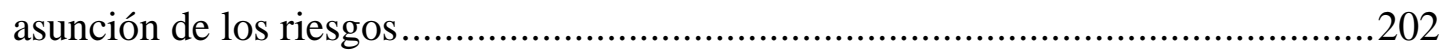

3.2.3.5.3 Daño por pérdida de la oportunidad..............................................................207

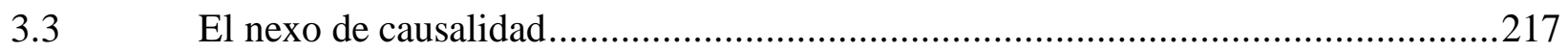

4 Valoración del daño moral por incumplimiento del consentimiento informado......220

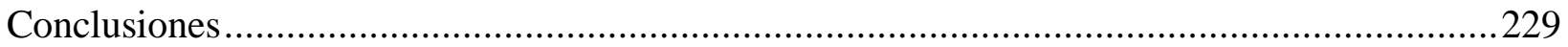

Referencias 


\section{Introducción}

La historia enseña que no siempre han existido las obligaciones de información y de obtener el consentimiento del paciente frente a un acto médico de forma que habilite el proceder de los profesionales de la salud, tal y como es obligatorio hoy, en virtud del reconocimiento de los derechos de los pacientes a la autonomía, la libertad, la dignidad, la integridad y el consentimiento informado.

La evolución de una medicina paternalista a una relación médico-paciente de carácter horizontal, dio paso a considerar al paciente como un ser autónomo capaz de tomar decisiones sobre el rumbo de su vida. Tal aseveración, implica en el profesional de la medicina la obligación de garantizar el consentimiento informado del paciente, lo que permitirá, igualmente, otorgarle legitimidad a su proceder médico.

El derecho progresa, a veces lo hace cautelosamente, en otros momentos a pasos colosales, por la evolución y el cambio de la sociedad. Por ello, no puede permanecer indeleble, ya que sobre él “...influyen poderosamente los más variados factores sociales, culturales y políticos y cada época imprime carácter propio" (Monsalve, 2008, p. 13). En esencia, el derecho debe responder a las nuevas situaciones para establecer un ambiente de seguridad jurídica.

Tiempo atrás hablar de responsabilidad por lesión de derechos de la personalidad era algo impensable jurídicamente. Sin embargo, el derecho ha evolucionado al punto de pasar de un enfoque netamente patrimonialista a otro personalista, en donde se protegen los intereses de la persona desde su dimensión corporal y espiritual. En la esfera de la protección jurídica de los derechos de la personalidad desde la responsabilidad civil, es notable el activismo judicial ${ }^{1}$ con el propósito de proteger a la persona y darle el valor que merece.

\footnotetext{
1 “El activismo judicial -entendido en el sentido de que los tribunales mantienen el poder legislativo y ejecutivo dentro del límite de la constitucionalidad- es esencial para la protección de las libertades individuales y la vigencia efectiva del Estado de Derecho" (Bolick, 2007).
} 
La responsabilidad por incumplimiento del consentimiento informado es una de las temáticas más controvertida en la doctrina y en la praxis judicial. El paciente ha abandonado la habitual actitud de resignación frente a errores e imprudencias médicas, puesto que el valor del ser humano y el respeto hacia sus garantías máximas, no admiten que un evento dañoso, en términos generales, propiciado por alguien no desencadene la obligación de reparar (Galán, 2016, p. 30).

No obstante, al ser el consentimiento informado una obligación, aún existe en muchos galenos la idea de que con brindar información al paciente y obtener el consentimiento se está cumpliendo con un requisito formal más del acto clínico (Monsalve y Navarro, 2014, p. 3), lo que se convierte en un problema jurídico cuando el usuario reclama la intromisión ilegítima en su cuerpo por no haber sido suficientemente ilustrado o ante la omisión total del consentimiento.

Determinar el daño a reparar por incumplimiento del consentimiento informado del paciente ha dado lugar a una disparidad de criterios, unos más vanguardistas que otros, tanto a nivel doctrinal como jurisprudencial, en aras de dar una solución. No se puede hasta la fecha catalogar uno de ellos como de aceptación mayoritaria, lo cual ha desencadenado inseguridad jurídica al no saber la tesis acertada a la hora de invocar respuesta judicial.

Así mismo, la identificación del daño al provenir de la lesión de un derecho, deja abierto el debate para diferentes observaciones relacionadas sobre qué se debe reparar, su alcance y si son necesarias manifestaciones de la infracción para proceder a su reconocimiento indemnizatorio.

En igual medida, al ser el incumplimiento del consentimiento informado una omisión/abstención de una obligación, complica el tratamiento del nexo de causalidad. La incertidumbre causal en torno cuál hubiese sido la decisión del paciente de haber conocido previamente la información omitida o si hubiese podido evitar la intervención en donde se materializó un riesgo, son de las cuestiones que no han permitido un equilibrio teórico-dogmático.

De esta forma, en las diversas providencias de las Altas Cortes colombianas se avizoran planteamientos que acogen una construcción teórica en un determinado momento, y luego, en un caso de similares características, se mueven hacia un diferente juicio de reproche. 
La infracción al consentimiento informado es un tema sensible y controversial por los derechos de la personalidad que cobija. Por tanto, el estudio de la responsabilidad amerita especial cuidado para no desviar la función reparadora de la responsabilidad civil, a una sancionadora/punitivapreventiva justificada en la protección de la persona.

También, no son admisibles indemnizaciones desmesuradas que desborden el principio de reparación integral y conlleven a un enriquecimiento injusto, concedidas con la excusa de salvaguardar por encima de todo los derechos de la personalidad. Ello, podría desencadenar en una medicina defensiva no humanizada y encarecer su costo ante el temor de los profesionales de la salud de ser condenados por este concepto, lo que los llevaría a optar por sistemas aseguradores, valores que al final de cuentas vendrían a asumir los pacientes.

En vista de la problemática palmaria y clara en torno al incumplimiento del consentimiento informado y la responsabilidad médica, este trabajo tiene como objetivo identificar y analizar el daño indemnizable del paciente frente al incumplimiento del médico de las obligaciones relacionadas con el consentimiento informado -con independencia de la corrección de la praxis médica-, ya sea que se concreten o no los riesgos previsibles que no fueron informados previamente.

En este sentido, la investigación se justifica al estar la inseguridad jurídica en su máxima expresión, ante los diversos planteamientos argumentativos que se han generado para explicar la responsabilidad por incumplimiento del consentimiento informado en la relación médico-paciente, en específico lo concerniente a los presupuestos daño y nexo causal. Lo cual, afecta no solo a los ciudadanos al acudir a la administración de justicia encontrándose con decisiones disímiles, sino también a la comunidad jurídica al no contar con una línea de argumentación que permita formular las pretensiones o las premisas de defensa con base en ella, ante la llamada igualdad de solución ante supuestos equivalentes.

La investigación constituye un debate vigente, de ahí su necesidad y pertinencia desde la urgencia del derecho de avanzar en este campo del conocimiento y sentar posiciones que den seguridad argumentativa al sistema jurídico. 
Más allá de presentar una exposición teórica-descriptiva, se pretende formular una postura crítica-reflexiva y estratégica sobre el daño a reparar, que vaya acorde con los parámetros de protección a la persona, pero que no desborde los lineamientos de la responsabilidad, su finalidad ni desconozca sus presupuestos -hecho, daño y nexo causal-.

Sin tener la pretensión de hacer una investigación histórica ${ }^{2}$, el capítulo I denominado «antecedentes trascendentales de la relación médico paciente en torno al manejo de la información y la toma del consentimiento», se orienta a conectar al lector, a través del tiempo, de aquellos acontecimientos relevantes que dan cuenta del cambio conceptual en torno a la toma de decisiones en la relación médico-paciente. De manera que, le permitirá al lector acceder brevemente a un conocimiento "no de la historia del consentimiento informado sino del manejo de la información médica" (Faden \& Beauchamp, 1986, p. 60).

Lo anterior, resulta esencial en esta investigación para proyectar la importancia que ha adquirido el consentimiento informado en la época actual, destacando su incipiente aplicabilidad en el sistema de salud inmerso en un mundo globalizado, que ha conllevado a que sea el epicentro de muchas demandas de responsabilidad médica.

Para tal propósito, se abordará la doctrina del consentimiento informado a partir de su origen y conceptualización, temática tratada en sentencias norteamericanas que se convirtieron en hito, con el fin de examinar el discurso y la manera cómo se insertaron los postulados típicos de la responsabilidad civil a este nuevo paradigma.

Seguidamente, se estudiará el consentimiento informado desde su perspectiva ético-legal, tanto en el plano internacional como nacional, para poner de presente que el consentimiento informado más que un formalismo de la praxis médica, juega diversos papeles en el ámbito sanitario al ser principio autónomo, derecho y obligación.

\footnotetext{
${ }^{2}$ No se hará una exposición histórica exhaustiva y detallada dado que desbordaría el objetivo de la presente investigación jurídica, además, existen investigaciones históricas de gran reconocimiento y amplitud que han plasmado todo el recorrido de la transformación de las relaciones sanitarias como por ejemplo Gracia (2008), Katz (2002), Simón (2000), Faden \& Beauchamp (1986), Laín (1964).
} 
En el capítulo II intitulado «aspectos relevantes del consentimiento informado», se estudiarán aquellas materias trascendentales del consentimiento informado que se consideran pautas necesarias a dilucidar y esclarecer antes de examinar lo relativo a la responsabilidad médica por incumplimiento de esta obligación, las cuales contribuyen a construir una argumentación razonable para apalancar las pretensiones de la parte demandante ora las excepciones de mérito de la demandada e incluso para el funcionario judicial sustentar su sentencia.

En un primer momento, en el acápite se tratará el consentimiento y la información desde la teoría general de los contratos para dar cuenta de su importancia y fundamento, para luego descender al terreno de la relación médico-paciente, de modo que permitirá diferenciar el consentimiento contractual del consentimiento que legitima un acto médico, y evitar imprecisiones que afecten la viabilidad de una reclamación.

En esa oportunidad, se hará referencia a la forma de la información, los riesgos a informar, el significado de la información adecuada, clara y comprensible y finalmente, el alcance del deber de consejo; debido a que, uno de los mayores motivos de los juicios de responsabilidad es el contenido del consentimiento informado en lo concerniente a la información y su alcance.

Finalmente, el capítulo III «de la responsabilidad civil por incumplimiento del consentimiento informado del paciente», estará dedicado a identificar el daño a reparar por incumplimiento del consentimiento informado desde el análisis detallado de la responsabilidad y sus presupuestos, identificando preliminarmente el tipo de obligación que encierra el consentimiento informado. Aquí, se expondrán los diferentes discursos jurídicos que se han planteado para resolver el tema del daño a indemnizar, los cuales serán analizados críticamente teniendo en cuenta la función de la responsabilidad y los presupuestos de la misma, en especial el debate que la materia suscita en torno al nexo causal y el daño, observando sus conveniencias, implicaciones y utilidad práctica.

El capítulo concluye con una propuesta en torno al daño indemnizable y su valoración, que pretende aportar al esclarecimiento del debate nacional, de manera que guíe la interpretación, argumentación y decisión de casos relacionados con este tema tan complejo. 
Dado el enfoque teórico de la investigación y el objetivo planteado, la metodología empleada será de tipo cualitativo. Se trata de desarrollar juicios, razones y críticas con base en los datos recogidos a través de fuentes predominantemente secundarias, sin olvidar las primarias como leyes y sentencias. La investigación es jurídica-dogmática ante la indeterminación del derecho positivo que lleva a que pueda ser interpretado de diversos modos, por eso se pretende describir las dificultades del ordenamiento jurídico vigente, sin que se proyecte cambiar este (Latorre, 2012).

El trabajo ofrece un análisis de las normas concretas que involucran, de una u otra forma, el fenómeno objeto de estudio -lege data-. De igual manera, se hará una tarea de sistematización, alcance, comentario y crítica de sentencias judiciales con orientación de sentencia lata, que permitirán observar el problema planteado y establecer la construcción teórica que sustenta las decisiones bajo rivales interpretativos con consecuencias relevantes para el futuro, buscando describir el conflicto y también “...ofrecer criterios que permitan superarlo, o privilegiar una línea de interpretación con respecto a otra" (Courtis, 2006, p. 131).

En cuanto a los métodos de la investigación dogmática, se ha optado por utilizar el método hermenéutico-analítico aunado a la técnica de revisión bibliográfica de literatura especializada, tanto nacionales como foráneas de aquellos lugares de tradición romano germánica que han dado un especial aporte a la temática, sin que implique un estudio de derecho comparado.

Finalmente, se proyecta que esta investigación sea una guía de aproximación interpretativa con rigor científico, construida a partir del contenido del derecho positivo, literatura especializada, de los principios y la jurisprudencia, de tal forma que orienten tanto a la comunidad jurídica como a la médico-científica. Debido a que, se ofrecerán recomendaciones con utilidad práctica que flexibilizarán la discusión al equilibrar la protección de la persona y la reparación justa e integral ante la lesión del consentimiento informado. A su vez, se tiene presente que la labor del investigador no es hallar una verdad inmutable, pues consiste en hacer una "crítica del conocimiento" (Latorre, 2012, p. 171). 


\section{Capítulo I. El consentimiento informado como derecho humano, principio y deber ético- legal.}

\section{Antecedentes trascendentales de la relación médico paciente en torno al manejo de la información y la toma del consentimiento}

El consentimiento informado es considerado uno de los grandes aportes del derecho -a partir de los tribunales de justicia- a la medicina (Faden \& Beauchamp, 1986, p. 100), marcando una transición de la concepción vertical de la relación médico-paciente a una de carácter horizontal, en donde el paciente cobra importancia al reconocérsele capacidad de autodeterminación en virtud de sus derechos a la vida, la salud, la integridad, la libertad, la dignidad, la información y el consentimiento informado. No obstante, el advenimiento de estos derechos generó dificultades de asimilación en los facultativos, quienes venían siendo educados con unos postulados paternalistas.

A continuación, se realiza una breve reseña de la evolución de la relación médico-paciente desde el ámbito de la información, toma de decisiones, poder del médico y posterior reconocimiento del paciente como portador de derechos, los cuales le permiten guiar el rumbo de su existencia, a través del protagonismo en las decisiones que lo afectan.

\subsection{Generalidades de la relación médico-paciente en la Grecia clásica}

Haz todo esto con calma y orden, ocultando al enfermo, durante tu actuación, la mayoría de las cosas. Dale las órdenes oportunas con amabilidad y dulzura, y distrae su atención; repréndele a veces estricta y severamente, pero otras, anímale con solicitud y habilidad, sin mostrarle nada de lo que le va a pasar ni de su estado actual; pues muchos acuden a otros médicos por causa de esa declaración, antes mencionada, del pronóstico sobre su presente y futuro. (Hipócrates, 1983, p. 209)

Así, iniciar con un fragmento del texto "Sobre la Decencia" de Hipócrates, a quien se le conoce como el padre de la medicina y ejemplo de la figura moral del médico (Kvitko, 2009, pp. 9-11), 
no es mera casualidad, dado que el mismo permite contextualizar como era ejercida la práctica médica en la antigüedad.

Tradicionalmente las relaciones humanas en ciertos escenarios se basan en vínculos de dependencia, de manera que, una parte ejerce poder y autoridad por el rol que juega -ya sea por su conocimiento, edad, carácter, profesión, etc.-, y la otra, manifiesta respeto, obediencia, escucha y en algunos casos hasta reverencia, como puede observarse entre padres e hijos, empleadores y empleados, gobernante y ciudadano, en la relación médico-paciente; esta última con ciertas características que se estudian a reglón seguido.

Como establece Gracia (2008), al menos desde la época de Heródoto "las relaciones humanas se dividen en tres categorías: las monárquicas, las oligárquicas o aristocráticas y las [d]emocráticas" (p. 24). Las dos primeras no son estáticas, evolucionan en su interior para pasar finalmente a la democrática, en donde la relación se vuelve madura y adulta, transformación que resulta evidente en el área médica (Gracia, 2008, p. 24).

El pensamiento griego clásico de los siglos VI y V a. C. ${ }^{3}$ se caracterizaba por ser naturalista; la naturaleza simbolizaba el orden, la belleza, la bondad y la armonía, por eso la salud era algo natural. Por su parte, la enfermedad era antinatural al romper la proporción del orden normal de la vida, era sinónimo de desorden, fealdad y disonancia. En suma, la enfermedad era destructiva para el hombre, al consumir su cuerpo y de paso afectar su capacidad de juicio (Gracia, 2008, p. 26).

La palabra enfermo proviene del latín infirmus que equivale a falto de firmeza y debilidad, era un incapacitado físico y a su vez moral, es decir, un desvalido para tomar decisiones buenas, debido

\footnotetext{
${ }^{3}$ En el presente documento se inicia con las breve referencia de la Grecia Clásica en torno a la relación médicopaciente, porque en esta época se comienzan a dar los verdaderos cimientos para entender la medicina como una ciencia técnica racional fundamentada en la physis o naturaleza, en donde quien la iba a ejercer debía tener: capacidad natural, enseñanza del arte que se debe adquirir con reflexión, lugar adecuado para el aprendizaje, instrucción desde la infancia, aplicación constante al trabajo y tiempo (Hipócrates, 1983, p. 94), dejando a un lado las explicaciones mágicas, míticas y empíricas de periodos previos, así "[1]a medicina hipocrática por tanto, es un hecho histórico sumamente trascendental, ya que se conceptúa como el modelo o matriz que va a regir durante los posteriores siglos la práctica médica en occidente. Además, es un hecho revolucionario, ya que se trata del primer intento de explicación científica, o al menos racional, de una parte de la realidad: el cuerpo humano, la salud y la enfermedad. No pretende únicamente una explicación teórica de esta realidad, sino que también busca una acción operativa y transformadora que no es otra que la de curar enfermedades" (Gómez-Ullate, 2015, p. 62).
} 
a que el equilibrio y la armonía en general eran el cimiento de la virtud moral (Gómez-Ullate, 2015 , p. 67). De acuerdo con ello, la enfermedad era al mismo tiempo inmoral, puesto que la moralidad iba unida a lo físico y al equilibrio de los humores; en este sentido, solo el Kalos - el hombre sano y bello- podía ser bueno (Gracia, 2008, pp. 26, 28 y 35-36).

Ante esa consideración, el médico asumió un papel importante en la sociedad, representaba el orden natural y moral y era el sujeto agente de la relación, que aplicaba sus sabios conocimientos científicos para restaurar el equilibrio, tanto físico como moral, perdido en el enfermo. Por tanto, el deber médico era hacer el bien y el paciente debía obedecer las órdenes del galeno (Simón, 2000, pp. 36-37).

De ahí que, la medicina fuera considerada por Hipócrates (1983) como un arte, el más ilustre y notable de todos; ser médico daba prestigio y elegancia teniendo en cuenta que no todas las personas poseían la capacidad natural, acompañada de una instruccción desde la infancia, para poder serlo. El médico tenía autoridad, autonomía y conocimiento frente a la perspectiva científica emergente (pp. 93 y 207-209), al ser un “...adelantado de la civilización frente a la práctica curativa folcrórica y mágica vigente" (Lorenzetti, 2016, p. 12). Esto, inspiraba al paciente a confiar en él.

Lo anterior, vislumbra una relación médico-paciente de tipo vertical y asimétrica, caracterizada por la inexistencia de la admisión del otro como un legítimo otro en plano de igualdad y valor. De esta forma, sobresalía la jerarquía médica por su sabiduría y el papel trascendental en ayudar al enfermo a recuperar su salud y moralidad, siendo un símbolo de la neutralidad del orden natural.

A pesar del desequilibrio notorio, como lo aseguró Platón: “[e]l enfermo es amigo del médico a causa de su enfermedad y con vistas a su salud", el médico manifestaba un amor a la perfección de la naturaleza humana individualizada en el cuerpo viviente del paciente, a saber, un amor a lo que era bello en la naturaleza (la salud y la armonía). Por tanto, la amistad del enfermo con el médico se fundamentaba en una confianza hacia aquel que podía devolverle su capacidad moral a través del arte de curar. En atención a lo cual, los intereses de las partes no se contraponían: el 
enfermo deseaba su bien y salud, y el médico buscaba su éxito en la misión de ayudar a la naturaleza (Laín, 1964, pp. 53-54).

Si el médico era cumplidor de sus deberes, como se establecía en el Juramento Hipocrático, recogería el fruto de su arte y sería honrado por todos los hombres. En caso contrario, su castigo era el deshonor social, lo que significaba una responsabilidad ética. En otras palabras, la responsabilidad era de tipo moral-religioso, en virtud del compromiso solemne del médico con el juramento. En consecuencia, había una permanente impunidad a nivel jurídico ${ }^{4}$ compensada con

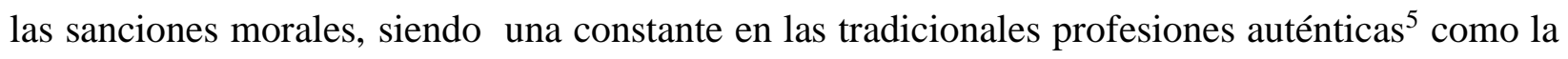
medicina, no por ausencia de normas, sino por lo que de facto ocurría, lo que contrariamente se daba en las ocupaciones u oficios (Gracia, 2008, p. 52) ${ }^{6}$.

Todo esto conllevó a que por mucho tiempo se "endiosara" la actividad médica y el que la practicaba ejercía una especie de sacerdocio docto, no de tipo ministerial, al ser un conocedor de la naturaleza, dador de la curación y de autoridad respecto del enfermo inmoral. Por lo cual, no había razón para no creer en la legitimidad de su actuación.

Dada la situación deplorable del enfermo a la hora de hacer juicios y tomar decisiones correctas para recuperar la neutralidad de su vida, para prevenir y tratar la enfermedad, que en muchos casos

\footnotetext{
${ }^{4}$ Afirmaba Hipócrates sobre el error de la medicina que "[e]l arte de la medicina es de todas las artes la más notable, pero, debido a la ignorancia de los que la practican y de los que a la ligera los juzgan, actualmente está relegada al último lugar. En mi opinión el error, en este caso, se debe fundamentalmente a la siguiente causa: que el arte de la medicina es el único que en las ciudades no tiene fijada una penalización, salvo el deshonor, y [e]ste no hiere a los que han caído en él. Pues son [e]stos parecidísimos a los actores extras en las tragedias: así como [e]stos tienen figura, manto y máscara de actor, pero no son actores, también muchos médicos lo son de nombre, pero en la práctica muy pocos" $(1983$, p. 93)

${ }^{5}$ Las profesiones auténticas de la época eran “...el sacerdocio, la realeza (y la judicatura como derivación suya) y, en fin, la medicina" (Gracia, 2008, p. 52).

${ }^{6}$ La naturaleza de las normas éticas del juramento hipocrático de la Grecia clásica que instituían una responsabilidad moral basada en el desprestigio social y el deshonor, diferían de las normas del Código de Hammurabi escrito antecedentemente por el rey, a quien debe su nombre, de la primera dinastía de Babilonia. Entre sus preceptos regulaba el ejercicio de la medicina asignándole al médico como castigo ante el fracaso de una cirugía, que su mano fuera cortada: "si un médico hace incisión profunda en un hombre con bisturí de bronce y le provoca la muerte, o si le abre la sien a un hombre con bisturí de bronce y deja tuerto al hombre, que le corten la mano" (218), por lo que se observaba un escenario de retribución de castigo y atribución de responsabilidades estricto basado en el "ojo por ojo diente por diente"-Ley del Talión. Sin embargo, parece que no todos los médicos de los pueblos mesopotámicos debían observar el código por igual, los médicos-sacerdotes no estaban obligados mientras que los sanadores de rango inferior (cirujanos o barberos) si estaban sometidos a las disposiciones (Gómez, 2015, pp. 23-25 y Llamas, 1988, pp. 6-9).
} 
es provocada por los excesos del mismo hombre ${ }^{7}$, se permitió el ocultamiento de cierta información sobre el diagnóstico, pronóstico y tratamiento, puesto que, ello podría ser un "powerful narcotic" (Nelson-Marten \& Rich, 1999, p. 82) que empeoraría el estado del paciente y/o conllevaría a que se rehusara a colaborar en lo que el médico consideraba que era bueno para él.

Asimismo, suministrar información al enfermo sobre su estado de salud era viable tan solo cuando fuera valioso para asegurar la activa participación en la curación. Sin embargo, esto dependía del estatus del médico y del enfermo: ciudadano libre rico o pobre y el esclavo. Cuando la relación se daba entre esclavos no había intercambio de información alguna y como un tirano, el galeno recetaba lo que le parecía, tomaba las decisiones en su individualidad y daba órdenes (Platón, 1872, p. 220).

Por otro lado, el trato con los esclavos era prácticamente repetido para el caso de los ciudadanos libres pero pobres como los artesanos. Si bien, no se aplicaba el trato dictatorial, los médicos no hacían el esfuerzo por entablar un diálogo, debido a que ellos tenían que trabajar y no disponían de espacio para enfermarse ni para tratamientos largos; así, una vez atendidos retornarían a sus labores habituales, dejando a la suerte sanarse y seguir ejerciendo su oficio, o por el contrario, si su cuerpo no respondía a resistir la enfermedad, moriría y quedaría liberado de todas sus preocupaciones (Platón, 1986, p. 183).

Entre tanto, con los ciudadanos libres-ricos, el médico interactuaba con el paciente como si fueran amigos, para obtener información y poder realizar el diagnóstico. Antes de recetar, el médico realizaba una labor persuasiva con el enfermo -paideia médica como una forma de educación moral-, para instruirlo sobre la efectividad del tratamiento, que por tanto había de aceptarse, y sobre los cuidados que debía tener para prevenir la enfermedad (Platón, 1872, pp. 220221).

\footnotetext{
${ }^{7}$ En cierta medida el hombre podía ser responsable de la enfermedad que padecía en virtud de los abusos rutinarios con respecto a ciertas costumbres o hábitos como comer y beber, que es lo que en esta época se conocía como enfermedades crónicas. Por otra parte, también se encontraban las enfermedades agudas que surgen de forma repentina y su origen se asociaba a un carácter más religioso que moral, y eran en su generalidad más graves que las crónicas (Gracia, 2008, p. 37).
} 
Vale mencionar que, el saber era la brújula del médico para manejar el discurso, de tal forma que lograra persuadir al enfermo y a sus familiares de "hacer lo correcto", en razón de que el enfermo “...tiene en su alma, por consiguiente, la sensación entre liberadora y humillante de ser un niño ante la persona del médico" (Laín, 1964, p. 362).

Conforme a lo anterior, no es válido afirmar que en el caso de los ciudadanos libres-ricos había un consentimiento informado o que estaba como patrón ético invitar al paciente a participar en la toma de decisiones clínicas, dado que revelar ciertos datos tenía como fin mantener una buena relación y doblegar, a través de la palabra, al enfermo de atender las recomendaciones, siendo permisible al médico manipular los datos para lograr el cometido (Díaz y García, 2002, p. 315).

Por consiguiente, la comunicación entre médico y paciente cumplía tres propósitos: de medicina preventiva, dar un diagnóstico más preciso a partir del conocimiento de los pacientes sobre sí mismos y/o ganar confianza a través de la persuación para una efectividad terapeútica (Katz, 2002, pp. 5-6).

De hecho, si a los médicos de la antigua Grecia se les hubiese exhortado a la toma de decisiones compartidas o participación activa del paciente, esto habría sido considerado innecesario y contraproducente; en primer lugar, porque veían al médico y al enfermo unidos por la amistad con un objetivo común, y por eso, las explicaciones más que innecesarias serían irrelevantes al tener identidad de intereses que cumplía el médico de forma filantrópica, lo que a su vez generaba en los pacientes el amor por el arte del médico. En segundo lugar, en la medida que para ganar la confianza y la cooperación se valía convencer por cualquier medio.

En relación con lo anterior, Platón consideraba que los médicos solo empleaban mentiras para fines buenos y nobles ${ }^{8}$. Además, las explicaciones revelarían las incertidumbres propias de la

\footnotetext{
${ }^{8}$ Platón en su obra La República acuñó la expresión “nobles mentiras" para justificar las mentiras políticas de los gobernantes para el bien de los gobernados. Lo cual, aplicaba también para el caso de los médicos con la excusa de que fuera un remedio y en beneficio del enfermo, por ello afirmaba que “... la mentira es en realidad inútil para los dioses, aunque útil para los hombres bajo la forma de un remedio, es evidente que semejante remedio debe ser reservado a los médicos, mientras que los profanos no deben tocarlos ... Si es adecuado que algunos hombres mientan, [e]stos serán los que gobiernan el Estado, y que frente a sus enemigos o frente a los ciudadanos mientan para beneficio del Estado; a todos los demás les estará vedado. Y si un particular miente a los gobernantes, diremos que su falta es
} 
medicina que crearía un estado anímico hostil en el enfermo, impidiendo su recuperación (Katz, 2002, pp. 6-7).

En este panorama, la actitud médica hacia el enfermo se atribuyó como "paternalismo hipocrático", a modo de extrapolación de la relación paterno-filial en donde un padre obra respecto a su hijo con beneficencia y legítima autoridad, toma decisiones en nombre de este y es considerado un educador moralista. No obstante, ese mejor interés estaba basado en lo que la medicina consideraba que era lo más adecuado para el paciente, sin tener en cuenta los deseos del enfermo.

Ahora bien, la relación hipocrática tenía como fin actuar para el bien del paciente apartándolo de todo perjucio e injusticia ${ }^{9}$-lo que grosso modo se conoce hoy como "principio de beneficencia y no maleficencia", siendo la tutela del médico proteccionista en bienestar del enfermo, dado que el obrar bien conducía a la excelencia, la armonía y la plenitud (Kvito, 2009, p. 11).

Los autores Beauchamp y Mccullough (1984) definen el paternalismo, en una visión amplia no enmarcada tan solo en los conceptos de la época clásica, como la restricción intencionada de la autonomía de una persona por parte de otra, con la justificación exclusiva de motivos de beneficencia. Su ejercicio implica dejar de lado el principio de respeto de autonomía, y se apoya en el principio de beneficencia para ese indivuo en particular y no para terceros. Esto último no es absoluto, debido a que se pueden enfrentar los intereses del paciente con el del resto de la sociedad y prevalecería el interés general sobre el particular (pp. 98-99).

igual o mayor que la del enfermo al médico o que la del atleta a su adiestrador cuando no les dicen la verdad respecto de las afecciones de su propio cuerpo ..." (p. 153)

${ }^{9}$ En el Juramento Hipocrático se lee "utilizaré el régimen dietético para bien de los enfermos, de acuerdo con mi capacidad y juicio; alejaré de ellos el mal y la injusticia", lo que puede considerarse como el fundamento moral de la medicina al cual los médicos debían comprometerse antes de iniciar el ejercicio de la profesión.

Los médicos debían buscar los mejores intereses para el paciente desde la óptica de la medicina, era su deber prevenir el mal innecesario; aquí el fin de la medicina no es como se entiende en la época moderna de mantener la vida por encima de todo, sino que se debía limitar el dolor y el sufrimiento, a menos que estuviera justificado para eliminar la causa que estaba afectando la salud, por ello las intervenciones médicas utilizadas debían tener expectativa de éxito para así como decía Hipócrates, en las epidemias, favorecer o al menos no perjudicar (Beauchamp y Mccullough, 1984, pp. 32-33). 
Ese poder que por varios siglos se le dio al médico produjo en muchas ocasiones que las relaciones se tornaran despóticas y arbitrarias. Aunque la medicina pregonara el mayor interés para el enfermo, el galeno actuaba al favor del suyo, aprovechándose de la confianza y obediencia casi a ciegas de los pacientes, ignorando por completo las preferencias de estos.

Al respecto, Gracia (2008), siguiendo las clasificaciones de Max Weber sobre dominación ${ }^{10}$, expone que el médico ejercía dominación -poder de mando autoritario e interés de la otra parte de obedecer- con el enfermo no basada en la fuerza, al cimentarse en el señorío como proceder moral apoyado en los títulos de legitimidad de dominación tradicional y carismático ${ }^{11}$, debido a que, el “médico tiene el «poder» de gratificar al enfermo, y [e]ste el «deber» de dejarse gratificar” (p. 73). De esa manera, el poder del médico no era ilegítimo o una aberración moral, era la única forma natural de actuar con los enfermos.

Es de mencionar que las conversaciones con los pacientes servían de consuelo, esperanza y para inducir al paciente para seguir las prescripciones, por eso se requería que el médico fuera autoritario, manipulador e incluso mentiroso, pues sin respeto por la autoridad médica no podría haber cura (Katz, 2002, p. 7). En tal grado, el modelo paternalista puede resumirse en la famosa frase que enmarcó el despotismo ilustrado de Luis XVI "todo para el pueblo sin el pueblo", adaptada al campo médico en "todo para el paciente, pero sin el paciente" (Cadena, 2018, p. 44).

Con todo, el paternalismo constituyó la orden de perfección para el ejercicio de la medicina, cuyo legado se extendió durante 25 siglos, por varias razones como que el saber del arte médico era ejercido por un grupo selecto, por la falta de comprensión objetiva del enfermo en razón de la inmoralidad de la enfermedad y finalmente, la consideración social del médico como ser altruista que velaba por hacer el bien (Monsalve y Navarro, 2014, p.14). Todo lo cual, estaba apoyado por

\footnotetext{
${ }^{10}$ Max Weber expone que existe tres tipos puros de dominación legítima que según sus pretensiones típicas de legitimidad pueden ser de carácter racional, tradicional o carismática (pp. 172-173).

${ }^{11}$ La dominación tradicional según Weber (2002) es aquella en que su legitimidad proviene "de la santidad de las ordenaciones y poderes de mando heredados de tiempos lejanos, creyéndose en ella en méritos de esa santidad" (p. 180). Con respecto a la dominación carismática, la cual es extraordinaria y fuera de lo cotidiano, su título de legitimidad nace y se mantiene por la corroboración y reconocimiento por parte de los dominados de las supuestas cualidades carismáticas del líder, por esto es necesario un proceso de comunicación de tipo emotivo para crear la fe en el carisma que proporcionará validez (pp. 193-195).
} 
la idea de que los intereses del médico y paciente coincidían, por lo tanto, el primero podía hablar por el segundo (Katz, 2002, p. 64).

Normalmente el paternalismo es visto con una imagen desfavorable por el juicio moral de reproche que se le hace de inmediato. Sin embargo, no siempre es negativo, pues entraña tanto poder como beneficencia; de ahí que, sea más conveniente añadirle el apellido de justificado o injustificado o débil o fuerte ${ }^{12}$, dependiendo de los móviles de beneficiencia del mismo.

Pese a lo anteior, el problema real de su ejercicio -en exclusivo- radica en que en ciertos casos puede representar la negación de los intereses, preferencias, expectativas y acciones de una persona, en especial cuando esta no tiene ninguna condición física o mental que disminuya su capacidad de jucio. Esto significa que, para establecer el grado de corrección del paternalismo, se debe examinar el contexto y el modo en que se ponderen los principios en juego, como beneficencia versus libertad y autonomía (Gracia, 2008, p. 99).

\subsection{El paternalismo medieval}

Durante el período de la Edad Media se mantuvo la influencia de la tradición hipocrática fortalecida por la teología, en donde el saber y la autoridad del médico se afirmaba era dado y guiado por Dios. Por este motivo, los enfermos debían honrar a los médicos, dado que recibían su autoridad de Dios, tener fe en sus médicos y prometer obediencia. La relación se establecía entre médicos, pacientes y su Dios, lo que hacía imposible cuestionamientos a la práctica médica al ser los galenos ungidos por la Divinidad, justificándose la autoridad, al mismo tiempo, que se fortalecía la fe, la confianza y la obediencia necesarias para curar de la enfermedad (Katz, 2002, pp. 7-9).

Cabe resaltar que el fundamento de la triada Dios-médico-paciente se encuentra en la Biblia, en el libro Eclesiástico, donde se consagró el respeto al médico por sus servicios, al ser estos elegidos por Dios, por lo que debían ser admirados (38:1-4); asimismo, no era acertado cuestionar a los médicos en su actividad, debido a que señalarían a Dios, pues Él otorgaba la sabiduría.

\footnotetext{
${ }^{12}$ Beauchamp y McCullough (1984) exponen ampliamente esta discusión.
} 
El médico francés Henri De Mondeville (1260-1325 d.C.) se destacó en la época por sus escritos, revelaba la tendencia benéfica del ejercicio de la medicina. Ante situaciones de peligro, recomendaba mantener la esperanza del paciente como ayuda terapéutica e informarle a los padres o amigos. Al mismo tiempo, insistía en advertirle al paciente las consecuencias de desobedecer las prescripciones médicas y la necesidad de entablar una relación de confianza para poder tratar al paciente (Le Goues, 2015, pp. 47 y 57; Beauchamp y McCullough, 1984, pp. 63 y 64).

Esta misma postura paternalista fue asumida en los médicos judíos y árabes de la época medieval (Katz, 2002, p. 8).

\subsection{Siglos XVIII y XIX}

Los siglos XVI y XVII siguieron incólumes a la práctica de la medicina tradicional paternalista de ocultación y manipulación de la información.

El mundo occidental del siglo XVIII se caracterizó por el período de la Ilustración, se le conoce como "siglo de las luces". En él la razón venció a la fe: el hombre se convirtió en el centro del universo. A pesar de las grandes ideas revolucionarias de la época ${ }^{13}$, la relación médico-paciente siguió dominada por el modelo hipocrático de hermetismo de la información. Sin embargo, hay tres referencias que se pueden considerar como los primeros esbozos sobre el consentimiento, mismas que se destacan a continuación.

En 1767 el caso inglés Slater vs. Baker \& Stapleton fue el primer bosquejo jurisprudencial en donde los médicos fueron acusados por malpractice, al no acceder a quitar el vendaje de una fractura de rodilla que se había consolidado, y en su lugar, la desunieron para experimentar un tratamiento ortopédico. El argumento de la Corte para condenar se fundamentó en la razonabilidad

\footnotetext{
${ }^{13}$ Las cuales desencadenaron en: una Revolución Industrial, declaración de independencia de los Estados Unidos Declaración de Filadelfia- en 1776 que incorpora por primera vez los derechos inalienables del hombre destacando la vida, la libertad y la búsqueda de la felicidad, razón por la cual Thomas Jefferson exponía que fue esta la que despertó a los pensadores de Francia del sueño despótico en el que se hallaba inmersa (Aparisi, 1990, p. 211), y en 1789 la Revolución Francesa marcada por el lema de igualdad, libertad y fraternidad, que dio lugar a la Declaración de los Derechos del Hombre y del Ciudadano.
} 
del hecho de que el paciente estuviere previamente informado del procedimiento, para que se preparara y asumiera la situación con valor (Kvitko, 2009, p. 88).

En este primer antecedente jurisprudencial, se observa que si bien se hace alusión al tema de brindar información anticipada al paciente sobre el tratamiento que se va a realizar, el énfasis de la malpractice se sustenta con más fuerza en el hecho de no comportarse de acuerdo con los lineamientos de la profesión, al someter al paciente a un sufrimiento innecesario y utilizar métodos experimentales en contra de la voluntad del paciente, es decir, ausencia total de consentimiento.

Tal precedente ha llevado a afirmar a la doctrina jurídica que los primeros movimientos sobre consentimiento e información, como factores independientes, se dieron por los jueces en su jurisprudencia y no precisamente desde el campo de la ética médica. Ello, porque los lineamientos éticos estaban gobernados básicamente por el principio de beneficencia y la información era ocultada con fines benévolos y altruistas (Kvitko, 2009, p. 88).

Por tanto, lo que se conoce hoy como autonomía del paciente, del cual deriva el principio del consentimiento informado, constituye una de las más grandes contribuciones que el derecho le ha dado al mundo médico, al punto que el consentimiento informado es considerado en tiempo presente como derecho humano, manifiesta aportación de la teoría de los derechos humanos (Gracia, 1993, p.115) ${ }^{14}$.

Décadas posteriores, se hizo célebre el caso norteamericano Carpenter vs. Blake (1871 y 1878) sobre investigaciones en desarrollo de aparatos médicos, en donde el facultativo es declarado culpable por negligencia profesional, al realizar imprudentemente un experimento en ausencia de información para con el paciente, ya que no le reveló su verdadera situación. De igual forma, el médico no dio a conocer los cuidados necesarios del método no habitual utilizado para reducir la dislocación del brazo, y fue un total fracaso.

\footnotetext{
${ }^{14}$ Este criterio también es avalado por la Corte Constitucional colombiana como se lee en la Sentencia T-762-2004 de $11 / 08 / 2004$.
} 
Los dos casos develan que las primeras incursiones de los jueces se basaron en sanciones médicas por no brindar información al paciente, y, asimismo, realizar conductas tachadas de mala praxis profesional al utilizar nuevos procedimientos cuyos beneficios no estaban comprobados ${ }^{15}$; por tal motivo, debían asumir las consecuencias de su actuar al generar daños al paciente. No obstante, en ese momento, el paternalismo seguía dominando la práctica médica, por eso, la situación era inestable para sentar postulados sobre consentimiento e información, lo que se evidencia en las decisiones, en donde las sanciones se encaminan más al reproche por la utilización de procesos experimentales y no dar información sobre ellos y para el éxito del tratamiento.

Sobre estos antecedentes judiciales, Tarodo (2006, pp. 231-232) asevera que de ellos se puede concluir lo siguiente: en primer lugar, descansan en la determinación de la responsabilidad médica en virtud del daño producido; y segundo, ante la ausencia de consentimiento informado o presencia de información falsa el médico incurre en malpractice - negligencia profesional, esa mala praxis era entendida como un desacato a la correcta asistencia sanitaria.

Por otro lado, en el campo de la ética se dieron unas pequeñas muestras del deber de dar información al paciente. Así, Thomas Percival, quién era un médico británico inquieto por establecer una identidad moral definida en la profesión médica, publicó en 1803 la obra Medical Ethics, considerado un código de conducta en donde por primera vez se utilizó el término de ética médica, siendo el libro fundador de la ética médica asistencial norteamericana. En un principio, ese documento fue diseñado para el servicio de los hospitales y otras instituciones médicas de caridad para superar la controversia sobre deberes y prerrogativas que enfrentaban a los médicos, pero el texto alcanzó cierta fama, que lo llevó a su público conocimiento (Simón, 2000, p. 81).

Percival daba las pautas para ser un médico político, es decir, un gentleman, triunfando nuevamente el modelo de beneficencia como amplio marco de la creación de la ética médica, en donde no se aboga por la divulgación ni se dice mucho sobre la comunicación (Faden \& Beauchamp, 1986, p. 68).

\footnotetext{
15 " [T] he rule protects the community against reckless experiments, while it admits the adoption of new remedies and modes of treatment only when their benefits have been demonstrated" (Caso Carpenter vs. Blake).
} 
Bien es verdad, su pensamiento, como lo referencia Gracia (2008), encuadra en un paternalismo juvenil, al no considerarse al enfermo como un incapaz absoluto -paternalismo infantil ${ }^{16}$-. Por tal motivo, era viable decir la verdad siempre, excepto en el caso de enfermedades graves o mortales, dado que conocer la verdad estaba aniquilado al ser perjudicial. Luego, el médico era libre para ocultar información, pero no era libre para decir la verdad, es decir, el privilegio médico de la veracidad anula el derecho a la información del paciente (pp. 91-93).

Estos postulados de Percival se fueron difundiendo, de modo que las asociaciones médicas británicas y estadounidenses redactaron sus primeros códigos de ética siguiendo con exactitud al Medical Ethics, un ejemplo de ello es el Código Ético de la American Medical Association de 1847.

\subsection{Siglo XX: de la oscuridad a la luz en la relación médico-paciente}

Aunque el siglo de las luces fue el XVIII, este no significó iluminación en el ámbito del consentimiento e información, dado que el manejo de la información y la negación de la capacidad del paciente siguieron dominando la práctica médica. Fue en el siglo XX donde comenzó el verdadero cambio del paradigma paternalista, a fin de dar paso a una visión del paciente con derechos y como protagonista en la toma de decisiones; de ahí que, se le denominara a este período como "siglo de las luces en la institución del consentimiento informado (del paternalismo a la autonomía del paciente)" (Monsalve y Navarro, 2014, p. 19).

\footnotetext{
${ }^{16}$ Gracia afirma que el paternalismo admite dos grados: infantil y juvenil, lo que desarrolla siguiendo a Thomas Szasz y Hollender (1956) quienes, expusieron tres modelos básicos de la relación médico-paciente: activity - passivity en donde el enfermo es un incapaz para responder o inerte y el médico hace todo por el paciente, por eso el prototipo es parent- infant y la aplicación clínica del modelo se da en casos de anestesia, trauma, estados de coma; el segundo es guía-cooperación (guidance-cooperation) en donde el médico le dice al paciente qué hacer y el enfermo coopera y obedece tal como lo hace un padre con su hijo adolescente (parent- child adolescent) como ocurre con los proceso infecciosos agudos y finalmente el modelo mutual participation en donde se concibe al paciente en plano de igualdad participando activamente y el médico ayuda al paciente para que aprenda a cuidarse por sí mismo como por ejemplo en caso de enfermedades crónicas o psicológicas, por ello es una relación adult-adult carente de paternalismo y donde reina condiciones democráticas y autónomas (Szasz y Hollender, 1956, pp. 586-587).
} 


\subsubsection{La jurisprudencia norteamericana y sus contribuciones al reconocimiento del consentimiento informado en las relaciones sanitarias}

A principios del año 1900, la jurisprudencia norteamericana tuvo un notable desarrollo al cuestionar la conducta médica autoritaria que manejaba con un silencio eterizado la suerte de los tratamientos en los pacientes y con un notable ausentismo de información sobre la naturaleza, técnica y riesgos del procedimiento. De esta manera, en sus inicios se dio paso a la idea de que cuando el médico no estaba legitimado por el paciente para realizar un procedimiento en su persona, se extralimita o brinda información engañosa, incurre en battery (agresión), es decir, en un contacto físico no autorizado. Posteriormente, se pasó a la responsabilidad médica por negligencia.

En ese orden de ideas, battery es la imposición de una fuerza intencional e ilegal sobre el paciente, a menos que exista justificación de la intromisión a la integridad de la persona, como cuando se ha dado el consentimiento o ante una situación de emergencia (Cadena, 2018, p. 56). Por ello, en la doctrina de battery, es indiferente que el médico haya actuado motivado por beneficiar al paciente, pues se sanciona el hecho de no contar con su autorización independientemente de los resultados obtenidos.

Entonces, se acciona por battery cuando existe ausencia total del consentimiento informado del paciente, ya sea porque aplica un tratamiento o realiza un procedimiento sin autorización o lleva a cabo una actuación contraria a la consentida por el paciente. Asimismo, cuando el paciente consiente sin información previa (Cadena, 2018, p. 57).

En este sentido, cuatro decisiones norteamericanas han sido aceptadas por la doctrina como las que formulan las primeras bases en torno al tema de consentimiento e información (Wandler, 2001, pp. 1-6). Su fundamentación jurídica estuvo marcada por el concepto de battery, son a saber:

Mohr vs. Williams en 1905, caso en el que el médico opera la oreja izquierda de la paciente sin su aprobación, al utilizar la autorización que había dado la paciente para que intervinieran quirúrgicamente la oreja derecha, pero en el curso de la cirugía el médico consideró que la 
izquierda estaba en condiciones más graves y necesitaba el procedimiento. Empero, luego del proceso, la paciente se vio perjudicada auditivamente, intromisión que fue sancionada por la Corte, y advirtió que, el paciente debe ser el árbitro final sobre si se arriesga o no con la operación, al ser libre y tener el derecho a decidir sobre sí mismo.

Pratt vs. Davis en 1906 en el cual el médico realizó una histerectomía sin autorización, alegando que al ser la paciente epiléptica carecía de capacidad para tomar decisiones y había un consentimiento implícito en una cirugía anterior; estos argumentos no fueron avalados por la Corte.

En 1913 Rolater vs. Strain donde el profesional no respetó los límites del consentimiento del paciente en un drenaje de absceso de un pie, sustrayendo un hueso cuando expresamente la paciente había prohibido cualquier extracción ósea. Además, la prueba pericial no avaló la decisión médica. En consecuencia, fue declarado culpable de agresión o battery. En 1914, el caso Schloendorff vs. Society of New York Hospitals, que se explica por su importancia en líneas posteriores.

Todos estos pronunciamientos se caracterizaron por la ausencia de consentimiento indicando agresiones e intromisiones severas en el cuerpo del paciente. Entre tanto, ni el consentimiento ni la información estaban categorizados como derecho, por lo cual, los inaugurales rastros jurídicos hicieron alusión a la vulneración de otros derechos como la integridad física, libertad y posesión y control de su propia persona ${ }^{17}$, lo que daba la potestad de oponerse a injerencias no deseadas y a conocer los peligros y riesgos del procedimiento, así como evaluarlos de forma precedente (Wandler, 2001, p.3).

Seguidamente, se exponen las decisiones jurisprudenciales más destacadas de inicio y mediados del siglo XX, donde se examina el incumplimiento del galeno con respecto a la obligación de

\footnotetext{
17 "Under a free government, at least, the free citizen's first and greatest right, which underlies all others - the right to the inviolability of his person; in other words, the right to himself - is the subject of universal acquiescence, and this right necessarily forbids a physician or surgeon, however skillful or eminent, who has been asked to examine, diagnose, advise, and prescribe (which are at least necessary first steps in treatment and care), to violate, without permission, the bodily integrity of his patient by a major or capital operation, placing him under an anaesthetic for that purpose, and operating upon him without his consent or knowledge" (caso Pratt vs. Davis).
} 
informar y de obtener el consentimiento del paciente, asociado al tema de la responsabilidad médica, que se erige en un nuevo enfoque jurídico. Todo lo cual, denota un cambio significativo en el modo de plantear y resolver las controversias suscitadas en el ejercicio profesional.

\subsubsection{Caso Schloendorff vs. Society of New York Hospital - 1914}

En el caso Schloendorff vs. Society of New York Hospital, el fenómeno causal consistió en que la paciente había dado autorización para un examen con éter de un tumor fibroide pero previno que no quería ninguna intervención quirúrgica. A pesar de ello, y ante el estado de inconsciencia por el éter, el médico extirpó el tumor. Ante esto, la paciente se sintió engañada, agredida, a más de que se le presentaron agravios físicos, como dolores insoportables y la amputación de varios dedos por una gangrena que se produjo en el brazo izquierdo.

El juez del asunto, Benjamín Cardozo, en virtud de los antecedentes del sumario, expuso que toda persona adulta con capacidad mental sana tiene el derecho de decidir qué hará con su propio cuerpo, excepto en cuando se trata de emergencias que requieren atención sin demora. De esta forma, quien no cuenta con el consentimiento incurre en battery o agresión y debe responder por los daños y perjuicios ocasionados ${ }^{18}$.

A pesar de la vulneración al consentimiento, la sentencia fue absolutoria por cuestiones de legitimación pasiva, dado que la demanda se dirigió contra Society of New York Hospital, que era una institución de caridad, y, por ende, gozaba de inmunidad (Dolgin, 2010).

De lo manifestado por el juez Cardozo se desglosa que, la vulneración al consentimiento afecta por sí sola la autodeterminación del paciente $^{19}$ y de forma inmediata genera responsabilidad

\footnotetext{
18 "Every human being of adult years and sound mind has the right to determine what shall be done with his own body; and a surgeon who performs an operation without his patient's consent commits an assault, for which he is liable in damages. This is true except in cases of emergency where the patient is unconscious and where it is necessary to operate before consent can be obtained" (Schloendorff vs. New York Hospital).

${ }^{19}$ Fue esta la primera sentencia que utilizó la autodeterminación como requisito del consentimiento, y de ahí deviene su popularidad (Faden \& Beauchamp,1986, p. 124), esto sin desmeritar que los proveídos anteriores desarrollaron con amplitud el alcance de la necesidad de comprensión.
} 
médica, sin que se haya consolidado un daño a la salud y aun en casos que el resultado haya sido exitoso.

El caso Schloendorff pasó a ser la primera sentencia que no solo hizo alusión a la necesidad de un consentimiento, debido a que consolidó la autodeterminación como derecho, permitiendo entonces, la independencia de esta omisión como generadora de responsabilidad, o sea, un daño con entidad propia en donde solo bastaba la intromisión en la integridad física y el desacuerdo del paciente.

De esa forma, el agravio por battery al buscar proteger la integridad del cuerpo hace que el nivel de defensa es más inflexible. El juez debe averiguar tan solo si el paciente sabía y estaba de acuerdo con lo que se le iba a hacer, y si la respuesta resulta negativa, se configura la responsabilidad al ser el contacto en sí mismo ofensivo. Tampoco, requiere consultar si de revelar los riesgos previamente el paciente se hubiese sometido o no a la intervención, puesto que lo sancionado es actuar sin legitimación (Katz, 1977, pp. 144-145) ${ }^{20}$. De ahí que, el juez del caso haya orientado el mismo como agresión y no como negligencia.

Por otra parte, si bien en la providencia se hace énfasis en la necesidad de consentimiento, no se aborda cómo debe darse el mismo y qué requisitos se requieren, es decir, al médico se le exige autorización para actuar, pero no que la misma esté antecedida por una información de los riesgos, cuidados, alternativas y consecuencias del tratamiento (Bastida, 2012, pp. 157-158) de forma clara, precisa y detallada, como se promulga actualmente.

Desde esta óptica, no se predica el consentimiento como toda una institución "consentimiento informado", lo cual aparece años después. Como se notó, se estudiaron como componentes separados el divulgar y pedir la aquiescencia, dando lugar entonces a la puesta en marcha de battery únicamente cuando se hace un toque intencional en el cuerpo del paciente sin su autorización.

\footnotetext{
${ }^{20}$ Una delineación sobre la teoría de la battery y su contraste con la negligencia se puede encontrar en Faden \& Beauchamp (1986, pp. 27-30).
} 


\subsubsection{Caso Salgo vs. Leland Stanford Jr. University Board of Trustees- 1957: el nacimiento de la doctrina del consentimiento informado}

A finales de los años 50 los jueces se plantearon un nuevo interrogante revolucionario, orientado a preguntarse si los pacientes tienen el derecho a conocer previamente el procedimiento o tratamiento que pretende realizar el médico; igualmente, si estos pueden decidir si lo aceptan o lo rechazan de acuerdo con los riesgos, beneficios y alternativas disponibles informadas de forma anticipada (Katz, 2002, p. 59).

Como lo estableció Katz, responder dicho interrogante no fue un paso fácil, significaba inmiscuirse en un terreno que por siglos había estado blindado por el lema del paternalismo médico e incapacidad del paciente (2002, p. 59). Pero, al decidir contestar la pregunta dieron un salto fundamental, consolidándose formalmente la doctrina del consentimiento informado el 22 de octubre de 1957, en la sentencia del caso norteamericano Salgo vs. Leland Stanford Jr. University Board of Trustees.

La plataforma fáctica indicó que el señor Salgo, el cual tenía un envejecimiento prematuro, presentaba calambres en las piernas que le provocaban cojera intermitente. Fue valorado en el Hospital de Stanford por el Dr. Gerbode, experto en cirugía vascular, quien encontró una insuficiencia arterial avanzada, diagnosticando una probable oclusión de la aorta abdominal que había alterado el suministro de sangre a las piernas y otras áreas, además de una arteriosclerosis avanzada.

Entonces, para confirmar el primer diagnóstico le fue realizada una aortografía con contraste por el departamento de rayos x del centro médico demandado, por prescripción del Dr. Gerbode, quien atestiguó que no explicó todos los riesgos. El proceso de la aortografía estuvo a cargo de un anestesiólogo, un radiólogo y un cirujano (Dr. Ellis), este último encargado del procedimiento admitió, de igual forma, que no fueron explicados los detalles y los posibles peligros. Como consecuencia del acto, el paciente no pudo movilizar sus extremidades inferiores, sufriendo una parálisis irreversible, razón por la que demandó por negligencia en la práctica de la aortografía y por no haber sido informado previamente de los riesgos y posibles complicaciones. 
La Corte de Apelaciones, con ponencia del juez Bray, declaró que un médico quebranta su deber para con el paciente si oculta cualquier hecho que sea necesario para consolidar un informed consent, arriesgándose a ser responsable por esta omisión, siendo inescindible la información y el consentimiento. Sin embargo, no se adujo explícitamente si se trataba de un supuesto de negligencia o de agresión, aunque los casos citados como apoyo de su decisión hacen alusión a la battery. Por esa razón, queda la incertidumbre sobre la teoría que realmente fundamentó la postura, teniendo en cuenta que, no hubo una intromisión pura, como ocurrió en los proveídos anteriores, debido a que se concretó fue la falta de información previa de los riesgos.

De esta manera, la Corte estableció una obligación de divulgación por parte del médico de acuerdo con la situación mental y emocional de cada paciente. Con todo, adujo que no era absoluto al encontrarse a discreción del médico la identificación y extensión de la información a revelar, con el propósito de que esa fuera útil para formar un consentimiento informado ${ }^{21}$.

Lo anterior, determinó entonces el criterio del estándar del médico para llevar a cabo el análisis de la responsabilidad, desde esta postura, el juez debía analizar en cada juicio qué hubiese ilustrado un facultativo en esa situación específica.

Adicionalmente, en el fallo se ven dos orientaciones contradictorias, compartiendo lo aseverado por Katz (1977), que presentan problemas a la hora de examinar la responsabilidad: discreción y revelación total. Por ello, no quedó claro lo que realmente debía ponerse de manifiesto para permitir la puesta en marcha del consentimiento. El juez del caso planteó en términos generales la discreción y la experiencia profesional médica en cada caso en particular (p. 150), y le asignó una tarea indefinida y ardua a un grupo que no había tenido ni la experiencia ni el compromiso con la autodeterminación del paciente -los médicos-, aunque no se puede negar que generó, a partir de entonces, grandes debates (Katz, 2002, p. 62).

\footnotetext{
${ }^{21}$ Textualmente fue expuesto por el Juez Bray de la Corte de Apelaciones lo siguiente: "The other is to recognize that each patient presents a separate problem, that the patient's mental and emotional condition is important and in certain cases may be crucial, and that in discussing the element of risk a certain amount of discretion must be employed consistent with the full disclosure of facts necessary to an informed consent" (Salgo vs. Leland Stanford etc. Bd. Trustees, 317 p. 2d 170 - Cal: Court of Appeal, 1st Appellate Dist., 1st Div. 1957).
} 
Es importante mencionar que, la solicitud de negligencia por mal procedimiento fue estudiada de forma separada de la omisión del consentimiento informado, tornándose entonces como dos situaciones diversas que merecían estudio independiente al dar cada hipótesis lugar a responsabilidad médica, aunque se unen en la necesidad de materialización de un daño a la persona.

\subsubsection{Caso Natanson vs. Kline- 1960}

Tres años después del nacimiento del consentimiento informado, la Corte de Apelaciones de Kansas, con sustentación del juez Schroeder, dirimió el caso Natanson vs. Kline. En él, la demandante reclamaba por las lesiones padecidas -quemaduras-, luego de un procedimiento de radioterapia en el sitio en el que previamente se le había practicado una mastectomía y en las áreas circundantes, las cuales alega que fueron ocasionadas por el presunto exceso en la utilización de cobalto radioactivo. Mientras tanto, en su defensa los demandados alegaron que hubo consentimiento, pero no se explicaron todos los riesgos.

La Corte encontró, luego del estudio de las evidencias probatorias, que, si bien no se podía afirmar error sobre la aplicación del cobalto, sobresalía que el tratamiento generaba cierto peligro de lesiones, las cuales dependían en gran medida de la tolerancia de la piel del paciente, tal y como lo reconoció el médico accionado, pero a su vez, esto no había sido advertido. Empero, advirtió que ese hecho no equivalía a casos de assault and battery, donde el paciente no ha dado anuencia alguna.

En ese sentido, la Corte expuso que los supuestos de cirugía no autorizada ${ }^{22}$ se diferencian de los tipos tradicionales assault and battery, dado que en los primeros el médico actúa generalmente de buena fe en pro del beneficio del paciente y es involuntario el hecho de no explicar al paciente los riesgos, pero debe responder si se concretan; mientras que en los otros se actúa por malicia, sin querer otorgar ningún beneficio a la víctima.

\footnotetext{
${ }^{22}$ Se recuerda que en este momento información y consentimiento son una sola doctrina y sin la existencia de la primera no puede consolidarse un consentimiento, por tanto, el procedimiento realizado no está autorizado al ser ineficaz cualquier documento de asentimiento que no lleve información previa.
} 
Es este orden de ideas, el Alto Tribunal sancionó que la cuestión debía dirimirse por negligencia -negligence-, siendo así, el primer cuerpo colegiado en acoger la negligencia como fundamento de la responsabilidad por omisión del consentimiento informado (Faden \& Beauchamp, 1986, p. 129).

En consecuencia, La Corte planteó que el desconocimiento de la obligación del consentimiento informado hace al médico culpable por negligencia, al desviarse del estándar de conducta de un profesional razonable ${ }^{23}$ y prudente en iguales o similares circunstancias -criterio del profesional razonable-. Entonces, se infiere que implicaría acudir a peritos médicos para desentrañar la validez o no de la extensión de la información.

Para la Corte era independiente el hecho que la destreza médica haya sido intachable, si se lograba confirmar que no era suficiente esa información, el médico era responsable, y, por tanto, se debían determinar los daños a partir de lo que no se ha sido consentido. En este sentido, aludió a un vínculo causal entre omisión de información y concreción de riesgos ${ }^{24}$, siempre y cuando la decisión del paciente hubiese sido el rechazo del acto al conocer los peligros propios del mismo.

Ahora, dirimir estos casos como la típica negligencia que se estudia en cualquier caso de responsabilidad impone una carga probatoria mayor a los pacientes, al tener que demostrar que de haberse brindado la información, no hubiesen otorgado el consentimiento ${ }^{25}$. En general, la responsabilidad médica por negligencia implica que de haber actuado de forma correcta y diligente las circunstancias dañosas no se hubiesen presentado ${ }^{26}$. Es decir, y si se centra a los supuestos de

\footnotetext{
${ }^{23}$ La regla del médico razonable era la utilizada ordinariamente en los supuestos de negligencia, pero la noción con el consentimiento informado era nueva, ya que no importaba si la praxis había sido correcta, siendo entonces, un incumplimiento que conllevaba inmediatamente responsabilidad. Sin embargo, hay que destacar que después del caso Natanson, battery y negligence se tomaron como idénticas en cuestiones de consentimiento (Faden \& Beauchamp, 1986, p. 131).

${ }^{24}$ Dice la Corte: "Under the rule heretofore stated, where the patient fully appreciates the danger involved, the failure of a physician in his duty to make a reasonable disclosure to the patient would have no causal relation to the injury. In such event the consent of the patient to the proposed treatment is an informed consent. The burden of proof rests throughout the trial of the case upon the patient who seeks to recover in a malpractice action for her injury".

${ }^{25}$ El problema deviene en cómo demostrar esa "verdad", a través de medios infalibles, cuando ya se han concretado unos daños, ya que el criterio del juicio médico razonable se utilizaría es para establecer si la información brindada era suficiente para otorgar o no un consentimiento informado, lo que implicaba una tarea desgastante para la parte demandante.

${ }^{26}$ En similar postura se encuentran Katz (2002, pp. 65-71) y Faden \& Beauchamp (1986, pp. 129-132).
} 
consentimiento informado, incluso dada la información no se hubiese impedido el daño padecido, entonces no habría lugar a indemnización alguna al romperse la relación causal.

Lo anterior demuestra que, saber por qué y hasta dónde debe responder el médico ante el paciente es una temática que ha generado diversas posturas jurídicas desde sus inicios, no siendo aún un tema zanjado en estos tiempos.

\subsubsection{Caso Gray vs. Grunnagle - 1966}

En 1966 la Corte Suprema de Pensilvania se pronunció respecto del asunto Gray vs. Grunnagle. A la paciente le fue practicada por el acusado una laminectomía exploratoria, generándose una parálisis mayor a la que venía padeciendo, riesgo que no le fue informado al momento de otorgar el consentimiento, pues la formalidad se llevó a cabo al ingresar al hospital en valoración previa, por un facultativo diferente al que realizó el procedimiento días después.

Lo característico de este proceso, es que el médico Grunnagle afirmó que previo a cualquier cirugía él informaba oralmente al paciente todos los riesgos. En su interrogatorio dijo no recordar el caso en específico por el período ya transcurrido - 5 años -, pero aseguró que sí tuvo que haberle dicho el riesgo de aumentar su parálisis. Por su parte, el demandante declara no haber tenido diálogo con el Grunnagle antes de la cirugía; pensaba y había entendido, por lo dicho de forma general por el primer profesional que lo atendió y lo remitió al Dr. Grunnagle, que era una mera operación exploratoria para determinar la causa de su mal.

De esa manera, para la Corte se mostraba evidente una clara contradicción entre lo dicho por los sujetos procesales; y frente a esa realidad, optó por darle veracidad al argumento del demandante, dado que la relación de tiempo de los hechos demostraba que el paciente no consintió con conocimiento de causa.

Resulta importante resaltar que el consentimiento otorgado fue dado de forma general: “[a]utorizo a los médicos a emplear cualquier procedimiento quirúrgico que consideren necesario", lo que deja entrever que, se trataría de un documento que no revela lo exactamente divulgado y, 
de él no se desprende que el paciente conocía, detalladamente y sin duda alguna, el procedimiento a practicar. Por todo, no podía constituir un aval de prueba a favor del médico.

Por otro lado, en opinión disidente de la sentencia se encuentra la postura del juez Bell, quien manifestó que el consentimiento conferido, al ser amplio y claro, es incuestionable y aplicable a la operación. Expuso que no aceptarlo despeja la puerta al fraude al basarse en suposiciones, pues hasta que los cirujanos no intervienen el cuerpo humano no pueden asegurar el procedimiento realmente necesario, y aceptar la nueva regla del consentimiento específico, generaría un aumento de reclamaciones por negligencia, independientemente de la autorización que haya dado el paciente.

Por último, el salvamento de voto es todas luces un atentado contra el actual proceso del consentimiento informado que requiere de información clara y específica para facilitar la decisión; además, las autorizaciones abiertas no definen realmente el querer del paciente, puesto que se someten a una incertidumbre y quedan en potestad paternalista del médico. Sin embargo, lo expuesto por el juez divergente, no resulta extraño para esa época, ya que cambiar de un día para otros siglos de silencio, oscuridad comunicativa y dominio del médico en la relación con el paciente, no se alcanza tan fácilmente.

\subsubsection{Caso Canterbury vs. Spence and Washington Hospital Center - 1972}

La doctrina acogió como hito la sentencia del caso Canterbury vs. Spence and Washington Hospital Center de la Corte de Apelaciones para el Distrito de Columbia. El demandante pretendió la reparación de daños por lesiones personales -incontinencia urinaria, parálisis intestinal y parálisis en sus extremidades inferiores que lo obligaban a usar muletas para caminar-, resultado de una laminectomía realizada por el Dr. Spence, en donde no se le informó el riesgo de $1 \%$ parálisis inherente a la misma.

También, se demandó al hospital debido a que la persona intervenida quirúrgicamente, un día después de la cirugía, se cayó de la cama al intentar utilizar un aparato para la micción por sí solo, pues no había personal del hospital para ayudarlo. Ello ocasionó un retroceso en la recuperación, 
que conllevó a la realización de una segunda cirugía, pero no se corrigió correctamente su malestar, por eso los daños reclamados incluyeron dolor y sufrimiento extenso, gastos médicos y pérdida de ingresos.

Por su parte, el galeno justificó su actuación aseverando que comunicar el riesgo leve de parálisis pudo impedir la aceptación y producir reacciones psicológicas adversas que hubiesen afectado el éxito de la operación. Afirmación que es un claro reflejo del clásico pensamiento paternalista.

La Corte reafirmó que el objetivo de informar es proteger al paciente contra las consecuencias que de conocerse se habrían evitado, renunciando al tratamiento; por tanto, todos los riesgos que puedan afectar la decisión del paciente deben ser revelados ${ }^{27}$, teniendo en cuenta que, la peligrosidad de una técnica se mide por la incidencia de la lesión y el grado del daño amenazado.

Para la Corte, el alcance de la divulgación debe ser examinado mediante un estándar común razonable -criterio de la persona razonable- de lo que es fundamental para la decisión del paciente, esto implicaba valorar sus antecedentes y situación actual, en lugar de un juicio profesional. De tal forma, distó de lo expuesto por el juez del caso Salgo, al afirmar que la costumbre médica no puede proporcionar la prueba de su corrección y apenas da un criterio legal, que permite medir la responsabilidad del médico.

Así, se anotó en la sentencia, en el análisis de la responsabilidad por este factor, que para que se generaran consecuencias legales, era necesario que un riesgo que debió relevarse se materializara. De lo contrario, la omisión, aunque reprochable, no generaba responsabilidad ${ }^{28}$ al requerirse una relación causal entre la falla del médico y el daño.

27 "In our view, the patient's right of self-decision shapes the boundaries of the duty to reveal. That right can be effectively exercised only if the patient possesses enough information to enable an intelligent choice. The scope of the physician's communications to the patient, then, must be measured by the patient's need, and that need is the information material to the decision. Thus the test for determining whether a particular peril must be divulged is its materiality to the patient's decision: all risks potentially affecting the decision must be unmasked. And to safeguard the patient's interest in achieving his own determination on treatment, the law must itself set the standard for adequate disclosure" (Canterbury vs. Spence, 464 F. 2d 772 - Court of Appeals, Dist. of Columbia Circuit 1972).

28 "No more than breach of any other legal duty does nonfulfillment of the physician's obligation to disclose alone establish liability to the patient. An unrevealed risk that should have been made known must materialize, for otherwise the omission, however unpardonable, is legally without consequence. Occurrence of the risk must be harmful to the 
De acuerdo con las consideraciones del juez, esa relación causal no debe basarse en una determinación subjetiva de lo que el paciente hubiese decidido si previamente conociera los riesgos, en virtud de que, cuando se investiga la causalidad en un ambiente posterior a la lesión, hacerle la pregunta al paciente de si hubiese declinado o no al tratamiento de haber conocido las consecuencias negativas, es algo puramente hipotético, que ya no obedecerá a la verdad de los hechos, pues será una suposición quizás matizada por las circunstancias acaecidas.

Por tal motivo, se definió por el Tribunal que la mejor forma de resolver la cuestión era sobre una base objetiva en términos de lo que una persona prudente en la posición del paciente habría decidido.

\subsubsection{Caso Cobbs vs. Grant - 1972}

Siguiendo lo dispuesto en el caso Canterbury, en octubre de 1972 fue debatido en California el caso Cobbs vs. Grant, basado en los hechos de que el paciente fue intervenido quirúrgicamente por una úlcera duodenal péptica, en donde si bien le explicaron la naturaleza de la operación, no se revelaron los riesgos inherentes de la cirugía y luego, se materializaron lesiones en el bazo, evolución de una nueva úlcera, gastrectomía y sangrado interno.

La Corte insistió en que la battery debe mantenerse en postulados de ausencia de consentimiento, y por su parte, la negligencia cuando se dio el permiso para el procedimiento, pero no hubo una divulgación de la información pertinente y razonable. En estos casos, la causalidad surgía entre la falta de información y la lesión, lo cual se da siempre y cuando, de haber hecho la revelación, de todos modos, se habría consentido. Sin embargo, como en Canterbury, no podía ser el paciente quien testificara sobre ello, ya que su credibilidad estaba afectada, por eso, se debía medir con el estándar de una persona prudente puesta en el lugar del paciente.

En esta instancia, la Corte puso de presente que los médicos debían tener en cuenta que el paciente, al no ser instruido en las ciencias médicas, no esperaba un curso especializado, puesto

patient, for negligence unrelated to injury is nonactionable. And, as in malpractice actions generally, there must be a causal relationship between the physician's failure to adequately divulge and damage to the patient". 
que, de ser así, estaría preocupado es por el riesgo de muerte, los daños corporales y los problemas con la recuperación. Con relación a los riesgos de muy poca incidencia, el Alto Tribunal señaló que el profesional debía analizar si de acuerdo con la condición del paciente el mismo estaba o no contraindicado, pero no se requería ninguna advertencia más allá de esto.

Para concluir, se establecen en la sentencia varios postulados que actualmente, de una u otra forma, siguen dirigiendo el proceso de la toma de decisiones: los conocimientos del paciente y del médico no son paritarios; el paciente, adulto y capaz, tiene derecho a ejercer control sobre su cuerpo; el consentimiento para ser efectivo debe ser informado y al ser el paciente indocto en la medicina, tiene una confianza implícita en su médico, lo que eleva la obligación profesional en el proceso de toma de decisiones.

\subsubsection{Caso Wilkinson vs. Vesey \& Hunt - 1972}

En 1972 también se destacó el caso Wilkinson vs. Vesey \& Hunt de la Corte de Apelaciones de Rhode Island, mediante el cual, se demandó por las consecuencias en la piel derivadas de tratamientos de radiación, luego de que los médicos acusados diagnosticaran a través de una radiografía, sin realizar biopsia alguna, un tumor maligno.

Este es el primer caso en donde la Corte de ese Estado aplicó la doctrina del consentimiento informado con el estándar de negligencia siguiendo el caso Natanson en este aspecto. Mas, se separó del mismo, en el aspecto probatorio al acoger lo expuesto en Canterbury. En el sentido que, no necesitaba el demandante probar a través de un testigo médico experto la razonabilidad de la comunicación teniendo en cuenta la costumbre médica, debido a que, la divulgación razonable puede cambiar de un caso a otro, por las necesidades informativas y las condiciones del paciente.

La Corte citó a los autores Morris \& Moritz $(1971)^{29}$ e invitó a que los galenos hicieran una revelación simple, prudente y honesta de los riesgos. Asimismo, permitieran que el paciente

\footnotetext{
${ }^{29}$ Literalmente se expone en la Sentencia la exhortación de los autores: "Accordingly, prudent advice to the doctor would seem to be as follows: All medical procedures have risks (the patient not allergic to penicillin yesterday may be violently so today); the greater the risk, the greater the duty to inform. Rule of thumb: unless therapeutic reasons contraindicate, make a simple, quiet, but honest disclosure commensurate with the risk in all cases and let the patient
} 
eligiera los riesgos que deseaba correr, a menos que por razones terapéuticas lo contraindicaran. Dijo que, ello además de ser una buena práctica médica y base para una defensa médico-legal, tenía un valor terapéutico. Así, el paciente en cuyo cuerpo se materializa un riesgo no estará tan conmocionado como aquel que no fue informado y se disminuyen las posibilidades de demandar. La Corte agregó que, más que comunicación entre el médico y el paciente, significaba "menos litigio" entre las partes de la relación.

Esto último, revela que la disertación de la Corte se orienta a que el consentimiento garantiza el derecho del paciente a decidir informadamente, como se venía trabajando de forma exclusiva en jurisprudencia anterior, $\mathrm{y}$, además, es una forma de proteger al médico contra futuras reclamaciones y de paso, evitar que entre a funcionar el aparato judicial desgastándolo en litigios que se podrían evitar.

Estas tres decisiones de 1972, como lo indicaron Faden \& Beauchamp (1986, p. 137), consolidaron la tendencia de esos tiempos, incluyendo una nueva perspectiva a la negligencia tradicional al adaptarla a la doctrina del consentimiento informado, pero buscando un equilibrio a nivel probatorio cuando establecieron el criterio de la persona prudente basada en las necesidades del paciente en cuestión, para evaluar la información que debió ser suministrada.

Finalmente, el recuento presentado sobre la jurisprudencia norteamericana destacada hasta los años 70, da cuenta de que fue la protagonista en marcar el inicio del cambio de perspectiva en la relación médico-paciente, influyendo con sus posturas tanto a los jueces de otras latitudes como también, de una u otra forma, a los facultativos, al sentar la pauta para crear una nueva ideología del ejercicio de la profesión.

choose what risks he wishes to run with his body (...) Besides being good medicine, good humanity, good public relations, and good medicolegal defense, the preceding advice has a therapeutic value all its own. The informed and consenting patient, aware of the risk, is not so shocked should the risk turn up in his case and, if patient-physician rapport is high, is much less likely to sue his doctor in the first instance". 


\subsubsection{El auge del consentimiento informado desde la perspectiva ética y legal de alcance internacional}

Después de la Segunda Guerra Mundial (1945), dados los aberrantes tratos y prácticas desarrolladas en la experimentación con humanos, se emprendieron movimientos internacionales a favor de los derechos humanos para evitar que las atrocidades del conflicto se volvieran a presentar, dando paso al Código de Nüremberg $(1947)^{30}$ y la Declaración Universal de los Derechos Humanos proclamada por Asamblea General de las Naciones Unidas (1948).

En 1947 se llevó a cabo la Primera Asamblea General de la Asociación Médica Mundial -en adelante la AMM- por la iniciativa de 27 médicos de varios países ${ }^{31}$, con el propósito de "asegurar la independencia de los médicos y para servir los niveles más altos posibles en conducta ética y atención médica, en todo momento" (AMM), reemplazando así a la Association Professionnelle Internationale des Médecins creada en 1926. Lo anterior, con el fin de ampliar los adeptos y los lineamientos que la gobernaban dada de su preocupación por el estado de la ética médica en todo el mundo y los problemas que se derivaban de la falta de aplicación, con rigurosidad y sentido, del ya histórico juramento hipocrático.

Aunque las prescripciones de las AMM no son vinculantes, han permitido el esclarecimiento de ciertos temas, al establecer pautas para la atención médico-científica y normas para la conducta ética, convirtiéndose en una autoridad en la materia que representa la opinión de los médicos del mundo. Entre sus políticas éticas, las cuales tienen reconocimiento como estándar ético global respecto del asunto del que tratan, se destacan, por la afinidad con la investigación, las siguientes: la Declaración de Ginebra (1948), el Código Internacional de Ética, Declaración de Helsinki sobre los Principios de Ética Aplicables a la Investigación Médica con Seres Humanos (1964) y Declaración de Lisboa sobre los derechos de los pacientes (1981).

\footnotetext{
${ }^{30}$ El Código de Nüremberg, en Alemania, fue el primer antecedente relacionado con la incorporación en un texto legal de los derechos de los pacientes a la información y consentimiento en las investigaciones para impedir que se siguieran cometiendo abusos y atrocidades en nombre de la ciencia.

${ }^{31}$ Entre ellos estaban de Francia, Dinamarca, España, EEUU, Gran Bretaña, Suecia, Canadá, Egipto, Suiza, entre otros.
} 
Como bien lo expuso la AMM, el espíritu de la época y los aires de modernidad, en virtud de los avances científicos, dieron pie para que en 1948 fuera proclamada la Declaración de Ginebra ${ }^{32}$ por la $2^{\text {a }}$ Asamblea General de la AMM. Esta, se considera como la actualización del juramento hipocrático y lo presenta como una "fórmula laica” (Pacheco, 2007, p. 96) al no invocar el espíritu de los dioses ni hacer referencia a carácter religioso alguno para ser aceptado como miembro de la profesión médica.

Entre los presupuestos del juramento se encuentra que los conocimientos médicos no sean empleados para violar los derechos humanos y libertades ciudadanas, incluso bajo amenaza. Lo cual, significó un gran avance porque se iba haciendo más visible la concepción del paciente como un sujeto agente que tiene derechos. No obstante, no se encontraba referencia exacta al tema del consentimiento informado, esto muy a pesar de que se exigía respeto y beneficencia del profesional hacia su paciente.

Vale advertir que, fue hasta la enmienda del 14 de octubre de 2017 que se introdujo a la Declaración de Ginebra aspectos claves como el respeto de la autonomía y dignidad, lo que a toda luz es un logro, aunque sigue faltando que el juramento consagre expresamente el proceso de consentimiento informado, que, si bien desde la perspectiva ética es una manifestación de la autonomía, actualmente es considerado un derecho y principio autónomo, como se evidencia más adelante.

En 1949 la $3^{\text {a }}$ Asamblea General de la AMM, proclamó el Código de Ética Internacional ${ }^{33}$, en donde inicialmente se estipula que el médico debe respetar los derechos del paciente, de los colegas y de otros profesionales de la salud. Luego, a través de enmienda, se incorpora como deber del médico "respetar el derecho del paciente competente a aceptar o rechazar un tratamiento"; además,

\footnotetext{
${ }^{32}$ Enmendada por la 22a Asamblea Médica Mundial Sydney, Australia, agosto 1968 y la $35^{\text {a }}$ Asamblea Médica Mundial Venecia, Italia, octubre 1983 y la 46ª Asamblea General de la AMM Estocolmo, Suecia, septiembre 1994 y revisada en su redacción por la $170^{\text {a }}$ Sesión del Consejo Divonne-les-Bains, Francia, mayo 2005 y por la $173^{\text {a }}$ Sesión del Consejo, Divonne-les-Bains, Francia, mayo 2006 y enmendada por la $68^{\mathrm{a}}$ Asamblea General de la AMM, Chicago, Estados Unidos, octubre 2017.

${ }_{33}$ Enmendado por la 22a Asamblea Médica Mundial Sydney, Australia, agosto 1968; por la 35a Asamblea Médica Mundial Venecia, Italia, octubre 1983 y por la 57a Asamblea General de la AMM, Pilanesberg, Sudáfrica, octubre 2006.
} 
se indica el respeto hacia los derechos y las preferencias, lo que es una manifestación de aceptar el consentimiento informado dentro de la práctica médica.

Desde otro ángulo, con el propósito de afianzar la obligatoriedad, el campo de acción, el reconocimiento y observancia universal de los derechos consagrados en la Declaración Universal de 1948, la Asamblea General de las Naciones Unidas en 1966 adoptó el Pacto Internacional de Derechos Civiles y Políticos, cuyo artículo $7^{\circ}$ dispone “[n]adie será sometido a torturas ni a penas o tratos crueles, inhumanos o degradantes. En particular, nadie será sometido sin su libre consentimiento a experimentos médicos o científicos"; esto deja ver cómo a nivel mundial se iba materializando la necesidad del consentimiento en la esfera investigativa y clínica.

El reconocimiento, la protección y la garantía de los derechos esenciales también cobró importancia a nivel interamericano, por ello en 1948 fue aprobada la Declaración Americana de los Derechos y Deberes del Hombre entre los que estaban la libertad e integridad.

Más adelante, se acogió la Convención Americana sobre Derechos Humanos -1969- "Pacto de San José de Costa Rica" ${ }^{34}$, que consagra en su artículo 13 la libertad de pensamiento y expresión que comprende el acceso a la información, el cual ha sido interpretado por la Corte Interamericana de Derechos Humanos -en adelante Corte Interamericana- como un derecho humano que permite el "buscar, recibir y difundir informaciones e ideas de toda índole" (Caso Herrera Ulloa. Sentencia de 02/07/ 2004).

El derecho a la información y a la libertad de expresión son sustanciales al permitir “...la consolidación, el funcionamiento y la preservación de los sistemas democráticos ... ha recibido un alto grado de atención, tanto por los Estados miembros de la OEA $^{35}$ como por la doctrina y la jurisprudencia internacional” (Comisión Interamericana de Derechos Humanos, 2009, p. 1).

\footnotetext{
${ }^{34}$ Aprobado por Colombia mediante la Ley 16 de 1972, ratificado el 31 de julio de 1973 entrando en vigor el 18 de julio de 1975.

${ }_{35}$ Organización de Estados Americanos.
} 
Entre tanto, en Estados Unidos fue publicado En 1978 el Informe Belmont ${ }^{36}$ redactado por la Comisión Nacional para la Protección de Sujetos Humanos de Investigación Biomédica y de Comportamiento, el cual, estipuló los principios y guías éticas para la protección de los sujetos humanos de investigación, a saber: respeto a las personas, beneficencia y justicia. Implanta el consentimiento informado como requerimiento básico para hacer efectivo el respeto de las personas, cuyo proceso debe constar de tres elementos: información, comprensión y voluntariedad.

Posteriormente, Tom L. Beauchamp, quien fue parte de la referida Comisión Belmont, y James F. Childress, publicaron la obra "Principles of Biomedical Ethics" (1979), en la cual reformularon los principios Belmont para que fueran aplicados al campo de la experimentación y en la clínica asistencial. Distinguieron cuatro principios ${ }^{37}$ : respeto a la autonomía (se modifica el de respeto a la persona), no maleficencia, beneficencia y justicia, no existiendo prima facie jerarquía entre ellos, pero cuando entran en conflicto su aplicación y prioridad de uno sobre otro, dependen de la ponderación en una situación concreta (Beauchamp \& Childress, 2013, pp. 20-21).

Desde la consideración del consentimiento informado como principio básico de la autodeterminación del paciente (1978), se ha dado una gestación de los derechos de los pacientes como fundamento de las relaciones clínico asistenciales, lo que ha marcado la necesidad de reconocerlos y protegerlos frente al desarrollo de la ciencia y la tecnología. Gracias a organizaciones internacionales competentes en el asunto -Naciones Unidas y sus organismos como Organización de las Naciones Unidas para la Educación, la Ciencia y la Cultura-UNESCO, Organización Mundial de la Salud OMS, Organización Panamericana de la Salud-OPM, la Unión Europea, etc. - (García, Cózar y Almenara, 2004, pp. 469-470), se ha fomentado su protección a través de por ejemplo, la Declaración Universal del Genoma Humano y Derechos Humanos de la Unesco en 1997, el Convenio del Consejo de Europa sobre los Derechos del Hombre y la

\footnotetext{
${ }^{36}$ El Informe Belmont fue el reporte realizado por la Comisión Nacional para la Protección de Sujetos Humanos de Investigación Biomédica y de Comportamiento, creada por Congreso de los Estados Unidos, tras el escándalo público de los experimentos de Tuskegee sobre Sífilis, para que le aconsejara cómo proteger los derechos y el bienestar de las personas incluidas en ensayos clínicos y en experimentos biológicos y médicos a través de principios para establecer la ética en las investigaciones, a lo que llegaron a través de la casuística de hechos concretos para dar paso a unas prácticas moralmente aceptadas por todos y no morales particulares de un grupo o comunidad específica (Gracia, 2008 p. 444).

37 El enfoque de los cuatro principios desarrollado por Beauchamp \& Childress, es conocido ahora como principalismo, al ser una teoría acerca de cómo los principios se vinculan y guían la práctica (2013, p. 25).
} 
Biomedicina del 4 de abril de 1997 (Convenio de Oviedo) y la Declaración Universal sobre Bioética y Derechos Humanos en el 2005 elaborada por la Unesco, en los cuales se consagra la obligatoriedad, cada uno en su campo de aplicación respectivamente, de un consentimiento de carácter previo e informado como requisito independiente.

Así, en 1981 se adopta por la AMM la Declaración de Lisboa Sobre los Derechos del Paciente, cuya última reafirmación se dio en abril de 2015, en donde se señalaron como derechos la autodeterminación del paciente para tomar decisiones libremente y el derecho a la información para poder decidir.

Cabe mencionar que en 1986 se realizó en Ottawa-Canadá la primera Conferencia Internacional sobre la Promoción de la Salud en donde se concretó la Carta de Ottawa para la promoción de la salud y se planteó el propósito de "salud para todos en el 2000" para alcanzar equidad sanitaria, lo que requería promocionar los medios para que la población tuviera acceso a la información y desarrollar las aptitudes y oportunidades que la llevaran a hacer sus opciones en términos de salud.

Es de resaltar que el 20 de noviembre de 1989 fue aprobada por la Asamblea General de las Naciones Unidas la Convención Sobre los Derechos del Niño que establece que el niño que esté en condiciones de formarse un juicio puede expresar su opinión sobre los temas que lo afectan de acuerdo con su edad y madurez (art. 12). Por tanto, los Estados Partes deben respetar las funciones parentales en cuanto a impartir dirección y orientación para que el niño pueda ejercer sus derechos, teniendo en cuenta la "evolución de sus facultades" (art. 5).

Esa "evolución de sus facultades" ha sido acogida como un principio de interpretación de derecho internacional, al no ser homogéneo en todos los niños la adquisición y el desarrollo de la capacidad y competencia para asumir responsabilidades (Lansdown, 2005, p. 19).

Lo anterior, es fundamental en materia sanitaria y ha servido como instrucción en los casos en que se presentan conflictos entre padres, hijos menores de edad y médicos, pues si bien por regla general, los padres representan al niño en la toma de decisiones médicas, ello debe hacerse de acuerdo con el mejor interés y beneficio para él. Sin embargo, cuando sea posible, en simetría con 
su capacidad, derivar su querer y opinión, se le debe escuchar, sobre todo, en aquellos asuntos determinantes de su identidad, como en los casos de intersexualidad para reasignación o readaptación del sexo. Al respecto, la Corte Constitucional colombiana ha expuesto lo siguiente, sustentándose en conceptos médicos:

...a medida que el infante crece, adquiere mayor autonomía y por ello debe respetarse con un margen más amplio su libre desarrollo de la personalidad, pero esto debe ir en compañía de apoyo psicológico y de sus padres, así como de la información suficiente sobre los tratamientos más benéficos en su condición de ambigüedad sexual ... (Sentencia T-622-14 de 28/08/2014)

En 1991, se comenzó a ver más explícito el asunto del consentimiento, aprobándose verbigracia en el Sistema Interamericano los Principios para la Protección de los Enfermos Mentales y el Mejoramiento de la Atención de la Salud Mental, siendo el consentimiento un principio con categoría independiente.

La Declaración de Malta de la AMM sobre las personas en huelga de hambre, adoptada en 1991, destaca el principio de respeto de la autonomía del huelguista, lo que debe ser acatado por el médico. Por tal motivo, "dar instrucciones o ayudar a la alimentación forzada contra un rechazo informado y voluntario es injustificable", aunque, durante el proceso se exige una comunicación continúa del médico con la persona en huelga, para que el primero se cerciore si el huelguista desea o no continuar con dicha decisión y si actúa de forma voluntaria.

Seguidamente, en el 2006 fue aprobada en la Asamblea General de las Naciones Unidas la Convención Internacional sobre los Derechos de las Personas con Discapacidad. Ella cambia el paradigma del trato, actitudes y enfoque en el ejercicio de los derechos de las personas con discapacidad, al tener como propósito "promover, proteger y asegurar el goce pleno y en condiciones de igualdad de todos los derechos humanos y libertades fundamentales por todas las personas con discapacidad, y promover el respeto de su dignidad inherente" (art.1). Sobre el ejercicio del derecho a la salud, dispone que los profesionales deben brindar una atención de 
calidad con las personas con discapacidad, al igual que con el resto de la población, sobre la base de un consentimiento libre e informado (art. 25).

Por otra parte, la Comisión Interamericana de Derechos Humanos, en adelante CIDH, ha hecho énfasis que los Estados miembros de la OEA deben garantizar el derecho de las mujeres al acceso a la información en materia reproductiva, de planificación y salud sexual, por ello los profesionales de la salud tienen como deber:

...[A]sesorar la comprensión por parte de la paciente, con la finalidad de que tome una decisión respecto de la intervención y/o tratamiento. Para ello, se deben considerar las necesidades específicas de información que pueden tener algunos grupos de mujeres, debido a contextos de exclusión, marginalización o discriminación, como las indígenas, afrodescendientes, las adolescentes, las que habitan en zonas rurales y las migrantes. (CIDH, 2011, p. 17)

En el 2007 la OMS anunció las recomendaciones sobre la circuncisión masculina como forma de prevenir la infección por VIH. En este sentido, el procedimiento debe observar los principios de la ética médica y de los derechos humanos, como el consentimiento informado, la confidencialidad y a la ausencia de coerción; pero deben tener en cuenta que, su práctica puede tener connotaciones culturales que pueden estigmatizarla.

Lo anterior, como muestra del compromiso de la OMS de incorporar los derechos humanos en los programas y políticas de atención de salud, por eso básicamente defiende “...la idea de la atención centrada en la persona, que es la materialización de los derechos humanos en la práctica clínica” (Adhanom, 2017, párr.10).

Asimismo, en octubre de 2017 la 68 a Asamblea General de la AMM emitió la Resolución sobre la prohibición de los exámenes anales forzados para probar las relaciones sexuales con personas del mismo sexo, al no tener esos exámenes fundamento científico y violar la ética médica, aun cuando se dé un consentimiento libre, los médicos se deben abstener de realizarlos, debido a que, esos actos resultan "infundados, discriminatorios y potencialmente incriminatorios". 
Mientras tanto, en el plano regional europeo se ha visto también la lucha por la reivindicación de los derechos humanos y en específico, de los pacientes aunando en su libertad y capacidad de decisión, es así, como en 1950 fue acogido el Convenio para la Protección de los Derechos Humanos y de las Libertades Fundamentales.

En 1994 como resultado de unas conferencias realizadas en Ámsterdam, la Oficina Regional para Europa de la OMS definió los principios y estrategias para promover los derechos de los pacientes a través de la Declaración de los Derechos de los Pacientes Europeos, entre los que se encuentra el consentimiento informado.

En 1997 los Estados miembros del Consejo de Europa proclamaron el Tratado Sobre los Derechos del Hombre y la Biomedicina (Convenio de Oviedo) ${ }^{38}$, donde se estipula que toda intervención en el ámbito de la sanidad solo podrá efectuarse después de que la persona afectada haya dado su libre e informado consentimiento (art. 5) y se reafirma, el derecho a ser informado (art. 10).

Para el año 2000, la Unión Europea expide la Carta de los Derechos Fundamentales o Tratado de Niza, reconociendo en el acápite del derecho a la integridad que, en el ámbito de la medicina y la biología debe ser respetado "el consentimiento libre e informado de la persona de que se trate" (art.2).

En el 2002 fue firmada la Carta Europea de los Derechos de los Pacientes que proclama catorce derechos del paciente, e incluye en su catálogo, el consentimiento, la información y la libre elección. Igualmente, hace hincapié que los referidos derechos son una "encarnación de los derechos fundamentales y como tales, deben ser reconocidos y respetados independientemente de las limitaciones financieras, económicas o políticas, teniendo en cuenta los criterios de adecuación de los cuidados médicos".

\footnotetext{
${ }^{38}$ Este Convenio resulta relevante dado que tiene carácter jurídico vinculante para los Estados que los suscribieron.
} 
El reconocimiento de los derechos humanos ha evolucionado a través del tiempo, se ha ampliado y concretado su contenido y esfera de protección, por eso desde su núcleo inicial -la libertad- se fueron articulando los derechos individuales en todos los ámbitos de la vida y la sociedad, hasta llegar a los derechos socioeconómicos, colectivos y los correspondientes a la era digital. Por todo, los derechos se perfilan como “...el primer criterio inspirador y el límite estricto de cualquier normativa, tanto jurídica como ética" (Casado, 1998, p. 118).

El conjunto de convenciones y declaraciones enseñan que los derechos humanos son parte fundamental de la sociedad y deben estar presentes en cualquier relación. La protección de los derechos constituye un principio general de derecho internacional y cimiento de los ordenamientos jurídicos internos, ratificando la dignidad de la persona y su reconocimiento como sujeto de derechos merecedor de respeto, lo que implica que en el plano estatal, junto al principio de soberanía, reina hoy “...el principio constitucional y estructurante del orden internacional contemporáneo de los derechos humanos" (Nogueira, 2000, p. 4).

En razón a ello, a nivel interno de los Estados se ha debatido y legislado sobre el consentimiento informado, como derecho digno de reconocimiento y protección en la práctica médica e investigativa-experimental, dado que los pactos internacionales de derechos humanos y de derecho humanitario internacional, como derecho supraestatal, dan pie para que los países miembros se supediten "al bien jurídico superior de la dignidad y de los derechos esenciales de las personas, constituyendo [e]stos un derecho, inmediatamente vinculante para los Estados" (Nogueira, 2000, p. 5).

\section{Marco ético-legal del consentimiento en Colombia}

\subsection{Legislación}

La Ley 23 de $1981^{39}$ «Código de Ética Médica», reglamentada por el Decreto 3380 de $1981^{40}$, consagra de forma tímida aspectos generales de la obligación de información del médico y de la

\footnotetext{
${ }^{39}$ Ver artículos $11,12,14,15$ y 18.

${ }^{40}$ El tema de información y consentimiento es tratado en los artículos 7 y 9-13.
} 
obligatoriedad de requerir la autorización previa del paciente a cualquier tratamiento con la advertencia de los riesgos previstos. Además, en ellos no se desarrolla el consentimiento informado del paciente como institución.

La Ley 1098 de 2006 «por la cual se expide el Código de la Infancia y la Adolescencia» aboga por la garantía de los derechos a la autonomía y libre desarrollo de la personalidad de los niños, niñas y adolescentes, por ejemplo, la familia debe "formarles, orientarles y estimularles en el ejercicio de sus derechos y responsabilidades y en el desarrollo de su autonomía" (art. 38, núm. 3). Además, consagra que en los procesos por delitos en donde son víctima los menores de edad, la autoridad debe tener en cuenta la opinión de estos en los reconocimientos médicos que deban llevarse a cabo (art. 193, núm. 8), lo que pone de manifiesto la prevalencia de respetar su dignidad, intimidad, autonomía e integridad, y en caso de no poder manifestar su voluntad, el consentimiento debe ser otorgado por los padres, representantes legales o en su defecto el defensor de familia o comisaría de familiar y a falta o ausencia de estos, el personero o el inspector de familia.

La Ley 1306 de 2009 «por la cual se dictan normas para la Protección de Personas con Discapacidad Mental y se establece el Régimen de la Representación Legal de Incapaces Emancipados» dispone que, para la garantía y protección de los derechos de las personas con discapacidad mental debe tenerse como principio "el respeto de su dignidad, su autonomía individual, incluida la libertad de tomar las propias decisiones y su independencia” (art.3), así como la participación y el respeto a las capacidades evolutivas de los menores de edad en condición de discapacidad (art. 3).

Entre tanto, en el 2010 fue promulgada la Ley 1412 «por medio de la cual se autoriza la realización de forma gratuita y se promueve la ligadura de conductos deferentes o vasectomía y la ligadura de trompas de Falopio como formas para fomentar la paternidad y la maternidad responsable», cuyo art. 5, intitulado "del consentimiento informado y cualificado" hace expreso la obligación de los médicos de informar sobre el procedimiento a practicar y las alternativas de otros

El Decreto 3380 fue compilado por el Decreto 780 de 2016 -por medio del cual se expide el Decreto Único Reglamentario del Sector Salud y Protección Social - del Ministerio de Salud y Protección Social, con el propósito de simplificar y unificar las normas de la misma naturaleza. 
métodos anticonceptivos no quirúrgicos; así mismo, se prohíbe la anticoncepción quirúrgica a menores de edad ${ }^{41}$.

También, se debe mencionar la Ley 1566 de 2012 «por la cual se dictan normas para garantizar la atención integral a personas que consumen sustancias psicoactivas y se crea el premio nacional "entidad comprometida con la prevención del consumo, abuso y adicción a sustancias psicoactivas"» dispone la necesidad del consentimiento informado del consumidor para poder preceder a la atención integral, mismo que puede ser revocado. Además, se requiere de una información de calidad que incluya explicación sobre el tratamiento, riesgos, beneficios, alternativas, eficacia, duración, restricciones durante el proceso, sus derechos y todo lo que se pueda considerar relevante para la persona, su familia o red de apoyo social o institucional (art. 4).

Por otra parte, la Ley 1616 de 2013 «por medio de la cual se expide la ley de Salud Mental» consagra entre los derechos de las personas en el ámbito de la salud mental, recibir información, exigir que sea tenido en cuenta su consentimiento informado ante un tratamiento y que las intervenciones sean lo menos restrictivas de la libertad (art. 6).

La Ley 1733 de 2014 «mediante la cual se regulan los servicios de cuidados paliativos para el manejo integral de pacientes con enfermedades terminales, crónicas, degenerativas e irreversibles en cualquier fase de la enfermedad de alto impacto en la calidad de vida» consagra el derecho a la información clara, detallada y comprensible por parte del médico tratante, sobre el diagnóstico, pronóstico, las opciones terapéuticas paliativas y los riesgos en caso de rehusar la alternativa recomendada. Igualmente, la facultad de suscribir voluntades anticipadas de negación de tratamientos nimios para prolongar la vida (art. 5).

\footnotetext{
${ }^{41}$ La Corte Constitucional se pronunció sobre la exequibilidad de dicha prohibición señalando que no se afecta el derecho a la autodeterminación: "la prohibición de practicar la anticoncepción quirúrgica de los menores de edad es constitucional porque es el desarrollo de la facultad que la Constitución otorgó al Legislador para regular la paternidad responsable y la protección de los niños. De este modo se salvaguarda su consentimiento futuro pleno y en todo caso no se impide a los menores adultos ejercer la paternidad responsable a través de otros métodos de planificación. En todo caso, cuando la vida del menor corra peligro a raíz del embarazo o del parto y no existan otras alternativas eficaces para evitarlo, se admitirá la esterilización siempre y cuando se cuente con la autorización informada del paciente, exista un concepto médico interdisciplinario que certifique el riesgo inminente para la vida y se obtenga una autorización judicial previa" (Sentencia C-131-2014 de 11/03/2014).
} 
A través de la Ley Estatutaria 1751 de 2015 se instituyó el derecho a la salud como fundamental, e incluye en el listado de derechos, el de gozar de una comunicación plena, expresa y clara con el profesional tratante; asimismo, una información óptima que permita tomar decisiones libres, conscientes e informadas (art. 10).

La Ley 1799 de 2016 prohibió expresamente la realización de procedimientos médicos y quirúrgicos estéticos en pacientes menores de 18 años (art. 3), y señala que el consentimiento de los padres no constituye excepción válida a dicha proscripción, disposición que en análisis de constitucionalidad por la Corte Constitucional fue declarada exequible, pero en el entendido que los previsto en la norma no es aplicable a los adolescentes mayores de 14 años $^{42}$ con capacidad evolutiva que les permite participar, con quienes ostentan la patria potestad, en la decisión sobre los riesgos que se asumen, autodeterminarse y en función del consentimiento informado y cualificado tomar decisiones reflexivas (Sentencia C-246-17 de 26/04/2017).

En tanto, cursa en el Congreso el Proyecto de Ley 042 de $2017^{43}$ en aras de expedir un Nuevo Código de Ética Médica. Actualmente, se encuentra pendiente segundo debate y votación en Plenaria de Cámara ${ }^{44}$. El contenido del proyecto en lo relacionado con el consentimiento informado, será presentado y analizado en el cuerpo de la presente investigación.

\subsection{Resoluciones del Ministerio de Salud y Protección Social}

A nivel legislativo no se han presentado los verdaderos cambios que adapten la relación médicopaciente a las nuevas visiones de horizontalidad entre los sujetos involucrados, el Ministerio de Salud y Protección Social es quien ha abanderado el diseño de los derechos del paciente y su exigencia en todas las órbitas de la práctica clínica e investigativa, teniendo en cuenta que entre su objetivo se encuentra el formular, adoptar, dirigir coordinar, ejecutar la política pública en materia

\footnotetext{
42 "[1]a edad de 14 años es el momento que, en general, se ha establecido que los menores de edad pueden tener la madurez para comenzar a asumir obligaciones y responsabilidades en la sociedad, como, por ejemplo, el matrimonio" (Sentencia C-246-17 de 26/04/2017).

${ }^{43}$ En el año 2015 se presentó el Proyecto de Ley 024 con el mismo objetivo, pero fue archivado por razones de trámite. ${ }^{44}$ Esto a fecha 24/04/2019, conforme a la información suministrada por la Unidad Coordinadora de Atención Ciudadana del Congreso de la República.
} 
de salud (Decreto 4107 de 2011 art. 1). En este orden de ideas, se destacan las siguientes resoluciones:

Resolución 13437 de 1991, que acogió el Decálogo de Derechos de los Pacientes aprobado por la Asociación Médica en Lisboa en 1981, en el parágrafo 2 del art. 1 dispone que todo paciente, sin discriminación alguna, tiene derecho a disfrutar de una comunicación plena y clara con el médico, para recibir información y consentir o rechazar un procedimiento.

Cabe señalar que el término consentimiento informado fue acuñado por primera vez en la Resolución 8430 de 1993 «sobre requisitos para el desarrollo de actividades investigativas en salud», definiéndolo como un acuerdo que se realiza por escrito, mediante el cual el sujeto de investigación o su representante "autoriza su participación en la investigación, con pleno conocimiento de la naturaleza de los procedimientos, beneficios y riesgos a que se someterá, con la capacidad de libre elección y sin coacción alguna" (art. 14); de la misma forma, "para la fertilización artificial se requiere obtener el Consentimiento Informado de la mujer y de su cónyuge o compañero ... previa información de los riesgos posibles para el embrión, feto o recién nacido en su caso" (art. 30).

El consentimiento informado también cobra relevancia para la práctica de terapias alternativas en la prestación de servicios de salud (Resolución 2927 de 1998), por lo que su ejercicio debe contar con la autorización previamente informada del interesado.

Mientras tanto, la Resolución 1995 de 1999 «por la cual se establecen normas para el manejo de la Historia Clínica» apuntó que, las autorizaciones para intervenciones quirúrgicas (consentimiento informado) son documentos que hacen parte de los llamados anexos de la historia clínica y sirven como sustento legal, técnico, científico y/o administrativo. Entonces, la práctica del consentimiento informado debe consignarse en la historia clínica del paciente, dado que la autorización puede ser oral o escrito, y en este último caso, adjuntar el instrumento.

En la Resolución 4905 de 2006 «por la cual se adopta la Norma Técnica para la atención de la Interrupción Voluntaria del Embarazo en los casos definidos por la sentencia C-355 de 2006 de la 
Corte Constitucional», se insiste en la necesidad de la gestante de dar su consentimiento informado previo a la provisión del servicio.

La prestación servicios de salud en la modalidad de telemedicina (Resolución 1448 de 2006) requiere el consentimiento del paciente, a quien anticipadamente se le debe explicar en qué consiste la modalidad del servicio, los riesgos y beneficios del mismo. Esto, con constancia en la historia clínica, plasmando el paciente su firma autógrafa o huella dactilar como muestra de comprender la información y aceptar la atención (art. 12).

En la Resolución 2378 de 2008 «por la cual se adopta el Manual de Buenas Prácticas Médicas para la Investigación con Medicamentos en Seres Humanos» se define el consentimiento informado, como un proceso que confirma el deseo del sujeto de participar en un estudio determinado después de haber sido informado, el cual concluye con un formato que requiere que sea firmado y fechado por el participante, dos testigos y el médico investigador.

En cuanto a las técnicas de planificación familiar se hace hincapié que previamente se debe dar consejería para dar paso al consentimiento informado (Resolución 001973 de 2008).

En el empeño de unificar la regulación respecto de los lineamientos de la Carta de Derechos y Deberes del Afiliado y del Paciente, fue promulgada la Resolución 4343 de 2012, entre sus lineamientos se destacan el derecho del paciente a disfrutar y mantener una comunicación plena y clara con el personal de la salud, teniendo en cuenta las condiciones sicológicas y culturales; estar informado de los procedimientos y tratamientos que se le vayan a practicar, así como del pronóstico y las consecuencias de estos. De igual modo, el derecho a que sea el paciente o su representante quien acepte o rechace cualquier tratamiento (4.2. capítulo de derechos).

A través de la Resolución 1441 de 2013 «por la cual se definen los procedimientos y condiciones que deben cumplir los Prestadores de Servicios de Salud para habilitar los servicios y se dictan otras disposiciones», se estableció el Manual de Habilitación de Prestadores de Servicios de Salud que contiene las condiciones mínimas para que los servicios de salud ofertados y prestados en el país cumplan con la condición de brindar seguridad a los usuarios en el proceso de 
la atención en salud, definiendo el consentimiento informado como "la aceptación libre, voluntaria y consciente de un paciente o usuario, manifestada en el pleno uso de sus facultades después de recibir la información adecuada, para que tenga lugar un acto asistencial", documento que se genera posteriormente a la aceptación haciendo parte de la historia clínica.

El referido Ministerio emitió la Resolución 2003 de 2014 «por la cual se definen los procedimientos y condiciones de inscripción de los Prestadores de Servicios de Salud y de habilitación de servicios de salud» a través de ella, se reitera el consentimiento informado como procedimiento obligatorio a todo tratamiento e intervención en salud, que debe quedar documentado.

Para hacer efectivo el derecho a morir con dignidad de las personas mayores de edad, la Resolución 1216 de 2015 fijó las directrices para la realización de ese acto médico, mismo que requiere de un previo consentimiento libre, informado e inequívoco de llevar a cabo tal garantía por parte del titular y en caso de incapacidad legal o física se permite el consentimiento sustituto.

Por su parte, la Resolución 001904 de 2017 adoptó el reglamento para garantizar que las personas con discapacidad accedan a la información y al proceso de consentimiento informado, en lo relacionado con sus derechos sexuales y reproductivos. También delimitó el consentimiento informado de personas con discapacidad para el ejercicio de sus derechos sexuales y derechos reproductivos señalando que "la manifestación libre e informada de la voluntad emitida por las personas con discapacidad en ejercicio de su capacidad jurídica y en igualdad de condiciones con los demás, utilizando para ello los apoyos, ajustes razonables y salvaguardias cuando sean necesarios" (art. 5 numeral 4).

Por otro lado, la Resolución 825 de 2018 estableció el procedimiento para garantizar el derecho a morir con dignidad de los niños, niñas y adolescentes, en donde el consentimiento libre e informado juega un papel trascendental para solicitar la aplicación del procedimiento eutanásico de acuerdo con las particularidades del caso y de la edad del paciente, lo cual puede desistirse en cualquier momento. 
Recientemente fue expedida la Resolución 2665 de 2018, con el propósito de reglamentar el llamado Documento de Voluntad Anticipada (DVA), a través del cual cualquier persona, en uso de sus facultades legales y mentales, puede declarar anticipadamente no ser sometida a procedimientos o tratamientos médicos innecesarios para para prolongar su vida.

Las anotadas disposiciones ministeriales concretan la política pública regulatoria del consentimiento informado en el campo médico, al promover su cultura para asegurar al paciente el goce efectivo de sus derechos.

\section{El consentimiento informado: perspectiva constitucional colombiana}

El consentimiento informado, como se desglosa de las regulaciones y orientaciones nacionales e internacionales, tiene la connotación de proceso, de obligación médico, de derecho y de principio base de la relación médico-paciente.

En los albores de la Corte Constitucional, el consentimiento informado era una manifestación del derecho de la autonomía, siendo vital para la efectividad y garantía de la toma de decisiones libres que orienten el curso de la vida del paciente. La autonomía se desprende del principio general de libertad, consagrado en la Carta Política, que marca los lineamientos de un Estado democrático social de derecho (Sentencia T-401-1994 de 12/09/1994).

Primeramente, a la obligación del médico de informar ${ }^{45}$ al paciente se le dio la categoría de principio adscrito al de la autonomía, por lo que no siempre resulta exigible en igual grado. A su vez, se estipuló que debía ser interpretada teniendo en cuenta otros valores de la práctica médica, como la finalidad curativa de la medicina (Ley 23 de 1991 art. 1), la dignidad y autonomía médica (C.P. arts. 16, 25 y 26) (Corte Constitucional, sentencia T-401-1994 de 12/09/1994). Lo que se justifica, dado que estos últimos pueden entrar en contradicción con las decisiones que tome el paciente, pero el facultativo no está atado a realizar una práctica que considere nociva para la vida

45 Es importante aclarar, que, una vez analizado el contenido de las sentencias constitucionales de la Corte Constitucional, el consentimiento informado como unidad y doctrina no fue considerado dentro del ámbito de principio, fue solo la obligación de informar quien adquirió primeramente este carácter, el cual da como consecuencia decisiones libres y conscientes. 
o salud del paciente y que contravenga los principios éticos de la profesión (Corte Constitucional, sentencia T-925-2001 de 29/08/2001) ${ }^{46}$.

Al ser la información un principio, su fuerza normativa se logra a través del ejercicio de la ponderación en caso de haber contradicciones con otros principios y reglas. Por ende, resulta primordial el elemento fáctico para determinar el alcance de la información en un paciente determinado (Corte Constitucional, sentencia T-401-1994 de 12/09/1994).

Luego, en 1995 fue definido como principio, por el Máximo Tribunal Constitucional, el consentimiento informado. Su carácter se construye desde la autonomía, la dignidad, la integridad y el libre desarrollo de la personalidad ${ }^{47}$. En esta línea, se afirmó que el consentimiento informado “...no es otra cosa que la tensión constante hacia el porvenir que le permite al hombre escoger entre diversas opciones. Es la existencia como libertad: tomar en sus manos su propio devenir existencial" (Sentencia T-477-1995 de 23/10/1995).

La inobservancia de los médicos del consentimiento informado niega no solo los derechos y principios constitucionales citados, adicionalmente, contraviene el principio de pluralismo (art. 1 y 7 C.P). Ello, en razón de que permite la diversidad de formas válidas de valorar los beneficios y riesgos de un procedimiento médico, dado que no es aceptable que la opinión del profesional se imponga sobre la del directamente afectado, lo que desconoce, de igual forma, el sentido del principio bioético de beneficencia (Corte Constitucional, sentencia SU-337-1999 de 12/05/1999).

\footnotetext{
${ }^{46}$ En esta acción de tutela la Corte Constitucional negó el amparo de los derechos a la vida, la salud y a la seguridad social, dado que no se podía obligar al centro de salud accionado a realizar una cirugía de dos hernias umbilicales a la paciente en contravía de las indicaciones médicas, pues el éxito de la intervención dependía de la reducción previa de peso, de no ser así la cirugía sería altamente peligrosa y aumentaría el riesgo de morbilidad.

47 "En el Estado Social de Derecho, que reivindica al hombre como individuo libre y autónomo, incurso en continuo proceso evolutivo, epicentro de la organización política, fin y no medio de las acciones del Estado, el consentimiento del paciente se erige como manifestación expresa del principio constitucional que reconoce en él un ser razonable, dotado de entendimiento que posibilita la realización de su libertad, pues es su "razón" la única que puede válidamente determinar, previa información sobre las características y posibles consecuencias de un determinado tratamiento médico, si lo acepta o no, decisión que será legítima y constitucional siempre que provenga de un individuo plenamente capaz y que con ella éste no incumpla con la obligación que tiene de brindarse a sí mismo el cuidado integral que su persona requiera, o con el deber de no infringir con sus decisiones daño a terceros o a la colectividad" (Corte Constitucional, sentencia T-474-1996 de 25/09/1996).
} 
El consentimiento informado implica en materia médica la formación “...de un pacto o convención entre el conjunto de profesionales tratantes y el paciente con el fin de adoptar las medidas curativas necesarias para la recuperación o rehabilitación del enfermo" (Corte Constitucional, sentencia T- 1025-2002 de 27/11/2002). En atención a lo cual, denota que se encuentra íntimamente relacionado con el derecho a la información (art. 15 C.P), se complementan entre sí, ya que solo con una información clara, objetiva, idónea y oportuna se puede manifestar posteriormente una aceptación o rechazo de un procedimiento (Corte Constitucional, sentencia C313-2014 de 29/05/2014).

En consecuencia, la facultad del paciente de tomar decisiones -consentimiento informadocomo "dispositivo de tutela" (De La Maza, 2010, p. 116), se considera entonces como un derecho de carácter fundamental (Corte Constitucional, sentencia T-452-2010 de 15/06/2010).

Recientemente, la Corte Constitucional ha consolidado el consentimiento informado bajo cuatro consideraciones. En primer lugar, con la categoría de principio autónomo que no se encuentra adscrito al de autonomía; seguidamente, hace parte del derecho a la información como componente del derecho a la salud; también, permite la materialización y protección de otros principios y derechos fundamentales (Corte Constitucional, sentencia C-182-2016 de 13/04/2016) y a finalmente, como derecho ${ }^{48}$ “....indispensable para la protección de la integridad personal dado que el cuerpo del sujeto es inviolable y no puede ser intervenido ni manipulado sin su permiso" (Corte Constitucional, sentencia C-405-2016 de 03/08/2016) ${ }^{49}$.

\footnotetext{
${ }^{48} \mathrm{La}$ existencia del catálogo de garantías fundamentales no implica que sea un listado cerrado y taxativo que niegue la consideración de tal categoría a otros propios de la existencia humana, lo que se conoce como derechos innominados o no positivizados, esto deviene precisamente del artículo 94 constitucional que reza "la enunciación de los derechos y garantías contenidos en la Constitución y en los convenios internacionales vigentes, no debe entenderse como negación de otros que, siendo inherentes a la persona humana, no figuren expresamente en ellos". Sin embargo, determinar qué es o no un derecho fundamental, cuando el mismo no está estipulado expresamente, no ha sido tarea fácil para los jueces constitucionales, al no estar definido por la Carta Política tal concepto, por lo que la Corte Constitucional como guardiana de la Carta Política, ha expuesto dos criterios principales para hacer la verificación: la persona humana y el reconocimiento expreso, conteniendo el primero una base material (lo que es esencial a la persona - inherente e inalienable) y el segundo una formal; y cuatro criterios auxiliares que servirán de apoyo a la tarea interpretativa del juez constitucional: a) los Tratados internacionales sobre derechos humanos (art. $93 \mathrm{CN}$ ), b) los derechos de aplicación inmediata (art. $85 \mathrm{CN}$ ), c) derechos que poseen un plus para su modificación (art. $377 \mathrm{CN}$ ) y d) los derechos fundamentales por su ubicación y denominación (Sentencia T-002-1992 de 08/05/1992).

${ }^{49}$ En la sentencia T-303 de 2016 la Corte Constitucional señala que "este derecho consiste en ser informado de manera clara objetiva, idónea y oportuna de aquellos procedimientos médicos que afecten en mayor o menor medida otros bienes jurídicos esenciales como la vida y la integridad personal".
} 
Por su parte, la Sala de Casación Civil de la Corte Suprema de Justicia le ha dado al consentimiento informado el carácter doble de derecho fundamental y "deónticamente, el consentimiento informado en materia de responsabilidad médica tiene la categoría de principio autónomo" (Sentencia SC7110-2017 de 24/05/2017) ${ }^{50}$. En la misma línea, se encuentra el Consejo de Estado-Sección Tercera ${ }^{51}$, quien ha señalado que al ser un principio su aplicación debe ajustarse a cada situación clínica (Sentencia de 06/03/2013, exp.1993-00356-01(25715)).

De tal manera, el consentimiento informado como principio constitucional irradia todo el ordenamiento jurídico al dotarlo de fundamento y justificación axiológica (ético-política). De ahí que, sea norma fundamental que por sí misma es percibida como justa o correcta (Guastini, 2016, pp. 76-77). Caracteriza la actividad sanitaria y, además, es exigible su observancia en todas las relaciones entre privados y entre particulares y el Estado donde se requiera voluntad para asumir obligaciones, responsabilidades y tomar decisiones.

Es de señalar que, los principios tienen carácter prima facie $e^{52}$. Implican que "algo debe ser realizado en la mayor medida posible, teniendo en cuenta las posibilidades jurídicas y fácticas" (Alexy, 1993, p. 99). Es decir, su funcionamiento se erige como "mandatos de optimización" (Alexy, 1993, p. 86), visualizándose como dispositivos de ponderación de los diversos intereses encontrados al momento de su aplicabilidad (De La Maza, 2010, p. 116). No siempre serán exigibles en su totalidad, pueden ser maleable y cumplidos en diferentes grados dependiendo de las circunstancias particulares, especialmente las condiciones clínicas de un paciente.

Los principios por sí solos pueden resultar demasiados indeterminados al ser generales, con supuestos de hecho abierto y defectibles al admitir excepciones implícitas no especificadas, que no permiten un mero razonamiento deductivo (Guastini, 2016, pp. 77-78). Se requiere que sean desarrollados para enriquecer su contenido, a través de la especificidad coherente con el resto de

\footnotetext{
${ }^{50}$ Sobre esta misma cuestión ver las sentencias STC4819-2017 de 05/04/2017 y SC9721-2015 de 27/07/2015 de la Corte Suprema de Justicia-Sala de Casación Civil.

${ }^{51} \mathrm{Al}$ respecto se pueden leer también las providencias de 27/03/2014 exp. 2000-01924-01(26660) y de 03/05/2007 exp. 1996-05556-01(16098).

${ }^{52}$ Decir que una norma es prima facie implica por sí misma que debe cumplirse, salvo si entra en conflicto con otra de igual o mayor valor, por ello compromete a menos que sea anulada o condicionada por otras (Beauchamp y Childress, 2002, p. 29).
} 
principios y normas, lo que permite determinar su aplicabilidad de acuerdo a la situación fáctica. No obstante, se pueden presentar casos difíciles, en donde el ejercicio de ponderación suele tener un grado alto de subjetividad, y no admiten reducir los intereses contrapuestos (Beauchamp y Childress, 2002, pp. 25-28).

En algunas ocasiones, mientras se especifica el principio también se pondera y a la inversa. Por ello, los dos -especificación y ponderación- son sistemas o métodos que facilitan el funcionamiento de los principios, y hacen parte de uno más genérico que es la coherencia. En este sentido, ponderar puede resultar más práctico en casos determinados al demostrar la prevalencia de un principio sobre otro, a través de un proceso de justificación con razones adecuadas; y la especificación, sería más útil para elaborar líneas de acción que desarrollen su significado (Beauchamp y Childress, 2002, pp. 28-30).

Por consiguiente, ante un eventual conflicto entre el consentimiento informado con otros intereses y postulados constitucionales, como regla general, se le debe dar prevalencia. Empero, al no tener un carácter absoluto, existen situaciones excepcionales ante los cuales debe ceder o su observación es menos estricta, como ocurre ante una situación de emergencia en donde esté en peligro la vida del paciente ${ }^{53}$.

Ahora bien, a nivel ético-legal se ha demarcado su ámbito de aplicación, pero ha sido la Corte Constitucional, a través de su jurisprudencia, quien ha establecido una línea amplia de las características estructurales de este principio-derecho, para guiar los actos en la relación médicopaciente. De esta forma, ha dispuesto subreglas a través de la solución de los casos concretos y en el análisis de constitucionalidad de ciertas normas.

Así, la doctrina del consentimiento informado debe cumplir con tres requisitos:

...(i) libre, es decir, debe ser voluntario y sin que medie ninguna interferencia indebida o coacción; (ii) informado, en el sentido de que la información provista debe ser suficiente, esto es -oportuna, completa, accesible, fidedigna y oficiosa- y en algunos casos; (iii)

\footnotetext{
${ }^{53}$ Esta temática será ampliada en el capítulo II.
} 
cualificado, criterio bajo el cual el grado de información que debe suministrarse al paciente para tomar su decisión se encuentra directamente relacionado con la complejidad del procedimiento. Así, en los casos de mayor complejidad también pueden exigirse formalidades adicionales para que dicho consentimiento sea válido, como que se dé por escrito... para todos los casos se requiere que la persona pueda comprender de manera autónoma y suficiente las implicaciones de la intervención médica sobre su cuerpo (Corte Constitucional, sentencia C-246-2017 de 26/04/2017).

Desde esta perspectiva, en el ámbito constitucional el consentimiento informado es un principio y un derecho humano individual y primario, con carácter positivo y negativo, pues el paciente puede rehusarse a recibir información. Entonces, el consentimiento informado se ha agregado al listado clásico de derechos, pero no es el único elevado a este rango en los últimos tiempos, junto a este, podrían situarse otros íntimamente relacionados con él, como la salud y el derecho a morir dignamente.

\section{Importancia del consentimiento informado en la praxis médica}

La relación médico-paciente es por naturaleza desigual por la complejidad de la ciencia médica, al tornarse de difícil comprensión. Ese desequilibrio nunca podrá remediarse por completo, aun con la obligación de informar que recae sobre el galeno (Llamas, 1988, p. 148).

Para paliar esas asimetrías y lograr la protección de los derechos de la personalidad, entra en funcionamiento el consentimiento informado, el cual, como principio constitucional y derecho fundamental, marca las directrices que deben definir y salvaguardarse en el ámbito de las relaciones sanitarias. Todo con el fin, de garantizar los derechos del paciente y darle efectividad al servicio de salud para obtener mejores resultados en todas las etapas de la prestación del servicio de salud -anamnesis, diagnóstico, tratamiento y actos posteriores para evaluar los resultados ${ }^{54}$-.

\footnotetext{
${ }^{54} \mathrm{El} \mathrm{Consejo} \mathrm{de} \mathrm{Estado} \mathrm{ha} \mathrm{establecido} \mathrm{que} \mathrm{la} \mathrm{responsabilidad} \mathrm{médica} \mathrm{se} \mathrm{desprende} \mathrm{de} \mathrm{la} \mathrm{negligencia} \mathrm{en} \mathrm{los} \mathrm{actos}$ médicos propiamente dichos comprendiendo las etapas de "diagnóstico y tratamiento de las enfermedades, incluidas las intervenciones quirúrgicas, y de otra, todas aquellas actuaciones previas, concomitantes y posteriores a la intervención del profesional médico, que operan desde el momento en que la persona asiste o es llevada a un centro médico estatal, actividades que están a cargo del personal paramédico o administrativo". Seguidamente, esta Corporación, siguiendo a Bueres (1994, pp. 424-225), expuso que dada distinción entre el acto médico propiamente
} 
La doctrina del consentimiento informado cambia la tradicional mutilación de la capacidad de decisión del enfermo, pero no pretende que facultativos hagan un "bello discurso" 55 , ni tampoco que sean oradores retóricos o habilidosos ponentes frente al enfermo. Por el contrario, busca adaptar al siglo XXI las dos exigencias fundamentales del logos kalós de Platón: “... adecuación real a las necesidades del paciente y empleo de la palabra «según arte», diciéndola bien y sabiendo en todo momento qué se dice con ella y por qué es precisamente eso lo que entonces se dice" (Laín, 1964, p. 335).

Además, el consentimiento informado aflora por establecer comunicaciones efectivas que requieren de dos instantes: información y decisión. De modo que, para cumplir con el mismo no es válido tan solo que el paciente firme una autorización, se requiere que el consentimiento se convierta en todo un proceso que permita la autodeterminación del paciente, legitime el proceder del profesional y a su vez, refuerce la relación de confianza entre las partes.

De acuerdo con Simón (2000, p. 252), el consentimiento informado es un proceso previo a un acto médico, de carácter comunicativo, deliberativo e interactivo de toma de decisiones entre el paciente y el profesional de la salud, donde se asumen riesgos y responsabilidades por parte de sus participantes. De igual forma, implica el deber del médico de ilustrar al paciente y la misión de estar abierto a las inquietudes y solicitud de consejo por parte del usuario del servicio.

Por su parte, el paciente atenderá, aportará sus valores, creencias y objetivos, manifestará sus inquietudes y se sincerará ante la incomprensión, para finalmente tomar una decisión de aceptación o rechazo a la práctica recomendada, y, en caso de ser la primera, legitimará el acto médico posterior. Pero, no podrá pedir modificaciones en la técnica, dado que esto depende del estado científico de la misma (Highton y Wierzba, 2003, p. 71).

dicho y los actos anexos que integran el llamado el acto médico complejo, se podía dar la clasificación en: “(i) actos puramente médicos, que son realizados por el facultativo; (iii) actos paramédicos, que lo son las acciones preparatorias del acto médico y las posteriores a éste; que regularmente, son llevadas a cabo por personal auxiliar, tales como suministrar suero, inyectar calmantes o antibióticos, controlar la tensión arterial, etc. y (iii) actos extramédicos, que están constituidos por los servicios de hostelería, entre los que se incluyen el alojamiento, manutención, etc. y obedecen al cumplimiento del deber de seguridad de preservar la integridad física de los pacientes" (Sentencia de 27/04/2011, exp. 1993-07622-01(19846)).

${ }^{55}$ Lógos kalós o bello discurso del que hablaba Platón sobre el poder de la palabra y la persuasión. 
Así entonces, el consentimiento informado del paciente fija el radio de acción dentro del cual puede actuar lícitamente el profesional, debe ser individualizado y no dado de forma general. Asimismo, es temporal y revocable en cualquier momento por el titular del derecho (Fraga y Lamas, 1999, pp. 66-67) ${ }^{56}$. El visado para un procedimiento no habilita todos los que se requieran posteriormente como consecuencia del primero $^{57}$, a menos que, debido a la urgencia para la realización de este, ya sea que suponga un riesgo vital o de lesiones, no haya tiempo para pedir un nuevo consentimiento informado ni al paciente o en su defecto a sus familiares.

De esta forma, el consentimiento informado se posiciona como manifestación de la lex artis ${ }^{58}$, es decir, del correcto desempeño del acto clínico, al observar las reglas propias de la profesión tanto a nivel técnico-científico como ético ${ }^{59}$, cuyo desconocimiento puede dar lugar a responsabilidad ética-disciplinaria y jurídica.

En virtud del desnivel informativo que caracteriza la relación sanitaria, la confianza juega un papel trascendental; al paciente no le queda otra alternativa más que confiar en aquel que tiene la potestad y dominio de la información -el médico-, por eso es válido afirmar que "el consumidor" suple la ausencia o déficit informativo con la confianza, que es su equivalente funcional" (Weingarten, 2011, p. 81).

\footnotetext{
${ }^{56}$ En el mismo sentido García (2016, p. 18) expone que los documentos que no hayan sido redactados de forma particular para un caso individualizado, no están protegiendo los derechos del paciente, no ampara de la responsabilidad profesional y legitimarán solamente prácticas impropias en el campo de la medicina.

57 "...no quiere decir esto que cada uno de los actos deban ir precedidos de una declaración de voluntad individualizada, sino que, tras la información pertinente a cargo del médico, que incluye el alcance del tratamiento, el paciente ha de consentir que ese tratamiento se lleve a cabo, conociendo de forma razonable los actos que comporta" (Llamas, 1988, p. 156).

${ }^{58}$ De dicho hecho, en general, no hay controversia ni doctrinal ni jurisprudencial.

${ }^{59} \mathrm{La}$ lex artis de forma general abarca "los conocimientos técnicos que al médico se le deben exigir para actuar como tal; también dichos conocimientos y prácticas actualizados y en un óptimo nivel de competencia... al deber de diligencia o exigencia y cuidado con que el médico debe ejercer su actividad; por tanto, se trataría de pautas de comportamiento, que funcionan a modo de "ordenamiento secundario", que los poseedores de un saber especializado muestran ante la opinión pública con la mejor respuesta ante un problema de salud concreto; sin olvidar que dichas pautas de comportamiento no son meras exigencias de excelencia, sino que en reiteradas ocasiones se ponen en relación con aquellos principios de nuestro Código Civil que consagran el criterio de la culpa como eje vertebrador de la atribución de la responsabilidad contractual y extracontractual ... la jurisprudencia usa también la expresión lex artis, para erigirlo en presupuesto del deber de información ... y como un presupuesto también del consentimiento informado ..." (Giménez, 2006, p.70).

${ }^{60}$ En el numeral siguiente será explícito la visión del paciente como consumidor en virtud de la consideración de la salud como un servicio dentro del mercado de la oferta y la demanda.
} 
La confianza tiene una función comunicacional, "es un poderoso emisor de mensajes y constituye un puente entre el consumidor y el proceso de consumo" (Weingarten, 2011, p. 81). A pesar, de que el paciente tiene la potestad de ser autónomo, el médico sigue siendo esa persona a la que el enfermo se entrega y confía en sus conocimientos y aptitudes para lograr la recuperación, porque al ser, por lo general, un profano de la medicina, por más explicaciones y datos que se le transmita, casi siempre pedirá esa recomendación o sabio consejo para poder finalmente elegir si se somete o no a un tratamiento. Esto es generado por la convicción de que el médico actúa en pro del paciente por encima de sus intereses, es decir, promueve la beneficencia en su ejercicio.

Ese proceso dialógico se perfila importante como respeto a los derechos del paciente y así mismo, desde el ámbito terapéutico, dado que el paciente quiere la curación y, además, tiene la necesidad de creer en la medicina y en la competencia de los galenos para lograr ello. De ahí que, en la actualidad, los médicos cumplan una labor asimilada a la del sacerdote ${ }^{61}$, es decir, escuchan, comprenden la situación del enfermo, aconsejan de acuerdo al diagnóstico y las alternativas posibles y alivian al prescribir lo mejor para lograr la salud de ese enfermo. Por tal razón, su tarea es integral, requiere a aquel experto clínico y demanda humanidad, tanto con el paciente como con sus familiares (Corte Constitucional, sentencia T-216-2008 de 29/02/2008).

Como lo considera Abad (2016), en el campo de la investigación, cuyo fundamento es adaptable a la atención hospitalaria, el consentimiento informado no es un simple formato estandarizado y replicado a todos los casos de igual forma. En cada situación no siempre va a resultar sencillo y automático el manejo, transmisión e intercambio de comunicación. Tampoco es una simple firma, ya que se basa en un "...proceso construido, negociado y reafirmado de forma continua" (p. 112).

Este proceso debe comenzar con un contacto inicial, en donde el canal de comunicación entre enfermo y profesional permita el clímax de confianza que brinde seguridad a la relación y permita un mejor desempeño del médico, la colaboración del paciente y deliberaciones libres de miedo y manipulación.

\footnotetext{
${ }^{61}$ Pero no ejercido desde los postulados del paternalismo hipocrático.
} 
La información clara y veraz que una persona reciba sobre la técnica médica a realizar será la impulsora de su decisión. Por tal motivo, y asimilado a la esfera económica del mercado y sus fallas, cuando la información es asimétrica e incompleta el mercado se torna ineficiente, afectando a uno de los participantes (Stiglitz, 2010, pp. 13-14). Esto implica que, se reduciría al paciente a la vieja concepción instrumentadora, con el objetivo de obtener los resultados queridos por el galeno sin importar los intereses del directamente afectado.

Ahora bien, es importante la toma de conciencia de la necesidad del consentimiento informado por parte de los médicos ${ }^{62}$, sobre este aspecto se puede destacar un escrito de una profesional de la medicina que se dirige a sus colegas, para invitarlos a educar a los pacientes, debido a que ello, permite que estos últimos comprendan el alcance de lo propuesto y colaboraren con el pre y post operatorio. Asimismo, afirma que el proceso del consentimiento informado requiere de tiempo para transmitir los datos imprescindibles de la propuesta médica, para escuchar al paciente, resolver las inquietudes y clarificar las dudas que puedan asaltarlo, desde la base que muchas veces la ansiedad o la timidez influyen en que no se hagan preguntas, a pesar de no haber entendido (Geller, 2002).

Resulta pertinente mencionar que, en el 2017 el Ministerio de Salud y Protección Social colombiano, a través de la Dirección General de Calidad de Servicios, presentó una guía técnica para «garantizar la funcionabilidad de los procedimientos de consentimiento informado». En esta guía se concluyó que, poner en funcionamiento el proceso de consentimiento informado requiere del esfuerzo de todos los involucrados, con el fin de introducir la mentalidad conjunta que este es esencial en el ejercicio de la medicina, de modo que, se constituya "en una forma de trabajo que no necesita de condiciones ideales para realizarla", pero se deben garantizar los medios, espacios y tiempos para darle eficacia al consentimiento, asimismo, la información puede brindarse a través de diferentes estrategias -escritas, orales o visuales- (pp. 71-72).

\footnotetext{
${ }^{62}$ Se requiere de educación en derechos en las instituciones para los médicos y así mismo, para los pacientes y todo el personal del equipo sanitario, para motivar y crear conciencia sobre el respeto de la autonomía para cambiar de un modelo informativo a uno deliberativo o participativo del proceso de consentimiento informado, en un clímax de confianza y cooperación (Ovalle, 2009, pp. 199-200).
} 
En este sentido, el consentimiento resulta benéfico para el paciente y se torna protector para los profesionales de la salud y las instituciones hospitalarias. Cuando el paciente asume informadamente los riesgos del procedimiento libera al médico de responsabilidad en caso de concretarse, siempre y cuando, el médico haya actuado conforme a la lex artis ad hoc, es decir, el consentimiento constituye a su vez un blindaje para evitar futuras reclamaciones judiciales y denuncias disciplinarias, pero no asegura resultados clínicos al ser la actividad médica, como regla general, una obligación de medios (Galán, 1999, p. 9).

En una medicina humanizada ${ }^{63}$, el médico no solo debe ejercer sus obligaciones en aras de evitar pleitos, como si se tratara de una de medicina defensiva. Su motivación principal debe ser el beneficio del paciente que lleva implícito reconocer sus derechos, teniendo presente al ser humano como centro de la atención del servicio de salud. Como lo afirma el Ministerio de Salud (2016, p. 46), no se puede ver al paciente como un "adversario"; por el contrario, se debe establecer una relación horizontal de respeto mutuo y confianza, siendo el aspecto dialógico fundamental, pues el diálogo "se ha constituido desde la antigüedad en la base de la entrevista clínica, la guía para la exploración del paciente y en el medio terapéutico fundamental” (Bohórquez, 2004, p. 1).

Al ser la enfermedad connatural a la condición humana, el profesional de la salud debería tener presente la conocida regla de oro moral: "actúa con los demás como quieras que ellos actúen contigo", resulta importante que tome conciencia que se está ante un ser humano y no frente a una simple patología. Así como entender que, el paciente puede sentir vergüenza, vulnerabilidad, angustia, que tiene que enfrentarse a un sistema de salud por lo general complejo, burocrático e ineficiente, pero a pesar de todo, pone su vida en manos del equipo sanitario confiando en sus conocimientos y recomendaciones, aun sabiendo que la medicina no es infalible ${ }^{64}$.

En ese orden, estudios sociológicos sobre el médico como paciente, han develado que cuando el médico experimenta su propio dolor a raíz de la enfermedad, puede entender aún más el de sus pacientes, se cuestiona sobre su profesión, la forma de ejercerla, el puente comunicativo que lleva

\footnotetext{
${ }^{63}$ Sobre la humanización de la medicina se puede consultar a Leone (2018).

${ }^{64}$ Una representación del médico como paciente se puede ver en la película "The Doctor” de 1991 dirigida por Randa Haines.
} 
a cabo con sus pacientes, sus conocimientos y la construcción social de la enfermedad. Es decir, todas las implicaciones que ello conlleva, generando cambios en la práctica frente a sus pacientes (Arroyave, 2010, pp. 53-55).

Lógicamente, no se pretende conjeturar que solo cuando los galenos enferman pueden ser más humanos en su ejercicio profesional, dado que ello sería un justificador de violaciones de derechos. Por el contrario, se debe abogar para que desde el inicio de los estudios de la medicina, y que esto marque toda su trayectoria laboral, se implante la postura de que el tecnicismo extremo genera distancia con el paciente, que una buena práctica médica está orientada por ver al otro como un ser humano igual de importante y no solo como un caso clínico más, pues “...la distancia y el procedimentalismo son una tentación ... sólo [sic] el médico que da y recibe de sus pacientes, dialoga y se inclina ante ellos, entrando en una verdadera relación, seguirá siendo además de médico, humano, demasiado humano" (De La Torre, 2008, p. 102).

\section{El consentimiento informado en la globalización de la salud: del papel a la práctica 65}

La globalización ${ }^{66}$ trae consigo repercusiones valiosas en el sector salud, la constelación de avances médico-científicos, biológicos y tecnológicos dan paso a la exploración en campos antes impensados o de difícil acceso por la ciencia médica; así como, el aceleramiento en procesos diagnósticos, suscitando mayores expectativas en los progresos de la ciencia, dando muestra del dominio de la perspicacia humana sobre ciertas esferas que eran desconocidas. Lo cual, ha conducido a una mejor calidad de los servicios a ofrecer.

\footnotetext{
${ }^{65}$ Este acápite es parte de un artículo investigativo, resultado de la presente pesquisa doctoral, titulado "la tensión de la globalización de la salud y el papel del Estado social de derecho colombiano en torno al consentimiento informado en la relación médico paciente" (Navarro, 2018).

${ }^{66}$ La globalización es un proceso que habilita la interacción y la interdependencia a nivel económico, comercial, de comunicaciones, ciencia, tecnología, el lenguaje, viajes, migración, ecología, clima, enfermedades, la guerra, la paz, la seguridad, etc. (Giddens, 1990), por lo que se puede afirmar es multidimensional, dado que simplifica en políticas económicas, apertura económica y el entrelazamiento entre diversos países en torno al comercio y a la economía, y también, permite "complejos procesos de comunicación e interdependencias entre países, sociedades, culturas, economías, los cuales han transformado de diversas formas las relaciones de poder en las sociedades y (...) las formas de gobierno de los estados alrededor del mundo" (Valencia, 2016, p. 192), intensificando y complejizando las relaciones en todas las dimensiones.
} 
Lo anterior, ha generado la posibilidad de asistir a diferentes médicos especialistas especialización de la medicina-, lo que deriva en el nacimiento de empresas e instituciones, en sus dos vertientes públicas y privadas, encargadas de la prestación y promoción de los servicios. De esta manera, se mira al médico como todo un empresario en el mercado ${ }^{67}$, que utiliza la publicidad para atraer pacientes.

Al mismo tiempo que se acrecienta la tecnificación y especialización, se aumentan los riesgos y peligrosidad, aunado a un ambiente multiplicador de aspiraciones y exigencias de los pacientes, creando una cultura de bienestar que hace, en la mayoría de los casos, frenar la asunción de los fracasos médicos generando reclamaciones judiciales (Galán, 2007, pp. 20-21).

Se ha forjado la idea de la medicina inserta en el mercado de la salud, al configurarse como un servicio más dentro del mercado, que se mueve bajo la ley de la oferta y la demanda. De esta forma, el paciente erige como un consumidor ${ }^{68}$ de productos y servicios sanitarios, al cual le es aplicable el Estatuto del Consumidor ${ }^{69}$, pero, se require una interpretación sistemática de la regulación de protección al consumidor con la normativa que dirige el sistema de salud, teniendo en cuenta el principio base pro consumatore -a favor del consumidor-, que adaptado al área de salud implica interpretación favorable al paciente ${ }^{70}$ (Woolcott, 2014, pp. 260-261).

Es válido afirmar, siguiendo a Lorenzetti, que la actividad médica hoy puede calificarse como una "empresa médica"71, en donde el Estado, los empresarios y los médicos ofrecen un conjunto

\footnotetext{
${ }^{67}$ Lorenzetti ofrece en su obra un concepto específico y adecuado en cuanto a lo que es el mercado: “....un modo de asignación de recursos escasos, que se basa en el intercambio voluntario de los mismos, producido por los agentes económicos a través de oferta y demanda (...) el mercado se presenta entonces, como un instrumento de planificación económica descentralizada" (Lorenzetti, 1998, p. 231).

${ }^{68}$ La postura de asimilar al paciente como un consumidor no es homogénea y tiene detractores que argumentan que los intereses entre los consumidores y los pacientes son superpuestos, dado que la salud es un derecho fundamental que debe ser garantizado por el Estado a toda la población, mientras que el mercado es liderado por los particulares que buscan lucrarse de la actividad y a él acceden quienes tengan la posibilidad económica de hacerlo. Así mismo, resaltan el riesgo que corren todas las garantías máximas universales de los pacientes al ser considerados como meros consumidores y la forma de defender las mismas (Pérez, 2014).

${ }^{69}$ En Colombia consagrado en la Ley 1480 de 2011.

${ }^{70}$ El derecho a la información del consumidor está consagrado explícitamente en la Carta Política en su artículo 78 correspondiente a los derechos colectivos.

71 "El término empresa está utilizado para englobar tanto a las clínicas polifuncionales, las especializadas y los financiadores del sistema, cuanto a las obras sociales y a la medicina prepaga, los vínculos asociativos como los equipos, y las redes contractuales" (Lorenzetti, 1998, p. 9).
} 
de servicios de forma organizada. Así, celebran contratos médicos -de consumo- con los usuarios destinados precisamente a “...prestar servicios médicos a los pacientes, por sí o por terceros, sujeta a la condición suspensiva que se dé una determinada enfermedad en el titular o los beneficiarios, contra el pago de un precio anticipado y periódico" (Lorenzetti, 1998, p. 127).

En el escenario globalizado la confianza se ha despersonalizado ${ }^{72}$, ha dejado de ser depositada de forma exclusiva en el galeno. Se cambia un modelo de confianza personal a uno de confianza en el sistema en donde los profesionales son prestadores de la institución (Weingarten, 2011, p. 83), se les presiona a ser productivos, debido a que todo está programado: el número de pacientes y el tiempo para cada caso, el médico debe aplicar estos estándares y así mismo, atender también los requerimientos del usuario (Bascuñán, 2005, p. 13).

Todo lo anterior, ha marcado el paso de una relación fundamentada en “...la necesidad, la confianza, la admiración, el respeto por la dignidad humana, a otra relación que se da en el marco de lo político, social y económico, en la cual confluyen la medicina, el derecho y la economía" (Fontanes, 2005, p. 1).

En este contexto, la relación médico-paciente se ha vuelto más distante y frívola, ahora se cuentan los minutos de atención entre cada paciente con limitaciones para extenderse ${ }^{73}$. A esto, Bedoya (2018) llama acertadamente como "medicina de 15 minutos"74, que permite ganar más tiempo en el modelo de eficacia financiera (tiempo-dinero), se atienden a más usuarios, sin embargo, se olvidan de la calidad y el fortalecimiento de la confianza a través de la comunicación.

\footnotetext{
${ }^{72}$ En el mismo sentido Galán enfatiza que "[e]ste sustancial cambio, en el que se pasa de un modelo de moral de código único a un modelo pluralista, que respeta los diferentes códigos morales de cada persona, ha sido motivado por muy diversos factores: por una parte, la pérdida de esa atmósfera de confianza que, en épocas pretéritas, presidía indefectiblemente las relaciones médico-paciente, $\mathrm{y}$, por otra parte, la complejidad creciente y correlativa especialización del ejercicio de la medicina, determinante, en último término, de una sensible deshumanización de su ejercicio" (1997, p. 18)

${ }^{73}$ La regulación en Colombia relativa al tema de los derechos del paciente y del consentimiento invocan la necesidad de que el paciente mantenga una comunicación plena y constante con su médico tratante. De ahí que, la atención médica no puede desconocerlos. De hecho, desde 1981 la Ley 23 consagró que "el médico dedicará a su paciente el tiempo necesario para hacer una evaluación adecuada de su salud e indicar los exámenes indispensables para precisar el diagnóstico y prescribir la terapéutica correspondiente" (art. 10).

${ }^{74} \mathrm{La}$ realidad da cuenta que de esos 15 minutos de atención en un gran porcentaje el profesional lo utiliza para llenar los datos de la historia clínica del paciente, es decir, sentado en frente del computador. Ello, porque no hay una sistematización que permita que el médico conozca los antecedentes clínicos del paciente como procedimientos previos, medicamentos, alergias, etc.
} 
Lo cual, es tendencia en Colombia, y como lo refleja el autor, la problemática es común en Latino América, Estados Unidos, Canadá, Rusia, España, México, entre otros.

Teniendo en cuenta que la medicina se ha burocratizado, la relación médico-paciente se transforma en mediata, al interponerse en su ejercicio terceros poderes o sujetos de la relación como el establecimiento de salud y la empresa médica, lo que influye negativamente en la atención médica, no obstante, el sorprendente desarrollo científico y tecnológico logrado (Fernández, 2007, p. 91).

La planificación social de la medicina con principios políticos, económicos y de rendimiento en medio de un mundo gobernado por la ciencia y la tecnología acabó por tecnificarla, anula la personalidad del médico al sustituirla por una institución técnico-administrativa (Lovece, 2004, pp. 179-181), en donde los usuarios al ser sometidos a amplias propagandas, se desinteresan por el médico como profesional y persona, el diálogo se acorta y simplemente el paciente se ha dejado deslumbrar por la garantía que para ellos representa el avance de la ciencia.

Vale aclarar que, la presente investigación no está en contra de las conquistas que el auge de la técnica ha logrado. Lo que ocurre, es que es partidaria de que en el encuentro entre médico y paciente no se puede abandonar la práctica humana de curar (Laín, 1964, p. 16). En razón, de que el sistema ha conllevado a que el médico pierda “...su carácter sagrado y venerable, y aparece como un ciudadano corriente, ansioso de dinero y seguridad, como los demás ciudadanos endebles, que formamos la moderna sociedad tecnológica” (Llamas, 1988, p. 23).

Ante el afán por mostrar resultados y atender en un mínimo de tiempo una cantidad de usuarios, el paciente es atendido sin un adecuado manejo de la información, en algunas oportunidades firmando un formato preimpreso donde afirma conocer todos los riesgos y cuidados relacionados con ese tratamiento, pero a la hora de la verdad la generalidad no demuestra más que un desconocimiento total sobre la materia (Monsalve y Navarro, 2014, p. 2), dejando entrever la deshumanización en la práctica médica. 
En virtud de las ansias de atender, diagnosticar y tratar, se olvidan de que la información debe ser también humana, es decir, "acompañarla del calor debido a algo tan trascendente como son las decisiones en las que puede estar afectada la vida, la integridad corporal o la salud física o psíquica” (Ruiz, 1996 citado por Galán, 2007, p. 28).

Bien lo denuncia la Asociación del Defensor del Paciente de España (2017), al alegar que muchas veces se firma un papel con espacios en blancos y sin anexo alguno, lo cual posteriormente es llenado por el profesional, no realizándose una comunicación ni verbal ni escrita sobre los datos necesarios para tomar una decisión. Además, se encuentran consentimientos firmados a pie de cama sin explicación alguna o en procesos diagnósticos es una recepcionista quien entrega un documento para firmar antes de pasar con el especialista.

Esto no escapa a la realidad de Colombia, en donde si bien no se puede catalogar como prácticas extendidas, si se puede aseverar, sin temor a error, que en la mayoría de los procedimientos clínicos va adjuntado un mal consentimiento informado, lo que se corrobora con el aumento de procesos judiciales en torno a este tópico.

No es que no se avale en este trabajo que las entidades y los profesionales cuenten con formatos para agilizar el trámite, dada la cantidad de pacientes a atender. En cambio, no se comparte que estos documentos constituyan por sí solos la información y den paso a ser considerados plenos consentimientos informados, debido a que se requiere que se lleve a cabo el proceso de intercambio de comunicación entre los implicados ${ }^{75}$.

Claramente, la aplicación de la doctrina del consentimiento informado puede ser vista hasta hoy, como un logro a nivel de derechos, pero como un fracaso, desde una perspectiva general, en su implementación; en la medida que, el sistema de salud burocratizado y las ideologías tradicionales paternalistas, a pesar de la normatividad y declaraciones de derechos, siguen imperando en su mayoría y no permiten que se haga un proceso gradual que motive la comunicación entre médico-paciente, teniendo en cuenta, que a este último "[y]a no es solo[sic] la fatalidad incomprensible lo que anula su capacidad crítica sino que también el cientificismo y la

\footnotetext{
${ }^{75}$ Sobre el contenido de la información y la forma ver capítulo II.
} 
tecnología lo abruman, y lo conminan a transferir las decisiones al médico” (Lorenzetti, 2016, p. 30).

Las decisiones respecto a elegir o no un tratamiento es algo complejo que requiere un diálogo continuado. No obstante, escoger qué información suministrar a un paciente en específico no es una tarea de un minuto, tener unos profesionales con capacidad de darse a entender a pesar de la dificultad de la terminología médica representa un desafío cuando no se les ha enseñado a cómo transmitir en lenguaje informal. Todo esto, lleva a considerar unos costos, en dinero y tiempo, en la toma del consentimiento informado, que, si bien el sistema promueve, la práctica no mira a fondo la aplicación en términos de calidad, eficiencia y eficacia ${ }^{76}$ (De La Maza, 2017, p. 8) ${ }^{77}$.

Sin embargo, nada de ello es óbice para desconocer el consentimiento informado, reconociendo por encima de todo la autodeterminación del paciente, dado que, en principio, nada justificaría su desatención (Pizarro, 2017, pp. 45-46). Ciertamente, el juez debe examinar todas las circunstancias que se desprenden de una causa fáctica particular al momento de definir la responsabilidad médica, como se detalla más adelante.

Como lo anunciaba ya Katz (2002, pp. 82-83) desde décadas atrás, para reconciliar "el cuento de hadas" ${ }^{\text {78 }}$ de la regulación del consentimiento informado con la realidad, se deberían primero preparar los legisladores ${ }^{79}$ para tener una visión más amplia que permita comprender el rol de los médicos en la práctica, las capacidades de los profesionales y pacientes para favorecer decisiones autónomas e informadas, así como los límites en el conocimiento.

\footnotetext{
${ }^{76}$ En Colombia como ente director del sistema de salud se encuentra el Ministerio de Salud y Protección Social, el cual si bien ha impartido resoluciones para mejorar el sistema ${ }^{76}$, políticas para la prestación del servicio, de disponer un observatorio de calidad y de mecanismo sistemático y continuo de evaluación y mejoramiento de la calidad de la atención de salud observada frente a la calidad esperada, la realidad da cuenta que no hay una verdadera ejecución y evaluación de políticas en torno a verificar específicamente el cumplimiento del proceso de consentimiento informado del paciente, que controle que la información sobre los procedimientos o tratamientos sea clara, completa e idónea, debido a que las graves falencias en su aplicación han dado lugar a un amplio movimiento de la institución de la responsabilidad patrimonial de particulares y del Estado.

${ }^{77}$ Mendoza y Herrera indican que en Colombia “...el ejercicio de la profesión médica camina sobre un hilo muy delgado, y en principio contradictorio, entre sus deberes, sus capacidades y las condiciones y limitaciones del sistema que lo sustenta" (2015, p. 158).

${ }^{78} \mathrm{Katz}$ (1977) asimila la regulación del consentimiento informado a un cuento de hadas porque precisamente esas historias reducen la complejidad de las relaciones humanas a finalmente una simplicidad en todas las circunstancias.

${ }^{79} \mathrm{El}$ autor se refiere al sistema norteamericano y por ello habla de los jueces como creadores del derecho.
} 
De acuerdo con lo anterior, contradicción entre el humanismo y el instrumentalismo amerita intervención del Estado para que las regulaciones, políticas y recomendaciones cumplan sus cometidos. Además, de la capacitación para el médico y para el paciente.

En este sentido, no se requiere de un exceso de normas que declaren derechos de los pacientes ${ }^{80}$ y deberes en la atención médica. Se debe propiciar es por la toma de conciencia, por las condiciones y espacios para la efectividad del consentimiento informado, por medio de estándares mínimos para asegurar la calidad del sistema ${ }^{81}$, con base en los lineamientos de: "libertad de elección (autonomía), competencia profesional (idoneidad), buena comunicación (diálogo), compasión (empatía), estabilidad de la relación (continuidad) y ausencia conflictos de interés (especialmente económicos)" (Bohórquez, 2004, p. 4).

\footnotetext{
${ }^{80}$ La innumerabilidad de reglamentación en torno a la prestación del consentimiento informado ha derivado en que muchos profesionales e instituciones sanitarias adoptan deformaciones en su ejercicio más vinculada a la medicina defensiva que a salvaguardar la autodeterminación del paciente (Martínez, 2012, p. 162).

${ }^{81}$ El Ministerio de Salud y Protección Social ha venido trabajando en directrices para mejorar la atención de salud, de tal forma que sea de calidad y humanizada enfocada en la dignidad humana, tal y como se observa en el Plan Nacional de Mejoramiento de la Calidad en Salud (PNMCS) - Plan Estratégico 2016-2021.
} 


\section{Capítulo II. Aspectos relevantes del consentimiento informado}

\section{El consentimiento y la información desde la teoría general de los contratos}

\subsection{El consentimiento: elemento de la existencia del negocio jurídico}

El consentimiento, como manifestación de la autonomía de la voluntad ${ }^{82}$, cobra especial relevancia en materia contractual al ser entendido como la voluntad libre, espontánea y consciente para crear, modificar o extinguir relaciones jurídicas, es decir, con el propósito de producir efectos jurídicos.

Para el nacimiento del contrato es indispensable la clara voluntad de cada una de las partes a obligarse $^{83}$, la cual puede resultar de una etapa previa de tratativas de negociación o se consolida de forma instantánea, a través de la aceptación pura y simple de la oferta, como ocurre en los contratos de adhesión o en aquellos de contratación masiva (Salinas, 2011, p. 141).

Con base en el artículo 1502 del Código Civil colombiano, en adelante CC, entre los requisitos para obligarse está la necesidad que se asiente sin vicio alguno. Lo que, apellida al consentimiento como un elemento esencial o de la existencia del negocio jurídico, su ausencia total no permite que el acto salga a la luz y, por ende, carece de cualquier efecto al predicarse la inexistencia del mismo (Corte Suprema de Justicia, sentencia de 11/04/2000, exp. 5410). Sin voluntad no puede

\footnotetext{
${ }^{82}$ Spota (2015) enseña que la autonomía de la voluntad se manifiesta como libertad para o de contratar, es decir, la libre celebración del contrato o autodecisión, y así mismo, la autonomía comprende la libertad contractual para establecer el contenido del contrato, o sea, la autorregulación (pp. 52-57), la cual no es absoluta y está supeditada en a las normas imperativas, al orden público y a las buenas costumbres.

En palabras de la Corte Constitucional Colombiana la autonomía de la voluntad contractual comprende las siguientes dimensiones: "(i) celebrar contratos o no celebrarlos, (ii) determinar con amplia libertad el contenido de sus obligaciones y de los derechos correlativos y (iii) crear relaciones obligatorias entre sí. Puede indicarse, de manera más precisa, que la autonomía privada en el ámbito contractual está conformada por cuatro expresiones concretas de la voluntad: (i) la libertad de selección que consiste en la facultad de elegir con quién se contrata (un proveedor, cliente, empleado y socio, entre otros); (ii) la libertad de negociación que consiste en decidir de qué forma se inician las tratativas preliminares; (iii) la libertad de configuración que comprende todas aquellas decisiones sobre cómo se estructura un contrato y cuáles son las obligaciones y derechos, y (iv) la libertad de conclusión que significa decidir si se celebra o no el negocio jurídico correspondiente" (Sentencia C-345-2017 de 24/05/2017).

${ }^{83}$ Al respecto ver sentencia de 05/10/1939 de la Corte Suprema de Justicia.
} 
existir obligación alguna, como parte del principio de la autonomía que encierra la libertad contractual.

El consentimiento como raíz de todo acuerdo, requiere que se haya formado rectamente sin falla alguna, será vicio todo lo que trunque ese fin (Diez-Picazo y Gullón, 1992, p. 55), a saber: el error $^{84}$, la fuerza y el dolo (art. 1741 CC). Ello, como mecanismo de protección de la ley para salvaguardar a los contratantes de su propia ignorancia, contra el fraude y la violencia del que pueden ser objetos al ejercer su facultad negocial ${ }^{85}$ (Corte Suprema de Justicia, sentencia de 11/04/2000, exp. 5410). Por tanto, aunque el acto existe se impone una sanción legal que es quedar afectado de nulidad, si se desplegara la figura de la inexistencia del acto no podría decirse que está viciado $^{86}$.

La declaración de voluntad debe ser emitida por una persona legalmente capaz, para que dichas estipulaciones puedan ser válidas -arts. 1502 a 1504 CC-. Si bien la capacidad está comprendida dentro del consentimiento contractual, la misma no afecta el negocio jurídico desde el ámbito de la inexistencia, al ser un presupuesto de la validez del contrato. De esta forma, no se pueden confundir entre sí, al estar sustantivamente diferenciados ${ }^{87}$.

La voluntad interna requiere de su exteriorización, puede expresarse a través del lenguaje ordinario o gestual, o inferirse tácitamente mediante señales concluyentes en el proceder. Esa voluntad tácita, se torna cardinal ante las discrepancias judiciales entre la voluntad y la declaración,

\footnotetext{
${ }^{84}$ No todo tipo de error vicia el consentimiento, pues cuando el error de hecho recae sobre la especie del acto o el objeto dicha circunstancia impide la formación del acto en sí mismo y, por tanto, ausencia de consentimiento (Alessandri, 1982, 695).

${ }^{85}$ El maestro Alessandri entiende que "los vicios del consentimiento son subjetivos, porque dicen relación con el fuero interno del individuo, con su voluntad misma; la persona que ha emitido un consentimiento viciado lo hace inducido por una falsa apreciación de la realidad, o debido a una presión que se ejerce sobre su voluntad" (1982, p. 690).

${ }^{86}$ La doctrina de los vicios del consentimiento no es fácil de aplicar, ella conlleva una serie de reglas codificadas e interpretaciones jurisprudenciales y doctrinales que hacen que en un juicio se acceda difícilmente a la pretensión de nulidad del contrato dando más valor a aquella interpretación que tienda a darle continuidad o conservación al negocio jurídico, al respecto ver Díez-Picazo (2004, p. 13).

${ }^{87}$ Sobre el asunto la Corte Suprema de Justicia ha enfatizado que "[1]a capacidad y la voluntad en los actos o negocios jurídicos están íntima y recíprocamente relacionadas porque una y otra, constituyen requisitos de validez necesarios de todo tipo de manifestación de la voluntad jurídica, con perjuicio de generar nulidad; sin embargo, tienen una fisonomía propia, sin confundirse, entre sí; así por ejemplo, la voluntad es requisito esencial o de existencia de los actos o negocios jurídicos, sustancialidad que no ostenta la capacidad, porque ésta, apenas es un presupuesto de la validez negocial" ( Sentencia SC19730-2017 de 27/11/2017).
} 
le corresponde al juez de la causa realizar una interpretación contractual objetiva, no guiada hacia la voluntad oculta, y más bien, buscar el sentido del comportamiento y la confianza que han generado (Diez-Picazo, 2007, pp. 176 y 179).

\subsection{El deber de información precontractual: manifestación de la buena fe}

En un sistema jurídico basado en la autonomía contractual, en principio, cada parte debe procurarse su información ${ }^{88}$. Existe una autorresponsabilidad a la hora de contratar, al no ser factible calificar de entrada a los agentes negociales como inhábiles para preocuparse de su propio interés y ser responsables de sus decisiones, dado que, se pierde "...el incentivo para la investigación y se atentaría contra la seguridad del tráfico de bienes y servicios" (Moggia, 2012, p. 21).

No obstante, hay situaciones que obligan a proteger los intereses de una de las partes por las asimetrías del conocimiento, verbigracia la condición de profesional o de experto en el área de una de las partes, cuando el comportamiento de un contratante genera la legítima confianza en el otro en resultar informado sobre los aspectos significantes del acto jurídico o también, en circunstancias en las que un agente, que no posee la información, espera que la otra le informe o asuma dicho deber (Basozabal, 2009, p. 649).

En razón de lo anterior, entra a operar la buena fe, al ser fuerza integradora y creadora del sistema jurídico ${ }^{89}$ (Monsalve, 2010, p. 117), para robustecer la gestación del consentimiento a través del deber de información. De esta manera, lo edifica como un deber secundario de conducta ${ }^{90}$ complementario a la obligación principal, para robustecerla y alcanzar el resultado útil de la prestación. Todo lo cual, adquiere considerable peso en los actos preparatorios a la

\footnotetext{
${ }^{88}$ En igual planteamiento se pueden leer García Rubio (1991, p. 47), Barros (2006, p. 1017), Diez-Picazo (2007, p. 312), Basozabal (2009, p. 649), De la Maza (2010-a, p. 247-249).

${ }^{89} \mathrm{La}$ Constitución Política colombiana proclama entre sus postulados la buena fe (art. 83). A nivel del derecho privado el Código Civil hace reza que "[1] os contratos deben ejecutarse de buena fe..." (art. 1603), disposición que se refleja en el Código de Comercio, en adelante CCO, art. 871.

${ }^{90}$ Sobre los deberes complementarios o secundarios de conducta se puede consultar a Diez-Picazo (2008, pp. 142144) y Solarte (2004).
} 
formalización del contrato, en virtud de que la eficacia del negocio está condicionada a una voluntad informada.

Así, la trascendencia práctica del deber de información en las tratativas parte del desequilibrio de conocimiento entre los actores, es decir, los futuros contratantes, que en la generalidad de los casos son el profesional y el profano-consumidor. Ese deber no siempre recae sobre el empresario o el avezado, depende de quien ejerza el control de la información sobre lo que será el objeto del contrato, como ocurre en el contrato de seguro, en el cual el tomador está obligado a declarar de forma sincera todos los hechos y circunstancias que determinen el estado del riesgo (art.1058 $\mathrm{CCO})$.

También, en la asistencia médica en donde el profesional de la salud en el proceso de valoración necesitará, siempre y cuando sea posible, que el paciente o su acompañante den a conocer todos datos relacionados con los síntomas que presenta, antecedentes de enfermedades y demás datos en respuesta a los interrogantes del médico, con el fin de que este último pueda dar un diagnóstico acorde con la sintomatología presentada.

Es importante afirmar que, la confianza juega un papel fundamental en torno a la imposición de deberes de información, puesto que en la etapa de tratativas se crean expectativas de contratar y confianza en el otro, lo que debe ser protegido por el Estado. Como lo expone De Ángel (2000, p. 189), cuando se informa se induce, de alguna manera, en la contraparte la creencia de que lo dicho está en acorde con la realidad, es decir, hay una confianza en sí mismo y en el otro. En efecto, cuando la confianza se genera y es razonable, predomina el principio de lealtad contractual (De La Maza, 2010, p. 375) y se sanciona a quien infringe tal deber.

El legislador de antaño reguló obligaciones de información en diversas situaciones, ante las desigualdades evidentes entre los contratantes, se observan en el Código Civil colombiano, que data de 1887, normas clásicas: saneamiento por evicción, saneamiento por vicios redhibitorios por las calidades de las cosas y vicios del consentimiento. En todas, se infiere la obligación de informar por las consecuencias que se derivan de su ausencia, más no por lo explícito y manifiesto de su contenido. 
Por otra parte, en el Código de Comercio (CCO) se encuentran, entre otros, la reticencia en los contratos de seguros (art. $1058 \mathrm{CCO}$ ), la notificación del cambio del riesgo asegurado (art. 1060 CCO), la información sobre la coexistencia de seguros (arts. 1076 y 1093 CCO) y en el transporte de cosas peligrosas (art. $1015 \mathrm{CCO})^{91}$.

Recientemente, por el empleo significativo en usos del tráfico, el deber de información se ha insertado en la jurisprudencia nacional para interpretar y decidir contextos problemáticos. Asimismo, se ha consagrado como obligación legalmente establecida en situaciones particulares, haciendo frente a las nuevas exigencias derivadas de los actuales modos de contratación y el desequilibrio de los contratantes, como en las relaciones médicas ${ }^{92}$, de consumo $^{93}$ y operaciones financieras ${ }^{94}$. Sin embargo, el problema más grave deviene en aquellos contratos donde no se ha estipulado expresamente la existencia de una propia obligación de información.

Dado que la buena fe conlleva a la salvaguarda de valores que propugnan la convivencia social $^{95}$, tales como la lealtad con cooperación y la fidelidad, las partes recíprocamente deben dar a conocer todo dato útil ${ }^{96}$ para que se orienten y decidan libremente, dentro del esquema de las reales expectativas que operan en función de la confianza, comportando también la obligación de

\footnotetext{
${ }^{91}$ A nivel internacional también ha tenido pleno reconocimiento. Como muestra de ello se encuentran, entre otros, los principios Unidroit sobre los contratos comerciales internacionales (art. 1.7), la Convención de las Naciones Unidas sobre los contratos de compraventa internacional de mercaderías (art. 7) y los Principles of European Contract Law (PECL).

${ }^{92}$ En el capítulo I se puede visualizar el tratamiento normativo colombiano de la información en el campo médico.

${ }^{93}$ La Ley 1480 de 2011 -Nuevo Estatuto del Consumidor- introduce en su contenido los deberes de protección, información y seguridad.

${ }^{94}$ Ley 1328 de 2009 a través de la cual se dictan normas en materia financiera, de seguros, del mercado de valores y otras disposiciones, incorpora la información y la seguridad como guías básicas para las operaciones financieras a través de deberes para el usuario del servicio como para la entidad prestadora del mismo.

${ }^{95}$ Esto por el respeto que tienen hoy la dignidad, la supremacía del interés general sobre el particular y la solidaridad (Godreau, 1992, pp. 305 y 344); además, se puede catalogar como un correctivo de la libertad individual (Díez-Picazo, 1992, p. 68 y Ordoqui (2012, p. 111).

${ }^{96} \mathrm{El}$ contenido de la obligación de informar está basado en aquello que sea suficiente y básico para tomar una decisión, la información debe estar dotada de idoneidad, claridad, transparencia y oportunidad en cuanto a las circunstancias, cualidades, características del objeto del contrato, efectos, riesgos, entre otros elementos, lo que refleja que es más que una simple formalidad (Chinchilla, 2011, pp. 332 y 339).

La Corte Suprema de Justicia en correspondencia con el deber precontractual de información ha destacado su importancia aduciendo que “....dentro de los deberes de corrección y lealtad que se exigen a toda persona que emprenda tratos negociales, se encuentra el que atañe con las informaciones o declaraciones que está llamado a suministrar, cuando a ellas hay lugar, en relación con el objeto, circunstancias o particularidades del acuerdo en camino de consumación, y cuya importancia, si bien variable, resulta substancial para efectos de desembarazar el consentimiento del destinatario de artificios o vicios que lo afecten" (Sentencia de 04/04/2001, exp. 5176).
} 
informarse para dar una mejor ilustración ${ }^{97}$. Todo esto, implica una bilateralidad en su ejercicio, justificable solo en cuanto a la ignorancia excusable o legítima de la otra parte o en virtud, de la confianza depositada a su contratante, por ejemplo, dada la profesionalidad del obligado en primer lugar a brindar la información (Stiglitz y Stiglitz ,1999, pp. 68, 90, 91 y 101) ${ }^{98}$.

De esta manera, la buena fe, siguiendo el planteamiento de De la Maza (2010-a, p. 373-374), exige deberes precontractuales de información, sin necesidad de intermediación legislativa, pero de ello, no se puede extraer un deber general de informar recíprocamente. Entonces, se requiere identificar los intereses en juego y cómo ellos se ponderan cuando resultan contradictorios, tarea que es asignada a los jueces, al tener que realizar en sus sentencias una labor de tipificación jurisprudencial de los deberes de información atípicos. Para tal fin, los jueces deben identificar cuando resulta justificada la imposición o limitación de dicho deber, valorando también la legitimidad en la ignorancia o en la reticencia.

Entre los límites al deber de información, la doctrina ${ }^{99}$ ha establecido, de forma general -a pesar que no es unánime, ni claro determinarlos y se han guiado por las ponderaciones realizadas por los jueces- los siguientes: el deber de auto información en aplicación de la autorresponsabilidad contractual -por la reserva y confidencialidad de cierta información-, la imposibilidad de conocerla o acceder a ella, la existencia de registros públicos respecto de la información, la prohibición del abuso del derecho a ser informado como cuando se ha violado el derecho a la intimidad o el secreto profesional, los costes de la información y cuando no existe una confianza que proteger ni una falta de diligencia que reprochar.

El deber de información como presupuesto para la etapa precontractual, se debe mirar como categoría autónoma a los vicios del consentimiento y a la garantía de los vicios ocultos u obligaciones de saneamiento. Debido a que, el fundamento único del deber precontractual deriva de la buena fe (Monsalve, 2010, p. 154).

\footnotetext{
${ }^{97}$ En igual postura se encuentra Spota (2015, p. 596).

98 Ver también Llobet (1996, p. 38-39).

${ }^{99}$ Sobre este punto De La Maza, 2010; Stiglitz y Stiglitz, 1992; Barros, 2006; Chinchilla, 2011; Moggia, 2012.
} 
En este sentido, el incumplimiento informativo en la etapa de las tratativas se encuadra, tanto a nivel doctrinal como jurisprudencial, dentro de la categoría de culpa in contrahendo ${ }^{100}$. Esto, por actuar en contra de los postulados de la buena fe, en aplicación del principio progresista de responsabilidad civil favor victimae o principio pro damnato o conocido también como pro consumatore, en protección y defensa a la parte más débil jurídicamente de la relación, para satisfacer y facilitar la indemnización al dañado ${ }^{101}$ (Llamas, 2000, p. 301).

De lo expuesto se colige que, es causal de responsabilidad sin necesidad de invocar la teoría de las nulidades. Se puede -en principio- ante la información inexacta o incompleta ejercer la nulidad del contrato. De igual forma, es viable optar por la acción de responsabilidad ${ }^{102}$ para demandar la indemnización de daños.

Aunque se ha presentado la información como accesoria a la prestación, no debe desconocerse que existen contratos en los cuales la obligación medular consiste en que una parte informe a la otra, constituyéndose en una obligación positiva de hacer, como acontece con los abogados ante una asesoría, con los auditores, el médico ante el diagnóstico o ante las consecuencias de un tratamiento o contraindicaciones de un medicamento.

\footnotetext{
${ }^{100}$ Prevista en el siglo XIX por el jurista alemán Ihering quien, con apoyo de los textos romanos de Digesto, estructuró una teoría de la culpa in contrahendo con una perspectiva de naturaleza contractual por inobservancia del deber de diligencia, que era exigible en la ejecución del contrato y en la etapa previa (Monsalve, 2010, pp. 38-39).

${ }^{101}$ Diez-Picazo en 1979 expuso el giro que había dado en la jurisprudencia la responsabilidad en civil, en virtud, de la multiplicación de daños y aumento de los riesgos derivados de la industrialización y la evolución a una sociedad tecnificada. Así entonces, la indemnización de daños adquiere un imperativo social, dando paso al surgimiento del primero de los principios del derecho moderno: pro damnato o del resarcimiento del daño, dada “...la necesidad de otorgar una protección y una defensa más vigorosa a la persona ... ya no hay que reparar, porque existió antes una conducta reproblable, sino que hay que reparar a secas; que no se trata de moralizar las conductas de los eventuales autores de los daños como de asegurar las indemnizaciones a las víctimas ... salvo que por una razón excepcional obligue a dejar al dañado sólo frente al daño" (p. 732 y 734)

${ }^{102}$ En palabras de Viney (2010) sobre la opción de que la insuficiencia de la información de lugar a impetrar acción de responsabilidad, como una forma de complementar la teoría de las nulidades, se lee: “... se habría podido pensar que la extensión aportada por las sentencias recientes a la definición de los vicios de consentimiento, y particularmente del dolo incidente o por simple reticencia, iba a rarificar la hipótesis en las cuales la responsabilidad constituye la única arma puesta a disposición del contratante decepcionado por una convención que su compañero logró hacerle creer más ventajosa de lo que es en realidad. Pero el desarrollo simultáneo de la obligación precontractual de información amplió sensiblemente el campo de la responsabilidad por insuficiencia de informaciones dadas durante el curso de la negociación, de tal suerte que aún existen casos en los cuales esta responsabilidad es admitida mientras que una acción en nulidad tendría pocas posibilidades de resultar” (p. 427).
} 
Lo anterior indica que, la información en esos supuestos adquiere mayor grado de importancia, al ser desde esta perspectiva claro y evidente su grado de exigibilidad y cumplimiento, lo que se ha materializado a través de las regulaciones en la materia, al elevarlo a la categoría de obligación, cuya inobservancia puede acarrear responsabilidad.

En este orden de ideas, la información se concibe como fundamental en todas las etapas del negocio, es la base para la génesis y consolidación del consentimiento e inclusive, es el paso para el nacimiento de otras obligaciones o la principal tarea obligacional, lo que depende del tipo de negocio jurídico que se celebre.

\section{El consentimiento informado en la relación médico-paciente}

\subsection{La relación médico-paciente como relación jurídica}

En el ámbito del derecho, ciertos vínculos interpersonales por su importancia y trascendencia en la sociedad merecen reconocimiento jurídico. Por eso, se establecen facultades y deberes para su desenvolvimiento, al igual que las consecuencias de su inobservancia, lo cual, las lleva a catalogar como una relación jurídica.

En otras palabras, una relación jurídica es aquella situación que en la vida social se traba entre dos o más personas, pero que el ordenamiento jurídico las mira como una unidad y la organiza conforme a "determinados principios, y que la considera además como un cauce idóneo para la realización de una función merecedora de la tutela jurídica", dado los fines e intereses que de la misma se consolidan (Diez- Picazo y Gullón, 1994, p. 216).

La relación médico-paciente es una relación jurídica. Está disciplinada y organizada por el ordenamiento jurídico y la jurisprudencia de las Altas Cortes. Tiene un rol definido para los involucrados -médico-paciente y/o familiares- al igual que sus derechos y deberes ${ }^{103}$, es decir, una determinada "situación jurídica subjetiva" (Fernández, 2007, p. 90).

\footnotetext{
${ }^{103}$ En la generalidad las relaciones jurídicas se caracterizan por estar presente un sujeto activo y un sujeto pasivo,
} siendo el primero a quien "se atribuyen posiciones activas de poder jurídico, es decir, derechos subjetivos y facultades. 
Las partes en la relación sanitaria deben actuar conforme a la buena fe y los postulados de lealtad, cooperación, confidencialidad, información, seguridad y responsabilidad de las actuaciones; a los facultativos se les exige tener como norte los fines de la medicina ${ }^{104}$ :

La medicina es una profesión que tiene como fin cuidar de la salud del hombre y propender por la prevención de las enfermedades, el perfeccionamiento de la especie humana y el mejoramiento de los patrones de vida de la colectividad, sin distingos de nacionalidad, ni de orden económico-social, racial, político y religioso. El respeto por la vida y los fueros de la persona humana constituyen su esencia espiritual. Por consiguiente, el ejercicio de la medicina tiene implicaciones humanísticas que le son inherentes. (Ley 23 de 1981, núm. 1, art. 1)

Toda relación jurídica “...nace, se modifica o se extingue en virtud de un hecho o acto jurídico, que es su causa generadora" (Moisset, 2014, p. 2). El vínculo entre el médico y el paciente se desarrolla principalmente desde la génesis de un contrato ${ }^{105}$, siendo posible también, el nacimiento

Por el contrario, se denomina sujeto pasivo a aquella persona a quien se impone una posición pasiva o de deber jurídico y frente a quien se dan los derechos y facultades de la otra persona ... la distinción ... no es sin embargo absoluta ... pueden confluir al mismo tiempo en una misma persona derechos y deberes" (Diez-Picazo, 2008, pp. 73-74), tal y como, se predica de la relación médico-paciente, en donde, no solo el médico está obligado con el paciente y se le exigen ciertos comportamientos en el ejercicio del acto médico, sino que también, el paciente está obligado a ciertas pautas para que se pueda lograr el objetivo médico, por ejemplo cooperar y brindar información de sus antecedentes médicos y de sus familiares o pagar los servicios de salud -honorarios o remuneración- cuando sea el caso. De igual forma, el médico adquiere unos derechos, como la objeción de conciencia (art. 6 Ley 23 de 1981), excusarse de asistir a un paciente en determinadas circunstancias como cuando no corresponde a su especialidad (arts. 1, núm. 7, y 7 Ley 23 de 1981), recibir remuneración (art. 22 Ley 23 de 1981) y trato digno, leal y respetuoso entre las partes (art. 1, núm. 4 Ley 23 de 1981).

${ }^{104}$ El objetivo histórico y cultural de la medicina se enfoca en curar, cuidar y modificar, con una clara influencia social y económica en cuanto a su práctica, técnicas y conocimiento. Todo lo cual, ha obligado a reformas en el ejercicio y cambios en la asistencia y prioridades sanitarias. Es así, como el grupo de investigación bioética The Hastings Center, presentó un documento con el fin de actualizar y ampliar los fines de la medicina, concretándolos en: "1. La prevención de enfermedades y lesiones y la promoción y la conservación de la salud; 2. El alivio del dolor y el sufrimiento causados por males; 3 . La atención y curación de los enfermos y los cuidados a los incurables, y 4. La evitación de la muerte prematura y la búsqueda de una muerte tranquila" (Hanson \& Callahan, 2007, pp. 37-47). El propósito de los mismo, es atender a valores universales, que busquen que la medicina en el futuro aspire a "... ser honorable y dirigir su propia vida profesional; ser moderada y prudente; ser asequible y económicamente sostenible; ser justa y equitativa y respetar las opciones y la dignidad de las personas" (Hanson \& Callahan, 2007, pp. 70-73).

${ }^{105}$ Resulta pertinente destacar que en la hora de ahora la doctrina mayoritaria y la jurisprudencia de la Corte Suprema de Justicia sostienen que la responsabilidad médica tiene como fuente un negocio jurídico, dejando de lado las posturas extracontractualistas que iban en contra de la posibilidad de definir un contrato médico ya sea por razones éticas, por el objetivo de la profesión o porque ningún contrato podía en sí mismo regular el ejercicio con excepción a que la relación se originara a través de la figura del mandato dado que con la misma se mantenía la jerarquización y el 
de la relación desde la órbita extracontractual. La Ley 23 de 1981, en su art. 5, dispuso los casos que dan lugar a establecer la relación médico-paciente:
a) Por decisión voluntaria y espontánea de ambas partes.
b) Por acción unilateral del médico, en caso de emergencia.
c) Por solicitud de terceras personas.
d) Por haber adquirido el compromiso de atender a personas que están a cargo de una entidad privada o pública.

De esta forma, la relación no solo nace a través de la contratación directa con un médico específico, de acuerdo con sus preferencias y necesidades. A su vez, para asumir los retos del avance de la medicina, su especialización, prevención de la enfermedad y los gastos que ello genera, la atención al usuario de salud ha tomado formas empresariales y administrativas de prestación del servicio, en donde se incluye la intermediación y terciarización, por medio de una serie de redes de contratos $^{106}$ y trabajo en equipo de médicos, con competencia profesional en un área determinada de la medicina (Lorenzetti, 1998, pp. 34 y 69-70).

A raíz de lo anterior, no siempre es visible para el paciente saber con quién ha contratado o quienes hacen parte de la relación sanitaria, dados los matices en que esta se puede presentar. Esto, generalmente disminuye la confianza del paciente en el profesional, tal y como se planteó en el capítulo I.

sacerdocio tradicional que caracterizaba al médico. Tal fuerza ha acogido la tesis contractualista que se aplica en aquellos supuestos en que el paciente contrata con un establecimiento médico los servicios de este prestados a través de su red de profesionales, esto sin desmeritar que hay casos que si es aplicable las reglas de la relación extracontractual por inexistencia de consentimiento contractual (Jaramillo, 2002, pp. 71-76). Sin embargo, escapa a los objetivos de este trabajo delimitar las características jurídicas del tipo de operación contractual emanado de la relación médico-paciente, es decir, estudiar el tipo de contrato en los que se puede encuadrar dicha relación, en el sentido que no se configuran como presupuesto para desarrollar los objetivos, baste con dejar claro la existencia de un vínculo obligatorio.

${ }^{106}$ Afirma Lorenzetti, quien ve la actividad médica como toda una a empresa médica, que esa empresa se mueve como una red compleja que actúa de forma organizada para poder prestar eficiencia en los servicios de salud, por eso "no hay un empresario ni un comerciante, sino una red compleja que reproduce dentro sí misma las estructuras del mercado, de manera tal que sus múltiples divisiones compiten entre sí para mejorar su eficiencia; no tiene una jerarquía centralizada sino una multiplicidad de centros de decisión; la información circula dentro de la empresa como dentro del mercado; está sometida a una mutación permanente y es absolutamente flexible; sus productos y servicios no se diseñan conforme a lo que le conviene internamente hacer sino de acuerdo a las demandas de los consumidores..." (Lorenzetti, 1998, p. 69). 
A nivel jurídico, con el fin de esclarecer el tema de responsabilidad cuando se genera un daño en el paciente, se deben tener presente tanto la relación directa como la forma en que encuentra organizado el Sistema General de Seguridad Social en Salud -SGSSS- en Colombia ${ }^{107}$; para acceder a este, unos lo hacen en condición de afiliados (cotizantes o beneficiarios) al régimen contributivo o subsidiado, y otros transitoriamente, como participantes vinculados.

$\mathrm{Al}$ régimen contributivo se encuentran afiliadas "las personas vinculadas a través de contrato de trabajo, los servidores públicos, los pensionados y jubilados y los trabajadores independientes con capacidad de pago" (art. 157 Ley 100 de 1993), mientras que, en el régimen subsidiado está aquel sector de la población sin capacidad de pago o con ingresos insuficientes para cubrir el monto total de la cotización al régimen contributivo ${ }^{108}$.

\subsection{Modalidades de la relación jurídica médico-paciente}

Con base en los lineamientos anteriores, en lo estipulado por el art. 5 de la Ley 23 de 1981 y la organización del SGSSS, la relación jurídica entre el médico y el paciente reviste las siguientes modalidades:

\subsubsection{Médico-paciente}

Es aquella que se establece directamente por el mutuo consentimiento de las partes -paciente y profesional liberal ${ }^{109}$ - en donde acuerdan el objeto de la prestación médica y la remuneración.

\footnotetext{
${ }^{107}$ La regla general, conforme al art. 157 de la Ley 100 de 1993, es que todo colombiano debe participar del SGSSS siendo afiliado a alguno de los dos regímenes previstos, en función de los principios que rigen el sistema de salud (art. 153) al ser la salud un servicio público (art. $49 \mathrm{CN}$ ) y asimismo, un derecho fundamental. Sin embargo, el legislador señaló el reconocimiento de regímenes exceptuados de las normas del SGSSS, encargándose estos de prestar a sus afiliados el servicio público esencial a "partir del establecimiento de unas mejores condiciones que respondan a su situación particular" (Corte Constitucional. Sentencia T-590-2016 de 28/10/2016), los cuales están señalados en el art. 279 de la referida normativa, entre otros se encuentran: los miembros de las fuerzas militares y de policía y los profesores pertenecientes al Magisterio.

${ }_{108}$ Para ampliar la información sobre la organización, integración, beneficios y manejo del Sistema General de Seguridad Social en Salud se recomienda revisar la Ley 100 de 1993. Así como, las leyes y decretos reglamentarios orientados a la modificación de la misma.

${ }^{109} \mathrm{La}$ actividad médica mediante la prestación directa del servicio como una obligación de hacer, se puede catalogar como una profesión liberal, pues de acuerdo con el art.1 del Decreto 3032 de 2013 se considera profesión liberal "toda actividad personal en la cual predomina el ejercicio del intelecto, reconocida por el Estado y para cuyo ejercicio se requiere: 1. Habilitación mediante título académico de estudios y grado de educación superior; o habilitación
} 
Situación que comúnmente ocurre en el consultorio independiente del profesional de la salud, al que ha elegido el paciente libremente, sin ningún tipo de intermediario en materia de afiliación o aseguramiento.

En la práctica, es común observar atención médica a un paciente a través de la solicitud realizada por un tercero, no teniendo el paciente ninguna injerencia en el contrato, solo siendo el beneficiario de la prestación. Comúnmente se presenta, cuando un familiar solicita los servicios médicos asistenciales a favor de su pariente, asumiendo la obligación económica de los mismos. Sin embargo, a pesar de que el paciente no participa en la etapa de concreción del contrato, entre este y el médico se establece una genuina relación con todas las implicaciones éticas y legales que ello conlleva, situación que se podría asimilar, en principio, a la denominada estipulación por otro ${ }^{110}$ prevista en el art. 1506 del $\mathrm{CC}^{111}$.

Dada las características especiales del ejercicio de la medicina y de la relación jurídica entre médico-paciente, en este tipo de estipulaciones nacen derechos a favor del beneficiario y deberes derivados de la buena fe. Más allá de caracterizar con una figura contractual cuando la relación nace por solicitud de terceras personas, vale la pena destacar que, el propósito fundamental de la misma no es hacer beneficios patrimoniales a favor de ese beneficiario o que brote un derecho en su patrimonio, dado que la intención es mejorar la salud y calidad de vida de esa persona en garantía de sus derechos fundamentales, lo que no daría espacios para descalificar la obligatoriedad de lo pactado y el compromiso asumido por el profesional.

Estatal para las personas que sin título profesional fueron autorizadas para ejercer. 2. Inscripción en el registro nacional que las autoridades estatales de vigilancia, control y disciplinarias lleven conforme con la ley que regula la profesión liberal de que se trate, cuando la misma esté oficialmente reglada.

Se entiende que una persona ejerce una profesión liberal cuando realiza labores propias de tal profesión, independientemente de si tiene las habilitaciones o registros establecidos en las normas vigentes".

${ }^{110}$ Respecto a la estipulación por otro la Corte Suprema de justicia enseña que “....en esta convención sui generis, que constituye una excepción al principio general de derecho contractual que enseña que los contratos sólo ligan a quienes concurren con su consentimiento a su formación, intervienen tres personas: el estipulante, que es quien estipula en favor de otro; el promitente o promisor, que es la persona que contrae la obligación, y el beneficiario, que es el tercero en cuyo favor nace el derecho del contrato, y quien no actúa en él para nada" (Corte Suprema de Justicia, sentencia de 15/01/2009, exp. 2001-00433-01).

111 "Cualquiera puede estipular a favor de una tercera persona, aunque no tenga derecho para representarla; pero sólo esta tercera persona podrá demandar lo estipulado; y mientras no intervenga su aceptación expresa o tácita, es revocable el contrato por la sola voluntad de las partes que concurrieron a él”. 
La relación médico-paciente también, aunque menos frecuente, puede establecerse desde la órbita extracontractual, es decir, cuando no media estipulación contractual o consentimiento previo alguno que autorice la intervención sanitaria, como ocurre en situaciones de urgencia o ante la inconsciencia de la persona que necesita la ayuda prioritaria. En virtud de que, el médico tiene la obligación legal de ofrecer a toda persona que lo requiera su experticia en medicina, excusándose tan solo en las situaciones en que la ley lo haya previsto, valga mencionar, cuando se traten de actos en contra de la moral y de sus principios (arts. 3, 5, 6, 7 y 23 Ley 23 de 1981).

Todo lo cual, exige al profesional adoptar una conducta solidaria en observancia tanto de los deberes que su profesión le impone, así como de lo que “...sugiere el más mínimo sentido común -mejor el buen sentido-, a la vez que la moral -debidamente concebida-" (Jaramillo, 2002, p. 92).

Es de resaltar que, la omisión de atención inicial ante una emergencia podría incluso generar consecuencias a nivel ético-disciplinario, civil e igualmente, en el ámbito penal en el tipo de omisión de socorro $^{112}$, como acontece en Colombia. Esta omisión médica en otras legislaciones ha sido tipificada, siendo el sujeto activo el profesional, como lo dispone el Código Penal español en su artículo 196:

El profesional que, estando obligado a ello, denegare asistencia sanitaria o abandonare los servicios sanitarios, cuando de la denegación o abandono se derive riesgo grave para la salud de las personas, será castigado con las penas del artículo precedente en su mitad superior y con la de inhabilitación especial para empleo o cargo público, profesión u oficio, por tiempo de seis meses a tres años ${ }^{113}$.

\footnotetext{
112 Art. 131 del Código Penal colombiano: “omisión de socorro. $<$ Penas aumentadas por el artículo 14 de la Ley 890 de 2004, a partir del 1o. de enero de 2005. El texto con las penas aumentadas es el siguiente:> El que omitiere, sin justa causa, auxiliar a una persona cuya vida o salud se encontrare en grave peligro, incurrirá en prisión de treinta y dos (32) a setenta y dos (72) meses".

En el 2017 fue radicado en el Congreso el proyecto de Ley 082 cuyo propósito era adicionar el tipo penal de "omisión o denegación de urgencias en salud y se dictan otras disposiciones", sin embargo fue archivado de acuerdo a lo dispuesto en el art. 190 de la Ley 5/1992 y el art. 162 de la CP, conforme a lo publicado por el Senado en su página web: $\quad$ http://leyes.senado.gov.co/proyectos/index.php/proyectos-ley/periodo-legislativo-2014-2018/20172018/article/82-por-medio-de-la-cual-se-hace-una-adicion-al-codigo-penal-se-crea-el-tipo-penal-omision-odenegacion-de-urgencias-en-salud-y-se-dictan-otras-disposiciones

$\frac{113}{113}$ El Tribunal Supremo español en la Sala de lo Penal en sentencia 648 del 22/10/2015 no dio lugar al recurso de casación interpuesto por el médico sancionado por no haber socorrido a un herido cuando se le requirió por la guardia civil, a pesar que el galeno se encontraba en un hospital cercano al lugar de los hechos. El Supremo argumentó que:
} 


\subsubsection{Médico - clínica o establecimiento privado - paciente}

El supuesto de relación entre médico-clínica-paciente encuadra en la asistencia de carácter privado. Se origina cuando el paciente recurre a una Institución Prestadora de Salud ${ }^{114}$-IPS- para requerir sus servicios. La IPS asignará un profesional de acuerdo con la especialidad y necesidades del paciente, o, por el contrario, el paciente lo selecciona de lo que dispensa la entidad. En estos casos, se origina una relación de tipo contractual entre médico y paciente, con sus obligaciones bilaterales, a pesar de que el vínculo se haya consolidado a través del centro de salud, “...sin perjuicio de la responsabilidad de esta por sus propias obligaciones relativas a infraestructura o de hotelería y aquellas por el hecho del médico, si estuviere comprendida en su prestación de servicios" (Pizarro, 2014, pp. 827-828).

Cuando la clínica es el deudor contractual y designa a un profesional adscrito a su planta para ejecutar las obligaciones adquiridas, según la tendencia jurisprudencial y doctrinal, este asume una obligación de carácter contractual con el paciente por la identidad de prestación. Así, ante el acaecimiento de un daño puede el acreedor-paciente demandar solidariamente a la clínica y al médico $^{115}$ :

\footnotetext{
"la mínima cooperación social exigible, la solidaridad humana, la vida o integridad física en peligro, la protección de los bienes primarios en desamparo, junto con el escaso riesgo en prestar el socorro; por tanto, la perspectiva dominante es la del interés de la persona desamparada y, secundariamente, el interés social en el recto comportamiento cooperativo entre los hombres. ... la prestación de auxilio era exigible, sin perjuicio de que sus esfuerzos pudieran resultar inútiles debido al fallecimiento objetivo e irreversible de la persona que necesitaba la asistencia; conocía las circunstancias de la inconsciencia no recobrada y en ningún momento tuvo la certeza de que su auxilio era inútil; tuvo noticia de los elementos que configuraban la situación crítica y no obstante ninguna asistencia prestó".

${ }^{114}$ Las IPS pueden ser de naturaleza privada como las clínicas, laboratorios, profesionales de salud independientes o agrupados, consultorios o pública como los hospitales y las empresas sociales del estado -ESE-, mixta, comunitaria y solidaria, encargadas de la prestación directa de los servicios de salud a los usuarios del SGSSS, dentro de las Entidades Promotoras de Salud EPS o por fuera de ellas (núm. i art.156 Ley 100 de 1993).

El Decreto 1011 de 2006 en su art. 2, compilado en el art. 2.5.1.1.31 del Decreto 780 de 2016, definió como instituciones prestadoras de servicios de salud a los grupos de práctica profesional que cuentan con infraestructura física para prestar servicios de salud.

${ }^{115} \mathrm{La}$ Corte Suprema de Justicia al definir un caso de responsabilidad respecto del paciente un afectado en uno de sus ojos a raíz de la deficiente y culposa atención médica, contra una clínica (contratante y deudor original) y el médico que llevó a cabo la realización de la prestación sanitaria, llegó a la conclusión que de los demandados se derivaba una responsabilidad contractual dado que: “...se explica en la estructura de la relación obligacional que entre dichas personas se generó, la cual se caracteriza por la unidad del objeto de la prestación, puesto que hay identidad entre el compromiso adquirido por la clínica (persona jurídica codemandada) y el del médico que con la aquiescencia (en el caso) del acreedor procedió a la ejecución del tratamiento, en su condición de agente o "sustituto", como lo llama el recurrente, de la citada sociedad. De suerte que si el objeto de la obligación es exactamente el mismo, razón por la que demanda un comportamiento uniforme, guiado por un mismo fin, cual es el cumplimiento de los deberes contractuales originalmente adquiridos, lógicamente se debe predicar una unidad de tratamiento jurídico en el ámbito de la
} 
...el acreedor contractual tiene una acción necesariamente contractual contra el subcontratista con quien el deudor contractual inicial había contratado la ejecución del contrato. Se considera que como el objeto de la prestación en ambos contratos es exactamente el mismo, el acreedor inicial perfectamente puede demandar por vía contractual a cualquiera de los deudores (Tamayo, 2007, p. 665).

\subsubsection{Médico- EPS- paciente}

En concordancia con la Ley 100 de 1993, las Entidades Promotoras de Salud -EPS-, la cual es de elección libre por parte del afiliado, son responsables de la afiliación, registro y recaudo de las cotizaciones. Su función básica consiste en la administración de los servicios prestados por las Instituciones Prestadoras de Salud ${ }^{116}$-IPS-, y suministra a los afiliados o sus beneficiarios el Plan de Beneficios en Salud -PBS-. Pueden ser de naturaleza privada, pública o mixta (art. 180) ${ }^{117}$.

Según la misma ley, las EPS “prestarán directamente o contratarán los servicios de salud con las Instituciones Prestadoras y los profesionales" (art. 179). De esta forma, los afiliados entablan una relación médico-paciente al ser atendidos por los profesionales por medio de la intermediación de las EPS.

responsabilidad para la clínica y el médico tratante, pues mientras que la primera responde por el incumplimiento del contrato que efectivamente celebró, el segundo lo hace como ejecutor fallido de idéntico objeto prestacional. De ahí que, se esté, como lo dice la doctrina, frente a una responsabilidad de índole contractual "indistinta" para ambos sujetos, puesto que es tan contractual el origen de la obligación como su ejecución.

Desde luego que esta unidad de tratamiento tiene asidero no sólo en la estructura fáctica de la relación obligacional establecida entre las partes del proceso, sino en los efectos que a partir de ella se derivan, porque con independencia del vínculo existente entre la clínica y el médico, lo cierto es que la atención al paciente (acreedor) por dicho profesional, fue dispuesta por la primera, se repite, con el consentimiento del último. De modo que la culpa del señalado agente es la culpa de la sociedad, en los términos del art. 1738 del C. Civil, que en atención al vínculo existente con el agente, estatuye como parte integrante del hecho o culpa del deudor, el hecho o culpa del agente, porque al fin de cuentas, como quedó dicho, se trata de la responsabilidad derivada del incumplimiento de una misma prestación, que por lo demás lesiona el mismo interés y produce el mismo daño, lo cual como seguidamente se analizará, incide en el campo de la solidaridad" (Sentencia de 11/09/2002, exp. 6430).

${ }^{116}$ Las IPS pueden ser de naturaleza privada, pública como los hospitales y las empresas sociales del estado -ESE-, mixta, comunitaria y solidaria, encargadas de la prestación directa de los servicios de salud a los usuarios del SGSSS, dentro de las Entidades Promotoras de Salud EPS o por fuera de ellas (numeral i artículo 156 Ley 100 de 1993).

${ }^{117}$ Las principales EPS de carácter público fueron: Cajanal, Instituto Seguro Social y Caprecom, las cuales ya fueron liquidadas, quedando principalmente en manos del sector privado el esquema de aseguramiento.

También existen las EPS-S que son aquellas entidades dispuestas para los beneficiarios del régimen subsidiado. 
La relación que se establece entre el afiliado -EPS- médico es de origen contractual con deberes determinados expresamente por la ley ${ }^{118}$, siendo solidaria la responsabilidad que se derive de la deficiente prestación del servicio de salud, independientemente de la relación jurídica entre la EPS y las IPS o profesionales mediante contratos reguladores:

(...) la prestación del servicio de salud deficiente, irregular, inoportuna, lesiva de la calidad exigible y de la lex artis, compromete la responsabilidad civil de las Entidades Prestadoras de Salud y prestándolos mediante contratación con Instituciones Prestadoras de Salud u otros profesionales, son todas solidariamente responsables por los daños causados, especialmente, en caso de muerte o lesiones a la salud de las personas (Corte Suprema de Justicia, sentencia de 17/11/2011, exp. 1999-00533-01) ${ }^{119}$.

\subsubsection{Médico - plan voluntario de salud - paciente}

Los planes voluntarios de salud, conforme al art. 169 de la Ley 100 de $1993^{120}$, pueden incluir coberturas asistenciales en materia de salud, son contratados y financiados totalmente de forma voluntaria por el afiliado o las empresas que lo establezcan, de forma diferente a las cotizaciones obligatorias al sistema de seguridad social. Su propósito es otorgar comodidad y agilidad a los usuarios en la atención médica que requieran, de acuerdo con el contrato establecido previamente al ser prestaciones adicionales a las que contempla el Plan de Beneficios en Salud. Estos planes podrán ser:

\footnotetext{
${ }^{118}$ Ver, entre otros, arts. 168, 170, 178, 183y 227 de la Ley 100 de 1993; Ley 1438 de 2011; Ley Estatutaria 1751 de 2015 art. .10.

119 “[1]a responsabilidad de las Entidades Prestadoras de Salud (EPS), es contractual o extracontractual. Con relación al afiliado o usuario, la afiliación, para estos efectos, materializa un contrato, y por tanto, en línea de principio, la responsabilidad es contractual, naturaleza expresamente prevista en los artículos 183 de la Ley 100 de 1983 que prohíbe a las EPS “en forma unilateral, terminar la relación contractual con sus afiliados", y los artículos 16 y 17 del Decreto 1485 de 1994, relativos a los "contratos de afiliación para la prestación del Plan Obligatorio de Salud que suscriban las Entidades Promotoras de Salud con sus afiliados" y los planes complementarios. Contrario sensu, la responsabilidad en que pueden incurrir las Entidades Promotoras de Salud (EPS) respecto de terceros perjudicados por los daños al afiliado o usuario con ocasión de la prestación de los servicios médicos del plan obligatorio de salud, es extracontractual (...) Ahora, cuando se ocasiona el daño por varias personas o, en cuya causación intervienen varios agentes o autores, todos son solidariamente responsables frente a la víctima" (Corte Suprema de Justicia, sentencia SC8219-2016 de 20/06/2016).

${ }^{120}$ Artículo sustituido en su contenido por la Ley 1438 de 2011- Por medio de la cual se reforma el Sistema General de Seguridad Social en Salud y se dictan otras disposiciones.
} 
- Planes de atención complementaria del Plan Obligatorio de Salud emitidos por las Entidades Promotoras de Salud.

- Planes de Medicina Prepagada, de atención prehospitalaria o servicios de ambulancia prepagada, emitidos por entidades de Medicina Prepagada.

- Pólizas de seguros emitidos por compañías de seguros vigiladas por la Superintendencia Financiera.

- Otros planes autorizados por la Superintendencia Financiera y la Superintendencia Nacional de Salud (Ley 100 de 1993 art.169).

De esta forma, también se establece una auténtica relación médico-paciente de carácter privado y origen contractual, ya sea que los servicios sean prestados directamente por esa entidad o a través de su red de prestadores, con quienes suscribe contrato de gestión para prestar servicios de salud a sus afiliados. Por consiguiente, la responsabilidad es solidaria entre prepaga, IPS o profesionales.

\subsubsection{Médico - ESE - Paciente}

El servicio público de salud cuando es prestado por la Nación o por las entidades territoriales se brinda a través de la Empresas Sociales del Estado -ESE-, que son una "categoría especial de entidad pública descentralizada, con personería jurídica, patrimonio propio y autonomía administrativa..." (art. 194 Ley 100 de 1993) ${ }^{121}$. Las ESE consolidan el nacimiento de una relación médico-paciente al atender las necesidades de salud de los usuarios de forma directa. El profesional de la salud actúa ya sea como dependiente o como prestador del servicio, pero no desde la materialización de un contrato con el usuario, ya que este último acude en virtud de que el servicio público de salud se encuentra a cargo del Estado.

Ante el daño antijurídico por la falla del servicio, la administración entraría a indemnizarlo al ser responsables por la atención negligente y descuidada del personal médico, administrativo o paramédico desde la perspectiva de una “...falla orgánica, funcional o anónima, donde no interesa el concepto de culpa de un agente identificado, el cual es sustituido por el concepto de falla de la

\footnotetext{
${ }^{121}$ Ver también art. 26 de la Ley 1122 de 2007 - Por la cual se hacen algunas modificaciones en el Sistema General
} de Seguridad Social en Salud y se dictan otras disposiciones. 
administración" (Fernández, 2008, p. 231). Sin perjuicio que la entidad pueda llamar en garantía ${ }^{122}$ a un tercero que considere causante directo del daño.

Así las cosas, en materia de responsabilidad pública el Estado es el principal sujeto de imputación; el funcionario, servidor o particular que cumpla funciones públicas no responderá patrimonialmente de manera directa por sus aciertos o desaciertos, esto con el propósito de proteger a la víctima al garantizarle la indemnización (Arenas, 2014, p. 198).

El Consejo de Estado ha manejado tradicionalmente como responsabilidad extracontractual cuando una persona es atendida en una ESE y se le causa daños por fallas en el servicio, en virtud de que, el art. 49 de la Constitución dispone que "la salud es un servicio público a cargo del Estado", y, entre las funciones del Estado se encuentran "organizar, dirigir y reglamentar la prestación de servicios de salud a los habitantes". Este servicio puede ser prestado por entidades privadas o suministrado de forma directa por la ESE, con un régimen especial, acorde a la función que desempeñan. Por ello, ante el anormal funcionamiento de la atención asistencial se origina una

${ }^{122}$ El art. 225 del Código Contencioso Administrativo -CCA- consagra que "[q]uien afirme tener derecho legal o contractual de exigir a un tercero la reparación integral del perjuicio que llegare a sufrir, o el reembolso total o parcial del pago que tuviere que hacer como resultado de la sentencia, podrá pedir la citación de aquel, para que en el mismo proceso se resuelva sobre tal relación ... El escrito de llamamiento deberá contener los siguientes requisitos: ... 3. Los hechos en que se basa el llamamiento y los fundamentos de derecho que se invoquen ... El llamamiento en garantía con fines de repetición se regirá por las normas de la Ley 678 de 2001 o por aquellas que la reformen o adicionen". En providencia reciente, el Consejo de Estado-Sección Quinta en sede de tutela contra la providencia de 5/10/2017 exp. 2000-01435-01(30122) de la Sección Tercera que declaró la responsabilidad solidaria del médico llamado en garantía -quien no fungía como agente estatal al ser miembro de la asociación médica con quien el municipio había contratado la prestación de servicios de cirugía-, del hospital y del municipio; negó las pretensiones al considerar que: "[e]n ese sentido, se tiene que si bien es cierto, cuando se demanda a la persona jurídica, en este caso el Hospital, para el pago de los perjuicios causados con ocasión a un servicio médico, aquella responde directamente por los actos de sus dependientes a la luz de los artículos 1738 o 2347 del Código Civil, también lo es que, en el ejercicio de la prestación del servicio médico, el profesional de la salud debe responder por su no actuar con pericia, cuidado y diligencia, propios de la profesión, por lo que, como lo afirmó la autoridad judicial accionada, el tutelante debía ser llamado en garantía, independientemente de su vínculo contractual con la Asociación Caldense de Médicos Especialistas.

En consecuencia, atendiendo a que el artículo 2341 del Código Civil establece el régimen de responsabilidad extracontractual al prever que, aquel que ha cometido con culpa un daño a otro está obligado a indemnizar los perjuicios que se deriven de ello, y en el caso en concreto es claro que el tutelante no tenía ninguna relación contractual con el Hospital San Juan de Dios, se concluye que la interpretación y aplicación de la norma mencionada por parte de la autoridad judicial accionada fue razonable, pues aquel fue llamado en garantía por su condición de médico tratante, más no por su relación con ACME o con el Estado.

Situación distinta es la que se desprende del artículo 90 de la Constitución Política, pues aquel trata del régimen de responsabilidad patrimonial del Estado y le permite repetir contra un agente suyo, por lo que no se comparte el argumento del actor, en cuanto a la presunta vulneración del derecho a la igualdad, ya que, el fundamento de la responsabilidad en ambos casos es diferente" (sentencia de 31/05/2018, exp. 2017-03336-01(AC)). 
responsabilidad extracontractual, que se deriva de forma exclusiva de la relación entre el paciente y la ESE, la cual es de naturaleza legal y constitucional, más no contractual (Consejo de Estado, sentencia de 11/04/2002, exp. 1995-2807-01(13227)).

\subsubsection{Médico - paciente - orden judicial o ley}

La relación médico-paciente se puede consolidar, de igual forma, a través de una orden judicial o por disposición legal, que determine la realización de específicos exámenes o valoraciones físicas o psiquiátricas a una persona por parte del médico perito. En esta situación el galeno debe asumir todas sus obligaciones deontológicas y legales, como si se tratara de una atención contractual. Asimismo, el paciente debe colaborar para el desarrollo de la actuación sanitaria.

En este sentido, el art. 1 de la Ley 23 de 1981 dispone la posibilidad del médico de operar como auxiliar de la justicia ${ }^{123}$, ya sea como servidor público o como perito, obligado a cumplir su deber con rectitud y en búsqueda de "la verdad y solo la verdad".

El Proyecto de Ley 042 de 2017 «por medio de la cual se crea el nuevo Código de Ética Médica», consagra en el art. 9 los casos en los que se concretiza la relación médico-paciente, los primeros de los cuales son dispuestos de manera similar a la Ley 23 de1981, pero agrega el literal $e$ que reza "por orden de autoridad competente para producir y obtener exclusivamente pruebas judiciales que impliquen valoraciones médicas”.

Un ejemplo de la practicidad de esta modalidad, es el art. 250 del Código de Procedimiento Penal, que regula el procedimiento a seguir por parte de los peritos forenses a los lesionados o víctimas de agresiones sexuales, para realizar el reconocimiento o examen respectivo, requiriéndose su consentimiento para ello.

123 "Los cargos de auxiliares de la justicia son oficios públicos ocasionales que deben ser desempeñados por personas idóneas, imparciales, de conducta intachable y excelente reputación. Para cada oficio se requerirá idoneidad y experiencia en la respectiva materia y, cuando fuere el caso, garantía de su responsabilidad y cumplimiento. Se exigirá al auxiliar de la justicia tener vigente la licencia, matrícula o tarjeta profesional expedida por el órgano competente que la ley disponga, según la profesión, arte o actividad necesarios en el asunto en que deba actuar, cuando fuere el caso.

Los honorarios respectivos constituyen una equitativa retribución del servicio y no podrán gravar en exceso a quienes acceden a la administración de justicia" (art. 47 del Código General del Proceso -CGP). 


\subsection{El consentimiento para el contrato médico y el consentimiento al acto médico}

Comúnmente la palabra consentimiento remite, como se vio en el apartado anterior, a la teoría general del contrato, en donde el consentimiento se convierte en el elemento fundamental para la existencia y eficacia del negocio jurídico.

Descendiendo al ejercicio de la medicina, no hay duda de que las relaciones entre médico y paciente están marcadas ordinariamente por un vínculo obligacional nacido del contrato, ya sea que se haya celebrado directamente con el profesional de la salud tratante, con una IPS, a través de las EPS o por planes complementarios como la medicina prepagada.

Al mismo tiempo, hay deberes implícitos a la relación médico-paciente que no requieren la existencia de un vínculo contractual para que sean exigibles, como es el consentimiento informado; el cual, se demanda en toda interacción donde el médico pretenda actuar sobre el cuerpo del otro para recuperar su salud, para realizar procedimientos quirúrgicos, tratamientos o atender a requerimientos estéticos, dermatológicos o embellecedores.

De esta manera, el consentimiento contractual requerido para la existencia de un negocio jurídico de orden médico difiere categóricamente del consentimiento al acto médico. Por tanto, el consentimiento se mira jurídicamente desde dos órbitas: como elemento del contrato y como derecho del paciente que incluye un deber prestacional del profesional de la salud.

\subsubsection{Consentimiento contractual en el ámbito médico}

Conforme al art. $1502 \mathrm{CC}$ el consentimiento libre de vicios es uno de los requisitos para la celebración del contrato y su validez, es obligatorio que el contratante cuente con capacidad de acuerdo con las reglas generales para obligarse.

El simple consentimiento perfecciona el contrato de servicios médicos, es decir, es consensual (art. 1550 CC) al no ser exigibles formalidades para su consolidación a menos que las partes 
estipulen lo contrario ${ }^{124}$. Por ello, se afirma que es “... signado por la libertad de forma (regla general de la contratación moderna), a cuyo amparo cualquier formalidad deviene innecesaria ... ya que lo que se requiere ... es la convergencia de las voluntades exteriorizadas..." (Jaramillo, 2002, p. 166).

Así pues, las partes de la relación modelan el contenido del contrato, teniendo como fuentes de obligatoria observancia las normas imperativas y las resoluciones, directrices y políticas emanadas del Ministerio de Salud y Protección Social. Pero, es la lex artis la fuente principal que marca los deberes médicos y protocolos para la ejecución técnica-científica del acto médico (Pizarro, 2014, p. 840).

A través del consentimiento contractual para la prestación de servicios médicos, quedarán concertado el objeto (servicios profesionales y remuneración) y la causa (atendiendo al fin de la medicina), dando paso a una relación obligacional.

De acuerdo con los estudios de Fernández (1987, pp.105-133), Llamas (1988, pp. 46-58) y Fernández (2000, pp. 135-2018) y la Ley 23 de 1981, los deberes principales del profesional de la salud, atendiendo a aquellos que por su trascendencia dan lugar a ejercer acciones de responsabilidad civil ante su incumplimiento total o defectuoso, se pueden resumir en los siguientes:

a) Deberes relacionados con la competencia profesional: prestación de los servicios técnicos-científicos con la debida diligencia y en observancia al estado de la ciencia; y obligación de eficacia, compuesta por el deber de tener los conocimientos y los medios técnicos en buen estado para ejecutar responsable y eficientemente el servicio.

b) Deberes relacionados con la información: obligación de información, actuar con consentimiento informado del paciente y secreto profesional.

\footnotetext{
${ }^{124}$ Como ocurre con los contratos nacidos a través de las complejas organizaciones burocráticas del SGSSS. Por tal razón, la consensualidad en la práctica mantiene su aplicación en los contratos de índole particular celebrados con el médico independiente que atiende a través de su consultorio o con IPS de naturaleza privada donde acude, por ejemplo, el paciente a solicitar la consulta especializada de alguno de los médicos ligados a dicha institución.
} 
c) Deber de asistencia y continuidad al tratamiento, que implica la vigilancia en la evolución del paciente. este deber no significa que el médico quede atado eternamente a esa relación, más bien, se orienta a no abandonar al paciente sin justificación alguna cuando se ha entablado una relación asistencial.

d) Deberes administrativos: el registro y actualización de la historia clínica del paciente. también, expedición de certificados médicos ${ }^{125}$ en los que conste la verdad del estado de salud del paciente, ya que su falsedad implica responsabilidad legal y disciplinaria (arts. 51 y 52 Ley 23 de 1981).

\subsubsection{Consentimiento informado: legitimación del acto médico}

El consentimiento informado, traducción literal de la expresión americana informed consent utilizada por primera vez, como se consignó en el capítulo I, el 22 de octubre de 1957 en la sentencia del caso norteamericano Salgo vs. Leland Stanford Jr. University Board of Trustees, hace alusión a la licencia dada al profesional de la salud por parte del paciente para actuar sobre su cuerpo, intromisión en la esfera corporal que de no ser así, por regla general, sería ilícita aunque tuviera una motivación terapéutica (Ribot, 2007, p. 33).

Para un amplio sector de acuciosos investigadores hispanos, la utilización del término consentimiento informado es poco acertada dada las diferentes asimilaciones de la expresión, tanto en el área del derecho como en la medicina. Verbigracia, se puede confundir con el consentimiento contractual $^{126}$ como requisito para validez de un contrato o con otros escenarios como en materia de investigación para acceder a la información confidencial del participante (Skegg, 1999, p. 138).

\footnotetext{
${ }^{125}$ En el Proyecto 042 de 2017 se encuentra consagrada el deber de expedir certificados médicos: "El certificado médico es un documento destinado a acreditar el nacimiento, el estado de salud, o el fallecimiento de una persona. Su expedición se supedita a los requisitos legales vigentes" (art. 28).

El Código Internacional de Ética Médica de la AMM establece que el médico solo debe certificar lo que ha verificado personalmente.

${ }^{126}$ En torno a la diferencia entre consentimiento contractual y el consentimiento para la legitimación del acto médico se puede consultar, entre otros, a: Ataz (1985, pp. 62, 63 y 157), Llamas (1988, pp. 156-158), Castaño (1997, pp. 5051 y 221-223), Jaramillo (2002, p. 223), Highton y Wierzba (2003, pp. 69-77), Domínguez (2007, p. 298), Agón (2016, pp. 296-297), López (2016, pp. 1-2), Lorenzetti (2016, pp. 271-274).
} 
Por tal motivo, algunos han optado por llamarlo consentimiento-legitimación, asentimiento o “voluntad jurídica del paciente" (Castaño, 1997, p. 222) ${ }^{127}$.

Con el transcurrir del tiempo, se ha consolidado la institución del consentimiento informado a través de la regulación y de estudios dogmáticos y jurisprudenciales. De ahí que, cambiar su alocución no sería del todo útil ${ }^{128}$. Asimismo, doctrinaria y jurisprudencialmente se utilizan de forma indistinta todos los términos que resultan ser sinónimos de la palabra consentimiento: asentimiento, aprobación, conformidad, aquiescencia, legitimación al acto, licencia, etc. Por lo tanto, en lo sucesivo de esta investigación se utiliza la voz consentimiento informado, así como los equivalentes descritos.

\subsubsection{Parámetros diferenciales}

Es importante plantear a continuación los lineamientos básicos que diferencian el consentimiento informado con el contractual. De la misma forma, mostrar aquellos supuestos que en ocasiones hacen que converjan uno con el otro.

\subsubsection{Ejercicio de derechos fundamentales}

El consentimiento informado es un acto que se desprende del ejercicio de los derechos fundamentales del paciente reconocidos en virtud de la intangibilidad de la persona que apareja el correlativo deber del profesional de recabarlo, a través de un proceso de decisión informado. Entonces, este no es el consentimiento simple o necesario para el nacimiento de la relación jurídica contractual, dado que el consentimiento informado se concibe como presupuesto de legitimación y licitud ${ }^{129}$ de la actuación del galeno (Bernate, 2006, p. 405).

\footnotetext{
${ }^{127}$ Castaño expone que prefiere llamarlo de esta forma porque la voluntad recoge el asentimiento al procedimiento y de igual forma, el rechazo o disentimiento que son las dos facetas en que se podría manifestar el querer racional del paciente (1997, p. 222).

${ }^{128}$ En igual opinión se encuentran Lorenzetti (2016, p. 273), Highton y Wierzba (2003, p. 79) y Castaño (1997, pp. 221-224).

${ }^{129} \mathrm{El}$ consentimiento informado junto a la finalidad curativa del acto médico articula la actuación del profesional de la salud sobre el cuerpo del paciente (Ataz, 1985, p. 59).
} 
Por lo que se sigue, el consentimiento informado no goza del significado “...contractual que la palabra menta naturalmente, al ser una expresión de la voluntad del paciente requerida por la jurisprudencia o la ley" (López, 2016, p. 2), que da cuenta de la adhesión o conformidad a la práctica médica y ello implica el ejercicio de derechos fundamentales por parte de su titular ${ }^{130}$.

\subsubsection{Temporalidad}

A pesar de los roles diferentes del consentimiento, en su funcionamiento se pueden encontrar vinculados y confundirse al momento de su otorgamiento, por devenir de un solo acto prestacional el consentimiento contractual y la autorización para actuar sobre el cuerpo del paciente. Así como cuando, la voluntad inicial del paciente es celebrar un contrato con un médico particular para la realización de determinado procedimiento (Castaño, 1997, p. 232). En concreto, una persona acude directamente al dermatólogo para que examine y retire una verruga de piel en su cara, situación en la cual las voluntades contractual y para el acto médico parecen fusionarse en una sola. Empero, no debe omitir el profesional su obligación de informar y cerciorarse respecto de la aquiescencia del paciente para ese procedimiento en $\operatorname{particular}^{131}$.

El consentimiento contractual como genitor de la relación médico-paciente que tiene como fuente el negocio jurídico, va encaminado normalmente a una primera etapa del acto médico consistente en valoración y/o diagnóstico, que marcará la pauta a seguir para lograr ya sea la recuperación, alivio o el objetivo específico del paciente.

En concordancia con Gitrama (1977, pp. 285-288), el consentimiento informado al tratamiento normalmente tiene aplicación en la fase de ejecución, una vez superado el momento de diagnóstico y de plan terapéutico, a fin de dar paso al momento operativo -en donde ya se ha entablado una

\footnotetext{
${ }^{130}$ Argani (2017) afirma que “...el intercambio de "prestaciones" que entre estas partes se entabla, en ocasión del ato médico, excede el mero ámbito de libertad que el orden jurídico reconoce a los ciudadanos, puesto que constituye un juego armónico de intereses convergentes que se sustentan en el cumplimiento de obligaciones y en el ejercicio de derechos expresamente reconocidos por la Constitución nacional y las leyes dictadas en consecuencia ..." (p. 181)

${ }^{131}$ Sobre el tema Llamas Pombo puntualiza “... no son dos fases o aspectos de una misma cosa, sino que se trata de ideas conceptualmente distintas, que responden a motivos bien diferentes, en un caso es algo puramente voluntario y en otro una exigencia ya incluso legal, y que en definitiva nada tienen que ver, aunque en la práctica lo normal es que vayan unidas ..." (1988, p. 157).
} 
relación de confianza- que requiere la aprobación previa e informada del paciente como reconocimiento y respeto de sus prerrogativas ${ }^{132}$.

A pesar de esa voluntad contractual inicial, el médico requerirá la autorización del paciente para llevar a cabo su actividad, ya sea para diagnosticar o como parte de la fase terapéutica o la de recuperación. Por ello, si la relación médica no se agota en un solo acto y requiere de un ejercicio sostenido y sucesivo para cumplir su fin, dado los matices en que se puede presentar el contrato médico $^{133}$, para prolongarse lícitamente requerirá de una información extendida y continua de los procedimientos que se necesiten ejecutar, junto con el correspondiente consentimiento. Precisamente, esto es catalogado como principio de temporalidad del consentimiento informado, que implica que el mismo modulado a lo largo de todo el proceso y fases del acto médico, en la medida que se requiera para proteger la libertad del paciente (Galán, 2016, p. 687).

De esta forma, el consentimiento otorgado para una intervención no cobija actos quirúrgicos o tratamiento posteriores que no hayan sido informados y aceptados preliminarmente; cuando se requiera un procedimiento ampliatorio se necesita "una nueva declaración legitimante del paciente" (Consejo de Estado, sentencia de 24/01/2002, exp. 1994-9875-01(12706)). A menos que, complicaciones intempestivas, que conlleven a la urgencia y gravedad del caso, lo requiera para salvaguardar la vida del paciente.

En desarrollo de lo anterior, puede leerse un pronunciamiento del Consejo de Estado de 2004, en donde una mujer ante un embarazo ectópico, originado en la trompa de falopio izquierda, otorgó el consentimiento para la extirpación de dicha trompa, pero en el transcurso del procedimiento le fue ligada también, y sin su aprobación, la trompa derecha. Justificó el médico su proceder, ya que con ello evitaba “...que la paciente volviera a presentar las mismas complicaciones relacionadas con el embarazo ectópico"; argumento tal, que fue reprochado por el Consejo de Estado, al haber

\footnotetext{
${ }^{132}$ Se pronuncian similarmente Llamas (1988, p. 159), Castaño (1997, pp. 50-56), Sánchez (1998, pp. 52-55) y Jaramillo (2002, pp. 221-222).

${ }^{133}$ El contrato médico puede ser de ejecución instantánea al agotarse con una sola prestación verbigracia una mera consulta como cuando el paciente ante un dolor de espalada acude al médico y este lo valora, diagnostica y formula el tratamiento a seguir de forma inmediata por no requerir otro tipo de análisis o exámenes; también puede emerger como un contrato de tracto sucesivo en donde por la naturaleza del objetivo final se requieren diversos actos médicos y sanitarios escalonados en el tiempo como ocurre con ciertos tratamientos láser para eliminación de vellos o manchas o en tratamientos psiquiátricos.
} 
actuado sin autorización y peor aún, sin que la intervención fuera de carácter necesario para salvar la vida (Sentencia de 13/12/2004, exp. 14722).

En el mismo sentido, un consentimiento otorgado en abstracto o general no es posible calificarlo como válido, pues si no se especifican y explican los actos médicos no hay autorización alguna, debido a que no se puede consentir de lo que no se conoce ${ }^{134}$.

Por otro lado, existe acuerdo general en cuanto a que el consentimiento debe ser dado posterior a la recepción de la información y previo al acto médico, de modo que, el paciente haya tenido el espacio para reflexionar y digerir los pros y contras de ese tratamiento o intervención, para poder poner en marcha su voluntad libre, consciente e informada, pues "[f]acilitar la información sin tiempo para prestar el consentimiento es tanto como privar de la información..." (Guerrero, 2004, p. 96).

No deviene conveniente estipular sacramentalmente el tiempo mínimo o máximo de anticipación suficiente ${ }^{135}$ con que debería darse la información y recabar luego el consentimiento $^{136}$, puesto que esto variará conforme, entre otros, a las circunstancias físicas, mentales y sociales que caractericen al paciente, a la naturaleza del procedimiento, la urgencia o no de la intervención, al grado de complejidad, opciones alternas posibles, el alcance y dificultad de comprensión de la información a suministrar y el nivel riesgos que acarrea el acto médico que se recomienda llevar a cabo. Así, no es igual el lapso que se necesita para sopesar la información respecto de un implante anticonceptivo, que el que requiere para una cirugía por un tumor en la médula espinal, dado el grado notorio de complicación, alternativas y riesgos entre uno y otro.

\footnotetext{
${ }^{134}$ Sobre el tema el Consejo de Estado estipuló que "[e]l consentimiento que exonera, no es el otorgado en abstracto, in genere, esto es para todo y para todo el tiempo, sino el referido a los riesgos concretos de cada procedimiento; sin que sea suficiente por otra parte la manifestación por parte del galeno en términos científicos de las terapias o procedimientos a que deberá someterse el paciente, sino que deben hacerse inteligibles a éste para que conozca ante todo los riesgos que ellos implican y así libremente exprese su voluntad de someterse, confiado a su médico" (Consejo de Estado, sentencia de 24/01/2002, exp. 1994-9875-01(12706)).

135 Se pronuncia en igual sentido Galán (2016, pp. 695 y 696).

${ }^{136}$ En algunas Comunidades Autónomas españolas como el País Vasco (Decreto 38/2012) y la Comunidad Valenciana (Ley 10/2014) han consagrado un tiempo mínimo de 24 horas previas a la intervención para dar la información a menos que se trate de intervenciones de carácter urgente.
} 
En consecuencia, se requiere que el profesional tome en cuenta las condiciones del caso médico y del paciente para que cumpla su deber de forma responsable, ya que “...s[o]lo puede entenderse como consentido un procedimiento si se demuestra que se asumió con seriedad y ética el suministro de suficiente información al paciente..." (Consejo de Estado, sentencia de 27/03/2014, exp. 2000-01924-01(26660)).

Es trascendental que en la historia clínica se deje consignado claramente la hora y la fecha en que se otorgó la información y cuando se da el consentimiento informado. Suele suceder que, en algunos supuestos la distancia sea breve, y en otros se haya necesitado ejercitar más profundamente y con antelación considerable la información, lo cual depende en su totalidad de cada circunstancia.

\subsubsection{Capacidad}

Sin estudiar a fondo los aspectos de la capacidad del paciente en torno al consentimiento informado y lo relativo a la representación, se puede afirmar que, se presentan notables diferencias entre la capacidad para contratar y la capacidad para consentir un tratamiento médico.

El contrato médico, como cualquier negocio jurídico, demanda que las partes que lo celebran cuenten con capacidad legal ${ }^{137}$, es decir, poder "obligar[se] por sí misma, sin el ministerio o la autorización de otra” (art. 1502 CC), también conocida como capacidad de obrar o de ejercicio, que se adquiere al cumplir la mayoría edad -18 años para Colombia-. Ella permite la realización de "...operaciones tendientes al desarrollo de la personalidad y de sus atributos y para crear, mantener, modificar o extinguir las relaciones que conciernen al sujeto contempladas por el derecho ... que se presume como regla general (art. 1503 CC)” (Hinestrosa, 2015, p. 210).

El consentimiento informado para una práctica médica implica el ejercicio de los derechos a la autonomía y la autodeterminación. Por ende, toda persona, en principio, por gozar de capacidad

\footnotetext{
${ }^{137}$ A diferencia de la capacidad de goce o jurídica que es inherente a toda persona, natural o jurídica, y se constituye en un atributo de la personalidad jurídica al ser la aptitud general para ser sujeto de derechos y obligaciones, es decir, ser titulares de relaciones jurídicas ya sea como sujetos activos o pasivos, ligada a toda la existencia de la persona (Hinestrosa, 2015, p. 209), y bien, para poder disponer de esos derechos se exige cierto desarrollo cognitivo, físico y madurez psicológica que permita juicios reflexivos.
} 
jurídica, puede manifestar su voluntad en todo aquello concerniente a su vida y salud, sin necesidad de contar con capacidad de ejercicio ${ }^{138}$.

De esta forma, el consentimiento informado, por su naturaleza y carácter de fundamental, admite que aquellos incapaces ${ }^{139}$, por razón de edad o por alguna discapacidad mental, puedan recibir información y participar en el proceso de decisión, en consideración a su proceso volitivo y reflexivo. Lo que dependerá, del tipo de discapacidad mental ${ }^{140}$ y las posibilidades ulteriores de recuperarse.

Cada persona es un agente moral autónomo, esto, lo hace responsable, libre de determinar y organizar su proyecto de vida conforme a sus convicciones, de decidir ante las alternativas que se le presenten, de definir su personalidad e identidad y establecer sus aspiraciones y relaciones sociales. Todo ello, como desarrollo de su dignidad, libertad y vida privada; en donde, la efectividad de este último derecho es precisa para “...ejercer la autonomía personal sobre el futuro

${ }^{138}$ La Convención sobre los derechos de las personas con discapacidad promueve el reconocimiento por parte de los Estados de la personalidad y capacidad jurídica de las personas con discapacidad para poder actuar en igualdad de condiciones con las demás en todos los aspectos de su vida. Por eso, deberán proporcionar las medidas adecuadas para que puedan contar con el acceso al apoyo que requieran para el pleno ejercicio de su capacidad jurídica (artículo 12). ${ }^{139}$ Art. 1504 del CC estipula lo concerniente a las incapacidades relativas y absolutas.

${ }^{140} \mathrm{La}$ OMS expone que existe gran variedad de trastornos mentales cada uno con manifestaciones específicas, pero en su generalidad se caracterizan por una mixtura de "alteraciones del pensamiento, la percepción, las emociones, la conducta y las relaciones con los demás" y entre ellos se encuentran la "depresión, el trastorno afectivo bipolar, la esquizofrenia y otras psicosis, la demencia, las discapacidades intelectuales y los trastornos del desarrollo, como el autismo" (2017).

En Colombia la Ley 1306 de 2009 define la existencia de discapacidad mental cuando la persona “...padece limitaciones psíquicas o de comportamiento, que no le permite comprender el alcance de sus actos o asumen riesgos excesivos o innecesarios en el manejo de su patrimonio. La incapacidad jurídica de las personas con discapacidad mental será correlativa a su afectación, sin perjuicio de la seguridad negocial y el derecho de los terceros que obren de buena fe" (art. 2).

De igual forma, esta ley diferencia entre discapacidad mental relativa y absoluta, encausando dentro de las primeras aquella personas que "padezcan deficiencias de comportamiento, prodigalidad o inmadurez negocial y que, como consecuencia de ello, puedan poner en serio riesgo su patrimonio, podrán ser inhabilitadas para celebrar algunos negocios jurídicos, a petición de su cónyuge, el compañero o compañera permanente, los parientes hasta el tercer grado de consanguinidad y aún por el mismo afectado" (art. 32). Serán incapaces relativos respecto de los actos o negocios sobre los que recae la inhabilidad (art. 15); y la absoluta es definida como “... una afección o patología severa o profunda de aprendizaje, de comportamiento o de deterioro mental" (art. 17).

La Ley 1616 de 2013 expone que la discapacidad mental "se presenta en una persona que padece limitaciones psíquicas o de comportamiento; que no le permiten en múltiples ocasiones comprender el alcance de sus actos, presenta dificultad para ejecutar acciones o tareas, y para participar en situaciones vitales. La discapacidad mental de un individuo, puede presentarse de manera transitoria o permanente, la cual es definida bajo criterios clínicos del equipo médico tratante" (art. 5, núm. 6). 
curso de eventos relevantes para la calidad de vida de la persona" (Corte IDH, caso I.V. vs. Bolivia, sentencia de 30/11/2016).

Por consiguiente, la autonomía requerida para las decisiones de tipo médico no se asimila a la capacidad legal para celebrar negocios jurídicos. Una persona a pesar de no ser legalmente capaz, puede que sea competente para ejercer su autonomía y expresar su voluntad, o inversamente, una persona plenamente capaz, puede estar afectada transitoriamente para emitir un juicio (Corte Constitucional, sentencia S-337-1999 de 12/05/1999).

Estos lineamientos han marcado la evolución de la jurisprudencia constitucional colombiana, de modo que, en un principio podía prescindirse del consentimiento informado totalmente, tanto en intervenciones de carácter extraordinarias como ordinarias ${ }^{141}$, en las siguientes circunstancias: “1) cuando el estado mental del paciente no es normal; 2) cuando el paciente se encuentra en estado de inconsciencia y 3 ) cuando el paciente es menor de edad"142 (Corte Constitucional, sentencia T401-1994 de 12/09/1994).

Ahora bien, se determinó que para poder proceder médicamente, en los supuestos mencionados, el profesional debía contar con el consentimiento de sus familiares, lo que se conoce hoy como consentimiento sustituto $^{143}$. El orden de prioridades estaba determinado analógicamente por la Ley 73 de $1988^{144}$ «de donación y trasplante de órganos», lo encabezaba el cónyuge no divorciado o

\footnotetext{
${ }^{141}$ Una intervención de tipo ordinario es aquella que su realización no afecta el curso normal de la vida del paciente, contrario a las extraordinarias, en donde el carácter invasivo y agobiante requieren la autonomía del implicado, por lo que en estas últimas se hace aún más indispensable la figura del consentimiento (Corte Constitucional, sentencia T401-1994 de 12/09/1994).

${ }^{142}$ Esto sumado a las situaciones de urgencia que exijan la intervención médica de carácter inmediato para preservar la vida de la persona (artículos 14 y 15 de la Ley 23 de 1981 y artículo 3 del Decreto 3380 de 1981).

${ }^{143}$ La Corte Constitucional a partir de la sentencia SU-337-1999 de 12/05/1999 empezó a utilizar el término de consentimiento sustituto para beneficio de aquellos pacientes que no puedan decidir sobre la realización o no de un tratamiento específico en pro de su salud.

El consentimiento sustituto debe cumplir con las condiciones de ser informado, cualificado y persistente, es decir, el personal médico debe informar claramente las implicaciones, riesgos, alternativas y consecuencias positivas y negativas del procedimiento indicado; que sea cualificado se acredita en la medida en que los padres son informados detallada y depuradamente, ya que entre más invasiva y riesgosa sea la intervención mayores la exigencia en el nivel de información; y finalmente, la persistencia va orientada a que los padres hayan sido interrogados en ocasiones y momentos diferentes para conformar la genuina y reiterada voluntad de practicar el procedimiento a su representado (Corte Constitucional, sentencia T-622-2014 de 28/08/2014).

${ }^{144}$ Modificada por la Ley 1805 de 2016, "por medio de la cual se modifican la Ley 73 de 1988 y la Ley 919 de 2004 en materia de donación de componentes anatómicos y se dictan otras disposiciones".
} 
separado de cuerpos, seguido por los hijos legítimos o ilegítimos mayores de edad, los padres legítimos o naturales, los hermanos legítimos o naturales mayores de edad, etc.

Para definir la aplicación del consentimiento sustituto, el Alto Tribunal Constitucional expuso la necesidad de que cada asunto fuera examinado y valorado en su singularidad, al no resultar adecuado establecer reglas comunes para los casos en que se analiza o debate la capacidad de autodeterminación. Lo anterior, porque no siempre un desequilibrio psicológico puede ser la razón justificante para excluir la voluntad del paciente y hacer que priorice el juicio asistencialista, benéfico y paternalista de otras personas, como el médico.

Un ejemplo de lo anterior, se visualiza en los hechos estudiados en una acción constitucional de tutela donde el galeno unilateralmente cambió el tratamiento de diálisis peritoneal a una hemodiálisis sin autorización del paciente. El galeno justificó su actuar, en un trastorno severo de personalidad del enfermo, que afectaba el éxito del primer proceso y conllevaba a acciones irresponsables con su salud. En el trámite, se determinó probatoriamente que el estado mental del paciente era normal y, por tanto, su autonomía prevalecía incluso para oponerse o rechazar un tratamiento (Corte Constitucional, sentencia T-401-1994 de 12/09/1994).

Con el paso de los años, la Corte Constitucional ha afianzado el valor de la persona y el ejercicio de sus derechos fundamentales, al matizar las posibilidades de operar del consentimiento sustituto. Es forzoso, antes de llevar a cabo el proceso de consentimiento con un tercero, establecer la competencia y lucidez de la persona para asentir en esa circunstancia. Cuando se acuda al consentimiento sustituto, las situaciones deben quedar justificas, informadas y con un consentimiento cualificado, a saber:

(i) cuando se presenta una emergencia, y en especial si el paciente se encuentra inconsciente o particularmente alterado o se encuentra en grave riesgo de muerte; (ii) cuando el rechazo de una intervención médica puede tener efectos negativos no sólo sobre el paciente sino también frente a terceros; (iii) cuando el paciente es menor de edad, caso en el cual el consentimiento sustituto de los padres tiene ciertos límites; (iv) cuando el paciente se encuentra en alguna situación de discapacidad mental que descarta que tenga la autonomía 
necesaria para consentir el tratamiento". (sentencias T-303-2016 de 15/06/2016; C-182-16 de 13/04/2016)

Así mismo, entre más invasivo ${ }^{145}$ y riesgoso sea el tratamiento, mayor autonomía para decidir se requiere, por lo que el consentimiento deberá ser cualificado. Por el contrario, entre menos invasivo y rutinario sea el procedimiento médico, menor será la exigencia de su cualificación.

Este reconocimiento del derecho al consentimiento informado para todas las personas independientemente de su edad o incapacidad cognitiva, también ha obedecido al marco normativo nacional y de carácter internacional ${ }^{146}$. Puesto que, en ellos, se ha enfatizado en el ejercicio de los derechos humanos de forma igualitaria para todos, ya que cada ser humano debe definir su destino, en especial, cuando está en juego su salud y su vida.

El Proyecto de Ley 042 de 2017 proclama como excepción al consentimiento informado cuando "el paciente no se encuentre consciente o se encuentre en incapacidad legal o mental para manifestar su voluntad, en cuyo caso podrá ser expresada legítimamente por los responsables del paciente" (art. 17). Dicha disposición, al momento de ser debatida en el Congreso, espera esta investigación, debería ser estudiada con detenimiento, en vista que de la simple lectura puede colegirse que, ante esos casos de incapacidad opera inmediatamente el consentimiento subrogado, sustituto o por representación. Lo anterior, podría derivar en un error garrafal ante los pasos

\footnotetext{
${ }^{145}$ De acuerdo con la Resolución 2263 de 2004 del Ministerio de Protección Social un procedimiento invasivo es aquel "realizado por un profesional de la medicina en el cual el cuerpo es agredido química y/o mecánicamente o mediante inyecciones intradérmicas y/o subcutáneas, o se introduce un tubo o un dispositivo médico" como cuando, se realiza una cirugía, una biopsia, endoscopias o estudios radiológicos con contraste.

En contraposición a ello, los procedimientos no invasivos serán aquellos que "no requieren incisión o perforación de tejidos o de estructuras intactas [como los] electrocardiogramas, estudios radiológicos (sin inyección de medio de contraste), el examen físico, los signos vitales y algunos procedimientos endoscópicos. Estos estudios se suelen realizar en el consultorio médico o en un ámbito ambulatorio. En general, no necesitan sedación ni monitorización" (Fuller, 2005, p. 423).

146 Revisar capítulo I en lo concerniente a los aspectos legales del consentimiento informado a nivel local y convenciones internacionales.

En países como Argentina (Código Civil y Comercial de la Nación de 2015, Decreto 1089 de 2012 y Ley 26.529 de 2009), España (Ley 41 de 2002), Ecuador (Acuerdo Ministerial 5316 de 2015, el Código de la niñez y la adolescencia) abogan por la participación del paciente y exceptúan esta cuando no está en capacidad de decidir y poder hacerse cargo de su situación, dado que todas las personas deben ser consultadas en los asuntos que los afecten, por ello la información se debe adecuar a las condiciones específicas del paciente.
} 
jurisprudenciales, legales y convenciones internacionales que han buscado ampliar la participación y limitar al máximo los sistemas de sustitución en lo relativo a la toma de decisiones.

\subsection{Cuestiones prácticas en torno a la capacidad para consentir}

A reglón seguido, se ilustrará sobre cuestiones básicas en torno a las excepciones del consentimiento informado en razón a la edad o a una discapacidad mental, siguiendo el desarrollo jurisprudencial de la Corte Constitucional colombiana en coordinación con la regulación al respecto.

\subsection{Incapaces en razón de la edad}

En 1995, a través de la sentencia T-477 de la Corte Constitucional, la excepción del consentimiento respecto de los menores de edad dio un giro trascendental. En ella se debatió el caso de un niño que a la edad de seis meses aparentemente un perro le cercenó sus genitales. Por tal motivo, le fue practicada por un grupo de especialistas una meatotomía o modificación del pene, ante la inexistencia de recursos médicos en el avance de la ciencia para restituir los órganos genitales externos.

El procedimiento fue autorizado por los padres del niño -semi analfabetas- a través de un consentimiento abierto para todo tipo de tratamiento. Los galenos justificaron su actuación exponiendo que, era más fácil que el niño creciera y se desarrollara con el sexo femenino y no quedara en una ambigüedad sexual.

Seis años después, se le practicó al menor de edad, quien estaba esto bajo la potestad del ICBF por medio de un hogar sustituto, una segunda intervención -readecuación de sexo- para remodelar los genitales externos femeninos, sin haber prueba alguna de un consentimiento nuevo y expreso de los padres biológicos. El niño con el paso del tiempo mostró una identificación masculina y no femenina, y comenzó a rechazar agresivamente el trato como niña, razón por la cual, se presentó ante el personero municipal, quien instauró una acción constitucional de tutela, cuya decisión fue 
favorable a los intereses y protección del menor de edad en la revisión efectuada por la Corte Constitucional $^{147}$. En la sentencia se sentó lo siguiente:

...en principio los padres pueden tomar ciertas decisiones en relación con el tratamiento médico de sus hijos, incluso, a veces, contra la voluntad aparente de éstos. Sin embargo, ello no quiere decir que los padres puedan tomar, a nombre de su hijo, cualquier decisión médica relativa al menor, por cuanto el niño no es propiedad de sus padres sino que él ya es una libertad y una autonomía en desarrollo, que tiene entonces protección constitucional. (sentencia T-477-1995 de 23/10/1995)

Conforme a estos supuestos, en los casos de intervenciones extraordinarias, como en las que se encuentra en juego la identidad sexual, la Corte puntualizó la necesidad de ponderar los principios de autonomía del paciente y el principio paternalista del Estado y los padres de proteger los intereses del menor de edad. Por tal motivo, se deben tener en cuenta la inmediatez, la gravedad del caso, la importancia del tratamiento, el impacto en la autonomía actual y futura del niño y, finalmente, la edad del menor de edad. Así, se establecieron límites a la potestad parental y del Estado al señalar el grado de injerencia del consentimiento sustituto (sentencia T-477-1995 de 23/10/1995).

Valga decir que, estos criterios para determinar la prevalencia de la autonomía no configuran un factor objetivo aplicado sin distingos o sin reserva en todos los casos, debido a que el carácter ordinario o invasivo, mira tanto la naturaleza objetiva del procedimiento como la subjetividad del paciente.

De la misma manera sucede respecto a lo que es la necesidad o urgencia del tratamiento, en virtud de que, la ciencia médica no cuenta con los beneficios de la exactitud para todas las

\footnotetext{
${ }^{147}$ La Corte dispuso en la parte resolutiva, entre otros puntos, “ordenar al Instituto Colombiano de Bienestar Familiar, representado por su director, que le preste a la persona vulnerada a cuyo nombre se instauró la tutela, la protección adecuada consistente en el tratamiento integral físico y sicológico requerido para la readecuación del menor, previo consentimiento informado, y en relación con la mutilación sufrida y a la cual se ha hecho referencia en este fallo. Este tratamiento integral podrá tener continuidad más allá de los 18 años siempre y cuando un grupo científico interinstitucional lo considere conveniente. El mismo grupo interinstitucional, junto con el correspondiente Defensor de Menores, hará el seguimiento al tratamiento".
} 
situaciones presentadas. Por tanto, deben evaluarse las condiciones de cada paciente y la edad, que si bien, es un indicador respecto de la madurez, exige mirar la capacidad evolutiva de cada persona, para llevar juicios de valor, dado que el nivel de comprensión no está atado inescindiblemente a la edad biológica, ello encauzado a la prevalencia del consentimiento orientado hacia el futuro, en especial, en los casos de los niños, niñas y adolescentes (Corte Constitucional, sentencia C-2462017 de 26/04/2017).

Con el transcurrir de los días, se ha marcado la tendencia de llevar a cabo, en la mayor medida posible, el proceso de consentimiento informado atendiendo a las capacidades evolutivas ${ }^{148}$ de los menores de edad (Corte Constitucional, sentencia C-752-2015 de 10/12/2015). Esto, con un acompañamiento y consentimiento conjunto, ya sea de sus de sus padres, tutores o representantes, según el caso, siempre y cuando, no sea un obstáculo para el ejercicio de la autonomía del paciente o constituya un desconocimiento de los derechos fundamentales del menor.

En este orden de ideas, cuanto mayor sea la voluntad reflexiva del menor de edad más amplia será la disposición de sus derechos, “...pero siempre guiada por la salvaguarda de su mejor interés y en concordancia con el ejercicio de la patria potestad y la responsabilidad parental" (Corte Constitucional, sentencia C-246-2017 de 26/04/2017) ${ }^{149}$.

En tanto, cuando el problema médico radica en la intersexualidad o ambigüedad sexual del menor, la Corte Constitucional ha establecido ${ }^{150}$ unas reglas a seguir en consideración a la injerencia del derecho a la identidad sexual, autonomía y libre desarrollo de la personalidad. De esta forma, ha resuelto matizar el consentimiento sustituto. En primer lugar, cuando no exista riesgo a la vida e integridad del menor de edad y segundo, cuando el niño haya superado el umbral

\footnotetext{
${ }^{148}$ De acuerdo con la Corte Constitucional la capacidad evolutiva implica "una relación de proporcionalidad inversa entre la capacidad de autodeterminación del menor y la legitimidad de las medidas de intervención sobre las decisiones que este adopte" (Corte Constitucional, sentencia C-246-2017 de 26/04/2017).

${ }^{149}$ Esta participación activa del paciente menor de edad encuentra sustento a nivel internacional en la Convención Sobre los Derechos del Niño arts. 5 y 12.

${ }^{150}$ La línea jurisprudencial en torno al tema de la ambigüedad sexual en los menores de edad está sustentada en las sentencias SU-337-1999 de 12/05/1999, T-551-1999 de 02/08/1999, T-692-1999 de 16/09/1999, T-1390-2000 de 12/10/2000, T-1025-2002 de 27/11/2002, T-1021-2003 de 30/10/2003, T-912-2008 de 18/09/2008 y T-622-2014 de 28/08/2014.
} 
crítico de identificación de género -5 años de edad en principio-, momento en el cual pierde validez el consentimiento paterno sustituto y entra a prevalecer la decisión del menor de edad.

Estos procedimientos invasivos en la identidad por sus efectos hacia el futuro, requieren de un apoyo constante a nivel psicoterapéutico y de un equipo interdisciplinario integrado por profesionales de la medicina y un trabajador social, para acompañar al paciente y a sus progenitores en todo el proceso clínico-asistencial (Sentencia T-622-2014 de 28/08/2014).

\subsection{Personas con discapacidad mental - esterilizaciones definitivas}

En el tema de la competencia para decidir sobre las esterilizaciones de las personas con alguna discapacidad mental, entran en conflicto diversos derechos y principios como la autonomía, el derecho a tener una familia y los derechos sexuales y reproductivos de las personas en situación de discapacidad vs. beneficencia e integridad de estas personas, alegada por terceros. En atención a lo cual, resulta indispensable ponderar los mismos y analizar las circunstancias que envuelven cada causa, ya que no es justificante el simple argumento de protección. Así, se requiere analizar el tipo y grado de dificultad del entendimiento y toma de conciencia para hacer elecciones libres.

Cabe destacar que, los casos que más han aportado al avance dogmático de la cuestión han sido aquellos en el que se debate el consentimiento para las esterilizaciones definitivas en personas con discapacidad mental, orientados con una perspectiva de género de protección a la mujer, quien históricamente ha sido víctima de discriminación, subordinación y violencia en relación con el ejercicio de sus derechos sexuales y reproductivos.

La salud ha sido definida por la OMS como "un estado de completo bienestar físico, mental y social, y no solamente la ausencia de afecciones o enfermedades" (Preámbulo de la Constitución de la OMS), es decir, un estado integral. De esta manera, los derechos sexuales y reproductivos hacen parte del derecho humano a la salud ${ }^{151}$ como un todo inescindible.

\footnotetext{
${ }^{151}$ El 23 de octubre de 2017 la CIDH, a través de un informe de prensa, exhortó a los Estados para la protección de los derechos sexuales y reproductivos de la mujer, por medio de medidas integrales e inmediatas, y destacó que "[e]1 derecho a la salud reproductiva trata de todos los aspectos relacionados con el sistema reproductivo así como la capacidad de disfrutar de una vida sexual satisfactoria y sin riesgos, y de tener la libertad para decidir si procrear o no,
} 
En razón de lo anterior, se han formulado instrumentos ${ }^{152}$ y adoptado medidas desde organizaciones internacionales, orientados a la protección de la mujer, como la Relatoría Especial sobre los Derechos de la Mujer fundada en 1994 por la CIDH, a fin de para brindar "atención específica a los derechos humanos de las mujeres y la equidad e igualdad de género"153, y crear conciencia de la necesidad de implantar medidas para que las mujeres puedan gozar de sus derechos sin violencia ni discriminación, a través, por ejemplo, de recomendaciones y estudios realizados y publicados.

Con respecto a los derechos de las mujeres, la CIDH ha resaltado el derecho a la información para que la mujer pueda tomar las decisiones que hacen parte de su esfera más íntima, como elegir entre tener hijos o no. De ahí que, la libertad de reproducción tenga la dimensión positiva de procrear y la negativa de no reproducirse, discusión que de igual forma concierne a la pareja dentro de su esfera familiar y personal, lo que cuenta con la protección del artículo 11 de la Convención Americana. Por tal razón, se han fijado unos lineamientos para el proceso de consentimiento informado en la materia:

i) informar sobre la naturaleza del procedimiento, opciones de tratamiento y alternativas razonables, que incluye los posibles beneficios y riesgos de los procedimientos propuestos; ii) tomar en cuenta las necesidades de la persona así como asegurar que la persona comprenda la información brindada; y iii) asegurar que el consentimiento que se brinde sea libre y voluntario. (CIDH, 2011, p. 15)

Por otra parte, las personas con discapacidad comprenden un grupo marginado y vulnerable a través de los años, con un desconocimiento abismal de sus derechos fundamentales y poca inclusión en la vida social. Por ende, la Constitución Política determinó que el Estado debe

cuándo hacerlo y con qué frecuencia. Para mantener su salud sexual y reproductiva, las mujeres, niñas y adolescentes necesitan tener acceso a información veraz y a un método anticonceptivo de su elección que sea seguro, eficaz, asequible y aceptable y deben estar informadas y empoderadas para auto-protegerse de las infecciones de transmisión sexual".

${ }^{152}$ Como la Convención sobre los derechos de las personas con discapacidad (2006); Convención Belém do Pará o Convención Interamericana para prevenir, sancionar y erradicar la violencia contra la mujer (1999); Convención sobre la eliminación de todas las formas de discriminación contra la mujer (1979), la cual es supervisada en su aplicación por un órgano de expertos en el tema de derechos de la mujer denominado Comité para la eliminación de la discriminación contra la mujer (CEDAW, por sus siglas en inglés).

${ }^{153}$ Sobre esta Relatoría se puede consultar la página web http://www.oas.org/es/cidh/mujeres/default.asp 
adelantar para beneficio de estos "política de previsión, rehabilitación e integración social" (art. $47)^{154}$, al ser sujetos de especial protección constitucional ${ }^{155}$.

La limitación de las facultades mentales no es óbice para que de forma inmediata sea cercenada la capacidad de disponer y participar, lo que permite cambiar el paradigma de limitación de autonomía y estigma de incompetencia para deliberar. Entonces, en principio está la independencia y autonomía de estas personas para todos aquellos asuntos en los que esté en capacidad de manifestar su voluntad.

La Ley 1412 de 2010, relativa a la realización de forma gratuita de la vasectomía y ligadura de trompas, señala que "cuando se trate de discapacitados mentales, la solicitud y el consentimiento serán suscritos por el respectivo representante legal, previa autorización judicial" (art. 6). Esta disposición que no debe ser interpretada de forma literal, sino en consonancia con los Pactos, Convenios y Convenciones Internacionales sobre Derechos Humanos referentes a las personas en situación de discapacidad ratificados por Colombia, los cuales integran el bloque de constitucionalidad, para el reconocimiento de la capacidad de jurídica de todo ser humano.

Por otro lado, la Convención sobre las personas con discapacidad mental propugna garantizar el pleno desarrollo de la autonomía, mediante la toma directa de decisiones e independencia en el ejercicio de sus derechos. De manera que, el Estado debe proveer los apoyos necesarios para el ejercicio de la capacidad jurídica o legal de estas personas (art. 12). Esto posibilita desafiar el estereotipo de discriminación por medio del ejercicio de la capacidad jurídica en condiciones de igualdad; lo que deriva, evaluar cada situación fáctica para que no opere de forma inmediata la abolición de la capacidad para decidir. Sin embargo, el paso de lo regulado a la práctica real y efectiva, aún es un reto para el Estado colombiano y la sociedad en general.

Recientemente, fue proferida por la Corte Constitucional la sentencia T-303 de 2016 de 15/06/2016, la causa fáctica se centró en una madre que solicitaba al juez la autorización para que le fuera practicada por la EPS la cirugía de ligamiento de trompas a su hija de 17 años con retraso

\footnotetext{
${ }^{154}$ Los arts. 54 y 68 también consagras garantías para las personas con discapacidad.

155 Sobre la especial protección constitucional ver la sentencia C-606-2012 de 01/08/2012 de la Corte Constitucional.
} 
mental moderado, por cuanto dicha entidad se había negado a realizarla, por no contar con autorización judicial para ello. Lo anterior, a juicio de la interesada quebrantaba los derechos a la salud, vida y dignidad de su hija, quien corría grave peligro de ser víctima de un embarazo no deseado al tener que dejarla sola en casa mientras ella debía ir a trabajar.

Pese a que no fue acogida la pretensión tutelar ${ }^{156}$, en virtud de que en el trámite de tutela la adolescente cumplió la mayoría de edad, la Corte constitucional hizo énfasis en la necesidad de un concepto médico especializado que diera cuenta del retraso mental y su grado, afirmando que “...no todas las enfermedades mentales anulan la consciencia del individuo y algunas permiten un cierto grado de razonamiento" (Sentencia T-303-2016 de 15/06/2016).

El Alto Tribunal estableció que ante un juez se debe adelantar el trámite de autorización para estos procedimientos. El funcionario judicial debe, con ayuda de los conceptos médicos, establecer el nivel de incapacidad para discernir y así mismo, sopesar la existencia de otras medidas alternativas de anticoncepción. En consideración a que, existen situaciones en que, a pesar de la discapacidad, se conservan ciertas facultades de autodeterminación sobre algunos aspectos de la vida. En oposición, hay enfermedades mentales completamente irreversibles que no dan paso a lucidez alguna (Sentencia T-303-2016 de 15/06/2016).

Además, son trascendentales las cuestiones relativas a las intervenciones irreversibles, completamente invasivas y restrictivas de derechos reproductivos, tanto que, no basta la sentencia de interdicción del individuo mayor de edad con discapacidad mental, pues se requiere autorización judicial previa, para que el juez analice ya no la capacidad de ejercicio en general, sino la real necesidad de ese procedimiento y hasta qué punto el incapaz puede manifestar o no su voluntad.

\footnotetext{
${ }^{156}$ No obstante, la Corte ordenó a la EPS accionada que una vez fuese adelantado el trámite de interdicción, se le brinde a la joven valoración médica especializada para determinar el grado de retraso mental, y en caso que la discapacidad sea tan alta, que no podrá ser consiente ni tener autonomía personal para decidir por sí misma si desea o no tener hijos, la entidad debe darle al representante de la joven toda la información necesaria del procedimiento quirúrgico para emitir el consentimiento informado sustituto, y luego de este, deberá el representante acudir ante el juez de familia, para que a través del trámite judicial especial autorice el procedimiento de ligadura de trompas o Pomeroy. Una vez surtido ello, procederá la EPS a gestionar todo para la práctica de la intervención.
} 
La referida providencia de tutela compendia la línea jurisprudencial ${ }^{157}$ de la materia de esterilizaciones, tanto en personas con discapacidad cognitiva como en menores de edad, armonizado con la normatividad de carácter nacional y convenios internacionales. De acuerdo con ello, el protocolo a seguir para el otorgamiento del consentimiento sustituto para esterilizaciones definitivas, dado su carácter excepcional al presumirse la capacidad, es el siguiente:

\begin{tabular}{|c|c|}
\hline & \\
\hline $\begin{array}{l}\text { 1. Verificación médica de que el menor de } \\
\text { edad es incapaz para expresar su voluntad a } \\
\text { través de su consentimiento informado, tanto } \\
\text { en momento presente como con el paso de los } \\
\text { años, dada la condición mental que padece al } \\
\text { ser profunda, grave y severa. } \\
\text { 2. Cumplido lo anterior, debe otorgársele a los } \\
\text { padres toda la información relacionada con el } \\
\text { procedimiento, como riesgos y consecuencias } \\
\text { definitivas. } \\
\text { 3. El consentimiento informado debe ser } \\
\text { otorgado por ambos padres titulares de la } \\
\text { patria potestad, excepto por ausencia, } \\
\text { abandono o sustracción de la patria potestad de } \\
\text { alguno de ellos. } \\
4 \text { Posteriormente, los padres deben adelantar } \\
\text { ante un juez }{ }^{158} \text { la autorización del } \\
\text { procedimiento de esterilización definitiva. }\end{array}$ & $\begin{array}{l}\text { 1. Proceso de interdicción judicial, con el } \\
\text { propósito de conocer el grado de incapacidad } \\
\text { mental y sea designado el respectivo curador. } \\
\text { 2. A reglón seguido, el curador o guardador } \\
\text { deberá adelantar un proceso ante un juez de } \\
\text { familia, para obtener la autorización del } \\
\text { procedimiento de esterilización del incapaz. } \\
\text { 3. El funcionario judicial debe analizar la } \\
\text { necesidad médica y la imposibilidad de un } \\
\text { consentimiento futuro. } \\
\text { 4. Cumplido lo anterior, el curador podrá } \\
\text { acudir ante la EPS o el médico tratante para } \\
\text { llevar a cabo la intervención, previo proceso } \\
\text { del consentimiento informado cualificado. } \\
\text { 5. En caso de negativa de la EPS de adelantar } \\
\text { el procedimiento, ya obtenida la autorización } \\
\text { judicial, el guardador puede acudir ante un juez }\end{array}$ \\
\hline
\end{tabular}

${ }^{157}$ Ver sentencias T-850-2002 de 10/10/2002, T-248-2003 de 21/03/2003, T- 492-2006 de 29/06/2006, T-1019-2006 de 01/12/2006, T-560-2007 de 26/07/2007, T-740-2014 de 03/10/2014, C-131-2014 de 11/03/2014, C-182-2016 de 13/04/2016, T-573-2016 de 19/10/2016, T-655-2017 de 30/10/2017.

${ }^{158}$ Conforme al Código General del Proceso entre los asuntos sometidos al conocimiento de los jueces de familia se encuentran aquellos relacionados con las controversias suscitadas por el ejercicio de la patria potestad y los "asuntos de familia en que por disposición legal sea necesaria la intervención del juez o este deba resolver con conocimiento de causa, o breve y sumariamente, o con prudente juicio o a manera de árbitro" (art. 21). En la misma disposición se establece que corresponde a los jueces de familia "la protección legal de las personas con discapacidad mental, sin perjuicio de la competencia atribuida por la ley a los notarios", por lo que se puede afirmar que son los jueces de 


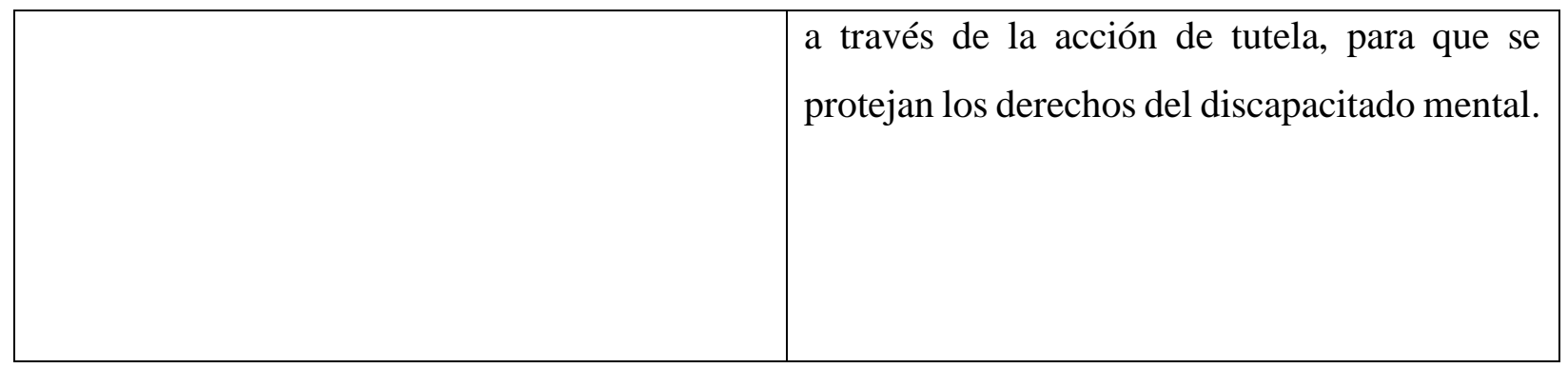

Tabla 1. Elaboración propia

Cuando el paciente es mayor de edad, se considera en este trabajo, resulta imperioso que previo a acudir el curador ante el juez con el objetivo de obtener la autorización para el procedimiento definitivo de esterilización del pupilo, se demuestre que previamente ha tenido la información relacionada con la naturaleza, riesgos, cuidados y consecuencias previsibles de la intervención, lo que da seguridad a la pretensión invocada, al tener el solicitante conocimiento de causa.

Vistas las cosas, el consentimiento sustituto en estos asuntos no se torna una tarea fácil, lo que exige que, el análisis del juez para dar o no la autorización debe ser completamente motivado y no basado en argumentos rutinarios. De igual forma, debe examinar la posibilidad de otras alternativas médicas anticonceptivas menos lesivas, riesgosas y reversibles en el futuro, dependiendo la posibilidad de que el paciente pueda recuperarse, en alguna medida, y tomar posteriormente y por sí mismo, la decisión de carácter irreversible. Así pues, es indispensable el concepto médico ante el juez para poder analizar y confrontar los hechos presentados, para que resuelva en pro del mejor interés para el sujeto de especial protección.

\subsubsection{Obligatoriedad y excepciones al consentimiento}

El acuerdo de voluntades para establecer la relación contractual en el ámbito sanitario tiene como característica la voluntariedad -libertad contractual-, es decir, ninguna persona está obligada a celebrar un negocio jurídico con otra. De modo que, el consentimiento sería la base para obligarse o no, requiriéndose la concurrencia de la voluntad tanto del médico como del paciente (Llamas, 1988, p. 157).

familia los designados para decidir estos asuntos especiales tanto en personas menores de edad como mayores de edad en situación de discapacidad. 
Por su parte, el consentimiento informado para el acto médico es una exigencia legal y moral, implica que el médico no puede obrar sin él, el paciente libremente decide si se somete o no a la intervención y puede retractarse antes de la ejecución del procedimiento.

El consentimiento informado permite unas excepciones a su otorgamiento que dan vía libre al profesional de la salud para actuar en pro único del beneficio y bienestar del paciente. Para ello, se acude a lo consagrado en el Decreto 3380 de 1981, el cual estipula las situaciones en que el profesional queda exonerado de hacer la advertencia del riesgo previsto: "a. Cuando el estado mental del paciente y la ausencia de parientes allegados se lo impidan; b. Cuando existe urgencia o emergencia para llevar a cabo el tratamiento o procedimiento médico" (art. 11). Igualmente, a lo dispuesto por la Corte Constitucional ${ }^{159}$ sobre las situaciones en las cuales la exigencia de consentimiento es menos estricta o se prescinde de él.

De lo que se sigue que, los límites y excepciones al consentimiento se concretan en: urgencia vital, riesgo para la salud pública ${ }^{160}$, frente a terceros ante la emergencia de la situación, por el rechazo del paciente a determinada intervención o tratamiento, el estado de inconciencia o la incapacidad del paciente para expresar su voluntad que no sea posible obtener el consentimiento informado por parte de los familiares o representantes y exista grave riesgo para su salud y vida de modo que hagan inevitable el proceder médico.

\subsubsection{Fundamento y justificación de la obligación de información}

Normalmente, el paciente es un lego de la medicina que limita su conocimiento simplemente a referir los síntomas que padece, al deseo de una intervención o que le sea resuelta cierta necesidad o duda en materia de medicina. No le es exigible tener plena información sobre la enfermedad, las

\footnotetext{
${ }^{159}$ Ver sentencia C-182-2016 de 13/04/2016.

${ }^{160}$ Narváez (2009) justifica la limitación al consentimiento informado por razones sanitarias establecida por la ley española 41/02, y dice: “...la preservación de la salud colectiva a la que debe tender la actuación de las autoridades sanitarias constituye un bien jurídico de interés general que en los casos de pandemia con elevado riesgo de contagio humano puede conllevar la limitación cuando no la privación de derechos y libertades fundamentales que, no solo se extiende a un variado catálogo de ellos, sino que también afecta a los que más relevancia tienen para el ser humano. La regla de la proporcionalidad de los sacrificios es la que debe ponderar su restricción tanto en su intensidad como en el tiempo de aplicación" (p. 87).

Argentina también establece como excepción al consentimiento informado cuando medie grave peligro para la salud pública (Ley 26.529 de 2009 art. 9).
} 
consecuencias del procedimiento recomendado, si es adecuado y qué podría pasar si no se somete a ello. Su principal fuente de conocimiento es que otro se los proporcione (Ataz, 1985, p. 68) de forma clara, completa y ajustada a un lenguaje común.

Lo anterior, permite el nacimiento de una obligación de información en cabeza del médico, que no puede ser cumplida a medias. Se le exige una labor completa, en algunos casos cualificada y persistente, como cuando se trata de un menor de edad, en garantía de los derechos del paciente.

Esa obligación se justifica en el carácter técnico, científico y especializado de la medicina que no resulta fácil de entender al ciudadano común, sin que medie una explicación pausada y comprensible sobre el tratamiento a seguir. Esta necesidad informativa ha sido enfáticamente reconocida por la jurisprudencia, así en sentencia (03/05/2007, exp. 1996-05556-01(16098)) proferida por el Consejo de Estado, se debatió el caso de una mujer de 43 años que con ocasión a la muerte del bebé que estaba esperando -aborto incompleto y espontáneo- se le recomendó por el médico la práctica de un legrado obstétrico, y se remite a la paciente a una "evaluación prequirúrgica por cardiología- Dx Miomatosis Uterina- Plan HTA simple [histerectomía simple]", posteriormente, la mujer fue intervenida por miomatosis uterina y se realizó "HTA simple".

La paciente alegó en los hechos de la demanda, haber autorizado solo la extirpación de unos miomas y no la histerectomía. El Alto Tribunal concluyó que el consentimiento firmado fue general, inespecífico y sin prueba de que se haya explicado previamente el plan quirúrgico, lo que lo privó totalmente de contenido. Añadió que, en la historia clínica no obraba esclarecimiento sobre otro procedimiento que no fuera el legrado, y, además, no era posible deducir que el término "HTA" debía ser entendido por la paciente, al tratarse de tecnicismo que debió aclararse.

Así pues, el fundamento de la obligación de información en el campo sanitario va más allá de la observancia de los postulados de la buena fe, como sucede en materia precontractual y en la generalidad de los contratos. A causa de que, su razón de ser se ampara en la protección de las máximas fundamentales que cobija todo el proceso de consentimiento informado y por el notorio desequilibrio informativo, el cual hace que la información sea parte de las obligaciones principales e inherentes de la actividad médica. 
La información en el ámbito precontractual, para dar paso al consentimiento contractual, se maneja de forma diferente, como quedó previsto en la parte primera de este capítulo, saltan a la vista las notables diferencias, en especial lo concerniente a la autoinformación. La medicina al ser una ciencia "hermética e impenetrable" (Gitrama, 1977, p. 279), no puede dejar a la deriva algo tan esencial como el hecho de que el paciente tenga pleno y claro conocimiento del procedimiento recomendado, pues podría llevar a confusiones que generarían rechazos de tratamientos indispensables para la salud, por una falsa creencia o información falaz.

\subsubsection{La forma del consentimiento}

La normatividad colombiana no exige una formalidad específica para la manifestación del consentimiento informado $^{161}$, pero la práctica revela la oralidad del mismo en procedimientos no invasivos y por escrito en aquellos que implican un mayor riesgo.

Obligatoriamente el médico debe dejar constancia en la historia clínica de su práctica, al ser el consentimiento un anexo de esta ${ }^{162}$. Aparte del registro, deben adjuntarse los soportes de consentimiento informado, ya sea el formato mismo o los apoyos utilizados para explicar el tratamiento o procedimiento. De tal manera que, no quede duda del ejercicio de la obligación de información y de la aceptación del paciente, la cual debe ser manifiesta y clara.

Es recomendable que se haga por escrito el protocolo de aceptación del acto médico, ante la complejidad del tratamiento o procedimiento a realizar, como aquellos que resultan ser invasivos y riesgosos, en aras de proteger los derechos del paciente y dejar constancia expresa, lo que sirve de prueba ante reclamaciones judiciales. Empero, la acreditación del consentimiento informado se puede realizar a través de diversos mecanismos probatorios, así, no solo es válido un documento escrito que contenga la elección del paciente (Consejo de Estado, sentencia de 06/03/2013, exp.1993-00356-01(25715)).

\footnotetext{
161 Tampoco lo hace el Proyecto de Ley 042 de 2017.

162 Ver las Resoluciones del Ministerio de Salud y Protección Social Nos. 1995 de 1999 y 1441 de 2013.
} 
En ese orden, se destacan varias legislaciones en torno a la regla que el consentimiento sea verbal, pero en situaciones particulares se requiere que sea por escrito. La ley española dispone que "se prestará por escrito en los casos siguientes: intervención quirúrgica, procedimientos diagnósticos y terapéuticos invasores y, en general, aplicación de procedimientos que suponen riesgos o inconvenientes de notoria y previsible repercusión negativa sobre la salud del paciente" (Ley 41 de 2002, art. 8).

En Argentina, el consentimiento escrito se prevé para los casos de “a) Internación; b) Intervención quirúrgica; c) Procedimientos diagnósticos y terapéuticos invasivos; d) Procedimientos que implican riesgos según lo determine la reglamentación de la presente ley; e) Revocación" (Ley 26.529 de 2009, art. 7).

En Perú también dispone del consentimiento escrito para eventos específicos como "tratamientos especiales, realizar pruebas riesgosas o practicar intervenciones que puedan afectar psíquica o físicamente al paciente" (Ley 26842 de 1997, art. 27). De esa forma, ha sido importante que se consagre tanto la afectación física que pueda ocasionar el procedimiento, como la psíquica, puesto que, hay procedimientos que más allá del dolor o las consecuencias a nivel corporal, su práctica puede incidir en la esfera emocional de la persona, como ocurriría con una citología vaginal o un tacto vaginal en donde a la paciente no se le informe previamente sobre ello y la forma en que se lleva a cabo, de modo que, la mujer puede considerar el acto como un atentado a su integridad y dignidad.

En la misma línea de las legislaciones enseñadas previamente, se encuentran, entre otras, Chile (Ley 20.584 de 2012), Uruguay (Decreto 274 de 2010), Panamá (Ley 68 de 2003) y Ecuador. En este último, se destaca la cláusula que obliga a que el consentimiento sea escrito, a más de lo ya anunciado, en todo lo que implique un riesgo mayor o afectación a la identidad o integridad de la persona o que pueda generar incapacidades, lesiones o daños (Acuerdo Ministerial 5316 de 2016).

Por su parte, el contrato médico no exige formalidad alguna su celebración, como se dejó sentado. 


\subsubsection{Reclamaciones frente al incumplimiento del consentimiento informado}

Desde la perspectiva de la teoría general del contrato, el incumplimiento del deber de información en la etapa de las tratativas puede dar lugar a una responsabilidad civil ${ }^{163}$, independiente y justificada en una culpa in contrahendo, por actuar en contravía de los postulados de la buena fe, no obstante, la validez del contrato ${ }^{164}$. Esto, depende de los antecedentes factuales e intereses del afectado, por lo cual, queda abierta la posibilidad de elección para reclamar la indemnización de daños de forma autónoma o complementaria a la acción de nulidad.

Descendiendo al plano sanitario, la defectuosa información sobre el procedimiento a realizar para algunos autores ${ }^{165}$ es sinónimo de un consentimiento viciado, conforme a las hipótesis tradicionales -error, dolo o fuerza-. Luego, da lugar a la nulidad del contrato médico celebrado, tal como se concibe para cualquier contrato en general, siendo el más común el consentimiento prestado por error (Ataz, 1985, p. 67), que se edifica cuando el paciente no está enterado claramente de los riesgos, naturaleza y consecuencias del tratamiento y emite un juicio no consciente, estando el acto afectado de nulidad relativa.

En lo que corresponde a las consecuencias derivadas por razón de un defecto o ausencia de información, otro sector de la doctrina afirma que, se está ante una responsabilidad precontractual, al margen de la posible nulidad del contrato por vicio del consentimiento (Llamas, 1988, p. 166); el resarcimiento iría hasta el límite del interés negativo ${ }^{166}$ (Lorenzetti, 2015, p. 293). Esto quiere

\footnotetext{
${ }^{163}$ Esto sin entrar en discusión sobre la naturaleza de la responsabilidad, es decir, contractual o extracontractual o una categoría independiente "precontractual", al ser un horizonte que no obedece al campo de estudio de la presente investigación.

${ }^{164}$ El interesado puede adelantar el juicio de responsabilidad independientemente del ejercicio de las acciones orientadas a declarar la nulidad del contrato por la existencia de un vicio en el consentimiento, da cuenta de ello Hinestrosa (2015, pp. 711-712) al exponer que "ello quiere decir que a la víctima se le abre un abanico de remedios, alternativos unos, concurrentes otros, a su elección y de acuerdo con los respectivos supuestos de hecho, como son la anulación del contrato por vicio de la voluntad (dolo o error) o por conflicto de intereses, rescisión o rebaja del precio por vicio redhibitorio, o resarcimiento de daños, y en algunos contratos de consumo, derechamente el poder dejar sin efectos el contrato".

${ }^{165}$ Llamas (1988, pp. 158-167); Fernández (2000, pp. 148-149); Gitrama (1977, p. 293); Castaño (1997, pp. 58-62).

${ }^{166}$ De acuerdo con Monsalve el interés negativo se resume en revertir las cosas como si el perjudicado jamás hubiese oído hablar de ese contrato (2010, p. 375). Se indemnizan los daños a la confianza al crear legítimas expectativas, por esto su reparación "...consiste en la pérdida que se origina al violar la expectativa que se tenía en no ser lesionado en el ejercicio de la libertad contractual, por haber confiado en la conclusión del contrato que no se celebre o que sea declarado nulo" (Oviedo, 2008, p. 109).
} 
decir, el restablecimiento a nivel patrimonial o económico de aquellos afectados en la confianza de que el negocio jurídico se concluiría.

Se precisa en esta investigación que, la posibilidad de hacer uso del instrumento jurídico de la nulidad por vicio del consentimiento, tendría razón y sentido en el terreno previo a la ejecución de la prestación. Dado que, una vez efectuado el procedimiento y se concreten los riesgos no informados, la pretensión del paciente sobre este aspecto, ya no será la de revertir la actuación por su imposibilidad material, más bien, estaría encaminada a la reparación de daños.

A guisa de ejemplo, después de una valoración diagnóstica inicial entre paciente y profesional se ajusta un contrato de prestación de servicios cuyo objeto es una abdominoplastia y liposucción, se pagan los respectivos honorarios, no se hace alusión alguna a los riesgos previsibles y se firma el consentimiento. El día de la cirugía, la paciente se retracta del negocio y le informa al médico que se enteró de los riesgos inherentes a ese procedimiento, por intermedio de otro profesional de la medicina a quien ulteriormente consultó y los cuales no fueron informados por el galeno inicial, tales como la aparición de coágulos de grasa o de sangre, la pérdida excesiva o acumulación de líquidos o la asimetría en el cuerpo, y conocidos manifiesta la paciente no asumirlos. Este evento, patentiza que el consentimiento prestado se encuentra viciado por error.

En consideración al supuesto, vale la pena preguntarse ¿cuál sería el interés de la paciente?, ¿su alegación va encaminada hacia el consentimiento contractual o el consentimiento para el acto médico?, a lo cual se puede responder lo siguiente: en los eventos preliminares a la realización del acto médico encomendado resulta jurídicamente viable la aplicación de la teoría del vicio del consentimiento para atacar el consentimiento contractual con el propósito de que todo vuelva al estado anterior de la celebración del negocio jurídico.

De igual forma, puede suceder que el consentimiento contractual y el consentimiento para el acto médico se den en un mismo momento y no se haya llevado a cabo la actuación del profesional sobre el cuerpo del paciente, cabe poner en ejercicio el vicio del consentimiento por error. 
En este orden de ideas, es viable afirmar que, respecto de los riesgos previsibles materializados no informados, el paciente no tiene otra alternativa que demandar la responsabilidad médica por el incumplimiento del derecho al consentimiento informado ${ }^{167}$.

Siguiendo a De La Maza (2010-b, p. 90) y a Barros (2006, pp. 667-670), la discusión sobre si es precontractual, contractual o extracontractual la responsabilidad médica no genera gran utilidad desde la perspectiva de las condiciones para que haya responsabilidad -hecho, daño y nexo causal. Por cuanto, el consentimiento informado al ser un derecho fundamental, aunado a las garantías básicas vinculadas al mismo, es exigible legal y éticamente en todas las esferas del acto médico, al margen de si es público o privado o si media o no un contrato o como se encauce la relación médico-paciente. Por ello, se puede sostener que el consentimiento informado es propio a la naturaleza de la relación médico-paciente y no necesita estipulación alguna para su cumplimiento.

\section{Contenido del consentimiento informado}

\subsection{Información para el consentimiento informado}

La información constituye un derecho de todo paciente o usuario de los servicios sanitarios, se circunscribe a conocer su estado de salud y todo lo relacionado con ello para que pueda ser consciente de su condición. Además, permite fortalecer el vínculo de confianza, la participación activa del paciente, la colaboración para mejores resultados del tratamiento a realizar y garantizar la toma de decisiones voluntarias y autónomas.

En el marco de la relación asistencial, toda persona también tiene derecho a recibir información sobre los servicios y centros asistenciales, oferta de profesionales de la salud, canales de atención para peticiones, quejas y reclamos, y, asimismo, recibir explicación o rendición de cuentas respecto de los costos de los tratamientos recibidos (Ley Estatutaria 1751 de 2015).

${ }^{167}$ Sobre el tema específico de responsabilidad ver capítulo 3. 
La obligación de información del médico no siempre está encaminada al consentimiento informado para un tratamiento preventivo, diagnóstico o terapéutico. En efecto, la información reviste dos aspectos fundamentales (Fernández, 1985, p. 129) ${ }^{168}$ :

- Información terapéutica -llamada también asistencial o de seguridad.

Es la indicada, necesaria e indispensable en el desarrollo de la actividad médica y curativa en todas sus etapas (diagnóstica, terapéutica o preventiva), por ello, es parte del deber asistencial del galeno (Llamas, 2007, pp. 36-37). Comprende, entre otros, la explicación sobre el estado de salud, diagnóstico, administración y efectos secundarios de medicamentos, recomendaciones a seguir, advertencias en torno a su condición de salud y resultados de un procedimiento o tratamiento.

Esta información permite la adopción de decisiones que no van encaminadas a darle legitimación a un acto médico. Se caracteriza por ser continua, al requerirse durante las diferentes etapas del proceso asistencial y permite, como indican Fraga y Lamas (1999, pp. 79-81), el deber de colaboración del paciente al conocer las instrucciones médicas para lograr optimizar los resultados ${ }^{169}$.

En consecuencia, su inobservancia significa un desconocimiento de los deberes de diligencia y cuidado que impone el ejercicio de la medicina, que puede desencadenar en que el médico tenga que indemnizar el daño acaecido como consecuencia de su actuar negligente, como cuando un dermatólogo no previene los posibles efectos colaterales de un medicamento para combatir el acné severo cuyo componente es la isotretinoína, generándose posteriormente secuelas como el síndrome de ojo seco o en el peor de los casos teratogenicidad (defectos de nacimiento o malformaciones), esto último, por no advertir que no se debe quedar en embarazo durante el tratamiento y un tiempo considerable después de este.

\footnotetext{
168 Sobre esta misma cuestión Romeo (1985, pp. 47-48), Xiol (2012, pp. 31-32) y Agón (2017, pp. 17-19).

${ }^{169}$ En esta línea se encuentra Guérez (2012, pp. 237-238).
} 
- Información como requisito para el consentimiento a un acto médico, es a la que hace referencia todo el cuerpo del presente trabajo.

La información para el consentimiento determina, como ciertamente lo establece Galán (2016, p 724), la validez y eficacia de este último; dado que, el consentimiento se extiende hasta donde se haya informado y aceptado las consecuencias del procedimiento o tratamiento. Por tanto, la información es un presupuesto para el consentimiento, de ahí la expresión consentimiento informado (Asúa, 2006, p. 1188).

\subsubsection{Forma de la información}

Para que el paciente al momento de exteriorizar su voluntad se considere ilustrado y se pronuncie con conocimiento de causa, es necesario que la información previa sea "clara, apropiada y suficiente" (Ley 1251 de 2015, art. 10) ${ }^{170}$. Se requiere que el profesional de la salud utilice en su alocución términos comprensibles y corrientes que permitan su entendimiento. Por tal motivo, la labor del médico con respecto al consentimiento informado es pedagógica, al tener que hacer inteligible lo revelado (Obando, 2016 p. 42).

Ahora, no basta con que se dé la explicación con palabras sencillas y accesibles, se requiere que se observen las condiciones cognoscitivas, culturales, psicológicas y competitivas del destinatario de la información ${ }^{171}$, con el propósito de determinar el lenguaje a utilizar y facilitar la comprensión, al ponerla al alcance del receptor. Luego, el proceso de revelación de la información no puede ser mecánico o superficial (Herrera, 2008, p. 23).

De antaño, la Corte de Casación Francesa-Primera Cámara de lo Civil entendió que la información brindada por el médico debe ser simple, leal, aproximativa e inteligible, para permitirle al paciente tomar la decisión de aceptación o rechazo (Sentencia 21/02/1961); debido a

\footnotetext{
170 El proyecto legislativo 042 de 2017 por el cual se busca crear el Código de Ética Médica dispone como características de la información que cobija el consentimiento informado que sea "clara, veraz, comprensible y oportuna".

${ }^{171}$ La Resolución 4343 del Ministerio de Salud y Protección Social que reza como derecho del paciente el mantener una comunicación plena y clara y que esté acorde a las "condiciones sicológicas y culturales" (art. 4.2).
} 
que, una explicación demasiado científica y técnica, por más completa que sea, puede catalogarse inadecuada por ininteligible y hermética que no equilibra la tradicional asimetría informativa.

La Corte Interamericana se ha pronunciado sobre la importancia de que el consentimiento informado derive de un proceso de comunicación en los siguientes términos:

...personal calificado presente información clara y sin tecnicismos, imparcial, exacta, veraz, oportuna, completa, adecuada, fidedigna y oficiosa... la forma como se presenta la información es muy importante porque tanto el personal de salud como el propio paciente pueden tener concepciones preconcebidas del tratamiento... el personal de salud deberá tener en cuenta las particularidades y necesidades del paciente... Ello hace parte del deber de brindar una atención en salud culturalmente aceptable. (Caso I.V. vs. Bolivia, sentencia de $30 / 11 / 2016)$

A nivel foráneo, la base de la información se concentra en que sea clara, comprensible y adecuada, en esta tesitura se encuentran: España (art. 4 Ley 41 de 2002), Argentina (Ley 26.529 de 2009), Perú (Ley 26.842 de 1997), Chile (Ley 20.584 de 2012) y en Ecuador el Acuerdo Ministerial 5316 de 2015 y su respectivo anexo pregonan la utilización de palabras comprensibles y evitar las técnicas.

En tanto, el profesional de la salud, para cumplir con su deber, se puede valer de estrategias discursivas y comunicativas, tales como herramientas y ayudas gráficas, numéricas, técnicas y/o tecnológicas que faciliten la transmisión de la información a fin de alcanzar un proceso de comunicación participativo que logre captar la atención del destinatario y buscar su comprensión ${ }^{172}$. Resuena apropiado, dejar abierta la gama de posibilidades a utilizar por el médico, para que este se acomode a su experticia y a la condición del paciente.

\footnotetext{
${ }^{172}$ Exponen Moore, Gómez, Kurtz y Vargas que "[c]on el uso de habilidades de comunicación efectiva, se busca aumentar la precisión diagnóstica, la eficiencia en términos de adherencia al tratamiento, y construir un apoyo para el paciente. Una comunicación efectiva promueve la colaboración entre el médico y el paciente, donde el foco de la entrevista no está centrado en el médico ni en el paciente, sino en la relación de ambos” (2010, p. 1052).
} 
Al respecto, la Corte Suprema de Justicia se pronunció sobre el caso de una señora que se sometió a unas cirugías plásticas de abdominoplastia y mamoplastia. La demanda de responsabilidad, entre otros puntos, se fundamentaba en el hecho de que no le fue informado el riesgo de cicatrización irregular, el cual se concretó; hecho que afectaba su vida laboral, ya que era modelo de ropa interior y bailarina de estriptis (Sentencia de 19/12/05, exp. 1996-5497- 01).

La Corte, luego de valorar las pruebas recaudadas, decidió no casar y adujo que, la ilustración, por el tipo de procedimiento, sus consecuencias y las particularidades de la paciente, aunque no informó al médico su verdadero oficio, debía cobijar en detalle la forma de llevar a cabo la cirugía, las incisiones y cortes que se realizarían, la posibilidad de cicatrices, riesgos, el proceso de recuperación y alternativas posibles que ofreciera la ciencia. Todo lo cual, se demostró que fue cumplido por el galeno demandado, al utilizar diagramas y dibujos en un papel para mostrar las incisiones que se realizarían, esto se derivó de la declaración de la misma accionante. Por consiguiente, el Alto Tribunal tuvo por informado el procedimiento (Sentencia de 19/12/05, exp. 1996-5497-01).

Por otra parte, para la comprensión es aconsejable que la información sea principalmente verbal $^{173}$, no solo por ser la forma de comunicación por excelencia utilizada en la relación médicopaciente, pues también, permite que al instante en que se lleve a cabo el intercambio comunicativo se puedan esclarecer dudas y contenido, se repita la información en otros términos y de forma inmediata cuando el receptor manifieste expresamente incomprensión del lenguaje o se deduzca por su actitud o gesticulación. De igual modo, refuerza la relación de confianza, lo que suele ser más difícil cuando la información se proporciona completamente por escrito.

Además, la comunicación verbal permite al médico conocer mejor al paciente y flexibilizar y adecuar la información, sin que deje de ser veraz y suficiente en su contenido ${ }^{174}$. Esto significa

\footnotetext{
${ }^{173}$ En España la regla general es que la información se dé verbalmente (Ley 41 de 2002 art. 4 No. 1). De igual forma, en Ecuador se enfatiza en la información presencial y verbal del responsable, y se indica que el documento de consentimiento informado deberá ser leído y comprendido por el paciente después de la correspondiente información dada por el médico (anexo del Acuerdo Ministerial 5316 de 2015). Chile a través de la Ley 20.584 de 2012 señala que se puede dar la información de forma verbal, visual o escrita.

${ }^{174}$ García (2006, p. 3) explica que el deber de diligencia exigible al médico en cuanto a la información le exige modularla por las circunstancias particulares del paciente, por ello si en una cuestión concreta el médico sabe que X situación es completamente relevante para el paciente, debe hacer énfasis en ello y revelar la información aunque para
} 
que, es más que un simple intercambio de información, al permitir que la relación sea recíproca y productiva, donde juegan un papel importante el tono, el modo y el lenguaje (Castañeda, 2013, p. $347)$.

Como se consignó en el capítulo I, no está en esta pesquisa en contra de los llamados formularios de consentimiento, pero los mismos no se pueden confundir con la etapa previa de revelación de la información ni con el consentimiento informado en sí mismo. Debido a que, esos formularios son "el soporte documental donde se verifica que el paciente ha recibido y ha entendido la información facilitada por el médico" (Rubiera, Arbizu, Alzueta, Agúndez y Riera, 2004, p. 154).

En la práctica sanitaria suelen coincidir información, consentimiento y documento de consentimiento informado, al consignar en forma conjunta información y declaración de voluntad, lo que muchas veces hace que se asimile el consentimiento al simple documento. Estos formatos por sí solos no siempre garantizan consentimientos realmente informados, por lo ilegible y/o parco del contenido en cuanto a su tecnicismo, amplitud de términos especializados o espacios llenados en blanco a puño y letra que no se logran descifrar; situación que se vuelve más compleja, cuando el tratamiento es de carácter invasivo y con riesgos altamente peligrosos y frecuentes.

Por ende, es recomendable que los documentos de consentimiento estén acompañados de un intercambio de información esencialmente verbal, que debe exigirse prolongado y detallado entre más complejo, delicado, invasivo y comprometido sea el procedimiento recomendado. Asimismo, debe haber correspondencia entre la información dada verbalmente y lo que se consigne en el documento y en la historia clínica.

la mayoría de los pacientes no sea significativo, como cuando puede presentarse la posibilidad de una transfusión si sabe que el paciente no está de acuerdo con ello por su religión al ser Testigo de Jehová. 


\subsubsection{Información comprensible o comprendida}

No remiten a duda los términos en que debe proporcionarse la información al paciente y la necesidad de su individualización. A la par de lo anterior, surge como interrogante si la obligación de información exige que sea comprensible y al mismo tiempo, comprendida la información o basta con que solo se brinde la información con claridad y suficiencia.

De acuerdo con la Real Academia Española, el vocablo "entender" tiene varios significados, como "tener idea clara de algo", "saber con perfección algo", "discurrir, inferir, deducir", "tener intención o mostrar voluntad de hacer algo" y "creer, pensar, juzgar". Por su parte, comprender implica, entre otros, el "entender, alcanzar o penetrar algo". Por tal motivo, se tratarán como sinónimos ambos términos.

El consentimiento informado como decisión reflexiva y libre, si se acoge a su literalidad, necesita que el destinatario o en cabeza de quien esté el ejercicio del derecho sea consciente de su elección y asuma las responsabilidades y consecuencias de sus actos, lo que se logra cuando comprende la información trasmitida y la sopesa con sus intereses y realidades. Por esto, De La Maza (2017) expone que "[t]res condiciones deben, entonces, quedar satisfechas: los médicos deben suministrar información, los pacientes deben entenderla y ser capaces de analizarla críticamente" (p. 122).

En esta instancia, Llamas (2014, p. 14) hace hincapié en que la obligación de información se cumple en la medida que el profesional verifica que la misma alcanza su objetivo, al cerciorarse de que el receptor ha entendido "ciertamente" las consecuencias de su declaración de voluntad, por eso, la cataloga como una obligación de resultado. El autor añade que si bien no son pocos los inconvenientes del deber información, la comprensión desde la ignorancia del paciente es la razón para requerir la claridad de los términos (Llamas, 2014, p. 25).

También, la CIDH (2009) destaca como elemento del consentimiento informado el "ii) tomar en cuenta las necesidades de la persona así como asegurar que la persona comprenda la información brindada...” (p. 15). En un primer momento, lo asentado llevaría a considerar que el 
médico debe cerciorarse que la información revelada ha sido entendida. Sin embargo, de la lectura completa del texto de la CIDH, se desprende que el mensaje va orientado a que la información sea dada tan comprensible como adaptada a las circunstancias del interesado.

Afirman Beauchamp y Childress (2002) que, una persona "es capaz de comprender si dispone de la información pertinente y una idea justificada y relevante de la naturaleza y las consecuencias del acto. La comprensión no tiene por qué ser completa; con entender los hechos fundamentales suele ser suficiente ...” (p. 149).

Lograr que un paciente entienda y sopese los riesgos y beneficios de un procedimiento no es una labor sencilla y elemental (Beauchamp y Childress, 2002, p. 151) porque la información no es procesada ni comprendida por todos de forma similar. Esto, se debe a diversos factores como ideas preconcebidas, conocimientos básicos, dispersión, miedos, deseos de no saber, no querer afrontar la realidad, dolor físico o problemas emocionales y la forma, el tiempo y el lugar donde se emite la información.

Es posible que, un paciente sea competente para recibir la información, pero durante el proceso de recepción distorsione la realidad, embrolle el razonamiento o exteriorice una aceptación sin reflexión alguna, circunstancias que no siempre podrá precaver y manejar el profesional.

En el ejercicio de la medicina, como lo narra el médico neurocirujano Marsh (2014, pp. 38, 58, 128 y 316), muchas veces el paciente solo pone su confianza en el médico, escucha la información y firma con apenas echar un vistazo al formato de consentimiento, sin poder el facultativo asegurar que esa persona realmente comprendió todos los riesgos. Casi siempre, los pacientes superponen hasta cualidades sobrehumanas en el médico, con la tesitura de que todo saldrá bien y confían en sus habilidades y conocimiento.

Estos inconvenientes sobre la comprensión de la información deben ser un punto de enlace e intercomunicación entre el derecho, la ética y la medicina. Es decir, los juristas no pueden sacar conclusiones automáticas acerca del incumplimiento de la obligación de informar, sin visualizar primero los problemas éticos y médicos que se generan en la relación sanitaria, especialmente en 
ese proceso de comunicación, que concreta luego las posibilidades reales que la decisión sea realmente autónoma.

Es acertada Gracia (2008, p. 184) al sostener que, si bien se requiere el conocimiento para una acción autónoma, cuando se hace exige a que sea completamente autónoma, se cae en una utopía y quizá nunca se haya llegado o se llegue a ese nivel. Las decisiones deben ser sustancialmente autónomas en cuanto a su adecuación, para que sea comprendida la naturaleza y riesgos del procedimiento $^{175}$.

En efecto, no se puede incurrir en imprecisiones y exigencias que desborden las posibilidades de control humano. Sería un error exigirle al profesional un paciente omnicomprensivo y en consecuencia, la decisión haya sido fruto de la prudencia y cordura, al depender esto de innumerables circunstancias. El médico no puede prever, intuir y cerciorarse de todo lo que rodea al paciente ${ }^{176}$, por tanto, la exigencia de comprensión escapa del radio real de acción del médico.

Ahora bien, pese a que no es viable materialmente la exigencia de garantía de comprensión, es innegable que el médico, en el proceso de comunicación, debe invitar y promover el intercambio de preguntas-respuestas y la retroalimentación para verificar que se ha comprendido en la mayor medida posible lo informado.

Seguido al intercambio y esclarecimiento de dudas, se recomienda al médico preguntar al destinatario de la información si ha entendido lo revelado y dejar el espacio suficiente y prudencial para que tome la decisión, lo que lógicamente dependerá de la urgencia y condiciones del caso clínico. Todo esto, debe ser consignado en la respectiva historia clínica, como una forma de cerciorarse, en la medida de sus posibilidades, de la comprensión del paciente e igualmente de protegerse ante futuras controversias, dado que, la jurisprudencia viene indicando que la

\footnotetext{
${ }^{175}$ En este punto, Gracia sigue los lineamientos Beauchamp y Childress en cuanto al contenido y desarrollo del proceso de comunicación entre médico y paciente.

${ }^{176}$ En el mismo sentido se puede leer a Castaño (1997, p. 93).

En opinión contraria se encuentra Arbesú (2015) quien afirma que la obligación de informar y que la información sea comprendida se erige en una obligación de resultado que deriva en una responsabilidad objetiva al no estar condicionada al análisis de la diligencia empleada (pp. 346-347).
} 
información se vuelve más relevante de forma posterior cuando se concretan los riesgos (Pizarro, $2017,59)^{177}$.

En definitiva, no es tolerable el escepticismo médico hacia la incompetencia del paciente para procesar y comprender. Los profesionales de la salud deben esforzarse por conocer los métodos ${ }^{178}$ y desarrollar habilidades que permitan revelar de mejor forma la información. Por esto, el proceso se fundamenta en la revelación y “... en descubrir cuál es la información relevante y en decidir cómo clasificarla y utilizarla" (Beauchamp y Childress, 2002, p. 139).

\subsubsection{Contenido de la información: información adecuada}

Se ha puntualizado que la información ha de ser clara, suficiente y adecuada para que pueda haber consentimiento consciente, pleno y libre ${ }^{179}$. La claridad fue tratada en el acápite de la forma de la información y, a continuación, se hace referencia a la característica adecuada que implica, en sí misma, la suficiencia.

${ }^{177}$ Si bien Pizarro se refiere al caso chileno, no es menos cierto que en Colombia la tendencia de la motivación a demandar se mueve en el mismo sentido.

${ }^{178}$ Un estudio doctoral comparativo del proceso de consentimiento informado en Colombia y Chile demostró que los pacientes cuando se les explica en términos de porcentajes la previsibilidad de los riesgos no siempre entienden adecuadamente (Ovalle, 2009, p. 202). Por esto, algunas formas de relevar la información pueden resultar engañosas y no lograr el cometido, si no son utilizadas adecuadamente y no se interesa el médico porque el paciente entienda y valore el asunto.

Beauchamp y Childress no descartan la exposición numérica, pero proponen un método que consiste en “....establecer analogías entre información y sucesos habituales conocidos por el paciente... los profesionales pueden exponer los riesgos en forma de probabilidades ya sean numéricas o no numéricas, y ayudar al paciente a comprenderlos comparándolos con otros riesgos más conocidos y con experiencias previas, como por ejemplo los riesgos que existen al conducir un coche o al trabajar con herramientas mecánicas" (2002, p. 151).

${ }^{179}$ La Corte Constitucional, al examinar una acción de tutela, denotó una precaria ilustración a la madre de un adolescente de 16 años, que padecía déficit parcial de hormona de crecimiento, respecto de la época en que se debía dar por terminado el tratamiento hormonal de crecimiento, que se seguía desde los 5 años edad. Lo cual, llevó a la señora a entender una vulneración de los derechos fundamentales de su hijo, cuando se dio por finalizado el tratamiento por parte del facultativo y la EPS, dado que, cuando dio su consentimiento para el tratamiento, creyó que solo había un criterio para que este pudiera finiquitar y por tanto, se negó a aceptar ello por razones que desconocía, pero que eran previsibles por los médicos endocrinólogos tratantes al tiempo en que se otorgó el asentimiento. En consecuencia, la Corporación rechazó esta afectación a la relación médico-paciente y afirmó que "[e]s incontrovertible entonces que el consentimiento debe ir precedido de una información adecuada, esto es, suficiente en cantidad y calidad, pues no podría hablarse de un consentimiento libre y consciente desde el momento en que quien lo otorga no sabe en qué ni por qué. Lo importante es hacer del consentimiento informado un instrumento para la realización de un principio esencialísimo: que la persona sea dueña efectiva de su destino, como corresponde a su dignidad, y que esta información sea auténtica, completa y humana, como corresponde a algo tan trascendental como son las decisiones en las que puede estar afectada la vida, la integridad corporal o la salud física o psíquica" (Sentencia T-762-2004 de 11/08/2004) (cursiva y subraya fuera de texto). 
La información debe ser adecuada ${ }^{180}$ en dos caracteres fundamentales: calidad y cantidad (Corte Constitucional Sentencia T-762/2004 de 11/08/2004). Para determinar la adecuación de la información deben observarse unos factores subjetivos y objetivos, los primeros están relacionados con la personalización de la información en correspondencia a las particularidades del paciente; por su parte, los factores objetivos aluden a la urgencia, gravedad de los riesgos, la necesidad del tratamiento, el tipo de intervención los cuales determinarán la rigurosidad y contenido de la información (Romeo, Emaldi, Escajedo, Nicolás, Romeo M. y Urriela, 2006, pp. 30-31) ${ }^{181}$.

También, la jurisprudencia constitucional ha establecido unos factores moduladores o de graduación de la información que permiten determinar el nivel de necesidad y extensión de los datos a revelar. No solo sirven de referencia para el profesional a la hora de cumplir su obligación de información, al ser igualmente útiles para el juez al momento de estudiar una controversia sobre estos aspectos, y son:

(i) el carácter más o menos invasivo del tratamiento, (ii) el grado de aceptación u homologación clínica del tratamiento o su carácter experimental, (iii) la dificultad en la realización del tratamiento y las probabilidades de éxito, (iv) la urgencia del tratamiento, (v) el grado de afectación de derechos e intereses personales del sujeto al efectuarse el tratamiento, (vi) la afectación de derechos de terceros de no realizarse la intervención médica, (vii) la existencia de otros tratamientos que produzcan resultados iguales o comparables, y las características de estos y, (viii) la capacidad de comprensión del sujeto acerca de los efectos directos y colaterales del tratamiento sobre su persona (Sentencia C-246/2017 de 26/04/2017).

\footnotetext{
${ }^{180}$ Pelayo (2009) entiende que el carácter adecuado de la información se puede delimitar “ “.. en función de lo que la ley [hace referencia a la ley española 41 de 2002] considera como contenido mínimo de la información, atendiendo también a las posibilidades de comprensión del paciente, teniendo en cuenta que se ha de ayudar a tomar una decisión y que por lo tanto ha de ser lo suficientemente amplia como para que el sujeto se haga cargo de la situación, pero no tan exhaustiva, como para crear en él una situación de angustia que le impida decidir, y pudiendo por último limitarse en el caso de que se considere razonadamente que el conocimiento puede perjudicar al paciente de manera grave" (pp. 85-86).

En Colombia el Tribunal Nacional de Ética Médica (2012, p. 154) afirma que la información adecuada es “...la información a la que una persona razonable tendería a conceder importancia a la hora de someterse o no a una terapia propuesta".

${ }^{181}$ Idéntico criterio se puede observar en Fraga y Lamas (1999, p. 96).
} 
De acuerdo con Skegg (1984, p. 89), inciden en el flujo de la información el deseo de información y los efectos que la información puede ocasionar en el paciente, para no generar un mal mayor, lo que se conoce como privilegio terapéutico ${ }^{182}$.

No ha sido ligero y sin controversias determinar a ciencia cierta el alcance y contenido de la información. De este modo, se han propuesto criterios para establecer qué información debe ser revelada, como se vio en el caso Natanson vs Kline (1960), donde se acogió el criterio del profesional razonable o de la práctica profesional para establecer la validez de la extensión de la misma. Con todo, dejaba un sin sabor al tener por sentado tan solo la costumbre médica para determinar o no la infracción, y olvidaba que, la última palabra corresponde al juicio de cada paciente (Beauchamp y Childress, 2002, p. 140).

Otro criterio calibrador, ha sido el de la persona razonable que nació en Canterbury vs. Spence and Washington Hospital Center. Sus partidarios lo defienden porque protege al paciente de una eventual "conspiración del silencio" de los médicos, fruto del criterio del estándar profesional al escudarse unos con otros, ante una exagerada discrecionalidad para fijar los límites y alcance de la información. A pesar de ello, este criterio no ha estado exento de críticas por la dificultad de definir el concepto de persona razonable, ante la diversidad de elementos y caracteres que se pueden presentar de un acto médico a otro (Highton y Wierzba, 2003, p. 517).

Los reproches a los estándares anteriores dieron paso al criterio subjetivo basado en cada paciente (Beauchamp y Childress, 2002, p. 140). A saber, para la graduación de la información se deben tener en cuenta las necesidades, características, condiciones, creencias, y antecedentes de salud propios y familiares. Para su consolidación, demanda el estrechamiento de la relación de confianza que debe caracterizar el ejercicio médico.

Aunque el criterio subjetivo resulta ser más óptimo, no deja de causar controversia el hecho de identificar, en la realidad del ejercicio profesional, qué necesita o qué puede ser crucial o relevante para una persona. Todo lo cual, se complica en escenarios en donde el paciente no desea hablar,

\footnotetext{
${ }^{182}$ A reglón seguido de la temática de los riesgos será abordado el privilegio terapéutico.
} 
conocer sobre su estado o simplemente quiere que el médico haga lo que considere necesario, siendo para él irrelevante la información.

Vale aclarar que, el consentimiento informado como principio autónomo no es una regla que deba ser cumplida o no, por cuanto busca su observancia dentro de las posibilidades fácticas reales. En efecto, la información no es una regla absoluta exigible en igual grado para todos los casos, implica que en cada situación se ponderen variables (factores de graduación o moduladores), para establecer la información adecuada para ese paciente (Corte Constitucional, sentencia T-850/2002 de 10/10/2002).

Al seguir de forma crítica los diversos estudios jurídicos y éticos, la legislación ${ }^{183}$ y la jurisprudencia local y extranjera que han buscado aclarar contenido mínimo de la información, se extraen unos puntos comunes, tomados precisamente de lo que el paciente puede considerar relevante a la hora de hacer una elección, a los cuales también se hace en este trabajo una agregación para buscar un listado completo y óptimo. Así, el contenido mínimo comprende:

a) La naturaleza del procedimiento.

b) Beneficios y efectividad - relación de riesgo vs. beneficio, en donde se debe hacer énfasis en el por qué esa opción terapéutica es la más recomendable, de acuerdo con el criterio médico y avance de la medicina.

c) Riesgos típicos en concordancia con las condiciones clínicas preexistentes y exteriorizadas del paciente.

d) Riesgos previsibles y típicos de la intervención o tratamiento.

${ }^{183}$ Como se ilustró en el capítulo I, el marco legal colombiano direcciona la información con la característica que se dé a conocer el procedimiento, beneficios y riesgos del mismo. La más avanzada en torno al contenido de la información es la Ley 1566 de 2012 «por la cual se dictan normas para garantizar la atención integral a personas que consumen sustancias psicoactivas» al disponer que, se dé a conocer "el tipo de tratamiento ofrecido por la institución, incluyendo los riesgos y beneficios de este tipo de atención, las alternativas de otros tratamientos, la eficacia del tratamiento ofrecido, la duración del tratamiento, las restricciones establecidas durante el proceso de atención, los derechos del paciente y toda aquella información relevante para la persona, su familia o red de apoyo social o institucional" (art. 4).

El proyecto de Ley 042 de 2017 establece que la información se considera suficiente cuando abraca "la patología, el procedimiento, las alternativas de tratamiento y las posibles complicaciones más frecuentes". No obstante, deviene inexacta la determinación del alcance de la información. Es conveniente que en el trámite de debate en el Congreso se amplíen los campos del contenido mínimo, para evitar contradicciones y desconocimiento del derecho del paciente y del deber del médico. 
e) Tiempo aproximado de incapacidad o convalecencia.

f) Alternativas de tratamiento.

g) Consecuencias a nivel clínico de no someterse al procedimiento.

h) Cuidados y advertencias previas y posteriores para el éxito del acto médico.

i) Proceso a seguir en el postoperatorio.

j) El derecho a retractarse de la decisión y el tiempo para ello, lo que dependerá del tipo de procedimiento o tratamiento.

k) La posibilidad de hacer preguntas y requerir más información para más claridad y resolver dudas al respecto ${ }^{184}$.

1) Consejo (facultad).

En esta investigación, se incluye, en el contenido de la información, el dar a conocer el tiempo de incapacidad que genera el tratamiento, al tener ello trascendencia en la decisión tanto desde el punto de vista físico como económico-patrimonial, con el propósito de que el paciente pueda visualizar y organizar los aspectos financieros de su vida.

Ahora, el paciente no solo debe conocer sobre los riesgos y alternativas de tratamiento, debido a que, es necesario que durante esta etapa de información conozca sus derechos a la información y al consentimiento, la posibilidad de retractarse y de manifestar su negativa a recibir información o no aceptar un acto médico.

Asimismo, la información debe cobijar las advertencias y recomendaciones médicas respecto de los cuidados anteriores y posteriores al procedimiento, al ser factores determinantes de la decisión que garantizan las probabilidades de éxito y recuperación. El paciente debe decidir si está dispuesto o no a seguirlos. En este sentido, la información no reviste carácter terapéutico porque está condiciona al consentimiento.

\footnotetext{
${ }^{184}$ El Ministerio de Salud colombiano en la Guía Técnica "Buenas prácticas para la seguridad del paciente en la atención en salud", versión 2.0. al ser instrucciones para la funcionabilidad de los procedimientos de consentimiento informado, establece que la información deber ser continuada y completa, por ello incluirá la indicación al paciente de qué hacer si necesita más información (a quien preguntar, dónde y cómo), lo cual se considera relevante para que el receptor no tenga miedo de preguntar o comunicar cuando algo no le haya quedado claro o requiera más información, lo que acontece muchas veces por temor o pena ante el profesional.
} 
En la última casilla, se observa el consejo, pero con el énfasis de que es una facultad del profesional de la salud acceder o no a brindarlo, tal como se detalla más adelante.

Si bien, el contenido de la información hace parte de la adecuación en cuanto a su cantidad, el exceso de información puede resultar perjudicial, al afectar la comprensión. De igual manera, la información incompleta puede dar lugar a decisiones no informadas; por esto, algunos datos en un determinado caso son irrelevantes y otros pueden ser cardinales para la comprensión y la decisión (Beauchamp y Childress, 2002, p. 149) ${ }^{185}$.

Por consiguiente, la cuestión principal está en la forma de transmitir la información, para no dar un mensaje equivocado, ilusionista, desproporcionado y/o asustar al paciente. Sin embargo, el contenido recomendado previamente, es lo mínimo que deberían transmitir los profesionales al ser cuestiones de perceptible importancia para una decisión sensata. Recuérdese que, el ejercicio de la medicina requiere una mezcla de humildad, humanidad y confianza.

\subsubsection{En torno a los riesgos a informar}

Los riesgos a informar son quizá uno de los asuntos que más complicación suscitan a efectos de definir el contenido de la información adecuada. Pueden catalogarse como focos de acciones de responsabilidad médica, en donde se debate la falta o insuficiencia de la información, en el entendido, de si el profesional de la salud tenía o no el débito de informar un determinado riesgo que se concretó.

La problemática tiene su origen en que la obligación de información se enmarca en dar la información adecuada según la necesidad de cada paciente. Pero, al mismo tiempo, se advierte que no es conveniente proporcionar un discurso médico que abarque todas las complicaciones posibles, ni tampoco se pretende que el paciente se convierta en un docto de la medicina; encrucijada que no deriva en posiciones pacíficas.

${ }^{185}$ En igual postura se encuentra Gracia (2008, p. 184). 
Las discusiones jurídicas sobre la obligación o no de informar determinado riesgo, son independientes del estudio de si fue o no acertada la praxis médica conforme a la lex artis ad-hoc. Esto, encuentra asidero en la definición que se defiende en la presente investigación de riesgo: contingencia previsible por la propia naturaleza del acto médico que se realiza atendiendo a las circunstancias clínicas del paciente, y, cuando se concreta, se comparte la alocución de Fernández (2008), es al margen de toda impericia y negligencia médica ${ }^{186}$ (p. 382).

\subsection{Diversidad de terminológica y de criterios}

Desde sus inicios la Corte Constitucional evidenció, ante la variedad de casos posibles, la dificultad de establecer un criterio único o pauta de conducta objetiva que permitan juzgar el contenido de la obligación de información, a efectos de determinar hasta qué punto estaba obligado el médico a divulgar ciertos aspectos. Así las cosas, la información a transmitir se debe considerar en el marco de un conjunto de circunstancias propias de cada relación médico-paciente (Sentencia T-401/1994 de 12/09/1994).

En Colombia, las referencias normativas en torno al consentimiento señalan la necesidad que se informen los riesgos previsibles, sin hacer énfasis sobre su gravedad o frecuencia. Así, la Ley 23 de 1981 indica, grosso modo, que el médico no expondrá a sus pacientes a riesgos injustificados (art. 15) y "la responsabilidad del médico por reacciones adversas, inmediatas o tardías, producidas por efecto del tratamiento, no irá más allá del riesgo previsto” (art. 16).

El Decreto Reglamentario 3380 de 1981 de dicha ley -compilado por el Decreto 780 de 2016fija que los riesgos injustificados son "aquellos a los cuales sea sometido el paciente y que no correspondan a las condiciones clínico patológicas del mismo". De igual manera, determina que el médico cumple con el deber de advertencia del art. 16 de la Ley 23, con "el aviso que, en forma prudente, haga a su paciente, o a sus familiares o allegados, con respecto a los efectos adversos

\footnotetext{
${ }^{186}$ Cuando el paciente otorga el consentimiento informado asume las consecuencias de los riesgos compatibles con la prestación de un servicio eficiente y seguro acompañado de una práctica profesional conforme a la lex artis, ya que no es admisible jurídicamente que el paciente avale y asuma las consecuencias de un inadecuado ejercicio profesional. La Corte Suprema de Justicia sostuvo que no hay lugar a responsabilidad civil cuando se concreta un riesgo que es inherente de la intervención realizada, y el daño causado no es indemnizable al no ser producto de un comportamiento culposo del médico (Sentencia SC7110-2017 de 24/05/2017).
} 
que, en su concepto, dentro del campo de la práctica médica, puede llegar a producirse como consecuencia del tratamiento o procedimiento médico" (art. 10).

Mientras tanto, la legislación extranjera presenta diversidad de criterios en torno a los riesgos que deben ser informados: en Argentina se dispone que la información debe versar, entre otros, sobre "los riesgos, molestias y efectos adversos previsibles" (art. 59 del Código Civil y Comercial de la Nación de 2014 y art. 5 de la Ley 26.529 modificado por la Ley 26.742 de 2012). La Ley chilena 20584, estipula que se deben comunicar aquellos riesgos que se puedan presentar (art. 10).

En Ecuador, la Resolución del Acuerdo Ministerial 5316 del 2016 regula que deben exponerse en los consentimientos por escrito los riesgos frecuentes (poco graves), riesgos poco frecuentes (graves) y los riesgos específicos relacionados con el paciente. El Decreto 274 de 2010 de Uruguay, reglamenta la revelación de los riesgos frecuentes, poco frecuentes "cuando sean de especial gravedad y estén asociados al procedimiento de acuerdo con el estado de la ciencia" y riesgos personalizados (art. 25).

En España, la Ley 41 de 2002 exige que la información básica en los consentimientos por escrito conste de: “a) Las consecuencias relevantes o de importancia que la intervención origina con seguridad. b) Los riesgos relacionados con las circunstancias personales o profesionales del paciente. c) Los riesgos probables en condiciones normales...” (art. 10). Por su parte, la Ley francesa 303 de 2002 señala en el art.1111-2 ${ }^{187}$ que la información de los riesgos debe referirse a las "consecuencias, los riesgos frecuentes o graves que normalmente son previsibles, así como las alternativas y las consecuencias previsibles en caso de rechazo".

A nivel jurisprudencia, se resalta un asunto sometido a conocimiento de la Corte Suprema de Justicia de Colombia, en él se aseveró que, aunque es un derecho conocer los peligros a los que una persona se enfrenta ante un procedimiento, no se puede llegar al extremo de exigir la

187 "Toute personne a le droit d'être informée sur son état de santé. Cette information porte sur les différentes investigations, traitements ou actions de prévention qui sont proposés, leur utilité, leur urgence éventuelle, leurs conséquences, les risques fréquents ou graves normalement prévisibles qu'ils comportent ainsi que sur les autres solutions possibles et sur les conséquences prévisibles en cas de refus. Lorsque, postérieurement à l'exécution des investigations, traitements ou actions de prévention, des risques nouveaux sont identifiés, la personne concernée doit en être informée, sauf en cas d'impossibilité de la retrouver" 
información de "...situaciones extraordinarias que, a pesar de ser previsibles, tengan un margen muy bajo de probabilidad que ocurran” (Sentencia SC9721-2015 de 27/07/2015, ${ }^{188}$.

Posteriormente, la Corte hizo referencia que deben informase los riesgos o consecuencias adversas y efectos secundarios inherentes al acto médico ofrecido (Sentencia SC7110-2017 de 24/05/2017). La problemática analizada refería a una paciente a la que se le practicó una extirpación de la vesícula biliar por laparoscopia o colecistectomía, para tratar una discinesia biliar, pero se materializó una perforación intestinal, riesgo propio de esa cirugía.

La demandante aseveró que no fue informada de ese riesgo específico y había dado un consentimiento genérico, mas no atacó el contenido de la historia clínica y una autorización escrita y firmada donde afirmaba conocer todos los riesgos. Por tanto, al no ser rebatida la presunción de legalidad de los documentos, la Corporación tuvo por demostrado que “...el médico tratante puso en conocimiento de la paciente que sus antecedentes médicos (obesidad y laparatomía infraumbilical) constituían condicionantes que dificultaban la realización del procedimiento, y que podrían disminuir las probabilidades de éxito de la intervención". De modo que, dedujo que no había lugar alguno para declarar la responsabilidad del galeno al haber actuado conforme a la lex artis, tanto en el procedimiento como en lo concerniente al consentimiento informado. Pero ello, deja el sinsabor que por asuntos procedimentales una autorización de carácter general haya cobrado total valor, de ahí la importancia de educar a médicos y a pacientes sobre el tema.

El Consejo de Estado en sus sentencias ${ }^{189}$ hace referencia general a informar los riesgos previsibles y conocidos del acto médico, aunque no hay indicación alguna de la extensión del

\footnotetext{
${ }^{188}$ La causa fáctica de esta providencia trató sobre el fallecimiento de una mujer a quien se le diagnóstico nefrolitiasis bilateral sin obstrucción, se le practicó una "nefrolitotomía percutánea de riñón izquierdo" que resultó en principio exitosa, pero horas después la paciente falleció a causa de "disociación electromecánica $2^{\circ}$ coagulopatía dilucional. Anemia hemolítica. Nefrolitiasis izq". La Corte constató que previamente fueron advertidos unos riesgos como las infecciones, pero en especial los anestésicos incluida la posibilidad de muerte; llegado el día de la cirugía se reiteraron y se recomendó por anestesiología la no ejecución del procedimiento dado el cuadro rinofaringitis viral que presentaba la paciente, pero esta y su familia decidieron seguir adelante con la intervención. En cuanto a la causa del fallecimiento expuso la Alta Corporación que pudo ser la infección o una "hemólisis" que es un riesgo de carácter secundario, este último no fue informado pero su probabilidad de presentarse según la literatura médica oscilaba en el 0,25\%, lo cual para la Corte encajaba en aquellos riesgos de difícil previsión que justifican su silencio. Finalmente, se tomó como generalidad que el riesgo de muerte fue informado y se había expuesto con claridad.

189 Ver por ejemplo sentencias de 01/08/2016, exp. 2001-01592-01(34578) y de 26/06/2015, exp. 1996-0092401(30419).
} 
deber. Lo cual, puede obedecer, al analizar la línea jurisprudencial de ese Tribunal, a que en los casos que han llegado a su estudio no se disputa el hecho de si el riesgo concretado era o no de poca ocurrencia.

La Sala Civil del Tribunal Supremo Español, en reiteración de su jurisprudencia, consideró que la información de los riesgos presenta diferentes grados de exigencia, dependiendo si se trata de actos médicos de carácter curativo-necesario o sean de medicina satisfactiva. Así, en la medicina necesaria no es necesario informar de forma detallada los que no son típicos por no generarse con frecuencia ni son específicos del tratamiento, siempre y cuando sean de carácter excepcional y el perjuicio no sea de gravedad extraordinaria (Sentencia 24/11/2016, R.J. 5161/2016).

En tanto, cuando la intervención se lleva a cabo en medicina satisfactiva, donde se busca un beneficio estético o funcional, se acentúa la obligación de información en los riesgos y pormenores dada la innecesaridad de la misma, a diferencia de la medicina asistencial en donde "...la relatividad de la necesidad podría dar lugar en algunos casos a un silenciamiento de los riesgos excepcionales a fin de evitar una retracción de los pacientes a someterse a la intervención, y esta información no fue proporcionada debidamente" (Sentencia 13/04/2016, R.J. 1639/2016).

La Sala de lo Contencioso del Tribunal Supremo Español en una providencia en la que analizó la falta de información de una reacción adversa de tipo escaso y raro ${ }^{190}$, que se presentó producto de una vacuna antigripal, cuya frecuencia estaba de "1-9 casos cada 10.000 pacientes, en lugar de 0,5-1 cada millón de vacunados", apuntó:

...el deber de información no puede entenderse genérico o en términos de probabilidad hipotética, ni ampara la exigencia de la información excesiva y desproporcionada con las finalidades curativas o preventivas de la ciencia médica, como es la relativa a los riesgos no normales, no previsibles de acuerdo con la literatura médica, o que se basan en características específicas del individuo, que previamente podían no haberse manifestado como relevantes o susceptibles de una valoración médica. También hemos dicho en múltiples ocasiones que la información no puede ser ilimitada o excesiva, so pena de

\footnotetext{
${ }^{190}$ Síndrome de Guillain-Barré que afectó en un $85 \%$ su funcionalidad y fue declarado inválido absoluto y permanente.
} 
producir el efecto contrario, atemorizante o inhibidor y que ha de ofrecerse en términos comprensibles, claros y adaptados al usuario de la asistencia (Sentencia 09/10/2012, R.J. $6645 / 2012)$.

Por su parte, la Corte de Casación francesa en una situación en donde no se le informó a la paciente sometida a una intervención en sus vértebras la posible ocurrencia de una tromboflebitis del seno Cavernoso que se presentó y ocasionó la pérdida funcional del ojo izquierdo, preció que la obligación de información del médico incluye los riesgos graves previsibles relacionados con la intervención, así sean excepcionales, es decir, si son raros pero conocidos deben ser comunicados (Sentencia 07/10/1998).

El Consejo de Estado francés fijó en el 2000 igual postura que la Corte al entender que, cuando el acto médico implicara riesgos conocidos de muerte y discapacidad deben informarse como condición para obtener el consentimiento. Que los riesgos sean de carácter excepcional no exime a los profesionales de su obligación (Sentencia 05/01/2000) ${ }^{191}$.

Desde la perspectiva doctrinal, la temática ha sido sumamente estudiada sin llegar a unidad de criterios ${ }^{192}$. Algunos autores se han lanzado a dar pautas en torno a los riesgos a informar, aunque aclaran que se trata de aproximaciones y no de exigencias únicas para todos los casos. En este sentido, Castaño (1997) conjuga los factores de gravedad o no del riesgo con la común o escasa ocurrencia, presentando cuatro alternativas: $a$ ). riesgo no grave, pero de común ocurrencia; $b$ ).

\footnotetext{
${ }^{191}$ El análisis del Consejo se hizo con relación a un paciente a quien se le practicó una intervención endovascular para tratar mediante embolización una malformación arteriovenosa, el micro catéter introducido en la arteria cerebral se rompió, causando un accidente isquémico, tras el cual el paciente quedó afectado por parálisis del brazo y la pierna izquierda. El accidente isquémico es un riesgo excepcional, pero era conocido por sus posibles consecuencias de muerte o parálisis, razón por la cual, el Consejo de Estado concluyó que debió ser informado previamente.

${ }^{192}$ En la doctrina los argumentos no escapan de ser disímiles y dejan ver de lo turbio que es llegar a puntos comunes, entre los que comparten que los riesgos a ilustrarse deben ser los frecuentes por su producción estadística y graves/relevantes/de importancia están Pizarro (2017, pp. 63-64), Lorenzetti quien añade los riesgos residuales (2016, p. 283), Reynal interviene señalando el deber para los riesgos inherentes, los típicos o específicos de cada intervención, los previsibles con la individualidad y los relevantes laboralmente (2017, p. 81), Barros (2009, 683-684), Galán (2001, pp. 204 y 210) y Sánchez (1993, pp. 197-198). Otro sector aboga que hacen parte de la obligación de información como pauta general los de común ocurrencia/frecuentes/ típicos, se destacan: Jalil (2013, pp. 786-787), Roca y Navarro (2011, p. 126), Fernández (2008, p. 153), Guerrero (2004, p. 92), Jaramillo (2002, pp. 236-238) y Ataz (1985, 73). Highton y Wierzba (2003, p. 535, 548 y 549) proponen que es importante revelar los riesgos graves, aunque sean poco frecuentes. Por su parte, Cadenas (2018, pp. 153-175) quien en su análisis sobre los riesgos escribe, siguiendo a la jurisprudencia del Tribunal Supremo Español, que en la medicina curativa deben informarse los riesgos típicos y previsibles y con relación a la medicina satisfactiva todos los riesgos incluso los excepcionales.
} 
riesgo no de gravedad y de escasa ocurrencia; $c$ ). riesgo de gravedad y de común ocurrencia; $d$ ). riesgo de gravedad y de escasa ocurrencia. En atención a lo cual, considera que las alterativas $a$ y $c$ deben ser informadas ante la probabilidad mayor de que se presente; por su parte, la opción $b$ indica que en términos generales no debe informarse a menos que por excepción deban ser informadas. En lo que cabe a la $d$ manifiesta que es la que más dificultad cobija, recomienda al médico ser bastante prudente para evitar generar desasosiegos prolijos en el paciente (pp. 198199).

Como puede evidenciarse, no son unánimes la ley, la doctrina ni la jurisprudencia nacional y foránea sobre el tema. Llama la atención que, la generalidad de posturas está orientadas a la exigencia que sean informados los riesgos y consecuencias previsibles, utilizando terminología cambiante (se habla de típicos, excepcionales, graves, menos graves, frecuentes, probables y relevantes).

En breve, se concluye que en general el espíritu del legislador, lo cual también ha sido parte de la motivación de las sentencias de los diferentes tribunales referidos y de la doctrina, no es exigir una información exhaustiva, intensa e ilimitada de cada uno de los riesgos enlistados, de acuerdo con su tipicidad, gravedad, frecuencia y probabilidad.

\subsection{Recomendación: riesgos previsibles y típicos}

El uso del lenguaje genera serios problemas, no solo por la vaguedad de las palabras sino por la ambigüedad de algunas, lo que conduce a utilizar los diferentes usos que tienen para referirse a un mismo asunto. Esta amplitud semántica fue llamada por Hart (1961) "textura abierta del lenguaje", característico también de las reglas jurídicas, de ahí la llamada "zona de penumbra" ante el margen de indeterminación del lenguaje, que lleva a los legisladores a regular una esfera de conducta a través de criterios y pautas generales, puesto que "...no pueden tener tal conocimiento de todas las posibles combinaciones de circunstancias que el futuro puede deparar ...trae consigo una relativa indeterminación de propósitos" (p. 159). 
Con el fin de esclarecer el panorama, es primordial definir la semántica utilizada para enmarcar los riesgos en su uso normal, con el propósito de no entremezclar o tomar como sinónimos lo que no lo es. Como se observó, algunas posturas tienden a confundir tipicidad y previsibilidad del acto con frecuencia u ocurrencia en términos estadísticos. El objetivo es buscar un campo de aplicación común del lenguaje, que sea entendible para los juristas, para el área médica y un lector cualquiera. Por ello, de acuerdo con la RAE:

- Anormal: 1. adj. Que accidentalmente se halla fuera de su natural estado o de las condiciones que le son inherentes. 2. adj. infrecuente.

- Frecuente: 1. adj. Repetido a menudo. 2. adj. Usual, común.

- Grave: 2. adj. Grande, de mucha entidad o importancia.

- Excepcional: 2. adj. Que se aparta de lo ordinario, o que ocurre rara vez.

- Extraordinario: 1. adj. Fuera del orden o regla natural o común.

- Ocurrencia: de ocurrir / ocurrir: 2. intr. Dicho de una cosa: Acaecer, acontecer, suceder.

- Previsto: part. irreg. de prever. / prever: tr. Ver con anticipación.

- Probable: 1. adj. Verosímil, o que se funda en razón prudente. 2. adj. Que se puede probar. 3. adj. Dicho de una cosa: Que hay buenas razones para creer que se verificará o sucederá.

- Raro: 2. adj. Extraordinario, poco común o frecuente.

- Típico: 1. adj. Característico o representativo de un tipo. 2. adj. Peculiar de un grupo, país, región, época, etc.

Indubitado es que la obligación en todos los casos llega hasta los riesgos previsibles, al ser un contrasentido exigir informar sobre lo que no se tiene conocimiento o certeza científica ni médica. Se deja a un lado, situaciones imprevisibles ${ }^{193}$ o atípicas que se puedan presentar al escaparse del control de la medicina ${ }^{194}$.

\footnotetext{
${ }^{193}$ Un resultado médico imprevisible se asimila en cuanto a sus consecuencias jurídicas al accidente imprevisible, así para que se catalogue de imprevisible "no basta con que el sujeto no lo hubiera previsto o no fuera para él previsible, si pudo ser previsto por otra persona puesta en su lugar" (Romeo, 1985, pp. 91-92).

${ }^{194}$ Es decir, "los riesgos no asociados por la ciencia médica a un determinado tratamiento no forman tampoco parte del caudal informativo" (Galán, 2016, p. 751). De igual forma, Jalil (2013, p. 782) enseña que no es razonable que el médico "... haga prospectiva y anticipe todo lo que puede ocurrir de manera anormal o fortuita, con habitualidad o lindando con la casualidad".
} 
La obligación de información del médico deberá cobijar los riesgos típicos y previsibles sin consideración a su frecuencia ${ }^{195}$ o a que sea la única alternativa disponible. A saber, incluye los riesgos de la intervención o tratamiento, los particulares de acuerdo con las condiciones clínicas conocidas y exteriorizadas del paciente y los generales de la normalidad del acto médico.

Lo anterior, deviene su fuente desde la medicina, que a través de diferentes estudios e investigaciones rigurosas marcan el rubro para considerar si algo es típico de un acto médico y la certeza de su presentación. Por tanto, el derecho se ilumina de la medicina para establecer los términos a seguir y dirimir controversias.

La variable de frecuencia no se puede considerar como un factor determinador general para divulgar o no el evento desfavorable por cuatro motivos:

a) En virtud de que la determinación de lo previsible y propio de un procedimiento es realizado y concretado por la literatura médico-científica, entonces el médico lo ha de conocer, y por eso, toma en el desarrollo del acto las prevenciones necesarias para evitarlo (Romeo, 1985, p. 92), minimizarlo, luchar contra él. Si lo conoce, en una primera consideración, lo debe comunicar, al no estar el paciente exento de que en su persona no se dará.

b) Concuerdan Sánchez (1998, p. 60), Simón (2000, p. 246) y Galán (2001, pp. 200-203) en que los datos numéricos de estudios de probabilidad representan un grado de abstracción, al derivar de situaciones específicas que no siempre van a coincidir en todos los casos, como ocurre cuando el estudio se ha aplicado en una determinada población. Así que, "resulta difícil sostener que exista una cifra mágica por debajo de la cual pueda defenderse, sin más matizaciones, que el médico no tenía la obligación de revelar los riesgos que se sitúen por debajo de ella” (Simón, 2000, p. 246).

${ }^{195}$ En esta misma línea se encuentra Arcos quien literalmente apunta que “... la información exhaustiva no es una obligación legal, por lo que una información objetivamente incompleta es compatible con el cumplimiento del deber impuesto a los profesionales sanitarios ... [n] o es conforme a la ley una referencia meramente genérica a la imposibilidad de contraer una cierta infección o, menos aún, a la todavía más imprecisa de contraer «infecciones». Informar de un riesgo es informar de probabilidades, y su concreción es lo que hace que el contenido sea realmente veraz, adecuado, suficiente y útil para el paciente, o para quien tenga que decidir por otro" (2016, pp. 113-114). También se encuentran en la misma postura Domínguez (2007, p. 401) y García (2006, p. 808). 
c) Puede darse que la producción de un riesgo sea escasa, pero de gran envergadura en la vida y salud de un paciente en particular, hecho que ineludiblemente requeriría la información al ser altamente influyente para su juicio, ya sea por la religión, creencias, profesión u oficio, entre otros.

d) La probabilidad estadística no puede ser el indicativo para que un riesgo deba o no revelarse, porque si el paciente puede hacer algo para evitarlo o estar atento a esas posibles consecuencias entonces, es vital que de antemano se sepa esa información; tal y como acontece con los riesgos residuales de un acto médico o en los tratamientos de infertilidad como la vasectomía. En este último caso, se puede presentar la reconexión espontánea de los conductos deferentes y provocar un embarazo indeseado, o de igual forma, se necesita que se revele cierta información para evitar el embarazo de la pareja, a pesar que la ocurrencia es mínima. Ergo, se debe advertir que para su efectividad han de esperarse alrededor de tres meses para que el esperma desaparezca de los conductos deferentes y hacer la respectiva prueba de laboratorio para descartar el esperma.

Otro ejemplo de lo anterior, se observa en la endoftalmitis, la cual se produce luego de una cirugía ocular como cataratas o de glaucoma, llevadas en la práctica diaria por los oftalmólogos. Tiene una probabilidad escasa de ocurrencia -uno entre mil-, pero las consecuencias son nefastas al ser una infección que afecta el globo ocular y puede conllevar a la ceguera y a la pérdida del ojo.

Las razones anteriores, no implican que el médico no deba utilizar los índices de probabilidades al momento de exponer la información al paciente, se recuerda que es una herramienta que puede ayudar a calmar las angustias. No es lo mismo decir que hay un riesgo de muerte, que contarle al paciente que de cien personas que se someten a ese procedimiento, no más de dos morirían.

A la par de lo anotado, no es conveniente, tampoco, cualificar la información de los riesgos en “grave (menos o más grave)", debido a que, la vaguedad del término llevaría a inespecificidades que complican el ejercicio de información al depender de la subjetividad. Usualmente se asocia a un riesgo grave a aquellos que producen la muerte o invalidez ${ }^{196}$, pero entonces, cabe preguntarse

\footnotetext{
${ }^{196}$ Como se vio lo entiende el Consejo de Estado francés.
} 
si no es grave el riesgo que a raíz de una vasectomía, si no se toman las precauciones necesarias, resulte un embarazo no deseado en la pareja. También, a manera de ilustración, piénsese que el riesgo de amputación de una pierna para una persona del común puede ser menos grave que para un jugador de fútbol profesional.

Igualmente, los calificativos de excepcionales o de normales generan ambigüedad y pueden conllevar a omitir riesgos que, a pesar de su escasa ocurrencia, pueden ser funestos cuando se materializan.

No es menos cierto que, la fórmula propuesta sobre los riesgos incrementaría los costos de transacción que de por sí genera el consentimiento informado, al requerir el médico de más tiempo para entrar en diálogo con el paciente, revelar la información, permitir el intercambio de preguntas, lo que incluso, implicaría una mejora de las instalaciones (De La Maza, 2017, pp. 124-125 ${ }^{197}$ ). De cualquier modo, para alcanzar el cometido del consentimiento informado se necesita generar la cultura del consentimiento, para que no siga en imperio el silencio médico; al crearse poco a poco la consciencia del respeto de los derechos, se torna más hacedera la obligación de información (Fernández, 2008, pp.526-527). De manera que, no es válida la tradicional excusa que de conocer los riesgos ningún paciente se sometería a un procedimiento o suponer que el paciente de todos modos se hubiese sometido al acto médico.

La práctica comunicacional permite la calidad, precisión y mejores resultados en la atención. Por ello, debe establecerse como un fin a lograr, al respecto Moore, Gómez, Kurtz y Vargas (2010) enseñan:

...no se debe olvidar que las habilidades comunicacionales complementan y enriquecen aquello que ya se está haciendo en la anamnesis tradicional y, de hecho, una vez que las habilidades comunicacionales son manejadas adecuadamente, ellas no toman mucho más tiempo que el habitual ... tomará más tiempo mientras el médico se encuentra en el proceso de aprender las habilidades. Una vez que las domina, los tiempos de consulta tienden a disminuir. (p. 1052)

\footnotetext{
${ }^{197}$ Comparte opinión en esta línea Pizarro (2017, p. 63).
} 
A mayor abundamiento, informar genera grandes ventajas al evitar conflictos jurídicos que desgastan a la justicia y empañan la actividad médica. Es preferible un paciente informado y sensato de las posibles consecuencias del procedimiento al que se va a someter, pues ello, lo hace reflexionar con anticipación sobre el asunto, tomar medidas de precaución, confiar en quien ejecuta la acción médica y en caso de producirse el riesgo, no acudirá de inmediato a formular demandas o reclamaciones contra el médico o la institución.

Indiscutiblemente la revelación no busca dar un curso intenso de medicina en unos minutos. Antes bien, su propósito es esclarecer el panorama, por eso la insistencia en la forma como se comunica. Como lo apunta Marsh (2014, p. 181), se debe decir la verdad, pero no debe ser negada toda la esperanza al paciente, a pesar de resultar complicado el contrapeso entre el optimismo y el realismo. En efecto, se demanda tacto en la transmisión de la información ${ }^{198}$, pero no mentiras piadosas que quebrajen finalmente la relación de confianza ${ }^{199}$; debido a que, en parte, hoy con el internet los pacientes y sus familiares pueden buscar información en cuestión de segundos, encontrarán datos ciertos y otros falsos, por lo que, la labor de información del médico se intensifica.

Lo dispuesto sobre "riesgos previsibles y típicos" se ajusta a los parámetros de una ley, al estar dirigido de forma impersonal y abstracto para los profesionales de la salud. Entonces, el galeno debe buscar adaptar su acción a satisfacer la voluntad para lo cual fue dispuesta la norma de consentimiento informado, labor que estará guiada por una relación de riesgo-beneficio de la información, para calibrar el contenido de la misma.

Cuando nacen las controversias jurídicas en torno a la extensión de la información que fue suministrada en una situación específica, es función del juez trasladar el(os) postulado(s)

\footnotetext{
${ }^{198}$ Marsh (2014, p. 95) expone que en el ejercicio profesional tuvo un caso muy particular, un joven ciclista padecía un grave pinzamiento del nervio ciático como consecuencia de un prolapso discal simple, que le impedía seguir en entrenamiento. La cirugía era sencilla y de mínimos riesgos. Por eso, cuando lo visitó le dijo "...la intervención era realmente simple, expliqué que siempre teníamos que prevenir a la gente sobre los riesgos quirúrgicos, pero le prometí que era muy poco probable que las cosas salieran mal", ello con el propósito de no aterrorizar al paciente y pasarle un listado de complicaciones. Afirma Marsh, que en situaciones parecidas menciona los principales riesgos, pero recalca claramente lo poco frecuente de su aparición (p. 213). Lastimosamente, la cirugía del ciclista se complicó por errores técnicos del residente que la inició, ocasionando un síndrome de píe caído, situación que sin duda conllevaría a una acción de responsabilidad, pero por negligencia en la actuación.

${ }^{199}$ En igual postura Gitrama (1977).
} 
normativo(s) al hecho específico para controlar la observancia del destinatario y verificar el alcance de las normas que gobiernan el caso. De esta forma, el operador judicial en su sentencia estudiará, interpretará y argumentará -de acuerdo con la ley y la jurisprudencia- las condiciones del paciente, las pruebas, los factores de graduación de la información y la literatura médica relacionada y controvertida en el curso del proceso $^{200}$. Por consiguiente, no se verifica una aplicación por deducción lógica, literal ni por inercia.

\subsection{Información en medicina curativa o de voluntaria o satisfactiva}

En líneas anteriores se expuso como en España es diferente la extensión y alcance de la información dependiendo de si se trata de medicina voluntaria o curativa. Se torna más exigente y rigurosa la revelación de los riesgos cuando son intervenciones o tratamientos con fines satisfactivos, ya que su causa es la mejora o perfeccionamiento de un aspecto físico o estético y no la recuperación de la salud.

Esta investigación no encuentra justificaciones razonables ni constitucionales para establecer criterios discriminatorios en cuanto a la exigencia de la obligación de información dependiendo el tipo de procedimiento a practicar, porque sería tanto aseverar que los derechos fundamentales penden en su consideración o son más importantes en determinadas situaciones médicas, o que, cuando el paciente acude a centros privados en donde asume directamente los costos económicos, su derecho a la información cobra mayor alcance que cuando es atendido a través de una EPS.

Estas desigualdades podrían dar lugar a una información sesgada e inexacta que afecta por consiguiente la declaración de voluntad. Además, independientemente si la cirugía es con fin curativo o satisfactivo, todo paciente o usuario de los servicios de salud tiene derecho a conocer las implicaciones y efectos adversos típicos y previsibles, para poder hacer una elección ilustrada y libre, y las únicas limitaciones a seguir serían aquellas en pro de su bienestar.

\footnotetext{
${ }^{200}$ Se destaca lo expuesto por Hart (1958) sobre la penumbra de la incertidumbre que rodea las reglas legales donde no es aplicable un razonamiento deductivo dada la complejidad de los hechos: "[f]act situations do not await us neatly labeled, creased, and folded, nor is their legal classification written on them to be simply read off by the judge. Instead, in applying legal rules, someone must take the responsibility of deciding that words do or do not cover some case in hand with all the practical consequences involved in this decision" (p. 607).
} 


\subsection{Necesidad o privilegio terapéutico}

El estado de salud física, psíquica o emocional del paciente puede limitar el derecho a la información y el posterior consentimiento, esto es, omisiones justificadas por privilegio terapéutico o necesidad terapéutica. Debido a que, al no ser las prerrogativas fundamentales absolutas, pueden ser objeto de excepciones.

El privilegio terapéutico busca garantizar el bienestar del titular del derecho, situaciones que deben ser examinadas y fundamentadas rigurosamente por el médico, para evitar atentados arbitrarios. Ello no implica que un diagnóstico grave o terminal no deba ser informado al paciente, pues, el paciente, como regla general, tiene derecho a conocer todo lo relacionado a su estado de salud.

En este orden de ideas, la Ley 41 de 2002 de España previó en el art. 5.4. este tópico, al disponer que el límite del derecho a la información debe basarse en razones objetivas que den muestra de la afectación a la salud de manera grave, dejando constancia en la historia clínica y comunicárselo a los familiares o personas relacionadas con el paciente.

La regulación referida resuena acertada teniendo en cuenta que, en ciertas circunstancias, al ponderar el derecho a la vida y a la salud vs. el derecho a la información y autodeterminación, pueden prevalecer los primeros en virtud del peligro que puede correr el enfermo de conocer la información. Por tanto, las razones deben estar basadas en la ciencia médica y no dejar espacio para la subjetividad, ya que todo límite de derechos merece un discurso lógico justificado.

Guerrero (2004, pp. 105-106) pone de presente la dificultad y no siempre claridad de establecer las circunstancias justificantes, debido a que, ese estado de necesidad terapéutica se vislumbra como un concepto jurídico indeterminado, que debe colegirse de la situación concreta del paciente. Por consiguiente, se necesita una especial laboriosidad al determinarlas, para evitar la evasión infundada de la obligación de información. 
El tema resulta polémico por el temor que se recurra a prácticas paternalistas, en donde el poder decisivo y determinante está en manos del médico tratante. Al mismo tiempo, encuentra su razón en los principios de beneficencia y no maleficencia en aras de no causarle un daño mayor al paciente; por eso, jurídicamente estaría justificada la excepción al consentimiento informado, sin que esto implique un poder absolutista e indiscriminado para todo paciente con cierta patología.

Como lo propone Marín (2008, p. 682), esta excepción no se puede mirar como una rotunda negación a dar la información, ya que debe concebirse, en la mayor medida posible, como una oportunidad para adaptar la información que pueda recibir ese paciente con criterios de gradualidad, temporalidad y de apoyo coordinado con los familiares. Todo esto, con el objetivo de lograr el equilibrio entre los principios de autonomía-consentimiento informado y beneficencia. De ahí que, este autor considere válidamente el privilegio terapéutico como el punto de conexión entre el paternalismo y la autonomía.

En Colombia normativamente no se hace alusión expresa a esta excepción. Sin embargo, en la Ley 23 de 1981 se lee: "si la situación del enfermo es grave el médico tiene la obligación de comunicarle a sus familiares o allegados y al paciente en los casos en que ello contribuye a la solución de sus problemas espirituales o materiales" (art. 18); texto que, aunque impreciso y abierto a diferentes interpretaciones, se adapta a la necesidad terapéutica de la que se habla, en el entendido que, el médico debe buscar el apoyo de los familiares del paciente en los casos complejos y evaluar conjuntamente hasta qué punto el paciente puede ser capaz de asumir la responsabilidad de su estado de salud, para no solo llevar a cabo el tratamiento a seguir, sino que le permite organizar su vida espiritual y materialmente.

Al respecto, la Corte Constitucional ha entendido lo siguiente:

Resulta evidente, que no todo se puede decir a todos los pacientes, dependerá de a quién y de cuándo así como de la enfermedad que lo afecta. Es entonces el paciente, en ocasiones, el que decide el quantum de la información que desea. Es claro, de otra parte, que como derecho del paciente también existe el derecho de no saber ... El médico deberá, en uso de su privilegio terapéutico, proporcionar la información que no genere en el paciente un 
aumento desproporcionado de su angustia, pues una información no medida en los factores señalados, puede dañar más al enfermo que beneficiarlo (Sentencia T-1131/04 de 11/11/2004).

Entre tanto, el Proyecto de Ley 042 de 2017 propone en el decálogo de principios el "principio del mal menor", indica que "se deberá elegir el menor mal, evitando transgredir el derecho a la integridad, cuando hay que obrar sin dilación y las posibles decisiones puedan generar consecuencias menos graves que las que se deriven de no actuar", lo que engloba con otras palabras la necesidad terapéutica.

\subsubsection{Deber de consejo}

Los riesgos y la incertidumbre son connatural al ejercicio de la medicina dada la complejidad del cuerpo humano, la variabilidad de las características clínicas de las personas, elementos psicológicos, actitudinales y la intervención en los procesos biológicos de variados factores que se condicionan entre sí (Loayssa y Tandeter, 2001, p. 106). En razón a ello, se ha afirmado que “...la medicina trata con probabilidades y suposiciones informadas, pero no con certezas" (Sandoya, 2014, p. 131).

Esa incertidumbre gravita no solo en el médico, sino que igualmente se presenta en el paciente a la hora de tomar una decisión, luego de conocer los riesgos previsibles y típicos del procedimiento o tratamiento prescrito y recomendado médicamente. Muchas veces, el paciente trata de aplacarla preguntándole al profesional de la salud qué consejo le puede dar ante esa situación, esto como fruto de la consolidación relación de confianza.

Recuérdese que la obligación de informar es de estricta observancia, salvo que se presenten algunas de las circunstancias excusables. Además, va cargada de objetividad al estar su contenido conforme con el estado actual de la ciencia y adecuado a las características del paciente. Su incumplimiento se considera una infracción de la lex artis y podrá dar lugar a reclamación de indemnización, en determinadas situaciones que se verán en el capítulo III. 
Contrario a la obligación de información, se avizora el deber de consejo que, parafraseando a Simón (2000, (pp. 170-172), se deriva del principio de beneficencia y constituye un deber moral deseable en terreno de la relación médico paciente, pero no es correlativa de derechos ni exigible de modo que, pueda constreñirse a cumplirlo. De hecho, se asume voluntariamente por los sujetos, ya sea porque el paciente lo requiera o el médico lo haga por iniciativa propia.

Cuando el profesional de la salud establece una propuesta terapéutica no está emitiendo un consejo, en razón a que actúa dentro de su deber médico-asistencial. Por eso, la información respecto de la alternativa de tratamiento lo obliga en su extensión, al dar la opción médicocientífica más aceptable para que el paciente elija.

De esa manera, el consejo es subjetivo al referirse a la postura particular del profesional respecto a qué hacer en una situación específica, si seguiría o no ese procedimiento y cuál de las alternativas él elegiría. Entonces, no obedece a una postura científica al estar basada en un criterio personal, por eso sería un error imponerle un carácter vinculante. Esto explica que en esta tesina se ubicara en el último lugar del contenido de la información, con la claridad que obedece a la facultad del médico su puesta en marcha.

La información de la terapéutica a seguir es probable que se complemente con el consejo médico, al tener este una carga orientativa hacia determinada decisión. Muchas veces, en la práctica se encuentran unidas en su ejecución ${ }^{201}$ (Sánchez, 1998, pp. 90-91), teniendo en cuenta que, el consejo puede que robustezca la recomendación clínica ${ }^{202}$ a seguir, pero no debe entrañar una actitud de persuasión, dado que desnaturaliza su propósito. En consecuencia, no puede confundirse lo uno con lo otro, no sería correcto hablar de consejo terapéutico ${ }^{203}$ para hacer

\footnotetext{
${ }^{201}$ Indica De Ángel (2000) que “... no pocas veces quien informa (sobre todo si lo hace en el ámbito de una relación contractual) está, de forma más o menos directa, aconsejando" (pp. 174-176), no obstante, hay que tener presente que la información que se da está soportada en la ciencia médica mientras que el consejo en el deseo particular del médico. ${ }^{202}$ De la Maza (2010-b, p. 97) se centra en establecer que si bien existe una obligación de información en ocasiones y siempre que las circunstancias lo ameriten de la transmisión de información nace un deber de aconsejar, es decir, de orientar al paciente en su decisión.

${ }^{203}$ En España la Audiencia Provincial de Islas Baleares señaló que "[l]a información que precede al consentimiento debe ser acompañada del llamado consejo terapéutico, esto es, de la opinión del facultativo de cuál de las alternativas posibles que se han hecho saber al enfermo es la más adecuada y provechosa, pero es importante repetir que el facultativo ha de limitarse a dar un consejo, sin sustituir al paciente, al decidir el tratamiento" (Sentencia de 03/02/2003, recurso 753/2002).
} 
referencia a la alternativa de tratamiento más adecuada, al confundirse el fin de la obligación de información.

En una situación expuesta por Marsh (2014, pp. 119-124) se destaca la encrucijada médica para dar un consejo ante casos difíciles: una paciente de 85 años tenía un tumor cerebral y había comenzado a presentar síntomas de demencia. Luego de analizar el escáner, el médico expuso a la paciente y a sus hijos que, si bien existía un tumor cerebral, no era posible asegurar hasta qué punto la situación podía complicarse hasta que se abriera la cabeza y se confirmara la dificultad o no de extirparlo, dio a conocer los riesgos en las dos posibilidades a encontrar. Seguidamente, informó que funcionaba más la extirpación completa y que la radioterapia o la quimioterapia no servirían, y afirmó que, lo único que él sabía era que si no se hacía nada, iría empeorando. Añadió, pero tan solo a los hijos de la paciente, que "tal vez, dada su edad, la mejor opción podía ser no operar y aceptar que se iría deteriorando poco a poco...", pero posteriormente, los hijos le preguntaron ¿qué haría usted si se tratara de su madre?, a lo que respondió, que trataría de convencerla de operarse si todos los hijos estaban de acuerdo.

En la primera parte se visualiza el cumplimiento de la obligación de información del médico al estar apoyado científicamente los datos proporcionados, pero cuando afirma lo que él haría en ese caso, su respuesta equivale a un consejo al ser su simple punto de vista. En estos contextos, se sugiere que el médico haga completa claridad de lo que corresponde a la información de la terapéutica propuesta y lo que puede considerarse un simple consejo, para evitar compromisos con sus palabras y representaciones equivocadas en el paciente.

En la doctrina se destacan Ataz (1985, pp. 175-177) quien entiende el deber de aconsejar con la propuesta terapéutica y argumenta que "...el médico aconseja cuando propone un tratamiento; sin embargo, no nos parece que este hecho se pueda configurar como un deber autónomo del médico". Asimismo, Parra en su tesis doctoral resaltó que "cargar al paciente sólo con información equivale a abandonarlo. El médico debe explicar las ventajas..., pero manifestando su opinión sobre las razones por las que se inclinaría hacia una u otra de ellas..." (2014, p. 146). En igual sentido, Cadenas (2018, p. 198) parece también asimilar el consejo con la alternativa médica más recomendable.

No se comparten en esta investigación los anteriores argumentos porque caen en confusión entre información y consejo, al no tener en cuenta que la información para el consentimiento viene determinada de la propuesta de tratamiento conforme a la medicina y de ahí se deriva el contenido a informar. 


\section{Capítulo III. De la responsabilidad civil por incumplimiento del consentimiento informado del paciente}

\section{Del enfoque patrimonialista al personalista de la responsabilidad civil}

Una gran conquista de inicios de la edad moderna ha sido el nacimiento de los derechos del hombre para la indemnidad de su dignidad y los valores de libertad, igualdad y solidaridad como camino para alcanzarla ${ }^{204}$; con una racionalidad abstracta teóricamente iguales para todos (PecesBarba, 1998, p. 22).

Junto a ello, emerge una sociedad antropocéntrica e individualista en el marco de un Estado liberal, que cambia la sociedad organicista tradicional para volcarse a una relación Estadociudadano, con primacía en los derechos del ciudadano y no en los deberes de los súbditos, lo cual, era propio de la relación política con prevalencia del soberano (Bobbio, 1991, p. 14-15).

A partir de la segunda guerra mundial, los derechos humanos direccionaron hacia su universalización y proliferación, aumentándose los bienes e intereses tutelados ${ }^{205}$ de acuerdo con las condiciones y necesidades de la sociedad en las esferas políticas, sociales, económicas y culturales. No son un fin acabado en sí mismo al no estar cerrados en su tipificación, van surgiendo y manifestándose en la evolución social ${ }^{206}$ (Zavala, 2011, p. 18).

\footnotetext{
${ }^{204}$ Peces-Barba (1998) enseña que la filosofía de los derechos fundamentales surge en el tránsito a la modernidad y alcanza su fuerza y reconocimiento en los inicios del siglo XVIII y suponen “...uno de los aspectos del desarrollo del individualismo y del protagonismo que adquiere el hombre individual en el nuevo orden económico y social que surge en el tránsito a la modernidad... Este cambio social y económico tiene su paralelo en el campo político, donde las estructuras del poder político medieval son sustituidas por el Estado como forma de poder racional centralizado y burocrático... Este Estado que aparece primero como estamental, y, por consiguiente, con factores y elementos propios del mundo medieval, se hará después un Estado absoluto... Entonces el individualismo y la filosofía de los derechos fundamentales, junto con los demás elementos de la filosofía liberal, usando como legitimación el iusnaturalismo racionalista, se separarán, combatirán y destruirán a ese Estado absoluto, que primero sirvió a sus intereses" (pp. 2022).

${ }^{205}$ No solo se mira a la persona en su individualidad, debido a que se han consagrado como titulares de derechos comunidades como las étnicas o las afrodescendientes, grupos específicos dependiendo de ciertas condiciones y situaciones de vulnerabilidad a saber los consumidores, las personas en condición de discapacidad, los niños, los enfermos e incluso se ha llegado a proclamar derechos ecológicos y para los animales (Bobbio, 1991, pp. 114-116).

${ }^{206}$ Por eso, en Colombia la Constitución de 1991 consagre en su art. 94 que "la enunciación de los derechos y garantías contenidos en la Constitución y en los convenios internacionales vigentes, no debe entenderse como negación de otros que, siendo inherentes a la persona humana, no figuren expresamente en ellos".
} 
Es indiscutible hoy el valor de la persona, entiéndase persona en la dualidad espíritu y cuerpo ${ }^{207}$ que abarca su “...íntegra realidad psicofísica, espiritual y social” (Zavala, 2011, p. 2). De ahí, el reconocimiento de sus derechos a nivel local de los Estados, internacional, en doctrina y jurisprudencia al plasmar aquellos aspectos inherentes e inseparables a la persona, que, en la mayoría de los casos, han adquirido visibilidad en razón a los atentados que se cometen contra ellos (Bercovitz, 1976, p. 199) ${ }^{208}$.

Desde tiempo atrás, no es un secreto la transformación del derecho hacia una perspectiva donde los intereses de la persona alcanzan una relevancia antes inimaginable. Se dio un corrimiento en materia del daño, respecto de un enfoque exclusivamente patrimonial a una tesis que abarca también la consideración de la inviolabilidad de la persona ${ }^{209}$; en virtud que, se debe proteger a esta en lo que tiene o pudiese llegar a adquirir y análogamente es digno de reconocimiento lo que es, su dignidad, derechos, esencia y en suma la plenitud de su proyección (Goldenberg y López, 1993, p. 173 y 191$)^{210}$.

Este giro de enfoque economicista y patrimonial del derecho y en particular, de la institución de la responsabilidad civil, a un humanista-personalista de valorización del concepto de persona, ha marcado el centro de atención del infractor a la víctima, en la trascendencia de los daños sufridos para repararlos en su integralidad. La vetusta culpa del agente, considerada como elemento

\footnotetext{
${ }^{207}$ Fernández ilustra que toda persona es un ser humano y todo ser humano, en la medida que es libre y espiritual, es persona, en este sentido "[e]l "ser humano" resulta así una unidad indisoluble, inescindible, entre lo que es su esfera psicosomática - su soma y su psique - y su centro existencial que es el espíritu de la libertad. A este ente, que es el "ser humano", se le designa filosóficamente como "persona"” (2001, p. 306).

${ }^{208}$ Para ampliar el tema de la persona humana en su protección, reconocimiento y centro del derecho se pueden revisar los escritos de Fernández (1993, pp. 21-80), Andorno (1993, pp. 163-172) y Goldenberg y López (1993, pp. 173-192). ${ }^{209}$ Explica Perlingieri que "[d]e un sistema pandectítico se pasa ... a un sistema que se inspira en la tutela de las necesidades de la persona: asume un renovado vigor el control de merecimiento de protección, cada vez más autónomo respecto del de mera ilicitud, y conquistan nuevos espacios en todos los Tribunales europeos la razonabilidad y el principio de proporcionalidad. El derecho privado, lejos de agotarse en la disciplina de las relaciones patrimoniales ... se plantea con fines más amplios y con una connotación intensamente diferente..." (2015-I, pp. 81-82).

De igual forma, Mosset ilustra que el incremento de las acciones de responsabilidad da cuenta de la variedad de pretensiones antes ignoradas y de situaciones que eran mantenidas en el silencio o justificadas por el destino o la fatalidad, lo cual se fundamenta con "...el despertar al conocimiento de las prerrogativas y facultades; con el conocimiento de las posibilidades que el ordenamiento jurídico le otorga a la víctima. De la fícción del "derecho conocido", se ha pasado, en muchos lugares, incluido nuestro país, a una toma de conciencia real. Tiene que ver, claro está, con la índole de la organización social, el tipo de Estado y de relaciones que posibilita entre los ciudadanos" (1998, p. 35).

${ }^{210}$ En igual sentido Zavala (2011, pp. 4-7).
} 
fundamental para sancionar la conducta ilícita ${ }^{211}$, se hace visible tan solo en la medida que es uno de los factores de atribución de responsabilidad (Fernández y Woolcoot, 2018-II, p. 309-311) 212 $^{2}$.

Lo anterior, significó el reforzamiento del carácter resarcitorio de la responsabilidad que inició con las codificaciones del siglo XIX, al establecer la diferencia entre la responsabilidad civil y la penal. Los preceptos civiles se dirigieron a dirimir las causas merecedoras de reparación de daños, en contraposición a la inicial finalidad sancionatoria y preventiva que fue asignada a la pena (Rojas, 2014, pp. 114-117) $)^{213}$.

El derecho de la responsabilidad encauzado en su génesis al autor del daño, tal como reza el art. $2341 \mathrm{CC}$ "el que ha cometido un delito o culpa, que ha inferido daño a otro, es obligado a la indemnización" en materia extracontractual, y así mismo, dirigida las consecuencias al incumplimiento contractual ${ }^{214}$, ha girado, y ese "otro" se convierte hoy en el protagonista (Llamas, 2014, p. 22). De acuerdo con ello, se hace alusión al principio progresista de responsabilidad favor victimae o principio pro damnato o también llamado pro consumatore.

En este sentido, el enunciado principal de la responsabilidad, como afirma Llamas (2014), podría cambiar a "todo aquél que sufra un daño antijurídico tiene derecho a ser indemnizado" (p. 22). Entonces, lo trascendental no está ya en la antijuridicidad de la conducta, al tornarse a veces inexistente ante la aparición de la responsabilidad sin culpa -o responsabilidad objetiva-, tanto en

\footnotetext{
${ }^{211}$ La responsabilidad en su génesis cumplió una labor sancionatoria de las conductas ilícitas. De ahí, la exigencia de la culpa para atribuir responsabilidad: "[e]n su forma más primigenia, esta se encargaba de la sanción o castigo, entendido como respuesta al perjuicio sufrido, diluyendo entonces las diferencias entre lo que hoy conocemos como responsabilidad penal y el análisis de responsabilidad civil. Lo anterior se hace claro si se tiene presente que la pena impuesta al causante del daño no correspondía, en modo alguno, a una reparación stricto sensu del perjuicio causado. Por el contrario, este castigo se enmarcaba exclusivamente en el ámbito punitivo, más concretamente en la retaliación o venganza, sin parámetros de asimetría o proporcionalidad" (Rojas, 2014, p. 113).

${ }^{212}$ En igual sentido se puede consultar a Sandoval (2013, p. 239).

${ }^{213}$ Para mayor amplitud del tema histórico de la evolución de la responsabilidad y su función se puede revisar las obras de Diez-Picazo (1999) y (2014), Fernández (2001) y Salinas (2011).

${ }^{214}$ El principio neminem laedere -no dañar a nadie- opera como principio general del derecho, se impone sin distingo alguno a la responsabilidad extracontractual y la contractual, es viable su invocación con el propósito de soluciones justas en cualquier disciplina jurídica, es decir, tanto en el derecho público como en el privado (Mosset y Piedecasas, 2009, p. 247).
} 
materia extracontractual como contractual, con las obligaciones de resultado ${ }^{215}$. De suerte que, la antijuridicidad se concreta en el daño en sí $^{216}$.

Todo esto, ha apuntado hacia una asombrosa ampliación en la conciencia jurídica de daños inferidos a los intereses inmateriales de la persona ${ }^{217}$, ya sea en su acepción general como daños morales, inmateriales o extrapatrimoniales. Incluso, los daños morales como una entidad de los extrapatrimoniales, subdivididos estos en una lista extensa de posibilidades. Verbigracia, daño a la salud, biológico, estético, sexual, al proyecto de vida, a la vida de relación o a los derechos de la personalidad.

En Colombia, la Corte Suprema de Justicia en 2014 mostró una tendencia proteccionista a los derechos fundamentales en el marco de las relaciones entre particulares. En torno a ello, indicó que “...el daño a los bienes personalísimos de especial protección constitucional que constituyen derechos humanos fundamentales..." es un daño autónomo indemnizable, de carácter extrapatrimonial junto con el daño moral y el daño a la vida de relación. Añadió que, se configuraba con la sola trasgresión de ciertos derechos de las víctimas, aun si dicha violación no generaba efecto adicional (SC10298-2014 de 5/08/2014) $)^{218}$.

Sin embargo, en la última jurisprudencia, a la fecha de la presente investigación, calificó como daños extrapatrimoniales los morales (incluye los dolores y padecimientos del fuero interno del individuo y asimismo los daños a los derechos humanos) y a la vida de relación (Sentencia SC5686-2018 de 19/12/2018).

\footnotetext{
215 En estos casos se prescinde del análisis de la conducta. Para exonerarse de responsabilidad, se requiere el rompimiento del nexo causal a través de la causa extraña, hecho de un tercero o culpa exclusiva de la víctima.

${ }^{216}$ Al respecto Mosset y Piedecasas arguyen que "[e]s absolutamente justo y equitativo que la persona dañada sea reparada, porque aun en el caso de involuntariedad o licitud, el daño ha existido y se violenta el deber de no dañar a otro y la preservación misma de la persona humana" (2009, p. 99).

217 Sobre el tema se puede consultar a M'Causland (2008) desde la perspectiva iberoamericana.

${ }^{218}$ La Corte Suprema de Justicia en sentencia de SC13925-2016 de 30/09/2016, cuyo planteamiento sigue la línea de lo expuesto en providencia SC10298-2014 de 5/08/2014, afirmó “"[e]s, entonces, perfectamente admisible y necesaria la reparación de los daños ocasionados a los bienes superiores, en cuyo caso la consecuencia lesiva (violación del bien jurídico) no puede confundirse con la conducta reprochable (cuyo demérito no consiste en la mera lesión del bien resguardado sino en la infracción de los deberes objetivos de prudencia que el ordenamiento establece para evitar producir daños). No hay, por tanto, ninguna razón para excluir del merecimiento indemnizatorio a esta tipología de daño, pues lo contrario supondría una visión reduccionista para la cual sólo [sic] serían dignas de resarcimiento las repercusiones económicas o patrimoniales, dejando los bienes superiores por fuera de lo que es objeto de tutela civil".
} 
Por su parte, la jurisdicción contenciosa-administrativa distingue desde el $2014^{219}$ como daños inmateriales: el daño a la salud derivado de una lesión corporal o psicofísica; el daño moral en caso de muerte o lesiones personales concebido desde el dolor, aflicción y en general, sentimientos de desesperación, congoja, temor, zozobra o desosiego. Esta indemnización se podrá incrementar cuando el daño moral provenga de la violación grave de los derechos humanos que intensifique su magnitud; y finalmente, la afectación relevante a bienes o derechos convencional y constitucionalmente amparados, en donde se privilegia medidas de reparación no pecuniarias.

Igualmente, el reconocimiento de los daños a la persona encuentra asidero en la constitucionalización del derecho privado, al abogarse por un papel puntual y congruente de los principios y reglas constitucionales en la normatividad del derecho privado. Esto, invita, en palabras de Perlingieri, a una relectura del derecho civil y sus instituciones con el foco de la constitución, “...en una superación de las barreras entre derecho civil y derecho constitucional, en la unidad del ordenamiento y en el sustancial respeto de la jerarquía de las fuentes y de los valores" (2015-I, p. 58).

No obstante, la incorporación del constitucionalismo no ha sido pacífica, por la dificultad de encuadrar nuevos fenómenos a la usual responsabilidad. Dado que, la constitucionalización desenmascara la ilusión de objetividad de las normas y de contera la interpretación literal. En consecuencia, los sistemas jurídicos deben armonizarse coherentemente “...según criterios o principios de idoneidad y proporcionalidad que solicitan el conocimiento también profundizado de las peculiaridades del caso concreto" (Perlingieri, 2015-II, p. 636) para buscar equilibrio y seguridad jurídica.

De acuerdo con lo anterior, el pronunciamiento del jurista español Diez-Picazo (2000) tiene plena vigencia, cuando afirmó que en España la institución de la responsabilidad civil se encontraba en un momento muy sensible de indefinición, al confluir en ella tanto tendencias jurisprudenciales como doctrinales, que la habían llevado, desde unas décadas atrás, a un contexto antes impensado de ampliación y cobertura. Con todo, convergían factores que abogaban por su

\footnotetext{
${ }^{219}$ Ver acta del 28 de agosto de 2014 "Referentes para la reparación de perjuicios inmateriales" del Consejo de Estado, Sala de lo Contencioso Administrativo.
} 
restricción (p. 19) ${ }^{220}$. Esto, no escapa a la situación que, a la hora presente, aún experimentan los países iberoamericanos e incluso europeos como Italia y España.

Asimismo, la aparición de fenómenos dañinos y realidades sociales se enfrentan a las tesis jurídicas tradicionales, a lo cual el derecho debe dar una respuesta, para salir de la perplejidad en una búsqueda de los ideales de justicia. En razón a que, el derecho "es una práctica social que se crea como medio para alcanzar el florecimiento humano ${ }^{221 "}$ (Boggio, 2013, p. 628), y, al mismo tiempo, avanza y se recrea conforme a la realidad social, por eso ya lo aventuraba Josserand (1936) cuando expuso que la verdad de ayer quizás no sea la de hoy y así misma ceda su paso a la de mañana.

El derecho-principio del consentimiento informado es un fiel reflejo de las cambiantes circunstancias de la relación médico-paciente que han tocado a la institución de la responsabilidad civil, y a pesar de las décadas de reconocimiento, siguen superlativas las discusiones doctrinales y jurisprudenciales sobre el daño resarcible.

\section{De la función reparadora de la responsabilidad civil}

La finalidad primordial y clásica de la responsabilidad civil apunta a la reparación de todos los daños causados con el propósito de que la víctima quede indemne (Corral, 2013, p. 60), lo más cercano posible a la situación anterior. Es decir, retornar al status quo ante que lleva implícito la equivalencia entre el daño y la reparación.

La inobservancia del alterum non laedere-responsabilidad extracontractual- o del incumplimiento de una obligación preexistente -responsabilidad contractual- apareja restablecer el

\footnotetext{
${ }^{220}$ Salinas explica que a partir del siglo XIX se está en una era de garantismo caracterizada por la estimación de las personas de “...un sinnúmero de derechos, acciones, posibilidades de reclamar ante la más mínima molestia, lo que es amplificado por los medios de comunicación social en el afán de obtener mayor rating, es el mundo globalizado y mediático en el cual predominan los derechos por sobre los deberes ... surge lo que se ha denominado el mercantilismo o la cultura de la judicialización, esto es, la cultura del enriquecimiento fácil” (2011-I, p. 97).

${ }^{221}$ Explica Boggio que el florecimiento humano es fruto de las capacidades y derechos fundamentales y recursos materiales que las nutren, por ello ante un daño que impide florecer a la víctima se debe proporcionar su reparación (2013, p. 628).
} 
equilibrio que hasta entonces gozaba el ahora perjudicado en todas sus extensiones: física, patrimonial, afectiva, psicológica y social.

Por consiguiente, con la puesta en marcha de la acción la responsabilidad civil se busca reponer y/o compensar la pérdida sufrida ${ }^{222}$, ya sea patrimonial o extrapatrimonial ${ }^{223}$ o el costo que ha generado dichos daños. Así pues, se habla de una reparación en principio in natura o de una de tipo pecuniario o por equivalente ${ }^{224}$.

Es una falacia pensar que con la reparación desaparece el daño y todo queda como estaba previamente, dado que, cuando "se destruyen las vidas humanas o los bienes materiales, la indemnización no borra la destrucción” (Díez-Picazo,1999, p. 42).

Entonces, de lo que se trata es de traspasar el daño ocasionado a otro, para que asuma económicamente la compensación de los mismos. Por eso, se exige el estudio y justificación de las razones para cambiar el daño de bolsillo; esto es, sustentación en los criterios de atribución de responsabilidad, ya sea subjetiva como la culpa o de tipo objetivo (Pantaleón, 2000, p. 174).

Desde esta perspectiva, la responsabilidad civil se enmarca en la reparación de la víctima, en un análisis de la intensidad y medida del daño sufrido. La regla de oro de esta institución es "reparar todo el daño, pero nada más que el daño", sin que para la valoración del daño se tenga en cuenta la conducta del dañador. Mucho menos, la indemnización puede constituirse en una fuente de enriquecimiento para el dañado, en virtud de que, atentaría contra el principio de proporcionalidad entre el daño y la indemnización otorgada (Henao, 2015, p. 349).

\footnotetext{
${ }^{222}$ Kemelmajer apunta que "...el derecho de la responsabilidad civil se ha visto tradicionalmente como el derecho que opera después de producido el daño; antes de su acaecimiento, se dice, nada se puede hacer" (2001, p. 675). Sin embargo, para esta autora la responsabilidad civil debe girar también en torno a la función preventiva en aras de no seguir con la separación de lo civil-sustantivo con lo procesal, debido a que se deben dar soluciones operativas y establecer medidas preventivas por parte de los jueces, así no sea objeto de la pretensión.

${ }^{223}$ También llamados materiales e inmateriales.

224 "Tradicionalmente se reconocen tres formas distintas de cumplimiento de la obligación de reparar el daño: a) Reparación específica o in natura, en el sentido de arreglo de la cosa dañada o mediante su sustitución por otra igual. b) Indemnización por equivalente, mediante la entrega de la cantidad de dinero correspondiente al daño sufrido; c) Reparación en especie, mediante la entrega de bienes, cuyo valor equivalga al daño sufrido" (Luna, Piñeiro, Ramos y Rubí, 2002, pp. 2-3).
} 
A diferencia de lo que sucede en los sistemas del common law con los conocidos punitives damages, las normas que reglamentan la responsabilidad civil, en el ordenamiento jurídico colombiano y en general los de tradición continental ${ }^{225}$, no tienen como función sancionar o castigar al autor por su conducta o prevenir a la comunidad, pues pretenden es compensar a la víctima lesionada en sus intereses. Aunque, indirectamente pueden influir en la disuasión (De Ángel, 1993, p. 60).

Muy a pesar que la persona obligada a reparar el daño experimente sentirse castigada, como al que se le impone una pena o multa, o amedrentada a raíz de la indemnización, de modo que ello persuada en su conducta para tomar precauciones y evitar daños a futuro, la finalidad de la responsabilidad civil no varía (Pantaleón, 1991, 1971).

Así, sería un desacierto volver al superado pasado sancionador de la responsabilidad, debido a que, para castigar o reprochar el actuar del infractor el mismo derecho da cuentas de diferentes remedios para ese objetivo particular, como es el derecho penal y el disciplinario sancionador. En Colombia, el régimen disciplinario en materia de actividad médica es precedido, en primera instancia, por los diferentes Tribunales Seccionales de Ética Médica y, en segunda instancia, por el Tribunal Nacional de Ética Médica ${ }^{226}$.

La presente investigación no es ajena a las discusiones doctrinales que desde años atrás se vienen suscitando respecto a las funciones de la responsabilidad civil, generándose posturas hacia una multiplicidad de funciones al lado de la reparadora. De esta forma, se le han asignado fines

\footnotetext{
${ }^{225}$ En Argentina el reciente Código Civil y Comercial de la Nación acoge como funciones de la responsabilidad la prevención del daño y su reparación -art. 1708-. Asimismo, esta normativa consagra sanciones conminatorias e indica que "los jueces pueden imponer en beneficio del titular del derecho, condenaciones conminatorias de carácter pecuniario a quienes no cumplen deberes jurídicos impuestos en una resolución judicial. Las condenas se deben graduar en proporción al caudal económico de quien debe satisfacerlas y pueden ser dejadas sin efecto o reajustadas si aquél desiste de su resistencia y justifica total o parcialmente su proceder" (art. 804).

${ }^{226}$ El régimen disciplinario médico está consagrado en el título III de la Ley 23 de 1981 - Código de Ética Médica, las sanciones autorizadas a imponer de acuerdo con la gravedad de la conducta o con la renuncia en ellas son: a) Amonestación privada; b) Censura, que podrá ser: 1. Escrita pero privada. 2. Escrita y pública. 3. Verbal y pública. c) Suspensión en el ejercicio de la medicina hasta por seis meses; d) Suspensión en el ejercicio de la medicina, hasta por cinco años (art. 83). El Proyecto de Ley 042 de 2017 consagra en el libro segundo- título III lo relacionado con el régimen disciplinario y en el capítulo III lo particular al proceso disciplinario ético profesional médico.
} 
distintos a una institución que parecía haber dejado atrás matices de punición de las conductas. Entre el listado ${ }^{227}$ se destacan como primarias la función punitiva o sancionadora y la preventiva ${ }^{228}$.

Sin embargo, en este trabajo se acoge como única función de la responsabilidad civil la compensatoria o resarcitoria, no siendo estas líneas el espacio apropiado para discusiones trascendentales sobre la materia.

Esta postura encuentra sustento en estudios doctrinales de gran envergadura, los cuales concluyen, con razones de peso, la legendaria función como la única que realmente identifica y caracteriza a la responsabilidad civil en sus objetivos, y se pueden armonizar en la siguiente síntesis:

a) La graduación de la indemnización va acorde con la gravedad del daño no de la conducta, pues la función sancionadora se cae por su propio fundamento.

b) La responsabilidad es transmisible a terceros, ya sea mortis causa a los herederos o en razón de un seguro de responsabilidad civil.

c) Al ser asegurable ciertos daños y ser asumida por terceros esa reparación, se pone en tela de juicio una verdadera función preventiva.

d) No opera en la responsabilidad civil el principio de retroactividad de la ley más favorable.

e) La función punitiva o sancionadora de la conducta es asignada al derecho penal.

\footnotetext{
${ }^{227}$ Se ha hablado de la función de demarcación de la libertad con quien coinciden Salvador y Castiñeira (1997, pp. 103-104), Diez-Picazo (2000, p. 43) quien reiteró su postura en (2014, pp. 22-23) y Corral (2013, pp. 60-61) que la apunta como función de garantía de la libertad de actuar o delimitación de la libertad de los privados y la enmarca como función concurrente o complementaria.

Salvador y Castiñeira hacen referencia también a una función distributiva de la responsabilidad que alude a distribuir "ex ante (incentivando, p. ej., la contratación de un seguro de responsabilidad civil) o ex post (forzando, mediante la condena a indemnizar, transferencias de recursos de dañador a víctima) la estimación económica del daño, idealmente: de sus costes sociales, no sólo de los privados. La función distributiva se asocia con el otro gran fundamento de imputación de responsabilidad civil: la creación lícita de un riesgo legalmente definido, es decir, la responsabilidad objetiva" (1997, p. 107).

${ }^{228}$ Sobre el tema se pueden consultar, entre otras, las obras de Jaramillo (2016), Méndez-Monasterio (2016), Acciarri y Irigoyen (2015, pp. 189-242), Picasso (2015), Rojas (2014, pp. 109-145), De Ángel (2013, pp. 114-135), De Ángel (2012), Roca y Navarro (2011, pp. 22-24), Salinas (2011, pp. 411-417), Viney (2010, pp. 88-100), Concepción (2009, pp. 44-47), Mosset y Piedecasas (2009, pp. 19-35), Barros (2006, pp. 33-48), Reglero (2006, pp.75-96), Martín (2011, 23-31).
} 
f) Reparar es cuestión diferente a una pena o multa, surge la inquietud en manos de quien quedaría esa pena, es decir, a favor del lesionado como multa privada o del Estado en un fondo común.

g) Es incierto hablar de una prevención general cuando la responsabilidad entra en acción después del hecho y la reparación mira el daño y no la conducta dañina.

h) La prevención especial puede que tenga relevancia en la persona infractora para casos futuros, pero tampoco, se puede asegurar el éxito de la disuasión a raíz de la reparación.

i) Puede existir responsabilidad sin culpa, pero no sin daño.

j) Los daños extrapatrimoniales dan lugar a su reparación, no son consecuencia de una sanción al dañador, pues resultan de la lesión a los intereses de la víctima que se busca sean compensados de alguna manera. (Pantaleón, 2000; Llamas, 2007-II) ${ }^{229}$

\section{Presupuestos de la responsabilidad médica por incumplimiento total o parcial del consentimiento informado del paciente}

Los presupuestos generales de toda responsabilidad -llámese civil -contractual o extracontractual- o del Estado-, son la tríada: hecho, daño y nexo o relación causal. No puede predicarse responsabilidad sin alguno de esos tres elementos.

La responsabilidad médica no es ajena a dichos presupuestos generales, requiere un comportamiento activo o pasivo imputable subjetivamente, como criterio general, al obrar del profesional de la salud “... a título de dolo o culpa, el daño patrimonial o extrapatrimonial y la relación de causalidad adecuada entre el daño sufrido y el comportamiento médico primeramente señalado)" (Corte Suprema de Justicia, sentencia SC12947-2016 de 15/09/2016).

Por tanto, el comportamiento de omitir parcial o totalmente la información y/o el consentimiento informado del paciente se puede examinar desde varias perspectivas conforme al

\footnotetext{
${ }^{229}$ Respecto de defensa de la función meramente compensatoria o resarcitoria se encuentran Roca y Navarro (2011, pp. 22-24), De Ángel (1993, p. 60), De Ángel (2012), Tamayo (2014, p. 26) quien plantea como función el restablecimiento de los bienes y la prevención pero esta última basada en el art. 2350 del CC para evitar un daño contingente, este mismo autor expuso en otra obra que la responsabilidad civil engloba la obligación de indemnizar daños a quien se ha comportado de forma ilícita, entiéndase esta última como el incumplimiento contractual, cuasicontractual o la violación del deber general de prudencia (2007, p. 8).
} 
incumplimiento de la obligación, la corrección de la conducta y la cristalización o no de un riesgo previsible del procedimiento practicado, posibilidades que se abordan en el análisis del daño.

A continuación, se estudian los elementos básicos en el campo de la actividad médica ante la omisión del consentimiento informado del paciente.

\subsection{El hecho dañoso}

La institución de la responsabilidad civil requiere una conducta o un hecho ${ }^{230}$ de un agente que sea el generador del daño por el cual se reclama. Esta conducta puede ser activa u omisiva. En algunas oportunidades se requerirá de la existencia de la culpa en los casos de responsabilidad subjetiva -culpa probada o culpa presunta- para predicar la responsabilidad y en otras, bastará la conducta dañosa del agente sin que sea necesario la mediación del análisis de su comportamiento o el estudio de si tomaron o no las precauciones necesarias a fin de evitar el daño, como sucede en la responsabilidad objetiva.

Es impensable que un daño se origine sin una acción u omisión que lo cause, inclusive hasta la responsabilidad de orden moral o religiosa precisa de un comportamiento a partir del cual se haga el juicio de reproche (Tamayo, 2007, p. 189).

La valoración de la conducta médica requiere que sea observada en toda su extensión. Esto es, no solo la diligencia, competencia y prudencia profesional en cuanto a las reglas y saberes médicocientíficos, sino que también, esos parámetros son requeridas en el trato y consideración del paciente como persona con derechos y responsabilidades. Por eso, es necesario que el paciente conozca su estado de salud y las medidas para su recuperación, independientemente si se encuentra

\footnotetext{
${ }^{230}$ Tamayo arguye que es preferible hablar de conducta y no de hecho o culpa. Lo primero porque la conducta que causa un daño constituye en sí misma un hecho ilícito, entiéndase ilícito, por este autor, el atentar contra los intereses protegidos por el ordenamiento, por tanto, "[e]l hecho está compuesto por la conducta más el daño causado por dicha conducta. Esta última es la parte y el hecho ilícito, incluido el daño, es el todo" (2007, p. 188). Sin embargo, se prefiere en la investigación aludir al término general hecho dañoso, para cobijar todo acto perpetrador de un daño ya sea que haya sido realizado directamente o de forma indirecta a través de las cosas, animales o en virtud de alguna actividad de las consideradas -por ley o jurisprudencia- peligrosas.
} 
o no en una relación contractual. De esta manera, no es suficiente una buena práctica si no hay probidad en el actuar (Alonso, 2000, pp. 43-44).

La inobservancia total o parcial del consentimiento informado del paciente, como se apuntó en el capítulo I, se inserta como una transgresión de la lex artis. Su omisión puede dañar los sentimientos, la dignidad o los bienes del paciente, ya que el cumplimiento del ejercicio de la práctica profesional correcta (lex artis estricta) solo se consuma si va acompañado de una información veraz, prudente y fidedigna al paciente (lex artis complementaria) (Alonso, 2000, p. 43).

En este sentido, la omisión parcial o total no comporta solo un incumplimiento de la lex artis, pues apareja un desconocimiento de las garantías máximas de las personas en donde se afecta la libertad de decidir sobre su vida, su cuerpo y su salud. De ahí, se desprende la trascendencia de esta obligación, que con el paso de los días aumenta su carácter exigible en aras de garantizar y respetar la dignidad humana.

Conforme a lo señalado en esta investigación, al caracterizarse el consentimiento informado por la dupla derecho-principio, su exigencia se hace imprescindible tanto en el desarrollo de un contrato de servicios médicos, como en el plano de una relación extracontractual -entre particulares o siendo el Estado el prestador del servicio-.

No es coherente asumir que en el campo contractual o cuando media una contraprestación, o si se trata de obligaciones de resultado, el consentimiento informado adquiere más rigurosidad o es ineludible. Debido a que, los deberes de cuidado e incluso las reglas probatorias, como se observa más adelante, son aplicables, en igual medida, en cualquier sede en que se plantee la responsabilidad por este concepto. Por tanto, no existen ni serían aconsejables las diferencias en la construcción del comportamiento culposo médico (Barros, 2006, pp. 667-668).

Así las cosas, el consentimiento informado exige una obligación positiva de hacer, que demanda un comportamiento preciso y delimitado por parte del profesional de la salud en cuanto a brindar 
una información clara, suficiente y adecuada, y posteriormente, de acuerdo con la decisión del paciente, obtener el consentimiento informado para dar paso a una práctica médica.

\subsubsection{Factores de atribución}

Con respecto a los factores de atribución de la responsabilidad civil médica, la culpa es el criterio utilizado básicamente ante la incertidumbre ínsita del acto médico y al estar los riesgos que campea justificados por la ciencia y la ética, en pro del principio de beneficencia y no maleficencia en atención a los fines de la medicina.

Cuando un acto se califica como culposo se predica del mismo una censura por inobservar un comportamiento determinado y exigido. La culpa no existe en abstracto, se estudia en la situación fáctica concreta (Mantilla, 2007, p. 134). Por ende, la prueba de la diligencia y cuidado en la circunstancia específica son la base para la exoneración del demandado.

En principio, la responsabilidad médica implica un reproche culpabilístico con relación a la diligencia, cuidado o pericia que debe observar el galeno en su ejercicio profesional. Las directrices están marcadas por la lex artis y los deberes éticos-legales de su actividad, junto con un parámetro de conducta estándar, que no es otro que, el obrar de un buen profesional que obedece los preceptos establecidos para el correcto funcionamiento del ejercicio médico ${ }^{231}$, asimilable a una “diligentia diligentissimi propia de la culpa levísima” (Corte Suprema de Justicia, sentencia de 08/08/2011,

\footnotetext{
${ }^{231}$ Llamas reflexiona sobre la culpa y expone que "[s]ólo [sic] puede hablarse de verdadera culpa como violación de deberes de diligencia previamente establecidos (es la llamada duty situation). Así, coincidiendo con la doctrina tradicional, se explica la culpa paralelamente al dolo; si éste requiere el conocimiento de la ilegalidad de un acto, así como la voluntad de realizar el mismo, en la culpa se sustituye el elemento intelectivo por la previsibilidad del resultado y el elemento volitivo por la omisión de la diligencia debida. De esta forma, se cifra la noción de culpa en la idea de negligencia; pero ésta siempre requiere la presencia de un elemento de comparación, de un modelo de comportamiento o nivel de diligencia preestablecido que, en definitiva, será el que marque dónde comienza la previsibilidad y dónde termina el caso fortuito o la fuerza mayor" (2014, p. 10).

Barros (2006) indica que el acto culpable a nivel médico es “...el que no hubiese realizado una persona diligente y razonable; sin embargo, ésta no puede evitar tropiezos estadísticamente ineludibles. Por esto, no se justifica calificar per se de negligente a un médico por la lesión accidental de un nervio o corte de una arteria durante una intervención, si se asume que un porcentaje de las operaciones difíciles ese daño se produce inevitablemente, aunque se emplee la diligencia debida... el daño que se debe al error no imputable pertenece, en definitiva, a los riesgos generales de la vida que son soportados por la víctima" (pp. 674-675).
} 
exp. 2001-00778-01). Todo lo cual, debe observarse “...conforme las circunstancias de las personas, del tiempo y del lugar” (Ataz, 1985, p. 290).

Tradicionalmente, la responsabilidad civil médica se ha basado en la culpa ${ }^{232}$, en particular, en la culpa probada de ese comportamiento, radicado en la violación de los deberes médicos que han de observarse en la práctica asistencial, sujetos a las reglas propias del ejercicio de la medicina. Cuando en cualquiera de las fases de la praxis médica “...prevención, pronóstico, diagnóstico, intervención, tratamiento, seguimiento y control, se causa daño, demostrados los restantes elementos de la responsabilidad civil, hay lugar a su reparación a cargo del autor o, in solidum si fueren varios los autores" (Corte Suprema de Justicia, sentencia de 13/09/2002, exp.6199).

Por otro lado, en la órbita de la responsabilidad médica ocupa un lugar destacado la clasificación de obligaciones en las modalidades de medios y de resultado, para, en principio, solucionar los problemas de la culpa y su prueba ${ }^{233}$. En las obligaciones de resultado el deudor se compromete a un resultado claro y preciso de "contornos definidos", mientras que, en las obligaciones de medio el deudor no promete exactamente un resultado determinado o preciso, dado que, se compromete solamente a hacer todo lo posible para conseguir un resultado determinado por su actividad, esfuerzo y diligencia (Corte Suprema de Justicia, sentencia de 31/05/1938).

${ }^{232}$ En Colombia la Corte Suprema desde la sentencia de 05/03/1940 (G.J. XLIX) inició a estructurar la doctrina de la culpa probada en el ejercicio de la profesión médica, a partir de la distinción entre las obligaciones de medio y de resultado para el caso en que mediara un contrato, y en los supuestos extracontractuales, la acreditación de la conducta negligente, defectuosa o inapropiada del médico, dejando a un lado la aplicabilidad del art. $2356 \mathrm{CC}$ relacionado con las actividades peligrosas. Sin embargo, en dicha providencia se acotó al lado de la culpa la condición de su "gravedad", graduación que, como a bien lo manifiesta la Corte, no puede tener cabida hoy porque "....aún teniendo en cuenta los aspectos tecnológicos y científicos del acto profesional médico, la conducta sigue siendo enmarcable dentro de los límites de la culpa común, pero, sin duda alguna, sin perder de vista la profesionalidad" (Sentencia 30/01/2001, exp. 5507). A lo cual, es factible agregarle la finalidad reparadora de la responsabilidad civil en aras de garantizar la reparación de un daño que no tenía la persona que soportar, independientemente de quien haya sido el causante del mismo. Lo que, si resulta importante determinar, como se verá más adelante, es el daño y su gravedad para su indemnización.

A nivel legislativo, el art. 104 de la Ley 1438 de 2011 consolidó la relación asistencial como de medios.

${ }^{233}$ Con la caracterización de las obligaciones de medios y de resultado se justifica la inaplicación generalizada de la presunción de culpa médica en materia contractual (Jaramillo, 2010, p. 127) que devendría de aplicar el párrafo tercero del art. 1604 CC "la prueba de la diligencia o cuidado incumbe al que ha debido emplearlo". Lo que, encuentra asidero en la parte final de la misma regulación, al establecer que "todo lo cual, sin embargo, se entiende sin perjuicio de las disposiciones especiales de las leyes, y de las estipulaciones expresas de las partes". Sin embargo, el reconocimiento de este tipo de obligaciones fue asumido por primeramente por la jurisprudencia. 
En las obligaciones de medios le corresponde al acreedor la prueba de la negligencia o impericia. En las de resultado, opera la presunción de incumplimiento al no conseguirse el resultado esperado o prometido; en estos casos, la carga de la prueba le corresponde al deudor y su liberación se subsume a la causa extraña, al hecho de un tercero o la culpa exclusiva de la víctima $^{234}$, sin perjuicio de otras reglas de atenuación o flexibilización de la carga probatoria consignadas en el art. 167 del CGP.

No obstante, la utilidad de la distinción en materia de carga de la prueba, la clasificación también constituye una herramienta importante para el juez en la determinación y esclarecimiento del contenido de la obligación, en cuanto a la verificación de las exigencias, compromisos y comportamiento de las partes (Corte Suprema de Justicia, sentencia de 05/11/2013, exp. 200500025-01). Por ello, su alcance es perfectamente extensible a la relación asistencial surgida por fuera de un contrato en lo que corresponde al consentimiento informado, al ser una prestación de la naturaleza de la actividad médica, que exige su acatamiento.

Ha precisado la Corte Suprema de Justicia que las obligaciones en la actividad asistencial son en general de medios, ante la dinámica complejidad del cuerpo humano que encierra una dosis de alea que escapa a la previsión de la ciencia médica y complejiza la asegurabilidad de resultados. En consecuencia, el galeno no debe obligarse a sanar al enfermo, más bien a ejecutar correctamente los actos médicos necesarios en atención a los requerimientos del paciente (Sentencia de 30/01/2001, exp. 5507).

En las obligaciones de medio al paciente/demandante, en línea de principio, le corresponde acreditar el comportamiento negligente del facultativo al inobservar las reglas de la profesión que implica un criterio subjetivista basado en la culpa. Para defenderse el médico deberá demostrar diligencia en su actuar y en el manejo de los medios utilizados conforme a los saberes de la ciencia para alcanzar el objetivo pretendido.

\footnotetext{
${ }^{234}$ Sobre la materia se pueden revisar las sentencias de la Corte Suprema de Justicia de 05/11/2013 exp. 2005-0002501; SC7110-2017 de 24/05/2017.
} 
No obstante, el profesional de la medicina, en virtud de la autonomía de la voluntad, se puede comprometer expresamente con la consecución de un resultado, es decir, pactar una obligación de resultado, como puede ocurrir con las cirugías estéticas.

Asimismo, particulares actos médicos hacen exigible alcanzar el propósito específico, sumado a que en ellos la presencia de la contingencia se reduce a su mínima expresión, lo que hace que sean por sí mismos obligaciones de resultado, verbigracia la colocación de aparatos de ortopedia, instalación de implantes anticonceptivos, análisis clínicos, elaboración de dictámenes (Llamas, 2014, p. 6) ${ }^{235}$. En estos supuestos, la culpa no es el criterio de imputación, se consagra un régimen objetivo $^{236}$.

En la presente investigación se estudia igualmente la responsabilidad del Estado, al compartir con la civil los elementos generales de toda responsabilidad. Por tanto, para los supuestos de responsabilidad del Estado se hace alusión al título de imputación basado en la falla del servicio ${ }^{237}$, mirado con relación a las funciones o servicios del Estado y su anormal funcionamiento, “...punto a partir del cual, en armonía con el apedillado daño antijurídico y el vínculo o nexo causal, se fundamenta esta especie de responsabilidad de la administración, en sentido amplio" (Jaramillo, 2010, p. 123).

${ }^{235} \mathrm{Al}$ respecto se puede consultar a la Corte Suprema de Justicia, sentencia de 05/11/2013, exp. 2005-00025-01.

${ }^{236}$ Ilustra la Corte Suprema con respecto a la diferencia en la exoneración de responsabilidad entre obligaciones de medios y de resultado, que al demandado "[e]n las obligaciones de medio, le basta demostrar diligencia y cuidado (artículo 1604-3 del Código Civil); y en las de resultado, al descontarse el elemento culpa, le incumbe destruir el nexo causal entre la conducta imputada y el daño irrogado, mediante la presencia de un elemento extraño, como la fuerza mayor o el caso fortuito, la culpa exclusiva de la víctima o el hecho de un tercero" (Sentencia SC003-2018 de $12 / 01 / 2018$,).

${ }^{237}$ No le falta razón a Arenas cuando consigna que en Colombia “...existen dos títulos de imputación en materia de responsabilidad estatal que son el subjetivo, como regla general y el objetivo, para casos específicos. El único título que requiere la presencia de la culpa, es el de la falla del servicio; por oposición, a los títulos sin culpa que son el daño especial y el riesgo excepcional" (Arenas, 2014, p. 308).

La jurisprudencia consolidada del Consejo de Estado respecto a las infecciones nosocomiales o intrahospitalarias, es decir, aquellas que se contraen en los establecimientos de salud, ha marcado un énfasis objetivo de responsabilidad como se puede constatar en la última jurisprudencia a la fecha en donde se lee: "En torno a las infecciones nosocomiales contraídas por un paciente, la jurisprudencia del Consejo de Estado señala que la persona que alega haber sufrido un daño como consecuencia de una de ellas tiene la obligación de acreditar que ésta fue contraída en el centro hospitalario o asistencial o que se produjo como consecuencia de un procedimiento médico, sin que en tal evento resulte necesario que se pruebe que la entidad demandada actuó de manera indebida o negligente; en cambio, para liberarse de responsabilidad, la demandada debe acreditar la presencia de una causa extraña, esto es, fuerza mayor, el hecho determinante y exclusivo de la víctima o el hecho determinante y exclusivo de un tercero" (Sentencia de 24/05/2018, exp. 2005-06780-01(45925)). 
Esta falla del servicio alude a la culpa de la administración "...cuando el servicio no ha funcionado, no lo ha hecho correctamente o la actuación se ha producido tardíamente; o sea, se ha llevado a cabo una actuación inadecuada o incorrecta en relación con los parámetros exigidos" (Arenas, 2014, p. 311)

La responsabilidad del Estado por falla del servicio médico, como en la Corte, ha girado con el paso de los años a través de la jurisprudencia del Consejo de Estado ${ }^{238}$, destacándose hoy un criterio subjetivo de atribución basado en la falla probada del servicio y carga dinámica de la prueba.

\subsubsection{El consentimiento informado: entre obligación de medio y de resultado}

En el terreno práctico del consentimiento informado, transmitir la información al paciente y obtener de este el consentimiento informado se erige como una obligación de resultado ${ }^{239}$, que se verifica con su mera ejecución. Es excusable la obligación por las causales generales de rompimiento del nexo causal y por las propias del acto médico establecidas por ley y jurisprudencia, como cuando se está ante una emergencia en donde peligre la vida del paciente de forma tal que, obligue a actuar sin su asentimiento ${ }^{240}$.

\footnotetext{
${ }^{238}$ La responsabilidad del Estado inició con un régimen de culpa probada. Luego con la sentencia del 24/10/1990 exp. 5902 pasó a la falla presunta del servicio estando en el demandado la carga de la prueba para demostrar diligencia y cuidado en la prestación del servicio médico. Posteriormente, en el año 2000 a través de la sentencia de 10/02/2000 exp. 11.878 se acogió la carga dinámica de la prueba o distribución de las cargas probatorias atendiendo en cada caso quien estaba en mejor posición de probar la falla o ausencia al cuestionar la aplicación generalizada de la falla presunta, y finalmente, en el 2006 en sentencia de 31/08/2006 exp. 15772 se retornó a la falla probada ante la complejidad que se origina en el debate probatorio cuando el Estado tiene la carga de desvirtuar la presunción, lo que justificó, en principio, con el siguiente argumento “.... en materia de responsabilidad médica deben estar acreditados en el proceso todos los elementos que la configuran, para lo cual se puede echar mano de todos los medios probatorios legalmente aceptados, cobrando particular importancia la prueba indiciaria que pueda construirse con fundamento en las demás pruebas que obren en el proceso, en especial para la demostración del nexo causal entre la actividad médica y el daño". Para ampliar el tema de la evolución de la jurisprudencia en el ámbito médico se pueden consultar las sentencias del Consejo de Estado de 12/08/2014 exp. 1994-07946-01(29131) y de 31/08/2006 exp. 2000-09610-01(15772), y a nivel doctrinal Ruiz (2016, pp. 143-160).

${ }^{239}$ Con igual criterio Pizarro (2018, p. 82).

${ }^{240}$ Tanto en las obligaciones de medios como en las de resultado el profesional debe actuar con prudencia y diligencia, de tal forma, que no es ese el argumento diferenciador entre una u otra obligación, por ello, como alude Jaramillo no es correcto atribuir a las de medios el nombre de diligencia ya que se caería en una imprecisión, porque todas las obligaciones de hacer requieren un determinado comportamiento correcto y diligente en aras de alcanzar el fin así finalmente no se logre (2002, pp. 340-343).
} 
En lo que respecta a los términos de adecuación, transmisión y la garantía de comprensión o de discernimiento de la información y decisión consciente del paciente, son obligaciones de medios. Lo cual, se deriva desde la concepción del consentimiento como un principio. En estos eventos, el galeno se compromete a desplegar sus capacidades y habilidades en procura de que el receptor de la información capte el contenido, al margen de poder asegurar el resultado específico al escapar de su control, lo que no significa que no se actúe con diligencia y cuidado ${ }^{241}$.

En las obligaciones de medios al ser subjetiva la atribución, se requiere una previa demostración del carácter culposo del actuar del facultativo. Empero, si bien se hablaría de una culpa probada, con el consentimiento informado ocurre una situación particular que determina la carga probatoria.

En este sentido, cuando el paciente alega que el médico no cumplió con sus deberes de informar y de consentimiento informado se está ante una negación indefinida. Conforme al art. 167 del CGP “...las afirmaciones o negaciones indefinidas no requieren prueba”, y, en consecuencia, la contraparte debe aportar la evidencia probatoria del hecho negado. De modo que, corresponde al galeno la carga de demostrar asertivamente su actuar diligente.

Esa regla probatoria resulta acertada al evitar la imposición de cargas probatorias diabólicas al demandante, ante la dificultad de aportar, en determinadas circunstancias, los medios de prueba ${ }^{242}$. En contraste, con los profesionales y las entidades de salud, a los cuales, dada la cercanía y

\footnotetext{
${ }^{241}$ Castaño quien las califica como "obligación de resultado mínimo" (1997, p. 93).

${ }^{242} \mathrm{La}$ Corte Suprema con relación a las negaciones o afirmaciones indefinidas ha indicado el principio de flexibilización de la carga de la prueba en un sentido dinámico, socializante y moralizador, pues "pues éste es el principio implícito en la norma cuando exonera de prueba las afirmaciones o negaciones indefinidas, precisamente por la dificultad de concretarlas en el tiempo o en el espacio, y por ende de probarlas, resulta pertinente hacer ver que el meollo del problema antes que en la demostración de la culpa, está es en la relación de causalidad entre el comportamiento del médico y el daño sufrido por el paciente, porque como desde 1940 lo afirmó la Corte en la sentencia de 5 de marzo, que es ciertamente importante, "el médico no será responsable de la culpa o falta que se le imputan, sino cuando éstas hayan sido determinantes del perjuicio causado" (Sentencia de 30/01/2001, exp. 5507). La Corte Constitucional también ha hecho alusión a las negaciones o afirmaciones indefinidas y señala la justificación de las excepciones y morigeraciones al principio general de la carga de la prueba -onus probandis- por la dificultad en ciertos casos de demostrar los hechos, por ello alude que "[a]lgunas excepciones son derivadas del reconocimiento directo de un acontecimiento por cualquiera que se halle en capacidad de observarlo debido a su amplia difusión (hechos notorios). Otras se refieren a aquellos hechos que por su carácter indeterminado de tiempo, modo o lugar hacen lógica y ontológicamente imposible su demostración para quien los alega (afirmaciones o negaciones indefinidas). Y otras son consecuencia de la existencia de presunciones legales o de derecho..." (Sentencia C-0862016 de 24/02/2016).
} 
disponibilidad de la documentación clínica, les resulta con mayor facilidad asumir la defensa de su diligencia.

En ese mismo sentido, la obligación de medios resulta importante para la definición del contenido y alcance del deber legal y el análisis probatorio de la culpa conforme a lo alegado y probado por el facultativo, mas no trasciende en cuanto a la carga probatoria.

Por otra parte, la cuestión más complicada a analizar por el juez es el incumplimiento de la obligación de información, es en cuanto a la extensión, contenido y transmisión. Se deben estudiar todas las circunstancias que rodean el caso y las diferentes pruebas aportadas, como la historia clínica -donde por ley ${ }^{243}$ debe constar la anotación del consentimiento informado ya sea que se haya realizado este y el proceso previo de información de forma oral o escrita-, el formato de consentimiento, plegables de información, dibujos, videos, testigos, audios, etc.

Recuérdese que en cuanto a la información de los riesgos, como se recomendó preliminarmente, se deben dar a conocer todos los previsibles y típicos del procedimiento conforme al estado de la ciencia. En un primer momento, no se examinaría la diligencia cuando de lograr ese fin se trata, como apunta Pizarro (2018), si el médico no informa los riesgos incumple su deber “... sin que sea relevante considerar si para alcanzarlo hizo más o menos esfuerzos” (pp. 66-67).

A pesar de esto, existen situaciones a las que el médico debe acudir a la prudencia y altruismo para graduar la información, dada las condiciones del paciente, en orden a no alterar su estado de salud -privilegio terapéutico- o ante la negativa de este de recibir información. Casos en los cuales, la justificación de la graduación de la información debe ser expresa y fundamentada clínicamente por el profesional, para evitar abusos y desconocimientos de derechos humanos.

Desde este ámbito, en materia médica el análisis de la responsabilidad, aunque se base en obligaciones de resultado, no puede excluir totalmente los estándares de la lex artis para el buen y correcto ejercicio sanitario, asociada a los parámetros fácticos que caracterizaron la relación

\footnotetext{
${ }^{243}$ La consagración normativa se encuentra en las Resoluciones del Ministerio de Salud y Protección Social Nos. 1995 de 1999 y 1441 de 2013.
} 
médico-paciente ${ }^{244}$. Debido a que, en la concreción de las reglas “...no son indiferentes las circunstancias en que el profesional actúa ... el estándar de cuidado se aprecia en concreto de cada profesión y para las distintas circunstancias en que ellas se ejercen” (Barros, 2006, p. 663).

Por lo anterior, las obligaciones relacionadas con la información y el consentimiento informado revisten características particulares que exigen un especial estudio y valoración de las pruebas por parte del operador judicial, para evitar arbitrariedades en las decisiones.

\subsection{El daño}

Metafóricamente el elemento daño se concibe como la columna vertebral de la responsabilidad civil (Corte Suprema de Justicia, sentencia SC10261-2014 de 04/08/2014), es la razón que da paso a hacer un reclamo de responsabilidad. Se puede presentar un acto culposo, pero si este no repercute en un interés tutelado por el ordenamiento jurídico no deviene obligación de reparación a cargo del infractor. De hecho, si en un juicio de responsabilidad no se demuestra la existencia de un daño se desvanece la pretensión resarcitoria, siendo inútil el estudio de los otros presupuestos al desconfigurarse la función de la responsabilidad civil ${ }^{245}$.

Sea lo primero, establecer la noción de daño que servirá de bastión a la investigación, para justificar las conclusiones y propuesta respecto del daño a reparar en torno a la omisión del consentimiento informado del paciente.

El concepto de daño ha sido dinámico en las latitudes continentales, por lo cual no existe una sola definición al respecto. En Colombia, el Código Civil solo apunta a la indemnización del daño (arts. 1612 y 2341), y en su especificidad lo clasifica desde la perspectiva patrimonial contractual en el lucro cesante y daño emergente (art. 1613 CC).

\footnotetext{
${ }^{244}$ Con igual postura Salinas (2011, p. 295) y Barros (2006, p. 663).

245 La doctrina en general asume que no puede haber responsabilidad sin daño alguno, en este sentido señala Barros que el daño es condición indispensable y objeto de la responsabilidad civil, lo que conlleva a la diferencia de la responsabilidad penal, dado que para la primera solo resultan trascendentales las conductas si de ellas se deriva un perjuicio para el demandante, pues la sola negligencia no es fuente de responsabilidad (2006, p. 215).

Los hermanos Mazeaud arguyen que “...mientras el individuo no haya sido lesionado, no podrá demandar indemnización. De lo contrario, tropezará con el principio fundamental: donde no hay interés, no hay acción. Mientras no haya una víctima, no se podrá hablar de responsabilidad civil” (2005, p.27)
} 
En general, el daño constituye un menoscabo, lesión o pérdida de un interés legítimamente ${ }^{246}$ protegido, ora patrimonial o extrapatrimonial, que la víctima no está obligada a soportar. En atención a lo cual, se deriva una obligación de reparar para el sujeto dañador ${ }^{247}$.

La Constitución de 1991, en lo correspondiente a la responsabilidad estatal, adicionó al daño la voz "antijurídico" (art. 90), de esta forma se desplaza la acostumbrada antijuridicidad de la causa/hecho al daño, ya que este último puede ser consecuencia de un comportamiento ilícito o lícito $^{248}$ que sobrepasa las cargas públicas tolerables por toda persona ${ }^{249}$.

\footnotetext{
${ }^{246}$ Entiéndase legítimo en el sentido que no va en contra del ordenamiento jurídico ni de los principios que lo gobiernan, no es reprochable ni prohibido ese interés.

${ }^{247}$ En la doctrina se pueden destacar diferentes definiciones de daño, pero en conjunto van orientadas a la aminoración de un bien, derecho, facultad e interés: para Tamayo $(2017$, p. 1) el daño civil indemnizable es el menoscabo o pérdida patrimonial o extrapatrimonial, derivada de la lesión a las facultades jurídicas que tiene una persona para disfrutar de un bien patrimonial (económico) o extrapatrimonial (no económico) ese daño es indemnizable cuando en forma lícita es causado por alguien diferente de la víctima.

Henao (2015, p. 280) define daño como "toda afrenta a los intereses lícitos de una persona, trátese de derechos pecuniarios o de no pecuniarios, de derechos individuales o de colectivos, que se presenta como lesión definitiva de un derecho o como alteración de su goce pacífico y que, gracias a la posibilidad de accionar judicialmente, es objeto de reparación si los otros requisitos de la responsabilidad civil -imputación y fundamento del deber de reparar- se encuentran reunidos".
}

De Cupis aludía que daño no es más "que nocimiento o perjuicio, es decir, aminoración o alteración de una situación favorable" (1975, p. 81).

Sobre el particular la Corte Suprema de Justicia recientemente expresó que el daño es "todo detrimento, menoscabo o deterioro, que afecta bienes e intereses lícitos de la víctima, vinculados con su patrimonio, con su esfera espiritual o afectiva, o con los bienes de la personalidad" (Sentencia SC5516-2016 de 29/04/2016).

${ }^{248}$ Sobre el concepto de daño antijurídico, al no estar expresamente definido por la Constitución, la Corte Constitucional dispuso que: “...la fuente de la responsabilidad patrimonial del Estado es un daño que debe ser antijurídico, no porque la conducta del autor sea contraria al derecho, sino porque el sujeto que lo sufre no tiene el deber jurídico de soportar el perjuicio, por lo cual éste se reputa indemnizable. Esto significa obviamente que no todo perjuicio debe ser reparado porque puede no ser antijurídico, y para saberlo será suficiente acudir a los elementos del propio daño, que puede contener causales de justificación que hacen que la persona tenga que soportarlo" (Sentencia C-333-1996 de 01/08/1996).

El Consejo de Estado en su jurisprudencia ha concluido que el daño antijurídico es el que ha sido causado o provocado a una persona que no tiene el deber jurídico de soportarlo, "[d]e esta manera, con observancia de que para dilucidar la antijuridicidad del menoscabo ya no se impone verificar la conducta adoptada por la entidad estatal a la que se le desea atribuir, sino que para ello se debe revisar si el ordenamiento jurídico le impuso a la víctima la carga de padecerlo" (Sentencia de 08/06/2017, exp. 2007-02596-01(50352)).

${ }^{249}$ En el ámbito de la responsabilidad civil algunos autores han hecho estudios sobre la posibilidad de ubicar la antijuridicidad en el daño y lo relacionan con el daño injustamente sufrido. Otros doctrinantes, como un juicio de desvalor del resultado y asimismo, un sector no comparte la antijuridicidad adicionada al daño. Sobre el asunto se puede consultar De Ángel (1993, pp. 258-263), Busto (1998), Diez-Picazo (1999, pp. 290-298), Zannoni (2005, pp. 4-10) y Reglero (2006, pp. 71-75).

En la reglamentación civil colombiana no está consagrada la antijuridicidad como presupuesto de responsabilidad, y dado que la obligación de reparar puede originarse por un hecho lícito o no prohibido por las normas, decaería el juicio de antijuridicidad. Sin embargo, Rojas encuentra a la antijuridicidad como un principio fundamentador de la acción de responsabilidad, a partir de la cual se compone su estructura, al haber un sujeto transgredido el deber de no dañar a otro se le impone el deber de rectificar dicha transgresión a través de una indemnización (2014, p. 93). Tamayo ubica la antijuridicidad en la conducta al afirmar que el daño es indemnizable cuando "...en forma ilícita es causado por 
El diario vivir en su interacción social, como apunta De Cupis (1975), puede desencadenar una serie de eventos adversos que causan daños, pero no todo daño adquiere relevancia jurídica o una reacción reprochable del derecho que apareje una reparación (p. 81). Así, unos quedan en el plano de las molestias y contrariedades del curso de la vida que hay que asumir o sobrellevar.

Resulta ser una tarea espinosa para el derecho determinar el daño reparable -jurídico o indemnizable-, al tener que establecer criterios de valoración y discriminación, principalmente por parte del legislador. O bien sea, por la jurisprudencia cuando el sistema de daños es abierto o atípico como en Colombia respecto de los daños inmateriales, y por tanto, le corresponde a los jueces fijar las categorías conforme a las pruebas presentadas, a fin de que queden reparados todos los efectos perjudiciales de la conducta dañosa ${ }^{250}$.

La respuesta jurídica debe ir orientada a garantizar el respeto y la prevalencia de ciertos intereses que son significativos para la persona, la sociedad y la vida en comunidad ante conductas que ocasionan la pérdida o limitación en el goce y disfrute de aquellos. Mas, es necesaria la prudencia para evitar enriquecimientos injustos o desprotección de intereses legítimos. En resumen, es válido afirmar que "lo que el derecho tutela, el daño vulnera" (De Cupis, 1975, p. 109).

Por otra parte, el daño reparable, como lo ha sostenido la jurisprudencia colombiana, debe ser directo como consecuencia de la culpa o del hecho dañoso y cierto, de forma tal que no exista duda de que es real y ha sido efectivamente causado. No se requiere que el daño sea actual, dado

alguien diferente" (2017, p. 1), y ese hecho ilícito puede consistir en el incumplimiento contractual, desconocimiento de obligaciones legales, cuasicontractuales o del deber general de prudencia (2007, p. 8).

${ }^{250}$ En general, la labor demarcatoria de los límites y clasificación de los daños es asumida por las Altas Cortes como órganos de cierre jurisdiccional, que dictan el precedente judicial vinculante para permitir mayor seguridad jurídica e igualdad ante la ley: "[r]econocerle fuerza vinculante a la jurisprudencia sentada por la Corte Constitucional, la Corte Suprema de Justicia, el Consejo de Estado y la Sala Disciplinaria del Consejo Superior de la Judicatura, redunda en una mayor coherencia del sistema jurídico colombiano, lo cual no se contradice con imperativos de adaptación a los cambios sociales y económicos ... La fuerza vinculante de las decisiones de las denominadas altas cortes surge de su definición constitucional como órganos jurisdiccionales de cierre, condición que les impone el deber de unificación jurisprudencial en sus respectivas jurisdicciones. El mandato de unificación jurisprudencial, únicamente dirigido a las cortes jurisdiccionales de cierre, se erige en una orden específica del Constituyente para brindar cierta uniformidad a la interpretación y aplicación judicial del derecho en desarrollo del deber de igualdad de trato debido a las personas, mediante la fuerza vinculante de sus decisiones judiciales superiores" (Corte Constitucional, sentencia C-621-2015 de 30/09/2015). No obstante, los jueces tienen la facultad de apartase del precedente, decisión que debe estar motivada. 
que es resarcible el daño futuro del que se verifique su certidumbre y sea susceptible de evaluación al momento en que se solicita su reconocimiento, pues no es reparable el perjuicio hipotético o eventual:

...para que sea reparable, debe ser inequívoco, real y no eventual o hipotético. Es decir, “(...) cierto y no puramente conjetural, [por cuanto] (...) no basta afirmarlo, puesto que es absolutamente imperativo que se acredite procesalmente con los medios de convicción regular y oportunamente decretados y arrimados al plenario (...)”. (Corte Suprema de Justicia, sentencia SC2107-2018 de 12/06/2018) ${ }^{251}$

\subsubsection{Sobre la sinonimia de daño y perjuicio}

Definir el daño y los criterios para darle la relevancia jurídica hizo que una parte de la doctrina avocara por la diferencia entre los vocablos daño y perjuicio, al indicar que el primero consistía en la lesión del bien protegido, es decir, daño-evento, mientras que, el perjuicio sería el efecto negativo de dicho hecho o sea daño-consecuencia. Hogaño, tal distinción, carece de sustento legal en Colombia, perdió fuerza y se utilizan indiscriminadamente ${ }^{252}$, incluso en la jurisprudencia local $^{253}$ y extranjera.

\footnotetext{
${ }^{251}$ Sobre el tema de la certidumbre del daño se pueden revisar las sentencias de la Corte Suprema de Justicia SC204482017 de 12/06/2018 y SC16690-2016 de 17/11/2016.

${ }^{252}$ En Colombia actualmente es partidario de la distinción Polanía (2017) quien argumenta que “...si el daño tiene consecuencias en la esfera material del sujeto, dicha consecuencia es el perjuicio y es lo que se repara, es aquello por lo que responde el agente. Si el daño recae en la esfera inmaterial del sujeto, es decir, aquella en la que se agrupan bienes jurídicos sin contenido económico, imposible de amonedar, lo que se repara es el daño en sí mismo" (p. 56). En su obra Rojas (2015) alude al daño-evento y al daño-consecuencia e indica que lo reparable son las repercusiones desfavorables de la lesión al interés tutelado (p.182), así el daño a la persona dice que es un daño evento que permite determinar si existe o no responsabilidad civil y los perjuicios resultantes como daños consecuenciales o partidas que se deben indemnizar, es decir, atañen al monto que se debe indemnizar (pp. 202-206).

De los tratadistas más reconocidos que abogaban por la diferencia estaba Juan Carlos Henao. Con todo, en su escrito de 2015 no se alude a la misma y asimismo en el Encuentro Internacional de Responsabilidad Civil -Iarce 2017expuso que la distinción es útil, pero no necesaria y por eso actualmente los toma como sinónimos.

${ }^{253}$ De forma reciente el Consejo de Estado invocó la distinción entre daño y perjuicio y fijó que “....si la transgresión no trasciende, afecta o aminora intereses ajenos, no será posible reconocer indemnización alguna, pues lo que se repara no es el daño per se, sino las consecuencias que de él se derivan, o lo que es lo mismo, los perjuicios" (Sentencia de 17/09/2018, exp. 2009-01012-01(45902)).

La Corte Suprema de Justicia cercanamente abogó por la diferencia entre los términos como se observa en la sentencia SC2107-2018 de 12/06/2018. No obstante, en la providencia SC5686-2018 de 19/12/2018 parece que entrelíneas no hubiese distinción entre los conceptos daño y perjuicio como cuando indiscriminadamente se refiere a daño moral o perjuicio moral. Pero, en otro aparte este proveído señala que “...pues no es la trasgresión (hecho dañoso) en sí misma
} 
El presente trabajo investigativo respeta, pero no comparte las diversas posturas sobre el dañoevento y daño-consecuencia (perjuicio). Al estudiar a fondo los diversos planteamientos en la órbita de los daños morales por violación a los derechos de la personalidad, el sustento decae en imprecisiones insostenibles, al no poder identificar las repercusiones de dicha lesión. En estos supuestos, se tiende a argumentar que la carga probatoria se flexibiliza al poder predecir la realidad de un daño resarcible ante la "modificación disvaliosa del espíritu" (Pizarro, 1996, p. 48) ${ }^{254}$ o que por sí solos son un daño (Polanía, 2017, p. 56).

Luego, se observa más una cuestión descriptiva en búsqueda de justificar la función reparadora de la responsabilidad y no decaer en la sancionadora. Por tanto, su aplicación práctica cae en contrariedades que, al final de cuentas, terminan descalificando la lesión a los atributos de la personalidad en sí misma considerada.

Por consiguiente, para evitar confusiones terminológicas, y dado que su significado gramatical no los diversifica, se utilizan en esta pesquisa como sinonimia daño y perjuicio. Además de irrelevante la distinción, en materia de daños por vulneración de derechos no siempre, como se va a continuación, las consecuencias son palpables con raigambre probatoria.

\subsubsection{Del daño y su clasificación}

De la definición del daño presentada se desprenden dos arquetipos relacionados con el tipo de interés al que afectan: patrimonial y extrapatrimonial.

\footnotetext{
lo que se indemniza o sanciona a modo de daño punitivo, sino la lesión antijurídica acreditada y derivada de esa vulneración (lo que propiamente se ha dado en llamar perjuicio)".

La Superintendencia de Industria y Comercio en sentencia 1600 de 27/12/2018 a través de la Delegatura para asuntos jurisdiccionales al resolver un caso sobre propiedad industrial, precisó que la postura actual de la entidad es la necesaria diferencia entre daño y perjuicio.

${ }^{254}$ En similares términos Mosset (1999, p. 53) que alude al estado de equilibrio espiritual de la persona que a raíz de la lesión de los bienes más precipuos genera una modificación disvaliosa del espíritu que no corresponde exclusivamente al dolor, incluye la preocupación, irritación vivencial u otras alteraciones que quiebran el equilibrio. Zavala (2011) afirma que “... se proyecta más allá de lo que el sujeto realmente piensa, quiere o siente, para comprender la lesión a cualquier aspecto de lo que vive, en su proyección hacia valores e intereses, capte o no conscientemente la minoración vital. La materia resarcible no versa entonces sobre los objetivos sociales malogrados, sino en tanto ese menoscabo repercute negativamente en la subjetividad del lesionado, dando origen a un defecto existencial en comparación con la situación precedente al hecho" (p. 25).
} 


\subsubsection{Daño patrimonial}

El daño patrimonial o material se orienta a las afectaciones en el patrimonio, es decir, a las consecuencias económicas lesivas. Se traduce en una disminución del activo patrimonial (daño emergente) o en el truncamiento de que el activo aumente (Barros, 2006, p. 231), es decir, ganancias o ingresos esperados que de no ser por el hecho ocurrido se hubiesen presentado (lucro cesante). Por tal razón, es susceptible de valoración pecuniaria el detrimento económico a efectos de establecer la reparación ${ }^{255}$.

El daño emergente está conformado por las sumas de dinero que la víctima asume para atender las consecuencias directas del menoscabo sufrido. Tratándose de responsabilidad médica, lo constituye los gastos generados para atender las lesiones físicas o psíquicas del dañado (Corte Suprema de Justicia, sentencia 04/08/2014, SC10261-2014).

En cuanto al concepto de lucro cesante, extrapolado a la responsabilidad médica, engloba las ganancias, provechos o lo que ha dejado de reportarse en el patrimonio de la víctima “...en su aspecto físico o emocional en cuanto a la productividad que por la lesión originada en la actuación clínica se vio disminuida" (Corte Suprema de Justicia, sentencia 04/08/2014, SC10261-2014).

\subsubsection{Daño extrapatrimonial}

El daño trasciende la esfera material, no son necesarias solo secuelas económicas determinables para predicar su alcance jurídico. De hecho, el daño cobija también el ámbito inmaterial-moral de la persona.

La tipología del daño extrapatrimonial no ha sido pacífica, al generar divergentes conceptualizaciones y complejas discusiones jurídicas en torno a la identificación, la extensión, el contenido y la forma de reparación. Por eso, es una de las cuestiones, como alude Llamas (2011), que a pesar de los años sigue siendo una asignatura pendiente del derecho (p. 1).

\footnotetext{
${ }^{255}$ En otras palabras, los daños patrimoniales son daños reemplazables por un equivalente económico cuando su reparación no se puede hacer in natura (Gómez, 2015, p. 36).
} 
El daño extrapatrimonial también es conocido como moral o inmaterial. Se resalta que, fue catalogado desde sus inicios bajo la rúbrica del daño moral, para enmarcar el precio del dolor pretium doloris- al cobijar todo perjuicio que quedaba por fuera de lo patrimonial, orientándose a la persona y su interioridad. En Colombia, el daño moral tuvo como punto de partida la célebre sentencia del caso León F. Villaveces de 21/07/1922256.

Desde esa época hasta el presente, el daño no patrimonial se ha arropado en diferentes categorías autónomas, ya no exclusivamente el pretium doloris desde la órbita del daño moral, debido que, se han acogido nociones de daño como a la salud o fisiológico-biológico, sexual, estético, vida de relación, al proyecto de vida o a los derechos de la personalidad. Por tanto, esta investigación se refiere al daño extrapatrimonial como el género que aloja en sus postulados unos daños específicos.

La multiplicidad de conceptos ha dado pie a que en ocasiones se reparen dos o más veces un mismo daño con denominaciones diferentes. Es decir, se ampara en varias oportunidades el mismo interés protegido, en contravía de los postulados de justicia, equidad y reparación integral, al no diferenciarse plenamente su vertebración.

De hecho, ante la protección integral de la persona se ha llegado a aseverar que "...cada bien lesionado constituye un daño con entidad propia" (Tamayo, 2017, p. 3). Con esto, se puede generar indemnizaciones insostenibles y llevaría más que a una indemnización para la víctima, a un lucro descomedido con efectos perjudiciales injustos para el dañador.

Luego, debe optarse por una postura que englobe las diversas manifestaciones del daño y evite un desbordamiento del daño extrapatrimonial, en vista que entre más discriminaciones del daño se corre el riesgo de dobles reparaciones.

\footnotetext{
${ }^{256}$ En la sentencia la Corte Suprema de Justicia ordenó la reparación de daños morales causados al demandante a raíz de la exhumación no autorizada de los restos mortales de su cónyuge, lo que sustentó con los siguientes argumentos: "[t]anto se puede dañar a un individuo menoscabando su hacienda, como infligiéndole ofensa en su honra o en su dignidad personal o causándole dolor o molestia por obra de malicia o negligencia en el agente. En el caso que se estudia, al demandante Villaveces por el solo hecho de la extracción indebida de los restos de su esposa que él tenía depositados en una bóveda de su propiedad, se le infirió por culpa de los empleados del Municipio un daño moral que debe ser reparado, a la luz de los artículos 2341 y 2356 del Código Civil” (cursiva fuera de texto).
} 
A guisa de ilustración: ante una intervención médica negligente del que se derivan secuelas físicas para el paciente, se le otorga una indemnización correspondiente al daño moral por el dolor causado. Pero, al mismo tiempo, se podría encuadrar una indemnización independiente que cobije el derecho a la integridad y a la dignidad, al verse lesionados por el médico que no cumplió los protocolos de atención, lo que evidentemente se relaciona con una doble reparación.

Para mayor abundamiento, en un supuesto decidido por el Consejo de Estado (Sentencia de 28/08/2014, exp. 2001-00278-01 (28804)), no parece clara la franja demarcatoria de las categorías de los daños extrapatrimoniales - moral y a la salud-, cuando justifica su reparación y alcance como resultado de fallas en la atención médica a una madre gestante, del cual siguió una intervención cesaría prematura ante la muerte del bebé. En lo que respecta a los daños morales, se reconocieron a la madre y al padre, justificado a este último en la muerte de su hija y al tener que contemplar el sufrimiento físico y moral de su pareja.

En cuanto al daño a la salud, esa Corporación expuso:

...fue sometida a una cesárea innecesaria, con el consecuente aumento del riesgo, así como de las complicaciones propias de la convalecencia posquirúrgico. Así mismo, se infiere que la realización de la cesárea ocasionó necesariamente a la mencionada señora una cicatriz que no se habría causado en un parto natural. Adicionalmente, se tiene conocimiento de que la señora ... padeció alteraciones del ánimo que de ordinario se presentan, en los primeros años después del deceso fetal, aunque susceptibles de mejora paulatina. Finalmente, como se dijo ad supra se acepta los hechos traumáticos descritos en el fallo tienen aptitud de incidir negativamente en las posibilidades de maternidad y las condiciones de los embarazos futuros de la actora ... en la medida en que consta que el señor [padre de la criatura] ... padeció alteraciones emocionales con manifestaciones somáticas, se le ha de reconocer una indemnización por daño a la salud. (subraya fuera de texto)

Sobre la evidente indefinición del daño extrapatrimonial, Díez-Picazo y Arana (2009) aseguran que se ha propiciado un ensanchamiento de los presupuestos de la responsabilidad para ampliar el concepto de daños resarcibles, con una clara agudización del principio pro damnato y con 
fundamento en la regla general de la reparación de todos los daños y la excepcionalidad que el dañado quede solo frente al daño (p. 19).

En el mismo sentido, el doctrinante Díez-Picazo (2008-I, pp. 13-15) observa una deformación del concepto de daño moral, que, si antes no estaba clara, al presente se ha confundido mucho más, al utilizarse como comodín para justificar todo tipo de daño como merecedor de reparación. Luego, en búsqueda de ideales de justicia se ha terminado por proyectar una ligereza desmedida de reparaciones, que en el curso de los días sigue sin detenerse.

Pese a todo, y sin ser hacer una presentación de cada una de las tesis surgidas en cuanto al tema del daño extrapatrimonial ${ }^{257}$, en esta investigación se acoge una postura que simplifica las contrariedades de este daño y limita la expansión, para no caer en el fatal traspié jurídico de dobles indemnizaciones de un mismo perjuicio con el ropaje de diferentes conceptos de daños. Una adecuada caracterización del daño permite establecer sus alcances y facilita la tarea del juez a la hora de buscar la solución a un caso particular (Pizarro, 1996, p. 35).

Así, el daño extrapatrimonial es el perjuicio a la persona, en donde se afectan sus intereses inmateriales, está por fuera de la esfera patrimonial y no es viable su cuantificación económica a través de un equivalente, de acuerdo con una referencia de valor en el mercado (Casals, 2003, p.858). De manera que, le corresponde al juez de la causa definir prudencial y congruentemente la medida para su reparación -arbitrium judicis-.

De los daños extrapatrimoniales se pueden distinguir, según Casals (1990, p. 1234), dos aspectos, a saber:

a) Interno (moral): comprende las afectaciones a la esfera interna de la persona que se manifiestan en sensaciones como el dolor físico, efectos psicológicos o sufrimientos morales, como la angustia, aflicción, desosiego, preocupación, depresión o tristeza, el usual pretium doloris.

\footnotetext{
${ }^{257}$ El desarrollo en Colombia y su visión actual es un tema de gran interés y asimismo amplitud, pero su presentación no encuadra en el objetivo de la presente investigación. No obstante, sobre esto se puede consultar Tamayo, Botero, Polanía y Rojas (2017), M’Causland (2015), Rojas (2015), Koteich (2012) y M’Causland (2008).
} 
Asimismo, alcanza las lesiones a los valores más íntimos de la persona -sus derechos- como la libertad, dignidad, honor, intimidad.

b) Externo (vida de relación): abarca la lesión en el aspecto externo del individuo y se concreta en la disminución o alteración negativa de la relación con el mundo exterior. La Corte Suprema de Justicia lo designa daño a la vida de relación, es decir, la privación, limitación o dificultad de desarrollar actividades placenteras de las que el perjudicado disfrutaba antes del infortunio y que hacían más agradable su existencia ${ }^{258}$.

Esta clasificación no se orienta hacia una visión restringida de los daños a los intereses inmateriales, basada tan solo en los sufrimientos psicofísicos causados, dado que atiende la protección integral de la persona, es decir, su proyección interna y externa. También, evita caer en un sinnúmero de reparaciones que no serían otra cosa que supuestos que integran el contenido genérico del daño moral o la vida de relación.

Es importante aclarar que no debe confundirse el daño moral con sus posibles repercusiones o formas de exteriorización, las cuales resultan contingentes. Este daño no se limita a las afectaciones del bienestar psicofísico, dado que puede no haber lágrimas ni manifestación del dolor e incluso que la víctima del daño no se encuentre en condiciones físicas o psíquicas para percibir la afectación por ejemplo ante un estado vegetativo o muerte cerebral, y sin embargo, se concrete un daño moral (Pizarro, 1996, p. 128) ${ }^{259}$.

\footnotetext{
${ }^{258}$ La Corte Suprema define el daño a la vida de relación como “....un menoscabo que se evidencia en los sufrimientos por la relación externa de la persona, debido a «disminución o deterioro de la calidad de vida de la víctima, en la pérdida o dificultad de establecer contacto o relacionarse con las personas y cosas, en orden a disfrutar de una existencia corriente, como también en la privación que padece el afectado para desplegar las más elementales conductas que en forma cotidiana o habitual marcan su realidad»... Es así como de un momento a otro la víctima encontrará injustificadamente en su camino obstáculos, preocupaciones y vicisitudes que antes no tenía, lo que cierra o entorpece su acceso a la cultura, al placer, a la comunicación, al entretenimiento, a la ciencia, al desarrollo y, en fin, a todo lo que supone una existencia normal, con las correlativas insatisfacciones, frustraciones y profundo malestar ... la afectación de la vida social no patrimonial de la persona" (Sentencia SC22036-2017 de 19/12/2017).

“.. es una noción que debe ser entendida dentro de los precisos límites y perfiles enunciados, como un daño autónomo que se refleja en la afectación de la actividad social no patrimonial de la persona, vista en sentido amplio, sin que pueda pensarse que se trata de una categoría que absorbe, excluye o descarta el reconocimiento de otras clases de daño -patrimonial o extrapatrimonial- que posean alcance y contenido disímil, ni confundirlo con éstos, como si se tratara de una inaceptable amalgama de conceptos, puesto que una indebida interpretación conduciría a que no pudiera cumplirse con la reparación integral ordenada por la ley y la equidad" (Corte Suprema de Justicia, sentencia 13/05/2008, exp. 1997-09327-01).

${ }^{259}$ Sobre este mismo punto Zavala (2011, p. 25) y Zannoni (2005, p. 153).
} 
Entonces, el mismo disvalor del agravio a la persona constituye el daño moral que "...no se mide solo, ni fundamentalmente, por las repercusiones que contiene, sino por el menosprecio que la actividad dañosa en sí misma denota a la persona... y se estima en razón de la entidad del interés no patrimonial lesionado" (Zannoni, 2005, p. 156) ${ }^{260}$.

Además, las personas no expresan ni experimentan el dolor de igual forma, por eso no es viable exigir en todos los casos su exteriorización y prueba. En algunos escenarios, el daño moral debe presumirse por la perturbación del interés perjudicado, fluye directa y naturalmente por las circunstancias, lo que se corrobora en razón a las reglas de la experiencia o vivencia del hombre, como sucede con la muerte de un pariente cercano, la lesión al honor, a la intimidad, al buen nombre, a la autodeterminación, a la integridad o la privación de la libertad.

Esencialmente, la idea es que el daño moral en esos contextos se infiere in re ipsa, el hecho lesionador constituye la prueba luminosa de su causación ${ }^{261}$. Esto, respaldado en tanto a la precisa imposibilidad objetiva de probar el daño moral en todos los supuestos, lo que resulta inherente a la naturaleza de este tipo de daño. En atención a lo cual, su valoración está en manos del juez a través de su prudencia y buen juicio (De Cupis, 1975, p. 557).

\footnotetext{
${ }^{260}$ En esta postura se encuentra en Colombia Tamayo (2017) e incluso Polanía cuando, a pesar de la distinción entre daño y perjuicio, asegura que en la esfera inmaterial es impropio hablar de perjuicio y lo que se repara es el daño en sí mismo al recaer sobre la esfera interna de la persona, imposible de acreditar en forma directa, por ello "la existencia del daño, por regla general, se presume con base en hechos probados, como del parentesco acreditado se deriva el padecimiento moral" (2017, p. 39).

En contra de este planteamiento Rojas (2015) quien propugna la reparación de las consecuencias del daño, y tradicionalmente en España se destaca Diez-Picazo (1999): el “...daño moral debe reducirse al sufrimiento o perturbación de carácter psicofísico en el ámbito de la persona, sin proceder al respecto a concepciones extensivas, en las que la indemnización carece de justificación" (p. 328).

${ }^{261}$ Sobre el tema la Corte Suprema de Justicia ha venido afirmando que "[1]a cuestión es que la lesión inferida a la interioridad del sujeto, es inasible e inconmensurable, concierne a las condiciones singulares de la persona, a su sensibilidad, sensaciones, sentimientos, capacidad de sufrimiento y no admite medición exacta e inflexible, desde luego que el sujeto experimenta un menoscabo no retroaible (sic) y el dolor deviene irreversible, cuya existencia se considera en ciertas hipótesis señaladas por la jurisprudencia in re ipsa y cuya valoración se efectúa ex post sin permitir la absoluta reconstrucción del status quo ante" (Sentencia 17/11/2011, exp. 1999-00533-01). En la sentencia más reciente sobre el daño moral se puntualizó por la Corte Suprema de Justicia que: "[d]e tal modo que, ante la imposibilidad de una prueba directa y de precisar con certidumbre absoluta si existe o no y en qué grado el dolor, congoja, pánico, padecimiento, humillación, ultraje y en fin, el menoscabo espiritual de los derechos inherentes a la persona de la víctima, como consecuencia del hecho lesivo, opta válidamente el juez por atender a esas particularidades del caso e inferir no sólo la causación del perjuicio sino su gravedad. Es que el daño moral se manifiesta in re ipsa, es decir, por las circunstancias del hecho y la condición del afectado" (Sentencia SC5686-2018 de 19/12/2018).
} 


\subsubsection{Análisis del daño al consentimiento informado con independencia de la corrección técnica del acto médico}

Como se ha apuntado a lo largo de la investigación, la persona es inviolable. Un atentado a su derecho a decidir sobre su cuerpo, su vida y su salud constituye una agresión a los atributos de la personalidad y una instrumentalización del paciente en contravía de la dignidad humana (Corte Constitucional, Sentencia T-059-2018 de 22/02/2018).

De esta forma, el desconocimiento total o parcial del consentimiento informado afecta a la persona desde su proyección interna, al lesionar un derecho esencial para el desarrollo de su dignidad y libertad. Su omisión, al margen de que el acto médico a nivel técnico y/o la asistencia sanitaria haya sido correcto o no, constituye un $\underline{\text { daño moral autónomo }}{ }^{262}$, cuya existencia deviene in re ipsa.

Con anterioridad, se concretó que el daño moral no solo abarca el pretium doloris, por cuanto la esfera interna de la persona abriga sus derechos como fines en sí mismos que se involucran con su propia personalidad. Por ello, se resarce el ataque a ese atributo intangible en consideración a su naturaleza y los fines que proyectan (Zanonni, 2005, p. 155).

Igualmente, en algunos supuestos de intereses extrapatrimoniales es factible hacer presunciones de hombre por la materia lesionada y la imposibilidad objetiva de su prueba, que llevan a que per se constituyan un daño reparable, tal como ocurre con el desconocimiento del derecho al consentimiento informado en el ámbito sanitario.

\footnotetext{
${ }^{262}$ Como partidarios del daño moral autónomo al afectarse la autodeterminación del paciente en la doctrina se pueden leer: Fernández y Woolcott (2018-I, pp. 592-593 y 644-645), Cadenas (2018, pp. 346-350), Agón (2016, p. 367-376), Garay (2014, pp. 732-734), Giraldo (2013, p.713), Pelayo (2009, p. 146) y Zaplana (2004, p. 204-226).

Gallego ubica la lesión de la autodeterminación como gestante de un daño extrapatrimonial independiente, no encuadra dentro del daño moral porque "[e]n la clasificación a los daños extrapatrimoniales, el daño moral a pesar de ser un daño a la persona, es un daño a la parte afectiva del ser, caracterizado por el dolor físico y psíquico y no tiene nada que ver con un daño a la libertad, donde se atenta contra un derecho fundamental" (2015, p. 151), esto deviene de la concepción del daño moral solo desde el pretium doloris.

Vázquez (2002) explica que la lesión recae sobre un derecho de la personalidad que es la autodeterminación del paciente, y es esta precisamente la que se indemniza no el resultado final sufrido por el paciente a causa del tratamiento. En la indemnización este autor apunta que debe evaluarse cuál hubiese sido la decisión del paciente (p. 48), lo que entonces en el fondo sería un análisis desde la pérdida de la oportunidad.
} 
El quebrantamiento al consentimiento informado no se trata de una mera molestia que debe tolerarse. Exige, en virtud de su naturaleza, una mirada a la dimensión y gravedad del menoscabo del cual ha sido objeto, si se tiene en cuenta que es un derecho que protege la libertad de decisión sobre aspectos fundamentales de la persona, lo que lo posiciona como relevante y por ende, constituya un daño jurídico reparable ${ }^{263}$.

El fundamento de la reparación por daño moral se basa en la invasión de la existencia de una persona desde la órbita de actuar y decidir por ella, esa libertad ontológica junto con la unidad psicosomática es el “...núcleo existencial de la persona, su propio ser” (Fenández y Woolcott, 2018-I, p. 645) $)^{264}$.

Todo esto, se analiza al margen de la corrección de la conducta del profesional de la salud respecto al acto médico desarrollado, es decir, si se siguieron o no los estándares técnicoscientíficos. Debido a que, lo reprochable es el irrespeto al derecho del paciente a decidir informadamente, como interés autónomo protegido de carácter extrapatrimonial que genera un daño moral.

Aunque la praxis médica correcta requiere en conjunto de la observación de la lex artis desde el aspecto técnico como de las reglas éticas del ejercicio de la profesión, en donde se matricula el consentimiento informado, ambos aspectos constituyen deberes sustantivos de la atención sanitaria.

Incluso, el consentimiento informado no libera la responsabilidad por errores o fallas en la asistencia médica y de la misma forma, a pesar de un buen procedimiento médico la omisión del consentimiento informado se verifica en sí misma como un daño con entidad propia ${ }^{265} \mathrm{o}$, a mejor decir, autónomo.

\footnotetext{
${ }^{263}$ En los Principios de Derecho Europeo de la Responsabilidad Civil (Principles of European Group on Tort LawPETL) figuran la vida, la integridad física y psíquica, la dignidad humana y la libertad como intereses cuya protección es más amplia (art. 2:102), lo que indica que todos los intereses no se protegen de la misma forma, dependen de su naturaleza y “...su protección será más amplia cuanto mayor sea su valor, la precisión de su definición y su obviedad” (art. 2:101).

${ }^{264}$ En igual sentido Alonso (2000, p. 42) y Arcos (2007, p. 65) y Giraldo (2013).

${ }^{265}$ Postura igual es sugerida por Jaramillo (2002, p. 228).
} 
Ahora bien, estos deberes son independientes pero compatibles para ser indemnizados en un mismo juicio de responsabilidad, en el sentido que, ante una negligencia médica antecedida de una falta de consentimiento informado, los daños físicos se indemnizarían como consecuencia del primer supuesto y el moral derivado del segundo (Arcos, 2007, p. 65), que puede aumentar el monto indemnizatorio en virtud del pretium doloris por la afectación psicofísica del procedimiento haya causado.

\subsubsection{El consentimiento informado como daño moral autónomo}

En correspondencia con la definición de daño extrapatrimonial, más exactamente la manifestación como daño moral, y no compartirse la distinción entre daño-evento y perjuicio como daño-consecuencia, el daño moral por omisión del consentimiento informado del paciente se constituye ante la lesión del interés protegido, que por su relevancia en la esfera de la persona hace presumir la afectación, sin más exigencia.

De tal modo, demandar la prueba de efectos directos para que el daño por omisión del consentimiento informado sea resarcible, contradice la materia del interés extrapatrimonial protegido. La exteriorización de dolor, rabia, frustración, incomodidad, impotencia o desosiego por ser privado de la libertad de decidir serían posibles expresiones, pero que no se lograrían percibir y demostrar fehacientemente en todos los juicios.

En efecto, la lesión al derecho de tomar decisiones es tan íntima y el menosprecio que de ella se deriva se puede vivir de diferentes formas en cada persona dependiendo de sus convicciones, creencias, sensibilidad e ideologías, por ello su prueba puede representar una imposibilidad jurídica. De ahí que, no exista controversia que el daño moral, desde la órbita del pretium doloris, se pueda reconocer aun a personas que no estén en condiciones físicas o psíquicas para captar y experimentar materialmente el agravio, de lo cual, como se expuso, son partidarios incluso defensores del daño-consecuencia. 
No obstante, esas posibles formas de percibirse el daño moral podrán ser condiciones o instrumentos a tener en cuenta por parte del juez en la valoración del daño, para establecer la entidad que debe resarcirse como se detalla más adelante.

Por otro lado, no es correcto identificar el daño por omitir el consentimiento informado del paciente desde las repercusiones a la vida o a la salud que el acto médico no consentido o con defectos en la información ocasionaron en el paciente, propugnando por un nexo causal entre esas consecuencias y la omisión del consentimiento informado ${ }^{266}$.

Pues bien, este daño no requiere para su reconocimiento que se cristalice un resultado final adverso del acto médico en donde falló el consentimiento informado. Basta el desconocimiento del derecho a ser informado y decidir. De no ser así, se desconfigura la relación causal indispensable en toda responsabilidad. En efecto, las secuelas (lesiones corporales o muerte) no son fruto físico y mediato, desde la causalidad fáctica ${ }^{267}$, de la desatención del consentimiento informado. Son, desde luego, consecuencia directa del acto médico realizado.

266 Ribot apunta por la indemnización del daño moral por violación a la autonomía, pero con ciertas reservas en el sentido que, es procedente solo cuando el tratamiento médico no consentido ha causado secuelas, mientras que en los supuestos en que el tratamiento es satisfactorio, pero hubo fallas en la información, no sería viable la responsabilidad civil (2007, p. 60-62).

De la obra de Lorenzetti (2016) se desprende la omisión del consentimiento informado como una lesión autónoma por violar la libertad y en tanto, suficiente para generar responsabilidad, que adquiere relevancia cuando se han concretado los riesgos de la intervención. Pero, este autor para la determinación del perjuicio sugiere lo siguiente: "[e]n cuanto al nexo causal, la víctima debe demostrar que el daño proviene de un riesgo que debió ser avisado. Si el peligro hubiera sido advertido, la víctima no se habría sometido al tratamiento y el daño no hubiera ocurrido" (p. 293), lo que entonces vendría, a ciencia cierta, a ser un perjuicio desde la pérdida de la oportunidad. Lastimosamente, el doctrinante no profundiza sobre ello.

${ }^{267}$ La Corte Suprema de Justicia consideró, desde una perspectiva de la teoría de la causalidad adecuada, la bifurcación del estudio de la relación causal: causalidad material y la jurídica, lo que se comparte en la investigación, sin entrar en consideraciones sobre de los nuevos conceptos empleados por la Corte respecto al elemento causal (imputación jurídica-normativa).

En el tema, la Corporación concluyó: “...la relación, nexo o vínculo de causalidad, es el segundo elemento constante de la responsabilidad y consiste en precisar al autor del detrimento, mediante la imputación fáctica, física, material o causal del menoscabo a su conducta, sea por acción, sea por omisión. En una fase ulterior al quebranto y a la imputación material o autoría, es menester determinar el fundamento o justificación del deber de responder para establecer si el sujeto a cuya esfera jurídica se imputa el daño está obligado o no a repararlo.

Tal aspecto, atañe estrictamente a los criterios por los cuales un sujeto es o no responsable de un daño, esto es, a la determinación del deber jurídico de repararlo o, a lo denominado, “imputación jurídica"” (Sentencia de 24/08/2009, exp. 2001-01054-01). 
Entonces, es un error predicar un vínculo causal entre la omisión del consentimiento informado y los riesgos materializados, en virtud de que la causación de estos últimos no depende materialmente del consentimiento, al derivarse de la actuación médica. La decisión del paciente no determina su concreción, pues si el paciente acepta la intervención no está exento que el riesgo previsible ocurra ante la eventualidad del resultado en la medicina.

Un primer momento de análisis ante una omisión del consentimiento y concreción de los riesgos, llevaría a suponer cuál hubiese sido la postura del paciente en caso de haber conocido previamente los riesgos. Empero, la averiguación no generaría certeza en la edificación del hilo causal al realizarse ex post facto, en donde fácilmente puede influir la inconformidad y el rechazo ante la contingencia verificada.

La realización de un juicio contrafáctico, basado en si el evento que se considera como causa no hubiera ocurrido -omisión del consentimiento informado- y el evento que sería el efecto -riesgos materializados- no habría tenido lugar, en los casos de las omisiones se puede quedar sin sostén al analizar la eficacia del incumplimiento, al no tener siempre la certeza de cuál hubiese sido la decisión del paciente.

Por tanto, la prueba en la causalidad por omisión es complicada, al conllevar en muchas ocasiones “...la difícil tarea de establecer un contrafáctico no sobre el mundo físico, sino sobre la conducta humana" (Bárcena, 2012, p.220).

Desde esa óptica, se desprende una incertidumbre causal al especularse sobre causas hipotéticas. De manera que, es válido afirmar que sobre la acción omitida y la cadena causal que hubiere desplegado “... no cabe emitir un juicio de certeza, pues es imposible saber con precisión que hubiera pasado en caso de haberse realizado la conducta omitida ... porque no hay forma de verificarlo" (Serrano, 2012, p. 181). De aplicarse, se buscaría una probabilidad máxima en que se hubiese evitado el resultado, pero es mayoritariamente impracticable.

A este tenor, la causalidad material en los casos de omisión presenta cierta complejidad. De modo que, la explicación y justificación del enunciado causal para el derecho tiene lugar desde la 
consideración de la omisión como concepto normativo, que adquiere sentido cuando la inactividad se examina con referencia a una norma/comportamiento esperado que demandaba un hacer (Goldenberg, 2011, p. 201). Ante lo cual, el derecho tiene la tarea de determinar la relevancia jurídica para la responsabilidad a través de criterios de selección, para establecer las conductas omisivas que generan un daño indemnizable ${ }^{268}$.

En esta perspectiva, la vulneración al consentimiento informado determina una infracción a un deber legal y un desconocimiento de una garantía fundamental, hecho que jurídicamente es causa jurídica relevante que permite atribuir responsabilidad al afectar un interés legítimo. Aunque no se ubique en una norma la responsabilidad por este supuesto, su preeminencia se deriva del análisis sistemático de los fines de un estado social de derecho.

Por consiguiente, la relación causal se establece entre la inobservancia de la obligación de obtener consentimiento informado en la práctica médica y la intromisión y desconocimiento de los derechos de la persona, sin necesidad de aludir a expresiones como sufrimiento o dolor por dicha lesión.

La jurisprudencia del Consejo de Estado ha dado luces respecto a la causa relevante ante la omisión del consentimiento informado, al establecer su autonomía como daño moral con fundamento en la lesión de los derechos de la personalidad ${ }^{269}$ :

\footnotetext{
${ }^{268}$ Bárcena explica que las normas jurídicas determinan criterios de selección de la causa relevante para efectos de atribución de responsabilidad en dos momentos distintos: causalidad fáctica y causalidad jurídica. En la primera etapa se alude a cuestiones empíricas y a normativas, en este sentido las normas jurídicas permiten construir "las causas y los efectos de contraste indispensables para aplicar de forma adecuada cualquiera de los test causales. Y por otro lado, las normas también establecen pautas para llevar a cabo la selección ... si la causa ha pasado el primer proceso de selección, debe ser sometida a otro filtro en el ámbito de la «causalidad jurídica» que culmina con la selección definitiva. La causa que pasa este segundo filtro es la causa relevante para atribuir responsabilidad a un agente en un determinado contexto jurídico. Para realizar dicha selección aquí también puede utilizarse una combinación de criterios empíricos y normativos, como ocurre con la doctrina del incremento del riesgo. Con todo, la mayoría de las doctrinas de causalidad jurídica (o imputación objetiva, como prefieren ahora algunos civilistas) tienen criterios de selección que se basan primordialmente en consideraciones normativas" (2014, p. 210).

${ }^{269}$ Con la sentencia de 23/04/2008, exp. 1997-04547-01(15737) el Consejo de Estado consideró la lesión a los derechos fundamentales como una categoría autónoma del daño moral, la cual es la mayoritariamente acogida en los fallos en torno a la omisión del consentimiento informado del paciente.
} 
... para que se genere la obligación de reparar el daño causado por una intervención médica no consentida, no se requiere que dicha intervención cause al paciente un daño corporal. $L a$ materialización o no de los riesgos propios de la intervención de que se trate, cuando éstos debieron y pudieron haber sido advertidos al paciente, constituye un asunto marginal en este tipo de daño, porque el mismo se causa con la sola omisión del deber de obtener el consentimiento informado del paciente, o de quienes deban decidir por él, en tanto es esa omisión la que afecta sus derechos a su Dignidad, su Autonomía y su Libertad, los cuales constituyen en sí mismos bienes inherentes al ser humano, susceptibles de reparación cuando sean vulnerados. (Consejo de Estado, sentencia de 23/04/2008, exp. 1997-0454701(15737)) (cursiva fuera de texto)

Según el Alto Tribunal el nexo causal se establece entre la omisión de la obligación de advertir un riesgo que finalmente se materializó causándole un daño corporal y el "sufrimiento moral" “...que ese resultado causó al mismo por haberse practicado la intervención sin su consentimiento...”. Insistió que, “...no se trata de una relación entre la intervención y el daño corporal...”. De ese modo, aunque no se derive ningún desmejoramiento para el paciente procede la indemnización, ya que se indemniza el dolor moral que sufre el paciente al conculcarse su derecho (Consejo de Estado, sentencia de 23/04/2008, exp. 1997-04547-01(15737)).

Con todo, el Consejo de Estado, en la referida providencia, acogió la posibilidad de los juicios contrafácticos “...en circunstancias especiales (cuando esté claro que el paciente no se hubiese sometido a la intervención), se reconozcan perjuicios derivados de la condición final del paciente, pero ello no debe ser automático”, aunque reconoció su dificultad probatoria.

En una causa fáctica contigua, el Consejo de Estado reconoció el daño moral por no haberse informado el riesgo típico y previsible de invalidez, el cual finalmente se concretó a pesar de una buena praxis médica. A saber, consistió el riesgo en una fractura del tercio proximal del fémur al realizarse una artroplastia total de cadera o reemplazo de cadera para corregir una luxación congénita de cadera de larga evolución. 
En el proveído se deja entrever que el daño nace por la llana omisión del consentimiento informado, se le reconoció en esos términos a la paciente 40 salarios mínimos legales mensuales vigentes-SMLMV y también, se otorgó indemnización por este concepto a sus familiares (20 SMLMV) (Sentencia de 23/05/2008, exp. 1996-04798-01 (16095)).

En otra oportunidad, la misma Corporación estudió un caso de ausencia total de consentimiento informado, dada la ligadura de la única trompa de falopio que le quedaba a la paciente de 42 años, procedimiento que no era indispensable realizar en ese momento. Esto, en medio de la práctica de un legrado que generó una perforación profunda del útero, pero que no obedeció a un error en la atención sanitaria.

En virtud de lo probado, se condenó a la entidad hospitalaria por el daño moral derivado de la afectación del consentimiento, pero, al mismo tiempo, se reconoció un daño corporal emanado del procedimiento -incapacidad definitiva y permanente de procrear-, que ocasionó una profunda tristeza en la mujer. Reconoció 42.5 SMLMV por la práctica de la técnica de pomeroy sin su previo consentimiento informado y 42.5 S.M.M.L.V. por el daño corporal (Sentencia de 28/02/2011, exp. 1997-05218-01 (20027)).

En dicho pronunciamiento, si bien se indemniza el daño moral por la lesión a su derecho de decidir, emerge confusa la condena por el daño corporal. A la luz del contenido de la sentencia, no se entiende muy bien si solo se reprocha la omisión del consentimiento o se advierte una mala praxis médica, que puede devenir del hecho que la intervención no era necesaria ni relacionada para tratar la patología de la actora. Por esta razón, el hilo conductor de la decisión judicial no debe perderse y las conclusiones sin dubitación alguna justificadas, para evitar confusiones en su lectura.

En el Consejo de Estado la tesis del daño moral autónomo es la de mayor aplicación ${ }^{270}$. En algunos fallos, si bien se despliega la postura del daño moral, al momento de liquidar perjuicios se

\footnotetext{
${ }^{270}$ Las sentencias que solo indemnizan por daño moral son: 23/04/2008, exp. 1997-04547-01(15737); 23/05/2008, exp. 1996-04798-01 (16095)); 29/08/2012, exp. 2001-01816-01 (26025); 27/03/2014, exp. 2000-01924-01(26660); 01/02/2016, exp. 2006-03158-01 (45459); 05/07/2016, exp. 2001-00874-01(36136); 05/12/2016 exp. 2009-0005101(41262); 30/11/2017, exp. 1991-06582-02(43378).
} 
indemnizan las repercusiones del acto médico no consentido, a pesar de la inexistencia de mala praxis médica $^{271}$.

De la línea jurisprudencial del Consejo de Estado se observa que cuando hay un daño por consentimiento informado y, al mismo tiempo, se configura una negligencia médica/mala praxis, se reconoce la indemnización por el total de los daños causados ${ }^{272}$. Pero, en cuanto al daño moral no se matiza ni identifica hasta qué punto procede de la mala praxis y qué corresponde por falta de consentimiento informado, por lo que asalta la duda si se incluyó o no el consentimiento informado o este quedó subsumido por la totalidad de los daños.

En lo que respecta a la Corte Suprema de Justicia, hasta la fecha no se verifica pronunciamiento alguno en donde explícitamente se considere la omisión del consentimiento informado como daño moral autónomo. Resta esperar que llegue una causa sobre el tema para entrever la postura en torno a ello y su correspondiente reparación, debido a que en líneas generales se ha planteado que la lesión a los derechos fundamentales constituye un daño moral.

\footnotetext{
${ }^{271}$ En sentencia de 01/08/2018, exp. 2005-02541-01(35740) se estudió el caso de una paciente a la que le practicaron una descompresión neurovascular que generó la pérdida de fuerza del miembro superior y la lesión de la vía auditiva izquierda, riesgos previsibles de la intervención pero que no fueron informados. De hecho, en la historia clínica no hay constancia del consentimiento. A pesar de que no existió reproche de la intervención quirúrgica, la indemnización de perjuicios giró en torno a las consecuencias propias del procedimiento y ante el daño moral expuso el Alto Triubnal que "....inferir que la pérdida de la audición del oído izquierdo de carácter definitivo y la fuerza del brazo izquierdo generó angustia, tristeza y congoja a los demandantes, dado lo que un evento de esta magnitud normalmente representa para la víctima y su familia", y también le fue concedido un lucro cesante en correspondencia con el porcentaje de la incapacidad laboral.

Asimismo, en sentencia de 22/06/2017 exp. 2004-01011-01(38874) se concluyó que la atención médica fue adecuada ante la extracción de un tumor del cuerpo carotideo izquierdo en la que en su desarrollo se presentó una complicación consistente en una hemorragia de la arteria, una posterior embolia cerebral, y, finalmente, una paraplejia como secuela irreversible. Pero, se denotaron fallas en cuanto al consentimiento informado, debido a lo cual el Consejo de Estado insistió en el criterio de daño moral. No obstante, en la liquidación también se otorga un lucro cesante que deviene de la incapacidad para trabajar.

Igual perspectiva se desprende de la sentencia de 12/12/2013 exp. 1996-12661-01(27493), donde se hace énfasis en que no se informaron los riesgos de todas las intervenciones realizadas, repercusiones que se cristalizaron en el paciente (infecciones urinarias a repetición, impotencia por disfunción eréctil) y no se alude a una falla médica. En los perjuicios se reconocieron indemnizaciones por daño moral, daño a la salud y lucro cesante.

La pérdida de la capacidad laboral se determinó en el $70.40 \%$.

${ }_{272}$ Al respecto los proveídos: 15/10/2008, exp. 1994-00061-01(16350); 11/02/2009, exp. 1993-08025-01(14726); 28/02/2011, exp. 1997-05218-01 (20027); 27/04/2011 exp. 1999-00695-01(20636); 13/02/2013, exp. 1999-0263201(25870); 12/12/2014, exp. 2002-03054-01(33756); 26/10/2018, exp. 2006-01724-01(41144).
} 
El Tribunal Supremo Español, en la Sala Tercera de lo Contencioso, ha marcado la tesis que la vulneración del consentimiento informado produce una falla del servicio por inobservancia de la lex artis que genera un daño moral económicamente indemnizable, que no se produce per se. Por tanto, requiere que del acto médico se derive un daño (Sentencia 09/05/2017, Roj: 1820/2017):

...causa, pues, un daño moral, cuya indemnización no depende de que el acto médico en sí mismo se acomodara o dejara de acomodarse a la praxis médica, sino de la relación causal existente entre ese acto y el resultado dañoso o perjudicial que aqueja al paciente; o, dicho en otras palabras, que el incumplimiento de aquellos deberes de información solo deviene irrelevante y no da por tanto derecho a indemnización cuando ese resultado dañoso o perjudicial no tiene su causa en el acto médico o asistencia sanitaria (Sentencia 26/05/2015, Roj: 2316/2015).

Por otro lado, en Italia la Corte de Casación ${ }^{273}$ recientemente se pronunció respecto de un caso de esterilización no consentida, ni necesaria ni urgente practicada en medio de una cesárea. Señaló la existencia de un tipo de daño no patrimonial cuando es vulnerado el derecho a la autodeterminación del paciente, siempre que se cruce el umbral de severidad de la ofensa y la hagan intolerable en consideración de las molestias y sufrimientos que surgen en el paciente por la ocurrencia de consecuencias adversas y, por ello, más difíciles de aceptar (Sentencia 31/01/2018, No. 2369 $)^{274}$. Aquí, se puede observar la acogida de la doctrina del dañoconsecuencia. Asimismo, el incumplimiento del consentimiento es independiente de que la intervención se haya realizado correctamente.

Seguidamente en la misma providencia, la Corte Italiana manifestó que también puede solicitarse una indemnización por el daño a la salud por las secuelas no informadas y

\footnotetext{
${ }^{273}$ Corte Suprema di Cassazione.

${ }^{274}$ En palabras de la Corte: "in questa prospettiva, viene in rilievo il caso in cui, alla prestazione terapeutica, conseguano pregiudizi che il paziente avrebbe alternativamente preferito non sopportare nell'ambito di scelte che solo a lui è dato di compiere; nonchè la considerazione del turbamento e della sofferenza che derivino al paziente sottoposto ad atto terapeutico dal verificarsi di conseguenze del tutto inaspettate perchè nonprospettate $\mathrm{e}$, anche per questo, più difficilmente accettate. tale tipo di danno non patrimoniale è risarcibile (in via strettamente equitativa) ogniqualvolta varchi la soglia della gravità dell'offesa secondo i canoni delineati dalle sentenze delle Sezioni unite nn. 26972-26975 del 2008, che hanno condivisibilmente affermato che il diritto deve essere inciso oltre un certo livello minimo di tollerabilità, da determinarsi dal giudice nel bilanciamento tra principio di solidarietà e di tolleranza secondo il parametro costituito dalla coscienza sociale in un determinato momento storico;"”.
} 
materializadas. En estos supuestos, indica la Corte, el juez de la causa debe preguntarse si el cumplimiento correcto del deber médico de información habría producido el rechazo o la no ejecución de la cirugía por parte del paciente, de forma que si se demuestra el rechazo se configura un daño a la salud. El paciente tiene la carga de demostrar, a través de presunciones, que habría rechazado la intervención de conocer la información, de lo contrario no existiría relación causal entre la violación de la obligación de información y el daño a la salud (Sentencia 31/01/2018, No. 2369). Esta hipótesis encuadra en el llamado consentimiento hipotético que será estudiado líneas seguidas.

De todo lo expuesto en este punto, se puede en síntesis afirmar que: a). el consentimiento informado es un daño moral autónomo. b). El daño por omisión del consentimiento no excluye el estudio y la reparación por los daños derivados de una negligencia médica o vulneración de la lex artis ad hoc. c). Pueden coexistir las indemnizaciones por daño al consentimiento informado y por falla médica. d). En algunos casos la omisión total del consentimiento informado va aparejada una negligencia médica como cuando el procedimiento no es el requerido o necesario, pautas en las cuales se establece el daño moral por omisión del consentimiento y la indemnización de los daños que genere la culpa médica los cuales constituyen montos independientes.

Es menester puntualizar que, las consideraciones esgrimidas como sustento del daño moral no apuntan a que la responsabilidad por omisión del consentimiento informado implique un análisis objetivo sin más consideraciones. Puesto que, como ya se ha abordado en el contenido de este trabajo, el juez debe valorar cuándo se está ante una obligación de resultado -obtener el consentimiento- y cuándo la obligación se torna de medios -contenido, extensión, comprensión-, para de ahí realizar el respectivo análisis del caso y, si es procedente, imputar responsabilidad.

En contra del daño moral autónomo ${ }^{275}$ se observa por ejemplo la postura de Pasquau (2013), quien entiende que, si bien toda infracción de la obligación de informar y recabar el consentimiento constituye una vulneración del derecho a la autodeterminación, no se puede decir que

${ }^{275}$ Entre otros, Pizarro (2018), Asúa (2013), Galán (2016). Cuando se estudien los diferentes planteamientos teóricos que han surgido en torno al daño a reparar, se observarán más autores y jurisprudencia que no acogen como tesis el daño moral. 
automáticamente constituya un daño moral indemnizable, pues el daño moral es algo que hace padecer y no una violación abstracta de un derecho de la personalidad (p. 174).

Pasquau advierte que se requiere un daño ligado causalmente a la omisión, ya sea patrimonial o moral, y este puede ser la intervención misma cuando no sea exitosa y/o se desprendan secuelas, a raíz de lo cual, el médico debe asumir el daño íntegramente. Lo anterior, siempre y cuando en un juicio causal hipotético se demuestre que el paciente no se hubiese sometido a la intervención. Y agrega, que si existe incertidumbre sobre la decisión que tomaría paciente, “...el médico o cirujano han asumido el (caso fortuito) riesgo que no puede evitarse con la diligencia exigible, por lo que ha de responder por el daño íntegro" (2013, p. 176).

De igual forma, resuena importante traer a colocación y analizar la postura de Xiol (2012). Este autor español solo comparte la existencia de un daño moral independiente del resultado de la operación para situaciones determinadas, como cuando la intervención revista de gravedad por el riesgo/naturaleza/secuelas. Lo que justifica al afirmar que, se le ha privado al paciente de la posibilidad real de adoptar decisiones enfiladas a lograr una mejor preparación en el plano humano o terapéutico, para afrontar las consecuencias de la intervención o evitar/retrasar un tratamiento médico que considere atentatorio a su dignidad o a sus convicciones o buscar nuevas opiniones médicas o tratamientos para su enfermedad (2012, pp. 123 y 134).

Xiol ilustra que cuando se omite información sobre los riesgos, contraindicaciones, alternativas de tratamiento o posibilidades de fracaso es aplicable la teoría de la pérdida de la oportunidad sobre las probabilidades de que el paciente no hubiese aceptado/rechazado el tratamiento de conocer la información. Sin embargo, muestra que cuando la alternativa es igual de significativa que el tratamiento realizado, puede producirse a la par un daño indemnizable por la privación de la facultad de elección del paciente, el cual también se puede configurar cuando se omite información sobre las posibilidades de fracaso. Si la omisión de la información versa sobre las secuelas necesarias, se debe reparar el daño corporal (Xiol, 2012, pp. 120-131).

La propuesta de Xiol presenta diversas dificultades de aplicación, entre más diferenciaciones y separaciones se establezcan en una categoría (daño), mayor es el conflicto para encuadrar una 
situación particular. De ahí que, sea preferible, como se propone en este estudio, optar por un solo tipo de daño ante la omisión de consentimiento informado.

Además, no es factible constitucionalmente, desde la perspectiva colombiana, que el consentimiento informado, como daño independiente, revista altura jurídica para la institución de la responsabilidad solo cuando la intervención a realizar es de carácter "grave", porque desvirtúa la naturaleza misma de este derecho y daría paso a violaciones escondidas en esa justificación. El carácter grave puede resultar demasiado subjetivo como ya se ha indicado. Sin embargo, se puede observar a efectos de la valoración del daño, como se ve más adelante.

Otra postura contraria es la De Ángel (2001), quien expone la problemática en torno a resolver problemas de consentimiento informado por la vía del derecho humano. Afirma que, resulta innecesario, aventurado y se corre el riesgo de que ".... a fuerza de tratar de encontrar en ellos un soporte dialéctico para todo, acaso estemos contribuyendo a una cierta caricatura de los derechos humanos" (p. 4).

El primer argumento de la crítica, De Ángel lo hace con base en que los instrumentos jurídicos actuales permiten darle solución al problema, al partir de la consideración que hubo una vulneración a la lex artis. Con respecto a la segunda consideración, asegura que no se le deba dar a ese derecho el carácter de absoluto, y cualquier modulación judicial al mismo podría generar la impresión de que ese derecho humano se infama o degrada, y se debería utilizar la noción “elevada" cuando se niegue el mismo como principio, es decir buscando su tutela (De Ángel, 2001, p. 4$)^{276}$.

En respuesta a De Ángel, se puede exponer que, como se ha apuntado en esta investigación, el consentimiento no tiene carácter absoluto y dado el tipo de obligaciones que encuadra, su aplicación no deviene deductiva y requiere el estudio del caso concreto.

Con todo, lo apuntado no es óbice para que no se coloquen ciertos límites respecto del daño, como cuando la omisión del deber no resulta trascedente al no afectar en su integridad la

${ }^{276}$ Este autor adopta la teoría de la conducta alternativa conforme a derecho como se verá más adelante. 
autodeterminación, lo que permite evitar pretensiones bagatelas, tal y como se explica seguidamente.

\subsubsection{Las fronteras del daño moral por incumplimiento del consentimiento informado}

Se ha desarrollado el criterio que aboga por el daño moral autónomo ante el incumplimiento del consentimiento informado del paciente. Empero, no se pueden obviar los inconvenientes que, un enunciado general en estos casos tan particulares de violación a un derecho de la personalidad, podrían desencadenar, como lo es una desmesurada utilización de la responsabilidad civil para reparar todo disgusto, por más trivial que parezca, dando paso a abusos y especulaciones.

Por tal motivo, es dable hacer unas series de precisiones para determinar cuándo la lesión del derecho al consentimiento informado traspasa el límite de lo toreable por afectar hondamente a la persona. No cualquier falta de información acarrea responsabilidad profesional, así como no todo consentimiento informado plasmado en un documento conlleva la exoneración (Ariza, 2014, p. 68).

El consentimiento informado es un binario de información y consentimiento, una falta de información respecto de los riesgos y de alternativas de tratamiento “...acaba invalidando un eventual consentimiento, que debe considerarse viciado de error cuando no se presta con conocimiento de todas las circunstancias del acto médico consentido" (Llamas, 2010, p.1). El estudio de la responsabilidad se agrava cuando la omisión del consentimiento es total y cuando la información no ha versado sobre los puntos más álgidos determinadores normalmente de la decisión del paciente.

Para establecer la frontera del daño merecedor de indemnización, considerando que el quid del asunto es determinar qué se indemniza, se debe diferenciar entre una defectuosa información y una ausencia total de información. Teniendo en cuenta que, ello permite establecer los niveles en que se agudiza la libertad de decisión y de obtener información. Todo esto se justifica al ser la causa una omisión de una obligación, que da paso a establecer criterios para la imputación. 
Por lo tanto, es relevante que en esta investigación se presenten criterios a indemnizar por omisión del consentimiento informado, para propender por un equilibrio que no desenfoque la finalidad de la responsabilidad.

\subsection{Criterios para la determinación del daño}

Seguidamente se estudia la casuística que se desprende del consentimiento informado, para fijar los criterios que determinen cuando se alcanza la condición de ser daño moral indemnizable:

\subsection{Actuación médica correcta, información defectuosa y materialización de un riesgo previsible}

En este supuesto particular no hay duda de la protección a la persona por el impacto que encierra la afectación del consentimiento informado, en consideración a las circunstancias de un resultado negativo que se concreta.

Si el consentimiento de aceptar la intervención no cumple con una información completa, clara y adecuada, no se puede considerar cumplido a satisfacción la obligación. La responsabilidad civil del médico surge al fracasar el procedimiento, que hace obviamente que la trasgresión de los derechos de la persona traspase su nivel de tolerancia e irradien en la víctima un verdadero atentado contra sus garantías fundamentales.

Entonces, la imposibilidad de conocer a que se exponía y tomar una decisión en torno a ello, agrava la lesión del derecho, pues el paciente no pudo mitigar, prepararse, visualizar y concientizarse con tiempo de las posibles adversidades.

Como ejemplo, en la jurisprudencia colombiana está la sentencia del Consejo de Estado (29/08/2012, exp. 2001-01816-01 (26025)) a través de la cual, se ordenó indemnizar el daño moral sufrido por el paciente, cuando al practicarse la intervención el cirujano amputó la pierna izquierda a nivel del tercio medio por arriba de la rodilla, sin autorización del paciente ni de sus familiares, puesto que, el paciente había entendido que la amputación sería del antepié. No obstante, el 
procedimiento fue el adecuado, debido al estado de la enfermedad arterial, pero se reprocha el defecto en la transmisión de la información, que fue la creadora del error en el paciente.

Lo expuesto, no se puede confundir con la hipótesis de cuando la información defectuosa es propia del acto asistencial para lograr que el procedimiento sea exitoso y no se produzcan reacciones adversas, por lo que su omisión constituye en sí la causa del daño. Tal como sucede cuando no se le indica al paciente, luego de un procedimiento quirúrgico, los cuidados a tener de limpieza de la herida y posteriormente, se presenta un cuadro infeccioso que afecta la salud por un tiempo.

\subsection{Actuación médica correcta, defectuosa información y no se materializan riesgos}

Para una mejor comprensión de este criterio particular, imagínese un paciente que padece acromegalia, la cual es producida por un pequeño tumor en la glándula pituitaria que genera un exceso en la hormona de crecimiento hasta afectar finalmente el corazón, el neurocirujano prescribe su cirugía, dado el estado avanzado de la enfermedad. El médico tan solo le indica que es un procedimiento sin complicaciones mayores. Realizada la cirugía, todo salió bien y la recuperación del paciente fue exitosa. Tiempo después, el paciente se entera que había un riesgo, aunque mínimo, de accidentes cardiovasculares o el empeoramiento de la visión, a pesar de que estos no se produjeron, decide demandar al profesional por las fallas del consentimiento informado.

De una primera impresión emerge que el médico no cumplió con el contenido suficiente de la obligación de información, lo que supone una decisión sin conocimiento pleno de causa. A pesar de la lesión a un interés, esta no deviene trascendente para la intervención de la responsabilidad civil, al no adquirir la sustancialidad necesaria y no sobrepasar los límites de los disgustos/malestares/menoscabos tolerables y soportables en la vida.

Además, el paciente al aceptar un acto médico, como sostiene acertadamente Ribot (2007), aunque solo conozca su finalidad o algunas características, se representa un desenlace que coincide con el propósito previsto por el médico cuando recomendó ese procedimiento. Como quiera que, 
el resultado producido es el deseado por el paciente, no se quebrantan las expectativas (p. 57) y no hay lugar a que surja la responsabilidad.

De no ser así, se llegarían a los extremos de un sinnúmero de demandas que más que una reparación ubica la institución de la responsabilidad para subrogar derechos, sacar un provecho económico y sancionar la conducta del profesional de la salud, desviando la finalidad reparadora de la responsabilidad.

A mayor abundamiento, no puede la responsabilidad civil asumir funciones que el derecho tiene prevista para otras áreas. Si se trata de sancionar la actuación del médico respecto del consentimiento informado, el proceso ético-disciplinario ofrece medidas para ello.

Por su parte, Navia (2006) participa en la discusión sobre esta cuestión, comparte la existencia de un daño moral indemnizable. Añade que, cuando no se generan secuelas en el paciente la reparación debe ser simbólica ${ }^{277}$ (p. 163). A decir verdad, esta solución excede los postulados de la responsabilidad civil al enfocarse en una función preventiva más que compensatoria con una reparación simbólica, que no tendría utilidad práctica.

\subsection{Actuación médica correcta, información defectuosa de tratamientos alternativos y materialización de un riesgo previsible e informado}

En esta instancia sencillamente se reprocha el hecho de existir otros tratamientos alternativos y el profesional de la salud omite esa información al paciente. A todas luces, se evidencia el desconocimiento del consentimiento informado, al no poder el paciente valorar los riesgos y beneficios entre dos o más tratamientos posibles para su condición, de acuerdo con su querer y prioridades. Por tanto, hay lugar a indemnizar el daño moral para proteger a la persona en sus bienes más fundamentales.

\footnotetext{
${ }^{277}$ Literalmente el autor expresa “...lo lógico sería condenar aquí al médico en forma apenas simbólica. Con ello se resalta la importancia de cumplir a cabalidad con el deber de información, a la vez que se tiene en cuenta, en una especie de compensación, el alivio, la alegría y el mejoramiento del estado de ánimo del paciente, como consecuencia lógica del resultado favorable del acto médico" (2006, p. 163).
} 
Ante la existencia científica de más de un tratamiento, sería ilógico afirmar que no se vulnera el consentimiento informado del paciente, dado que el paciente tenía la opción también de rechazarlo, aunque este fuese completamente necesario para su recuperación, pues solo a él le compete tomar las decisiones que lo afecten.

\subsection{Actuación médicamente correcta y ausencia total del consentimiento informado}

En este evento se patentiza una omisión total del consentimiento informado desde la perspectiva que el médico actúa sin contar con la autorización del paciente, lo que entraña una conducta que afecta la libertad de la persona al constituir intromisiones ilegítimas que traspasan el margen de aceptabilidad general, a pesar que la lex artis desde el punto de vista de la técnica fue correcta.

Desde esta perspectiva, el daño no puede ser indiferente para el derecho y es viable su indemnización desde la categoría del daño moral, al ser una agresión grave e injustificable en la persona como fin y única dueña de su existencia, comporta la forma más radical de afectación del derecho a consentir informadamente.

En contra de este criterio se encuentra Ataz (1985) quien afirma que, si bien se puede generar un daño moral por el atentado a la libertad de decidir, cuando los resultados son beneficiosos para el paciente quizá se pueda compensar el daño moral y no otorgar por esta indemnización alguna $\left(\right.$ p. 82) ${ }^{278}$. Aceptar esta propuesta sería desconocer la intangibilidad de la persona y decaería todo el discurso de la protección de la persona como un fin en sí misma.

\subsection{Mala praxis médica y ausencia total del consentimiento informado}

Aquí se tiene en cuenta que el profesional de la salud incumple con dos deberes básicos de la relación asistencial, que dan lugar a predicar una responsabilidad independiente para cada daño presentado. En esta causa “....carece de sentido referirse a la obtención de un resultado querido y

\footnotetext{
${ }^{278}$ Este doctrinante afirma que si la información fracasa se transfieren todos los riesgos de la intervención al facultativo
} (1985, p. 82). 
esperado. Al paciente ni siquiera se le ha dado la ocasión de representarse tal desenlace" (Ribot, 2007, p. 57).

El médico está expuesto a responder de una manera bifronte por desconocer las reglas técnicocientíficas del arte de la medicina y vulnerar un derecho de la personalidad, valga por caso cuando el médico se equivoca en el procedimiento quirúrgico y opera el miembro inferior -pierna- no afectado, en consecuencia, entra a responder por todos los perjuicios causados.

Pueden subsumirse en este enunciado de ausencia total de consentimiento, el desconocimiento de la voluntad expresa del paciente, los procedimientos forzosos y la información engañosa o manipulada al constituir una afrenta grave a los derechos del paciente, que al mismo tiempo comportan una incorrección del acto médico.

A modo de aclaración, en el presente criterio se encuentran aquellos supuestos de ligaduras de trompas no consentidas en medio de otra práctica quirúrgica, cuando no resulta urgente ni necesaria, al no ser el procedimiento adecuado para tratar la sintomatología de la paciente, lo que justificaría su aplazamiento. Conducta médica que atenta gravemente contra el derecho de la mujer y son indemnizables todos los perjuicios demostrados ${ }^{279}$, a más, del consentimiento informado, como podrían ser, secuelas psicológicas que ameriten tratamiento por parte de un especialista o que le impida trabajar por un tiempo, lo cual genera repercusiones económicas que deben ser asumidas por el dañador.

\subsubsection{Función reparadora del daño moral por incumplimiento del consentimiento informado}

Cuando se afirma que la transgresión al consentimiento informado es un daño moral per se, que no requiere de la concreción de secuelas en la vida o en la salud del paciente, ello no significa que la función de la responsabilidad se trastoque de ser reparadora a una sancionadora-preventiva.

${ }^{279}$ Sobre esta cuestión Ariza (2014, p. 69). 
M’Causland (2015) exterioriza preocupación, de forma general, en cuanto al reconocimiento del daño a los derechos fundamentales por la sola lesión de los mismos sin tener en cuenta sus consecuencias. Expone que, la responsabilidad se tornaría en sí sancionadora y, algunas veces, se podría decir que preventiva, al abandonarse la reparación, que es su función principal, y entraría a gobernar la conducta del ofensor y no la afectación de la víctima (p. 44).

En el mismo sentido, Rojas (2015) recuerda que la doctrina tradicional de la responsabilidad es la consideración del daño como repercusión y no solo como infracción, en donde se busca primordialmente la reparación de las consecuencias desfavorables (p. 182).

Empero, en el caso del consentimiento informado sería un sofisma dichas alocuciones. Cuando se atribuye la existencia de un daño moral indemnizable, no se busca de ninguna forma sancionar la conducta dañina ni tampoco crear una prevención general y especial, en la medida que el objetivo es la protección de la persona desde sus bienes fundamentales, otorgándole una indemnización para satisfacer/compensar la agresión sufrida. Es preciso tener en cuenta, que en estos supuestos se trata de la libertad de decidir respecto a cuestiones tan propias y personales como es la vida y la salud, que en sí mismas constituyen una agresión grave que requiere de un nivel de protección amplio por el ordenamiento.

Al momento de la cuantificación de la indemnización correspondiente, el juez fija su monto proporcional a la magnitud del agravio (hasta qué punto la autonomía de decidir fue nugatoria) y no a la gravedad de la falta cometida por el galeno ${ }^{280}$.

\footnotetext{
${ }^{280}$ En igual postura Agón (2016) cuando enfatiza que "[e]n cada caso habría que determinar si la infracción del consentimiento informado pudo afectar a la autodeterminación decisoria provocando un daño moral en sentido estricto. Consideramos que no se trataría de un daño punitivo porque lo que se indemniza sería la afectación de ese derecho subjetivo del paciente. Debemos recordar que el núcleo del daño moral es la protección general de los bienes de la personalidad, los cuales se ven afectados cuando se vulnera el consentimiento informado" (p. 376).
} 


\subsubsection{El daño moral por incumplimiento del consentimiento informado no suprime los elementos de la responsabilidad}

Una de las mayores críticas para el daño moral per se puede forjarse desde el discurso que hecho y daño se suprimen y se unifican en un solo criterio, lo que implica que “...colapsan varios elementos dogmáticos de la responsabilidad (el daño se confunde con el actuar antijurídico) ...” (Rojas, 2015, p. 182).

Valga aseverar que, ante la vulneración al consentimiento informado no se cambia ni se confunde el concepto de daño con la causa que lo produce. La demostración de la trasgresión se identifica al tiempo con la prueba de la existencia del daño, lo que se verifica con la confrontación del hecho, que consiste en la vulneración de una obligación que otorga a favor de un sujeto un determinado derecho (Brebbia, 1950, p. 95).

Lo anterior, desde la presunción de la lesión por el relieve del interés lesionado - daño moral in re ipsa, lo cual, inclusive, es defendido por acérrimos defensores del daño-consecuencia como Zavala (2011, p. 630), en aquellas cuestiones que implica una lesión a la dignidad de la persona, al ser inexorable que el daño moral constituye el efecto natural de las ofensas a la dignidad.

\subsubsection{Otras posturas sobre el daño por incumplimiento del consentimiento informado}

Con respecto al daño producto de la falta total o parcial del consentimiento informado del paciente, no existe homogeneidad en la doctrina en torno a su categorización e indemnización. No hay duda de la importancia y obligatoriedad de esa obligación, pero surgen muchas discrepancias sobre el cuándo, de qué y por cuanto se responde, especialmente en aquellas circunstancias en que se materializa un riesgo previsible del acto médico no consentido, ya sea en su ausencia total o en virtud de una defectuosa información.

Aparte del daño moral autónomo, se ha abordado la temática desde otras perspectivas. Se ha explicado la responsabilidad desde la relación causal o su supresión, desde el plano de la hipotética 
decisión del paciente o desde la pérdida de la oportunidad como daño extrapatrimonial, las cuales se presentan a continuación.

\subsection{Asunción de los riesgos y atribución del daño final}

Un sector de la doctrina propugna que ante el incumplimiento del consentimiento informado del paciente, el profesional de la salud debe asumir los riesgos materializados independientemente de la corrección de la actuación, porque al privarse al paciente de decidir informadamente este no pudo valorar y hacerse responsable de una decisión, de modo que el médico usurpó dicho lugar y debe responder por todos los daños derivados del procedimiento (Pérez, 2008, p. 164; López y García, 2010, p. 73).

Dalcq, como precursor de este planteamiento, esboza que ante las omisiones del consentimiento informado no cabe hacer consideraciones sobre el nexo causal, al ser prácticamente imposible de encuadrar. Asegura, que no se está ante una responsabilidad por culpa, sino ante la obligación de indemnizar por las consecuencias previsibles desarrolladas producto de la intervención no legitimada, de las cuales se hizo cargo el médico al momento de obrar sin anuencia del interesado (Dalcq, 1967, pp. 380-381).

Esta postura presenta gran interés para Castaño (1997), pero la autora no suprime el análisis del nexo causal. Por su parte, explica la causalidad desde de la teoría de la equivalencia de las condiciones, debido a que el hecho de no contar con el consentimiento informado, que constituye por sí una conducta culposa, tiene incidencia causal en el resultado producido, pues con la equivalencia de las condiciones, de cualquier forma “...si se hubiese respetado la voluntad del paciente, el médico se habría abstenido de hacer la intervención y, en consecuencia, el daño no se habría producido" (p. 401).

Por su parte, Tamayo (2017) acepta la postura de Dalcq e indica que la indemnización debe ser equivalente al daño experimentado por el paciente fruto del procedimiento realizado, y se calcula conforme al estado real del enfermo -por ejemplo, el promedio de vida conforme a la enfermedad- 
y no con las tablas de supervivencia. De no ser así, indica que sería un enriquecimiento injusto (pp. 89-90).

De igual modo, López y García (2010) responde al problema de relación causal desde la perspectiva jurídica y no fáctica. Apunta a la imputación objetiva, que a su parecer, es la única forma de entender "racional y objetivamente" que el médico que ignoró el consentimiento informado responda de igual manera a uno que en su obrar desconozca la lex artis ad hoc, al atribuírsele todos los daños (p. 73).

En un principio, en Colombia, el Consejo de Estado ignoró el análisis de la relación causal y trasladó al médico y a la entidad hospitalaria todas las consecuencias derivadas del acto médico no consentido. En esta línea, se encuentra la sentencia de 09/07/1993, en donde se trató el caso de una mujer a la que en medio de una cesárea se le practicó sin su consentimiento una ligadura de trompas, no siendo este procedimiento de urgencia vital. La Sala ordenó reparar, de acuerdo con lo solicitado en la demanda, el daño fisiológico, al ser la cirugía no consentida e irreversible y el daño moral para la mujer, su esposo e hijo (exp. 7795).

Posteriormente, concluyó en sentencia de 03/05/1999, exp. 11169, en expresa acogida de la tesis de Dalcq, la asunción unilateral de los riesgos por parte de la entidad hospitalaria ante una paraplejia irreversible de un menor de edad, después de una biopsia realizada con un consentimiento general sin explicación de los posibles riesgos; claro está que, igualmente se alude a una falla del servicio médico en la atención, al omitir la práctica de exámenes de laboratorio previos.

En el año 2013 esa Corporación, después de haber optado por la línea del daño moral autónomo y también pasado por la pérdida de la oportunidad, se inclinó nuevamente por una asunción unilateral de los riesgos: "[c]omo... no se otorgó el consentimiento informado, los riesgos inherentes al procedimiento de la escisión de la ránula ${ }^{281}$ son de entera responsabilidad de las

\footnotetext{
${ }^{281}$ Las secuelas materializadas en la paciente fueron: a) pérdida parcial de la expresión verbal o del lenguaje y b) pérdida absoluta del sentido del gusto. Lo que produjo una incapacidad permanente parcial de 15.4\%. En la liquidación de perjuicios se reconoció daño moral a la paciente y sus familiares y daño a la salud para la paciente. Valga resaltar que en la demanda no se pidieron daños patrimoniales.
} 
demandadas y, por lo tanto, deben ser asumidos como tales" (12/12/2013, exp. 1999-0296201(26656)).

En esa misma fecha, se profirió la sentencia del exp. 1996-12661-01(27493) en donde se condenó por ausencia de consentimiento informado ante las diversas cirugías que le fueron realizadas al paciente para tratar una colitis ulcerativa y de las cuales, se presentaron complicaciones previsibles, que no fueron debidamente informadas. De modo que, se condenó a reparar todos los perjuicios causados. El Alto Tribunal adujo lo siguiente:

...el paciente asume los riesgos consentidos (y previamente informados), mientras que por lo que vaya más allá de tal consentimiento responde el médico, según el régimen de la responsabilidad objetiva ... Ahora bien, dado que el principal derecho de un paciente es el de recibir atención adecuada y acorde con su dignidad, se puede decir que el incumplimiento de estas exigencias de orden constitucional y legal constituyen en sí mismas una lesión, de donde se colige que, incluso en ausencia de otros daños, tendría que ser indemnizada. (subraya fuera de texto)

Igualmente, como se anotó en líneas anteriores, en dos pronunciamientos recientes (01/08/2018 exp. 2005-02541-01(35740) y 22/06/2017 exp. 2004-01011-01(38874)) aunque se estima la importancia del consentimiento informado en la práctica médica y su omisión como una afectación del derecho a la libertad de decisión, al momento de cuantificar los perjuicios se indemniza tanto el daño moral como los otros daños probados que fueron resultado directo de la intervención, a pesar de que, no se reprocha la técnica ni la atención médica.

En lo que concierne a la Corte Suprema de Justicia, en 2011 expuso que el incumplimiento de la obligación de informar y obtener el consentimiento informado hace responsables al médico y a la institución prestadora de salud tanto de la vulneración a los derechos fundamentales como de los daños patrimoniales y extrapatrimoniales que se deriven del tratamiento no autorizado con todos los requisitos legales, pues el médico asume los riesgos y existe una relación de causalidad entre el incumplimiento y el daño (sentencia de 17/11/2011, exp. 1999-00533-01). En este supuesto, también se probó la negligencia médica y se condenó por todos los daños resultantes del 
fallecimiento del paciente. De lo enunciado, se podría decir que rigió en esa providencia la tesis de la asunción de riesgos.

En sede de tutela, la Corte Suprema avaló en dos acciones la posición del ad-quem, al no encontrar reproche en el juicio y ser una hermenéutica respetable. En un primer proveído, no se informaron los riesgos y estos se concretaron, se otorgó una indemnización por daño moral conforme a lo solicitado por los demandantes (Sentencia STC9855-2015 de 30/07/2015). En el segundo caso, se condenó en sede de instancia por todos los daños que no fueron informados, a pesar que la atención médica fue adecuada (Sentencia STC1232-2016 de 09/02/2016).

En Argentina, la Sala "C" de la Cámara Nacional de Apelaciones en lo Civil en un fallo de 9/04/2014 (CIV 098236/2008) ante una omisión de los riesgos previsibles -de acuerdo con el estado de salud previo de la paciente sometida a una cirugía estética "electiva de lipoescultura de flancos, región lumbar, brazos y gluteoplastía"- resolvió condenar por la totalidad de los perjuicios causados porque “...para generar el deber de responder, la falta de información de un riesgo debe hallarse vinculación causal adecuada al daño ... el daño debe consistir en la concreción de un riesgo no informado en debida forma". Como se observa más adelante, esa Corporación ha recurrido en otros proveídos a la pérdida de la oportunidad.

En 2016 la Sala "B” de la Cámara Nacional de Apelaciones en lo Civil (Sentencia 18/03/2016) estudió la causa en la que a una paciente se le realizó una cirugía estética de levantamiento mamario "técnicamente denominado mastopéxia". No le fueron informados los riesgos del procedimiento, ni los directamente relacionados con la paciente, dada su predisposición a la cicatrización anómala, ya sea queloideas y/o hipertróficas, lo cual se concretó y se generó un afeamiento de su cuerpo. Además, arguyó la demandante que no se corrigió la asimetría mamaria ni la ptosis mamaria. Por otra parte, aseveró que el galeno por cuenta propia operó los pliegues de piel de las axilas "braquiplastía", sin haberle consultado previamente.

En oportunidad de emitir su fallo, la Cámara declaró la inexistencia de negligencia médica en la práctica quirúrgica. Esto, desde la concepción que las obligaciones del médico son de medios, aun en los procesos de embellecimiento, en virtud del alea presente en todo acto médico. El 
Tribunal juzgó lo concerniente al consentimiento informado teniendo en cuenta que en la historia clínica no contaba prueba de la recepción del mismo, ni de haber brindado información previa.

En síntesis, el Tribunal argentino consideró que el demandado asumió los riesgos de la intervención y debía responder por todos los daños que se ocasionaron a raíz de ella, aunque aclara que “...solo cabrá indemnizar a la pretensora por las consecuencias negativas que resultaron de la intervención efectuada [cicatrices], por el daño moral y psíquico sufrido, y por el afeamiento de su cuerpo emergente de ese acto médico". Por tanto, era improcedente indemnizar por la ptosis y asimetría mamaria que eran preexistentes ${ }^{282}$.

Como se vio en los antecedentes jurisprudenciales y doctrinales, la asunción de los riesgos requiere inexorablemente que se concreten los riesgos de la intervención médica no autorizada, puesto que, si el acto médico resulta favorable no podría encuadrar en la tesis. Es decir, la falta de información no es un daño indemnizable per se.

En estos supuestos, el debate probatorio queda reducido en la afirmación que no se suministró la información o que esta fue deficiente, y el médico se exoneraría demostrando que cumplió con su deber (Herrera, J. 2008, p. 7).

La postura de asunción de los riesgos no se defiende en esta investigación porque, como se planteó, exigir que el profesional de la salud responda por todos los efectos del acto médico a pesar de la corrección de la praxis médica atenta contra el requerido nexo causal, al no darse este entre el resultado final y la omisión del consentimiento informado.

Además, el consentimiento informado no tiene como fin evitar que los riesgos se materialicen, al depender estos del acto médico en sí. Por tanto, su propósito es proteger la libertad de decisión informada de las personas. En este sentido, es desproporcionado equiparar la indemnización por falta de consentimiento informado a aquella que deviene de una impericia médica, pues hasta con consentimiento informado, el evento dañoso -concreción de los riesgos- se puede presentar.

${ }^{282}$ En total la indemnización por daño moral, gastos futuros y daños materiales ascendió a 130.000 pesos argentinos. 
Respecto de los inconvenientes del nexo causal en las omisiones, es enormemente discutible que la abolición de este elemento sea la solución al problema. Debido a que, se enjuicia al profesional con un régimen de responsabilidad objetiva por asunción de los riesgos y se atribuyen consecuencias excesivas ante la omisión de una obligación, lo que deriva en una idea arriesgada, al hacer responsable al médico de unos daños no imputables a su proceder.

No se comparte la propuesta de López y García (2010), porque la imputación objetiva desde una atribución total de los riesgos, constituye una desfiguración de la misma. La imputación objetiva, como bien lo apuntó Pantaleón, pretende evitar que al responsable se le impongan “...absolutamente todas las consecuencias de las que su conducta es causa- es una cuestión claramente jurídica, un problema de valoración a resolver con pautas, más o menos precisas, ofrecidas por el sistema normativo de responsabilidad" (Pantaleón, 1990, p. 1563).

Sin embargo, realmente la imputación objetiva no destierra a la causalidad desde el plano nomológico-naturalístico. Puesto que, la causalidad se descompone en un análisis fáctico y uno jurídico, este último “...constituye un juicio de relevancia apoyado en principios normativos. En esta etapa de indagación causal se establece si el evento en cuestión puede ser considerado como la causa jurídicamente relevante del daño" (Bárcena, 2013, p. 296), que es en sí la llamada imputación. ${ }^{283}$

Por otra parte, tampoco la teoría de la equivalencia de las condiciones resuelve el problema causal-fáctico de las omisiones para imputar los riesgos de un procedimiento. A causa de que, implicaría para su efectividad la realización de un juicio contrafáctico, para poder comprobar que la omisión del consentimiento informado es la condición sine qua non al evento dañoso, es decir, sin esta no se hubiese producido el resultado.

\footnotetext{
${ }^{283}$ Se respetan las posturas que acogen la diferencia entre causalidad e imputación, pero se comparte la visión de De Ángel en el sentido que dicha discusión se acerca más a cuestiones de nominalismo que a contrastes entre las dos figuras: “...entendería la locución imputación objetiva si se quisiera dejar en claro que la imputación (Zurechnung) no deriva del curso físico de los acontecimientos, contemplados en sí mismos; es decir, sin un enjuiciamiento jurídico de ese curso. Pero, a mi juicio, esto último no es así (en el terreno de la responsabilidad extracontractual) desde hace muchas décadas; en concreto, desde que la causalidad dejó de ser contemplada (por la doctrina y los tribunales) a la luz de la equivalencia de las condiciones. Y ese enjuiciamiento jurídico, que entre los causalistas siempre ha implicado una considerable carga de apreciación subjetiva (la inherente a imputar, sin adjetivos ni predicados), no ha tenido nunca - es obvio- otra finalidad que la de lograr una solución de Derecho" (2014, p. 279).
} 
En el postulado de la asunción de los riesgos, la función de la responsabilidad civil no parece ser reparadora, sino que adquiere un matiz sancionador para el que ha desconocido el derecho de autodeterminación de otro, imponiéndole una indemnización por todos los daños, y a parte, se obvian los presupuestos de la responsabilidad.

Los argumentos presentados dan soporte para que en la presente pesquisa se opte por la causalidad adecuada desde la bifurcación de su contenido. En atención a que, al vulnerar una obligación se atribuye un efecto directo del mismo que es la afectación de la libertad de decidir informadamente, daño que se ubica en el contexto del daño moral, al ser un quebranto de la dignidad.

\subsection{Conducta alternativa conforme a derecho/consentimiento hipotético: moderación de la asunción de los riesgos}

Para resolver el problema causal y del alcance del daño a indemnizar, se ha propuesto el criterio de la conducta alternativa conforme a derecho, también conocido como consentimiento hipotético. Este planteamiento es utilizado básicamente para exculpar la responsabilidad médica; de ahí que, sea la regla del todo o nada ${ }^{284}$ la que gobierne en su mayoría el análisis de la responsabilidad guiado por el juicio hipotético.

El consentimiento hipotético parte del interrogante ¿qué hubiese pasado de cumplirse con el consentimiento informado del paciente?, si se prueba que el paciente de conocer los riesgos previsibles hubiera decidido aceptar el procedimiento, no le serán imputados al médico las secuelas del procedimiento; resultado contrario, se entendería cumplido el nexo causal entre el daño y la omisión del consentimiento informado (De la Maza, 2009, pp. 136-137).

A Pantaleón se le atribuye el hecho de introducir en la doctrina civil española el concepto de la imputación objetiva, siguiendo a la doctrina alemana y del common law. Este doctrinante plasmó

\footnotetext{
${ }^{284}$ La teoría del todo o nada es una tesis extrema y radical que históricamente ha sido base para negar la responsabilidad o afirmarla totalmente. Si se afirma la relación causal, la indemnización cobija el total del daño sufrido, pero si se niega, no hay lugar a indemnización alguna. Del mismo modo, cuando la incertidumbre de si el daño se hubiese producido o no, se elige la negación automática de la causalidad (Medina, 2007, pp. 322-324).
} 
la distinción entre causalidad e imputación objetiva, al manifestar que la primera corresponde a una cuestión de hecho, independiente de valoraciones normativas. Mientras que, la segunda es una cuestión jurídica-normativa que define los límites objetivos de la obligación de indemnizar (1990, p. 1563).

En su discurso, presenta diferentes criterios de imputación: riesgo general de la vida, prohibición de regreso, criterio de la provocación, fin de protección de la norma fundamentadora de responsabilidad e incremento del riesgo.

De igual manera, Pantaleón agrupa unos casos que en su opinión revisten grandes dificultades en torno a la imputación, como lo es la omisión del consentimiento previo del paciente, ya sea porque “...no se lo pidió, pudiendo y debiendo hacerlo, bien porque (supuesto más frecuente) no le informó adecuadamente de los riesgos y probabilidad de éxito de la operación, y de las posibles alternativas de tratamiento" (1990, p. 1587), desde la consideración de una práctica médica correcta.

Pantaleón coincide con el alemán Mertens en cuanto a que el médico es responsable si la falta de información ha afectado seriamente la libertad de decisión, lo que deviene de la prueba fehaciente que el paciente habría con seguridad o con una probabilidad rayana de certeza consentido la intervención. Y en los casos de graves infracciones de la obligación de información, se concedería una indemnización de daño no patrimonial por la lesión del derecho a la autodeterminación. En esa instancia, Pantaleón agregó que las dificultades probatorias del médico serían extraordinarias, ya que la prueba debe recaer sobre el paciente en concreto, con su especial idiosincrasia, y no sobre un patrón general (1990, p. 1589).

Por su parte, De Ángel (2003) respecto al problema del requisito del nexo de causalidad, expone que, en estos casos, más que una búsqueda de la causalidad material o física, la cual ubica entre la intervención quirúrgica y el daño al faltar la voluntad del paciente, debe partirse de una imputación objetiva por el desconocimiento del médico -culpa- de esa obligación, que, a su vez, es un derecho del usuario de los servicios de salud. Todo implica que hay una asunción de los riesgos propios de la intervención practicada (p. 20). 
A diferencia de Dalcq (1967), De Ángel (2003) plantea que no puede responder de igual forma el médico que no informa los riesgos al que actúa negligentemente en su técnica. Por eso, el quantum de la indemnización puede moderarse en correspondencia a un juicio de verosimilitud o probabilidad razonable de que el paciente hubiese aceptado el acto médico (p. 27).

No obstante, De Ángel acepta la dificultad de dicho juicio y propone que, si no se puede probar que el paciente hubiese de todos modos legitimado la práctica, entonces, es sensato que el médico indemnice el no permitir que el enfermo decidiera conscientemente, de modo que podría imponerse una “...condena parcial (e incluso simbólica, si se acepta la expresión)" (2003, p.27). Solución que dice estaría en la línea de la teoría de la pérdida de la oportunidad.

Por otro lado, Llamas puntualiza, en torno al debate, que en estos casos una de las dificultades se aborda desde la relación causal entre el perjuicio y la falta de consentimiento, al menos, “...sí cuando el estado del paciente permitiera tratamientos o soluciones alternativas al acto médico acertadamente realizado pero incorrectamente consentido" (2007, p. 37). En cuanto al alcance del daño y su cuantificación, Llamas (2007) comparte la reducción de la condena, lo que explica en palabras de Deusto "... amortiguar ese principio general y conducir a una condena inferior en su quantum a lo normal o natural valoración de dicho desenlace" (p. 37).

Asimismo, Domínguez (2007) considera que el paciente solo soporta el riesgo que ha sido previamente informado y aceptado, "...sin que pueda entenderse que el hecho de que hubiera igualmente consentido si se le hubiese informado adecuadamente, es suficiente para colocarlo en la misma situación. En su caso, será el médico quien corra con la carga de la prueba...” (p. 329) de que el paciente con seguridad hubiese avalado el procedimiento, lo cual es "enormemente difícil” (p. 329). En consecuencia, el resultado dañoso puede objetivamente imputarse al médico infractor.

En esa línea, Pasquau (2013) señala que, si con el curso causal hipotético es claro que la información no hubiese modificado la decisión del paciente, no hay lugar responder civilmente por el daño finalmente acaecido. En cambio, si la información pusiere en conflicto de decisión a su titular, hay lugar a responsabilidad por el daño total (p. 176). 
Respecto a la averiguación de la decisión del paciente, Pasquau (2013) indica que no es necesario establecer con plena certeza de que el paciente hubiera negado la intervención. Basta con convencer al juez que “...en una ponderación razonable de la entidad del riesgo y la necesidad/utilidad terapéutica hubieren situado al paciente en un conflicto de decisión, es decir, que, de conocer el riesgo, «se lo habría pensado dos veces»" (p. 175).

Barros (2006) apuesta por este criterio para esclarecer el tema de la causalidad, menciona que es una aplicación que evita que los deberes de información se superpongan a los deberes generales de atención, diagnóstico y tratamiento, de no ser así se expande la institución de responsabilidad más allá de sus límites propios (p. 686).

A nivel jurisprudencial en Colombia los Altos Tribunales no se han planteado esta posibilidad para resolver la responsabilidad por omisión del consentimiento informado.

Para el Tribunal Supremo español, en la Sala de Primera de lo Civil, la omisión del consentimiento no es per se causa de resarcimiento pecuniario porque "parece lógico cuando el resultado no es distinto del que esperaba una persona al someterse a un determinado tratamiento médico o intervención quirúrgica" (Sentencia 04/03/2011, Roj: 1804/2011). Considera que, el daño puede identificarse desde lo moral, corporal y patrimonial, y su cuantificación puede hacerse:

(i) Por los totales perjuicios causados, conforme a los criterios generales, teniendo en cuenta el aseguramiento del resultado, más vinculado a la medicina necesaria que a la curativa, pero sin excluir esta; la falta de información y la probabilidad de que el paciente de haber conocido las consecuencias resultantes no se hubiera sometido a un determinado tratamiento o intervención. (ii) Con el alcance propio del daño moral ${ }^{285}$, en razón a la gravedad de la intervención, sus riesgos y las circunstancias del paciente, así como del patrimonial sufrido por lesión del derecho de autodeterminación, integridad física y psíquica y dignidad. (iii) Por la pérdida de oportunidades o de expectativas. (Sentencia 04/03/2011, Roj: STS 1804/2011)

\footnotetext{
${ }^{285}$ El daño moral se podría deducir cuando la opción 1 no pasa el examen, es decir, cuando la decisión del paciente no hubiese cambiado de conocer previamente la información de los riesgos que se han materializado.
} 
El consentimiento hipotético ha tenido cuestionamientos de peso en la doctrina, Pizarro (2015) sostiene que "[m]irar al pasado para reconstruirlo ya es difícil, pretender que las cosas ocurrieron en forma distinta, aseverarlo y darlo por probado por vía de presunciones es demasiado ficticio" (pp. 114-115). Destaca que, la información no puede ser relevante solo cuando se pruebe que ella hubiese cambiado la decisión del paciente, pues la libertad del paciente ya se vio lesionada (Pizarro, 2015, p. 119) ${ }^{286}$.

Se comparte la crítica fundada de Pizarro, en tanto que, el consentimiento hipotético implica juicios de valor ex post facto que difícilmente demostrarían la real secuencia causal, al afinarse sobre conductas hipotéticas alternativas ${ }^{287}$. Aunado a que, constituye una prueba diabólica para el médico acreditar la decisión que hubiese tomado el paciente, en cuanto es algo personal que puede variar incluso en el último instante previo del acto médico por innumerables circunstancias personales, familiares, económicas, idiosincrasia o hasta por motivos religiosos.

En esencia, la aplicabilidad del consentimiento hipotético al final deviene ilusoria y con un alto margen de probabilidad que el proceso causal planteado no lleve a la seguridad de la decisión que hubiese tomado el paciente, mirado desde su particularidad y no en abstracto. La decisión sobre aspectos tan íntimos y personales es factible que cambie de una persona a otra, nadie podría sustituir el criterio final de un paciente y señalar que hubiese decidido si estuviera en su lugar. Por ello, es complicado determinar el trayecto que hubiese tomado el acontecimiento (Ribot, 2007, p. 43).

A menos, como lo propone Pizarro (2018), que se trate de la inferencia de la voluntad tácita del paciente, pero ello exige "... actos o hechos inequívocos que solo puedan interpretarse en términos de aceptación del riesgo" lo que llevaría a eximir al médico de responsabilidad (p. 80). No obstante, la misma se convierte igualmente en una prueba difícil de acreditar.

\footnotetext{
${ }^{286}$ Pizarro amplía su crítica diciendo que "[e]1 consentimiento hipotético requiere, por una parte, que se logre una prueba sobre qué debe informarse respecto a una intervención en particular a un paciente también específico. A esta tarea se suma considera qué información era relevante, en cuantos riesgos frecuentes o graves inciden en la decisión del paciente o, en cambio, si son irrelevantes. Esta última tarea es demasiado ficticia para ser cierta. Asumiendo que lo que justifica el derecho a la información es la libertad personal del paciente y no solo un supuesto derecho a escoger o la posibilidad de elegir, no corresponde que el juez intervenga asumiendo una irreal voluntad que nunca tuvo lugar" (2018, p. 77).

${ }^{287}$ Igual postura Ribot (2007).
} 


\subsection{Daño por pérdida de la oportunidad}

La pérdida de la oportunidad ${ }^{288}$ vendría a ser un remedio ante la incertidumbre causal con el que cuenta el dañado que materialmente "...no consigue acreditar la alta probabilidad de que, en ausencia del hecho ilícito, habría obtenido un beneficio, pero si la posibilidad seria y real de conseguirlo con que contaba" (Medina, 2007, p. 44). No se indemniza por el total de los daños, únicamente se toma en cuenta parte del daño, que depende de la probabilidad de que la víctima hubiese alcanzado el resultado esperado (Medina, 2007, p. 44).

No escapa la pérdida de la oportunidad de ser un tema que genera debate en materia de responsabilidad, precisamente por el requisito de certeza del daño a reparar en estas situaciones:

Algunos la niegan como sucede con los seguidores de la teoría del todo o nada; otros, si bien la aceptan, tienen diferencias sobre la forma como se debe dar respuesta al problema. Así, dejando a un lado la teoría ontológica y con fundamento en la doctrina de la causalidad probabilística, ven la pérdida de una oportunidad no como la afectación de un bien en sí diferente del perjuicio final, sino como un sistema alternativo de imputación, válido para casos de vacilación causal. (Yong y Rodríguez, 2011, p. 4)

De esta forma, la teoría de la pérdida de la oportunidad puede verse desde dos planos que constituyen en sí mismos dos daños diferentes y que han utilizado tanto la jurisprudencia como la doctrina en respuesta a la inseguridad causal. Una consiste en la causalidad probabilística y se indemniza el daño final en proporción a la probabilidad de que con la conducta diligente se hubiere evitado ese daño final. La otra posibilidad, es que la oportunidad sea un interés protegido y constituya un daño autónomo, y su cuantificación se debe hacer sobre la base de las probabilidades,

\footnotetext{
${ }^{288}$ Esta teoría tiene origen francés, pero la duda no es referida al campo causal, dado que se mira desde el perjuicio de las oportunidades pérdidas de lograr un determinado resultado, "[1] que le da especificidad a este asunto es que el perjuicio no es la pérdida de una "ventaja esperada" (sobrevivir, ganar un proceso judicial) sino la pérdida de la oportunidad de obtener esa ventaja que se espera. El alea es la característica de hecho de la noción" (Chabas, 2013, p. 21).
} 
en este caso la causalidad es cierta, pero respecto a un daño distinto del final (Asúa, 2013, p. $155)^{289}$.

Sobre la pérdida de oportunidad la Corte Suprema de Justicia ha especificado que, en ella existe un razonable juicio de posibilidad encaminado a la obtención futura de carácter real, verídico, serio y cierto de un resultado o de impedir una desventaja. De manera que, se armonizan la certidumbre y la fluctuación con la premisa que el dañado se encontraba en una posición privilegiada, que le permitiría alcanzar el beneficio esperado o evitar que sobreviniera un perjuicio, y el actuar ilícito de la otra persona, trunca la posibilidad de aprovechar la ventaja, como cuando una persona no recibe suficiente información y pierde la oportunidad de elegir una decisión diferente de la que se tomó frente a un negocio importante (Sentencia CS10261-2014 de 04/08/2014).

Entonces, la privación o frustración del chance o de una oportunidad causa por hecho propio un daño “...razón por la cual tiene un valor en sí misma, independientemente del hecho futuro, pues la lesión consistente en la desaparición absoluta de una probabilidad objetiva, posee una naturaleza cierta y directa (Corte Suprema de Justicia, sentencia CS10261-2014 de 04/08/2014).

En el ámbito médico, las posibilidades de aplicación del daño por pérdida de la oportunidad se reducen a dos opciones: la pérdida de curación o de vida desde la perspectiva de errores, retrasos en el diagnóstico y en el tratamiento y atención al paciente; y la segunda, deriva de la falta de información y/o consentimiento informado del usuario de los servicios de salud, sobre la base de una buena praxis médica.

Con relación a ello, Galán (2016) expone que esta teoría puede resultar útil ante las condenas por omisión del consentimiento informado a efectos de modular la indemnización. En el entendido que, lo que se indemniza, en casi todos los casos, es la pérdida de la oportunidad del paciente de

\footnotetext{
${ }^{289}$ Asúa es partidaria de la pérdida de la oportunidad desde la causalidad porque resulta menos artificioso que considerarlo como un daño autónomo, que en muchas ocasiones es categorizado como un daño moral conectado lógicamente a la situación de incertidumbre y no como lesión de otros intereses de naturaleza moral. Pero, reconoce que actualmente es la teoría minoritaria, dado que la mayoría ha optado por la teoría automatista que identifica un daño distinto (2007, p. 79). Sin embargo, sea que se adopte uno u otra posibilidad la indemnización debe calcularse con base en la mayor o menor probabilidad de que se hubiese cambiado el hilo de los hechos con una conducta diligente.
} 
no aceptar la actuación médica de haber conocido los riesgos de ella. Agrega que, la causalidad debe establecerse figurativamente entre la omisión del deber y la posibilidad de haber evitado el procedimiento médico del cual se materializaron unos riesgos, y no así, entre la omisión de la información y el daño cristalizado (pp. 875-876).

Respecto al criterio indemnizatorio, Galán (2016, pp. 894-917) distingue tres casuísticas por omisión del consentimiento informado, que conllevan a diferentes formas de reparar:

- Casos en que de haber existido la información previa adecuada la decisión del paciente no hubiese variado: ante una correcta técnica médica en estos supuestos en principio no habría lugar a una indemnización. A menos que, se cause un daño moral por el impacto psíquico que genera el riesgo cristalizado y hasta entonces desconocido e inesperado.

Para apoyar su conclusión, Galán arguye que se utilizaría la conducta alternativa conforme a derecho-consentimiento hipotético, pero reconoce la dificultad de la prueba por parte del médico.

- Si la decisión del paciente de haber existido información hubiese sido no intervenirse: al no existir incertidumbre causal se debe otorgar una indemnización íntegra del perjuicio materializado.

- Supuestos en que de haber existido información previa y adecuada la decisión del paciente podría haber variado: cuando no se puede probar con absoluta seguridad o con una probabilidad próxima a la certeza que el paciente no se hubiese sometido al procedimiento o lo hubiese consentido, se puede concluir que el paciente ha perdido la oportunidad de sustraerse del procedimiento aplicado o retrasarla u otro tipo de decisiones. Implica que, la indemnización ha de modularse “...en función del valor de la pérdida de probabilidades sufrida por el paciente y no por la integridad del daño a la salud que ha experimentado" (Galán, 2016, p. 904).

En la pérdida de la oportunidad, al momento de establecer el quantum indemnizatorio no se debe promediar por la totalidad del daño aisladamente considerado, como si se hubiese originado por una mala praxis médica. En consecuencia, se debe fijar en función de la potencialidad o 
probabilidad de que el paciente, de haberlo conocido, no se hubiere sometido a dicha intervención ${ }^{290}$.

Lo anterior, lleva a tener en cuenta diversos factores como lo son la urgencia y necesidad del procedimiento, las alternativas del tratamiento, circunstancias de modo, tiempo, personal y familiar, el tipo de riesgo acaecido, diagnóstico del paciente (Galán, 2001, p. 223). Para lograr esto, se realiza un juicio de verosimilitud - de probabilidad cualificada que permitirá hacer la condena más razonable (Galán, 2001, p. 223).

En la mayoría de los supuestos fácticos en torno al tema, existe un margen de duda encaminada hacia la respuesta de cuál hubiese sido la decisión del paciente de haber conocido los riesgos de la intervención y las alternativas al tratamiento. Al juez le corresponde una labor de examen probatorio espinosa, debe tener en cuenta las circunstancias de cada asunto en particular, no es lo mismo estar en presencia de una cirugía necesaria para recuperar el estado de salud del enfermo, que enfrentarse a un procedimiento satisfactivo y voluntario, ya que de esto también dependerá la decisión del usuario de los servicios de salud (Monsalve y Navarro, 2014, p. 263).

La pérdida de la oportunidad es una de las teorías más aceptadas en el mundo académico ${ }^{291}$ y así mismo, con acogida en plano judicial, pero no deja de inquietar el cómputo del quantum indemnizatorio, o sea, el cálculo de las probabilidades con un umbral mínimo y máximo que

290“" $[$ S]olo se indemniza la parte atribuible a las expectativas perdidas, valorada en atención a la probabilidad de evitación del daño final" (Martínez, N. 2014 p. 1).

291 A favor de esta doctrina en materia de consentimiento informado: Pizarro (2018, p. 63), Martínez, N. (2014), Fernández (2015, p. 157), Asúa (2013), Seijas (2016), Xiol (2012, p. 126), Berrocal (2011), Herrera, J. (2008), Arcos (2007, p. 116).

Se destaca lo expuesto por Seijas que si bien no está seguro si la doctrina de la pérdida de la oportunidad está generando una interpretación discordante o salomónica, lo cierto es que se ha consolidado y se dota de una mayor protección al perjudicado dado que la salida avante de su pretensión no depende exclusivamente de una relación causal acreditada "hasta el céntimo" entre la conducta y la pérdida sufrida (2016, p. 277).

En Francia la jurisprudencia era partidaria de la reparación por pérdida de la oportunidad de no poder escapar del riesgo no ilustrado y materializado. Para poder lograr su reparación, se requerirá que se demuestre que en caso de haber sido adecuadamente informado el paciente, la decisión hubiese sido otra (Namén, 2008, p. 198). Sin embargo, Agón (2016, p. 75) enseña que parece ser que la postura se ha abandonado y los jueces han emitido decisiones sobre la configuración un daño moral autónomo dando protección a la dignidad humana, lo que se ha visto desde el 2010 con la sentencia de la Corte de Casación de 03/06/2010 y fue reafirmado en el 2012 con la sentencia del 12/06/2012. Pero, este lineamiento ha sido más que todo trazado por los jueces de inferior jerarquía, las decisiones son disímiles y no está claro del todo si ha sido abandonada la teoría de la pérdida de la oportunidad. Por tanto, el camino aún no está despejado. 
permita determinar qué oportunidad es reparable y cual no, ya sea que se establezca en valor específico o franjas de valor ${ }^{292}$.

En Colombia ${ }^{293}$, el Consejo de Estado ha utilizado, algunas veces, la teoría la pérdida de la oportunidad como fundamento de su decisión. En pronunciamiento que data del 24/01/2002 (exp. 1994-9875-01(12706)), se estudió el caso de un paciente que tenía una masa en región submaxilar izquierda y le fue practicada una Cervicotomía. En la evolución del post operatorio, presentó un deterioro de su salud y un cuadro de embolización; fue llevado nuevamente a cirugía por trombosis de carótida interna izquierda, realizándose una embolectomía. Al paciente le dieron múltiples infartos cerebrales correspondientes a una isquemia cerebral, que limitó totalmente el funcionamiento de sus órganos vitales y lo redujo a una incapacidad física del $100 \%$.

En el curso del proceso quedó acreditado la inexistencia de falla médica en la atención y manejo clínico, pero quedó evidenciada la omisión de la información sobre los riesgos previsibles propios de las condiciones de salud del paciente y del procedimiento en general ${ }^{294}$. Por consiguiente, se condenó “...por la omisión en el deber de información al paciente, hecho que le impidió optar por someterse o rehusar la intervención médica y con ello perdió la oportunidad de no resultar afectado por una intervención que podía aceptar o no".

En ese orden, el Consejo de Estado enfatizó que “...la oportunidad habría consistido, si no en curarse, sí en no agravarse y mantenerse en el estado en que se encontraba...", y al establecer el monto indemnizatorio reconoció el 50\% del perjuicio final (morales para el paciente y su familia, materiales y daño a la vida de relación para el paciente), al tomar como referencia el estado previo de salud deteriorado y el dictamen médico laboral posterior.

\footnotetext{
${ }^{292}$ Expone Martínez, N. que "[1] cierto es que no hay umbrales mínimos a partir de los cuales se admita la aplicación de esta doctrina lo que provoca gran inseguridad jurídica y excesiva discrecionalidad por parte de los Tribunales. De ahí que podamos plantearnos la conveniencia de establecer la exigencia de un mínimo grado de probabilidad o un grado de probabilidad suficiente para poder aplicar la pérdida de oportunidad" (2014, p. 18).

${ }^{293}$ En La Corte Suprema de Justicia no se ha abordado la cuestión desde este planteamiento.

${ }^{294}$ Los riesgos que implicaba era hemorragia post operatoria, formación de coágulos, desprendimiento de la placa ateromatosa o arterioesclerótica, generadores de isquemia cerebral.
} 
Llama la atención que la referida sentencia en la cuantificación del daño, no aluda a las probabilidades de haber evitado el resultado final con base en la posibilidad del paciente de eludir la intervención (no consentir, retrasar o buscar otra alternativa), en un análisis de las circunstancias del caso. Como se observa, el cálculo se hizo con otro parámetro y subjetivamente se impuso el porcentaje, justificado en el arbitrio judicial.

En el 2008 (Sentencia de 23/04/2008, exp. 1997-04547-01(15737)), el Consejo de Estado dejó a un lado la pérdida de la oportunidad, para centrarse en un daño moral por desconocimiento del derecho a disponer de su cuerpo y de su vida, se materialicen o no los riesgos. Aunque expuso que, no habrá lugar a la reparación si se acredita que el paciente de todos modos hubiese consentido el acto médico.

En una sentencia de $2015^{295}$ el Consejo en sus consideraciones alude al perjuicio moral derivado de la "pérdida de oportunidad de haberse negado a la intervención" ante la falta de consentimiento informado. No obstante, su explicación no resulta del todo clara y deviene confusa cuando cita un pronunciamiento de ese mismo Tribunal, que reafirmaba que el daño moral consiste en el sufrimiento padecido por el paciente al haber sido privado de la información y poder decidir conforme a ello si se sometía o no, “...lo cual constituyó una vulneración a su intimidad y a su dignidad como ser humano, capaz de autodeterminarse y de decidir en coherencia con su proyecto de vida, si quería o no que se adelantara el aludido procedimiento irreversible" (26/02/2015, exp. 2000-01368-01 (32322)).

Luego en la liquidación de perjuicios se escribe respecto del moral:

...el perjuicio moral derivado de la falta de un consentimiento informado no se presume; debe ser probado, y no existe prueba en el expediente que acredite la aflicción, el sufrimiento que le causó a ... y menos a los otros demandantes, haber perdido la oportunidad de rechazar el tratamiento si hubiese conocido los riesgos, las pruebas que

\footnotetext{
${ }^{295}$ La causa fáctica consistió en que un paciente con luxación congénita de cadera izquierda le fue practicada una cirugía de reemplazo total de cadera, de la cual se derivó una lesión de la vena iliaca de la pierna izquierda, riesgo previsible que no fue informado, lo que se dedujo de la historia clínica al no constar la advertencia del riesgo previsto. La técnica médica en este supuesto fue acertada.
} 
obran es del sufrimiento de la lesión. Poor [sic] lo anterior resulta improcedente su reconocimiento. (26/02/2015, exp. 2000-01368-01 (32322))

Seguidamente, en el mismo proveído, y con base en la unificación de perjuicios inmateriales de 2014, el Consejo reconoce de oficio de la vulneración de la autodeterminación y otorga medidas de reparación no pecuniarias de ceremonia pública de disculpas y una indemnización de 20 SMLMV.

En suma, en el fallo referido el planteamiento del daño no puede considerarse como de pérdida de oportunidad, en vista de que la cuantificación no se realiza con respecto a la verosimilitud de que se hubiese consentido, sino que es explícita en acudir al pretium doloris.

Por otra parte, en España el Tribunal Supremo, en la Sala Primera de lo Civil, ha optado por el daño por pérdida de la oportunidad en los casos de incertidumbre causal sobre el resultado final. Aduce que la responsabilidad resulta de la omisión de información del riesgo previsible y su posterior materialización, privando al paciente de las decisiones que afectan su salud. En esta dirección, el daño y su cuantificación desde la pérdida de la oportunidad o expectativas:

.... no se identifica necesariamente con la gravedad y trascendencia del daño, sino con una fracción del daño corporal considerado en su integridad... previa ponderación de aquellas circunstancias que se estimen relevantes desde el punto de vista de la responsabilidad médica (gravedad de la intervención, virtualidad real de la alternativa terapéutica no informada, posibilidades de fracaso). (Sentencia 08/04/2016, ROJ 1427/2016)

Para el Tribunal Supremo, en el análisis de la incertidumbre causal se torna más débil las posibilidades de que el paciente hubiese evitado el daño final con su decisión cuando las intervenciones son necesarias/curativas, que cuando devienen satisfactiva como las estéticas.

A pesar de todo, la jurisprudencia del Supremo no evidencia la forma de cuantificar el daño por pérdida de la oportunidad. En las sentencias no es explícito el cálculo de la indemnización en torno al mayor o menor grado de la probabilidad que tenía el paciente, de forma tal, que se haga visible 
en el quantum asignado. De manera que, termina siendo una labor puramente discrecional del juez $^{296}$.

En este mismo orden, en sentencia 16/01/2012 (ROJ 279/2012) - en donde por una intervención de disectomía cervical el paciente quedó afectado de una tetraplejia con paresia severa de ambas extremidades inferiores, tronco y parte de las extremidades superiores y falta de control voluntario sobre esfínter rectal- el Tribunal Supremo consideró que, existía una evidente incertidumbre causal en torno a la secuencia que habrían tomado los hechos, al representar la intervención un porcentaje alto de recuperación y aunque no era vital, si era aconsejable clínicamente por la patología del paciente y el fracaso de otros tratamientos. La reparación del daño por pérdida de la oportunidad tomó como referencia el daño a la salud sufrido y la capacidad de decisión del paciente:

Ello exige una previa ponderación de aquellas circunstancias más relevantes desde el punto de vista de la responsabilidad médica, que en el caso se concretan en una intervención clínicamente aconsejable, en la relación de confianza existente entre paciente- médico, en su estado previo de salud, el fracaso del tratamiento conservador, las complicaciones de escasa incidencia estadística y en las consecuencias que se derivaron de la misma; todo lo cual permite cuantificar la indemnización en 254.977,45 euros a favor del Sr. Pedro Enrique y en la cantidad de 9.586,49 euros a favor de cada uno de los restantes codemandantes, es decir, un $50 \%$ de lo que hubiera correspondido por una mala praxis médica acreditada, tomando como referencia la misma que recoge la sentencia de la Audiencia, mediante la aplicación del baremo, que no ha sido cuestionada.

En Argentina la Sala “M” de la Cámara Nacional de Apelaciones en lo Civil en el 2012, acogió la pérdida de la oportunidad. Expuso que, esa pérdida de rechazar el procedimiento puede repercutir a nivel patrimonial como moral. Por tal razón, ajusta la indemnización conforme a ello, conforme al arbitrium judicis.

\footnotetext{
${ }^{296}$ Asúa (2007 y 2013) y Martínez, N. (2014) son dos estudios interesantes sobre la aplicación de la pérdida de la oportunidad por parte del Tribunal Supremo en materia médica y en especial en la temática del consentimiento informado.
} 
En el daño moral, la Cámara determinó que:

No cabe duda del daño causado por la omisión del médico del deber de dar adecuada información al paciente a unos de los derechos personalísimos de mayor importancia y trascendencia, como es el de disposición del propio cuerpo ... omisión que genera de modo directo daño moral en tanto le impidió adoptar una decisión contando con información suficiente y asumir los riesgos consecuentes. (Sentencia 28/06/2012, M578095) ${ }^{297}$

Es de resaltar, que la explicación del Tribunal se muestra contradictoria ante un enfrentamiento dialectico del daño a indemnizar. O se indemniza la pérdida de la oportunidad respecto de las probabilidades o se acoge la postura de que la lesión a los derechos de la persona genera un daño moral autónomo. De la forma vista, parece que se confundiera el daño indemnizable y se entremezclaran las figuras, generándose una indemnización que sobrepasa el postulado que la justifica.

En Uruguay, las resoluciones judiciales no escapan de la diversidad de posiciones en cuanto al daño y su extensión, no siendo dable hablar de una línea jurisprudencial al respecto ${ }^{298}$. Se encuentran posturas en que domina la pérdida de la oportunidad desde un análisis de lo que una persona promedio hubiese decidido en esas circunstancias (Tribunal de Apelaciones Civil 5 turno, sentencia 03/11/2015, DFA-0004-000579/2015) ${ }^{299}$. También, ha considerado la omisión del consentimiento informado como fuente autónoma de responsabilidad, pero en el entendido que se

\footnotetext{
${ }^{297}$ La situación fáctica se reduce a un paciente diagnosticado con estrechez de conducto cervical con una mielopatía, se le realiza una cirugía y como consecuencia de la misma se produce una isquemia postoperatoria. El riesgo era de baja incidencia (1.5\%), pero grave por generar cuadriparesia y este no fue informado al paciente anticipadamente.

${ }^{298}$ Chile no cuenta con línea jurisprudencial, son escazas sentencias aisladas sobre el consentimiento informado como lo plantea Pizarro (2017, p. 66).

${ }^{299}$ En providencia de 24/08/2016 (81/2016) el Tribunal de Apelaciones Civil 7 turno consideró que: "Ya los Tribunales de Apelaciones Civiles han afirmado que la falta de consentimiento informado no es relevante si el tratamiento hubiere sido de todos modos el mismo ("Doctrina y Jurisprudencia de Derecho Civil" Año IV No. IV, c. 909). Diremos que la falta o la insuficiencia del consentimiento informado por sí sola y como hecho autónomo no origina responsabilidad del médico ni de la entidad médico asistencial, si no se ha demostrado antes (como en el caso a estudio) impericia, error o negligencia inexcusables del facultativo, ni existe prueba de que la opción terapéutica fuera injustificada o que hubiere sometido a la paciente a secuelas innecesarias. Por ende, ni la existencia o no del consentimiento informado, ni las características con las cuales esté documentado, ponen en juego ni detonan legalmente "ipso jure et in genere" la responsabilidad médica. Pero haya existido o no probadamente el otorgamiento del consentimiento médico, es un elemento indiferente para relevar la responsabilidad siniestral médica si no se prueba cuál fue el acto terapéutico o la acción médica dañosa cometido con impericia o negligencia palmariamente injustificable”.
} 
reparan los perjuicios que se materialicen independientemente de la corrección de la conducta médica (Tribunal de Apelaciones civil 2 turno, sentencia 09/04/2014, 0005-000062/2014). En otro supuesto, ante la existencia de falla en la atención afirma que, resulta innecesario pronunciarse respecto al consentimiento informado (Suprema Corte de Justicia, sentencia 30/07/2018, $1.116 / 2018)$.

De lo expuesto en esta sección cabe hacer las siguientes reflexiones:

La pérdida de la oportunidad es una teoría atractiva para los casos de incertidumbre causal donde no ha existido mala praxis médica, pero desde el plano meramente teórico. Su aplicación práctica, genera un alto grado de dificultad en torno a establecer y valorar las probabilidades, por cuanto que, no hay una fijación de un margen aproximativo y tampoco está claro, ni en la doctrina ni en la jurisprudencia, como medir el porcentaje de probabilidad. Determinación que finalmente queda en manos del juez en su prudente y discrecional criterio ${ }^{300}$.

En algunos casos judiciales se observa como la materia a reparar no consiste en sí en la pérdida de la oportunidad propiamente dicha, al tratarse como un daño moral autónomo por la pérdida de la oportunidad de decidir. La cuantificación se deja al arbitrio judicial y no con base en un juicio de verosimilitud, que es lo que exige la teoría. Por tanto, se denota confusión en al momento de cuantificar el daño.

Se concluye que cuando se trata el daño por la pérdida de oportunidad de decidir como daño moral autónomo, y se cuantifica la indemnización en virtud del arbritio judicis, lo que realmente se está indemnizando es la lesión a la autodeterminación del paciente, o sea el derecho al consentimiento informado. En vista de que, no se discute el tema desde la incertidumbre causal, pues la justificación de la responsabilidad está cimentada sobre los derechos del paciente. Así entonces, se observa una cuestión de desencuentros terminológicos, que lleva a igual resultado que

\footnotetext{
${ }^{300}$ Esta teoría ha sido criticada por la doctrina porque “...no se ha fijado un procedimiento claro para concretar esta imputación moderada, es decir, no se han determinado los criterios que deben tenerse en cuenta para establecer las indemnizaciones. Además, este procedimiento de imputación parcial tiene algo artificioso, pues el consentimiento informado busca proteger el derecho de autodeterminación del paciente y una información insuficiente lesiona su autonomía, independientemente del resultado de la intervención” (Agón, 2016, p. 367).
} 
cuando se afirma categóricamente que el quebranto del consentimiento informado es un daño moral per se.

\subsection{El nexo de causalidad}

Durante el estudio del daño se abordó ampliamente el presupuesto del nexo causal, al ser inexorable, en la temática de omisión del consentimiento informado, su análisis en conjunto. A continuación, se presenta, de forma sucinta, la tesis que resulta de mayor interés para este trabajo, desde la consideración del daño como un daño moral por afectar un derecho esencial de la persona y descartar, que el daño consiste en los riesgos o consecuencias materializadas del acto no consentido o consentido con deficiencias de la información ${ }^{301}$.

Cabe señalar que, la causalidad en las omisiones es una de las cuestiones que más ha sido discutida por los juristas, ante la dificultad de explicar cómo un no hacer algo es causa de un resultado positivo. La causalidad natural/física/fáctica no siempre es suficiente para imputar responsabilidad, tal como ocurre con las omisiones, pues desde la perspectiva física la relación del hecho/daño no es posible explicarla. Por tal motivo, se descarta la teoría de la equivalencia de las condiciones, al implicar dependencia contrafáctica la indagación de la condición sine qua non, la cual resulta genuina cuando de conexión física entre dos eventos se trata.

En las omisiones se impone al intérprete esclarecer el concepto normativo de omisión “...que no se identifica con una mera conducta pasiva del agente; es necesario que el comportamiento que se omite sea una acción esperada, en cuanto supone la preexistencia de un deber jurídico de obrar en determinada forma" (Goldenberg, 2011, p. 199).

Identificar la violación de las obligaciones permite la selección de causas en la causalidad por omisión. En decir, “....en la mayoría de los casos los deberes no determinan la existencia de la causalidad por omisión, sino la relevancia jurídica de cierta abstención” (Bárcena, 2012, p. 201).

301 Esto teniendo en cuenta las fronteras del daño por omisión del consentimiento informado expuestas antecedentemente. 
En palabras de la Corte Suprema de Justicia:

...es posible endilgar la autoría de un hecho por las abstenciones cuando el agente tenía el deber legal de actuar para evitar una consecuencia dañosa, lo cual no puede ser explicado por una 'causalidad' desprovista de componentes normativos porque las omisiones no son eventos sino ausencia de éstos, es decir que no generan relaciones de causalidad natural. Es un principio general que no hay responsabilidad civil por las inactividades salvo que el demandado se encuentre bajo un deber legal preexistente o tenga la posición de garante respecto de quien sufre el perjuicio. (Sentencia SC13925-2016 de 24/08/2016) ${ }^{302}$

Por la mecánica de la teoría de la causalidad adecuada, esta sería la más apropiada para explicar la causalidad por omisión y justificar la atribución. Por cuanto en ella, la indagación causal se descompone en la causalidad fáctica y la jurídica. La mera omisión del consentimiento informado, si bien determina la selección causal por incumplir una obligación, requiere que esa causa pase por un filtro adicional, que sería la causalidad jurídica-imputación normativa, luego del estudio de las circunstancias particulares del caso.

Así, la actuación médica realizada sin el consentimiento permite imputar el daño moral por desconocer los derechos del paciente, con independencia de la decisión que hubiese adoptado el paciente de haber conocido la información omitida ${ }^{303}$.

De esta forma, se acredita la causalidad y no es necesario, para la situación particular, acudir a los criterios de imputación objetiva (incremento del riesgo o fin de protección de la norma que serían en donde se podría encasillar la cuestión) considerados solamente como "pautas de enjuiciamiento"304 (De Ángel, 2014, p. 281) que no desplazan la tradicional causalidad jurídica y

\footnotetext{
302 Ciertamente explica la Corte que “...esta imputación no lleva implícito el reproche de la conducta por haber creado un riesgo jurídicamente desvalorado y realizado en el resultado concreto típico, tal como se la suele entender en la dogmática del derecho penal, para cuya determinación la división entre la imputatio facti e imputatio iuris carece de toda importancia. De ahí que nada tiene que ver con la 'teoría de la imputación objetiva' que se ha desarrollado en aquella área recientemente" (Sentencia SC13925-2016 de 24/08/2016).

${ }^{303}$ En el mismo sentido Cadenas (2018, p. 404).

${ }^{304}$ Los criterios de imputación ofrecen marcos conceptuales para aquellas hipótesis en que el problema se basa en la relación de causalidad pero no desarraiga la misma, por ello se comparte con De Ángel que “... la doctrina de la imputación objetiva quizá pudiera llamase, mejor, doctrina de la no imputación objetiva, puesto, que, a mi entender, lo más valioso que esta teoría aporta consiste en determinar cuándo no está justificada la aplicación del principio (la
} 
se pueden entender incorporada a la misma. Debido a que, desde la causalidad adecuada se puede dar explicación a las situaciones de omisión de consentimiento informado.

Respecto al incremento del riesgo ${ }^{305}$ que implica el análisis de la conducta alternativa conforme a derecho para definir la imputación de los riesgos concretados del procedimiento no consentido, el juicio hipotético buscaría constatar si el resultado específico se habría producido -cristalización de los riesgos-. Todo lo cual, escapa de la realidad fáctica, puesto que, como líneas atrás se dijo, los riesgos no dependen de la decisión del paciente al ser consecuencia de la naturaleza del procedimiento. Por lo tanto, es incierto que el evento dañoso no se hubiera verificado. La única forma de exonerarse sería que se demuestre que el paciente hubiese consentido el tratamiento, y de antemano se ha explicado la dificultad de ello.

El fin de protección de la norma en donde “...no pueden ser objetivamente imputados aquellos eventos dañosos que caigan fuera del ámbito o finalidad de protección de la norma sobre la que se pretenda fundamentarse la responsabilidad del demandado" (Pantaleón, 1990, p. 1580) tampoco resuelve de la mejor manera la omisión del consentimiento informado.

Por un lado, la finalidad de la norma que exige el consentimiento informado para los procedimientos médicos no tiene por propósito que no se concreten las consecuencias de dicho acto o que no se generen afectaciones en la salud o vida del paciente. La naturaleza del consentimiento informado busca que las decisiones sean tomadas con conocimiento de causa, proteger la autodeterminación y que el médico no subrogue la voluntad del paciente ${ }^{306}$. En consecuencia, la imputación no tendría lugar cuando, como lo afirmó en su tiempo el propio Pantaleón (1990, p. 1589), se logre demostrar que el paciente con seguridad o rayana certeza habría consentido el acto médico.

genuina imputación objetiva) de que quien desencadena un proceso lesivo deba responder (conforme al criterio de la equivalencia de las condiciones) de todos los daños efectivamente resultantes" (2014, p. 10).

${ }^{305}$ En palabras de Pantaleón este criterio se fundamenta en que “...un evento dañoso no es objetivamente imputable a la conducta negligente que lo ha causado, cuando, dada la configuración de los hechos a enjuiciar, dicha conducta, comparada con su alternativa diligente (con la conducta que, en esas circunstancias, no habría sobrepasado los límites del riesgo permitido), no ha incrementado el riesgo de que se produzca el evento dañoso en cuestión" (1990, pp. 15771578).

${ }^{306}$ En los mismos términos se puede leer a Ribot (2007, pp. 47-49) y Agón (2016, p. 337). 
De lo anterior, se llega a la misma conclusión del incremento del riesgo, al tener que utilizar juicios hipotéticos, que en estos supuestos no serían las opciones más acertadas.

\section{Valoración del daño moral por incumplimiento del consentimiento informado}

Es antiquísima la dificultad que enmarca el daño moral para establecer su valoración y tasación, por tratarse de menoscabos a intereses inmateriales que se encuentran fuera del comercio e invaluables económicamente. Aun así, ello no ha sido un obstáculo para su reconocimiento a través de un sustrato pecuniario a favor del dañado, suma asignada por los operadores de justicia bajo un margen de discrecionalidad -arbitium judicis- en la mayoría de los ordenamientos y en otros, con el apoyo de una tarifación o baremos, como ocurre en la jurisdicción contenciosa administrativa colombiana a partir de 2014 .

La responsabilidad está presidida por la restitutio in integrum -reparación integral- de la víctima, para restablecer la situación lo más parecida posible al estado en el que encontraba la víctima antes del daño sufrido ${ }^{307}$, con la consigna de reparar todo el daño y nada más que el daño ${ }^{308}$, ni más ni menos. En Colombia, la Ley 446 de $1998^{309}$ puso en marcha la exigencia legal del principio de reparación integral atendiendo de igual forma a la equidad ${ }^{310}$, para el cálculo de los daños.

\footnotetext{
${ }^{307}$ La Corte Suprema de Justicia ha precisado que la reparación integral y equitativa implican “... tanto la obligación legal de resarcir todos los daños ocasionados a la persona o bienes del lesionado, como la restricción de no sobrepasarlos, pues la indemnización no es en ningún caso fuente de enriquecimiento" (Sentencia SC 16690/2016 de 17/11/2016).

${ }^{308}$ Esta alocución para referirse a la integralidad del daño fue diseñada por los franceses Toulemon y Moore: "le dommage, tout le dommage, mais rien que le dommage".

309 Art. 16: "dentro de cualquier proceso que se surta ante la Administración de Justicia, la valoración de daños irrogados a las personas y a las cosas, atenderá los principios de reparación integral y equidad y observará los criterios técnicos actuariales" (subraya fuera del texto).

El art. 283 del Código General del Proceso relacionado con la condena en concreto reprodujo el artículo 16 de la Ley 446 de 1998.

${ }^{310}$ En los términos de la jurisprudencia la equidad “...se erige en uno de los más caros criterios teleológicos que debe caracterizar la gestión judicial, no sólo para interpretar la ley cual lo disponen los artículos 32 del Código Civil y $8^{\circ}$ de la Ley 153 de 1887, sino para definir tópicos ajenos a la labor hermenéutica propiamente dicha, inclusive de naturaleza probatoria, pues, v. gr., de conformidad con la Ley 446 de 1998... "el juez está dotado de alguna relativa libertad para llegar a conclusiones que consulten la equidad, siendo, como es, irrealizable a todas luces una justicia de exactitud matemática", y que, tratándose de daños ciertos que se proyectan en el futuro, "la prestación de la indemnización debe consultar una compensación equitativa que ponga a los damnificados en una situación patrimonial más o menos equivalente a la que tenían antes del acontecimiento que les causó el menoscabo"' (Corte Suprema de Justicia, sentencia de 05/10/2004, exp. 6975).
} 
Restablecer a la víctima de un daño moral al estado anterior, es imposible desde la literalidad de las palabras. Aun cuando una suma de dinero no hace desaparecer el agravio sufrido, ello no es óbice para negar la indemnización. Como indican los Mazeaud (2005), debe establecerse un significado común para el término reparar, que cobije más allá de la simple afirmación de volver las cosas al estado anterior, reemplazar, hacer borrar algo porque de esta forma no cabría la reparación para el daño moral (p. 71).

Si bien la función de la responsabilidad civil es reparar ${ }^{311}$, esto no indica que si no se puede hacer en especie entonces la víctima debe cargar con su daño sola. En tano, reparar un perjuicio no solo es restaurar lo dañado, pues frecuentemente es imposible “... sino también suministrar a la víctima la posibilidad de procurarse satisfacciones equivalentes a lo que se ha perdido, que ella es libre de buscar donde le plazca ... el verdadero papel de la indemnización es un papel satisfactorio" (Mazeaud y Mazeaud, 2005, p. 71) (12. $^{312}$

Por tal motivo, es admisible hablar de reparación del daño moral cuando se le da una indemnización al ofendido a través de una suma de dinero, que cumple una función satisfactoria cuyo quantum se proporciona conforme a la dimensión del agravio experimentado y no a la gravedad de la falta cometida (Brebbia, 1950, p. 202). Es posible que, una culpa insignificante genere un detrimento moral o patrimonial de gran envergadura. Contrariamente, un hecho más grave, por mediar dolo en la conducta del dañador, puede dar paso a un quebranto de menor significado (Pizarro, 1996, p. 339).

\footnotetext{
${ }^{311}$ A lo largo de esta investigación se ha aludido al vocablo reparar. Así mismo y como sinonimia se ha hablado de indemnizar, lo cual es correcto desde el significado de estas palabras. Desde el significado corriente reparar, indemnizar y compensar son similares en su contenido. De acuerdo con la RAE resarcir es "indemnizar, reparar, compensar un daño, perjuicio o agravio", indemnizar es "resarcir de un daño o perjuicio, generalmente mediante compensación económica", reparar es "enmendar, corregir o remediar. / Desagraviar, satisfacer al ofendido", compensar implica "dar algo o hacer un beneficio a alguien en resarcimiento del daño, perjuicio o disgusto que se ha causado".

Henao documenta que gran parte de la doctrina, especialmente la francesa, prefiere utilizar el término indemnización para referirse a la pecuniaria, por ello este autor prefiere utilizar un término más amplio para evitar restricciones y acoge el de reparación como "... la manera como el responsable cumple la obligación de reparar asegurando a la víctima el retorno al status quo ante al acaecimiento del daño" y permitir así que cobije todas las formas de retorno al status quo (2015, pp. 285-287).

${ }^{312}$ En igual criterio De Cupis: “...el que ha sufrido un daño no patrimonial, no puede con el equivalente pecuniario alcanzar un resultado final que se acerque a la situación anterior ...s s[o]lo podrá alcanzar con dinero, aquellas ventajas y satisfacciones personales que puedan compensarlo en otros aspectos de su vida, procurando que el balance de su felicidad personal recupere nuevamente su equilibrio general y total" (1975, p. 766$)$.
} 
La Corte Interamericana ha señalado que el daño inmaterial es objeto de compensación para los fines de la reparación integral a la víctima “...mediante el pago de una cantidad de dinero o la entrega de bienes o servicios apreciables en dinero, que el Tribunal determine en aplicación razonable del arbitrio judicial y en términos de equidad" (Sentencia de 30/11/2016, caso I.V. vs. Bolivia) $)^{313}$.

Lo anotado, sin dejar a un lado que las reparaciones deben tener “....un nexo causal con los hechos del caso, las violaciones declaradas, los daños acreditados, así como con las medidas solicitadas para reparar los daños respectivos" (Caso Norín Catrimán y otros vs. Chile, sentencia de 29/05/2014).

Las reparaciones a las que alude la Corte Interamericana no solamente van orientadas a las indemnizatorias habituales, al optar por disposiciones de carácter general en busca del reconocimiento de la dignidad y la justicia, a través de medidas de no repetición y mecanismos de satisfacción (Rousset, 2011, pp. 66-67). Dado que, no siempre se puede devolver las cosas al estado anterior, se toman otros remedios para garantizar los derechos transgredidos y reparar las secuelas que las contravenciones produjeron ${ }^{314}$.

La omisión del consentimiento informado, como se vio a lo largo de este capítulo, no ha estado exenta de los problemas sobre cómo valorar e identificar la entidad del daño. Se observan argumentos heterogéneos que no sistematizan una guía práctica judicial y que varían dependiendo

\footnotetext{
${ }^{313}$ En la literalidad de la Corte: “[1]a reparación del daño ocasionado por la infracción de una obligación internacional requiere, siempre que sea posible, la plena restitución (restitutio in integrum), que consiste en el restablecimiento de la situación anterior. De no ser esto factible, como ocurre en la mayoría de los casos de violaciones a derechos humanos, el Tribunal determinará medidas para garantizar los derechos conculcados y reparar las consecuencias que las infracciones produjeron. Por lo tanto, la Corte ha considerado la necesidad de otorgar diversas medidas de reparación, a fin de resarcir los daños de manera integral. Así además de las compensaciones pecuniarias, las medidas de restitución, rehabilitación, satisfacción y garantías de no repetición tienen especial relevancia por los daños ocasionados" (Sentencia de 30/11/2016, Caso I.V. vs. Bolivia).

${ }^{314}$ Las reparaciones simbólicas han tenido eco en la jurisprudencia del Consejo de Estado para los supuestos de graves violaciones a los derechos humanos por parte del Estado colombiano: "[1]as medidas de reparación integral operarán teniendo en cuenta la relevancia del caso y la gravedad de los hechos, todo con el propósito de reconocer la dignidad de las víctimas, reprobar las violaciones a los derechos humanos y concretar la garantía de verdad, justicia, reparación, no repetición y las demás definidas por el derecho internacional. Para el efecto el juez, de manera oficiosa o a solicitud de parte, decretará las medidas que considere necesarias o coherentes con la magnitud de los hechos probados (Artículo 8.1 y 63.1 de la Convención Interamericana de Derechos Humanos)" (acta del 28 de agosto de 2014 "Referentes para la reparación de perjuicios inmateriales" del Consejo de Estado, Sala de lo Contencioso Administrativo).
} 
del juez de la causa, en su particular sentido de justicia y consideración del daño a los derechos de la personalidad. En general, se indica apreciar la magnitud o gravedad del menoscabo producido $^{315}$, mas en cuestión del daño moral puede ser abstracta la identificación.

Un asunto es determinar la existencia del daño y hasta dónde se extiende la obligación de reparación y otro, medir o valorar ese daño para traducirlo en una compensación económica. El daño por omisión al consentimiento informado se infiere in re ipsa, pero su dificultad deviene de la evaluación de la entidad del daño, para establecer un quantum determinado.

Al llegar a este punto, la presente investigación propende unos parámetros que pueden servir de guía para el operador judicial al momento de la valoración del daño moral, que permiten justipreciar la trascendencia del detrimento en la situación de una persona. La lesión del derecho a la autodeterminación puede variar de relieve e intensidad, dependiendo de ciertas circunstancias que exceden la órbita de la mera superficialidad de un fastidio, enojo o incomodidad, lo cual se verá reflejado en el monto indemnizatorio.

Se comparte la idea de Zavala en cuanto a que, se debe apreciar la entidad objetiva de la lesión y su específica repercusión en la víctima, lo que se conoce como el principio de individualización del daño, sin que esto implique que “...la tutela legal se subordine a caprichos y exageraciones subjetivas" (Zavala, 2011, p. 633).

Entonces, con las pautas se busca observar una plena reparación y generar argumentos para la fundamentación de la decisión, con el propósito de evitar tacha de arbitrariedad, no apreciación de las pruebas o la incongruencia. Esto, no indica que es el único norte y tampoco encierran un criterio de objetividad absoluta, al final será el juez quien, con su prudencia, las reglas procesales probatorias y el principio de equidad, definirá la entidad y el alcance del daño moral. Como bien

\footnotetext{
${ }^{315}$ El Consejo de Estado en el acta del 28 de agosto de 2014 alude a este criterio. La Corte Suprema de Justicia expuso que el Juez "....atender a esas particularidades del caso e inferir no sólo [sic] la causación del perjuicio sino su gravedad" (Sentencia de 19/12/2018, SC5686-2018).

En España por ejemplo la ley de "Protección civil del derecho al honor, a la intimidad personal y familiar y a la propia imagen" (art. 9.3.) señala tener en cuenta las circunstancias del caso, a la gravedad de la lesión efectivamente padecida, a la difusión o audiencia del medio a través del cual se haya producido la intromisión ilegítima y al beneficio obtenido del causante de la lesión como consecuencia de la misma.
} 
lo expresa Pizarro (1996), la prudencia judicial no implica que quede librada a la subjetividad, solo que esta debe apoyarse dentro del marco referencial que le ofrece la ley y con base en las realidades objetivas de cada situación (p. 337).

Recomendaciones a observar para la valoración del daño moral:

- El juez debe apreciar los elementos que enmarcan la situación particular del accionante y examinar las circunstancias en que operó la omisión del consentimiento informado, tales como el estado de necesidad de la intervención, el tiempo entre la información y la firma del consentimiento informado -dado que permite establecer si el paciente se le dio el espacio para reflexionar- y la cantidad de información revelada, que indica qué tan frágil fue lo conocido por el paciente, de forma que afecta notoriamente el derecho a decidir informadamente.

- Si bien las vivencias internas a raíz del daño pueden variar de una persona a otra en su grado e intensidad, ciertas condiciones (personales, religiosas o culturales) de la víctima pueden ayudar al juez para el ejercicio de su arbitrium judicis y darle mayor individualidad al daño aparejado, para estimar una equivalencia entre el daño y la indemnización. Una ilustración de esto ocurre con las transfusiones de sangre no autorizadas en un paciente que pertenece a los Testigos de Jehová, quienes no toleran esta práctica, lo que hace que la privación sea más honda en esa persona.

Se considera que es relevante que el afectado no solo invoque de forma general la lesión a su derecho de decidir informadamente. Así, en aras de ilustrar al juez, siempre que sea posible, especifique el alcance e incidencia de la lesión, las particularidades de su situación y estado de salud, para que el operador las estime y pondere a efectos de la valoración y estimación del daño.

- Es posible que la lesión a la autodeterminación de forma directa se exteriorice con manifestaciones como rabia, dolor, tristeza, frustración, irritabilidad o congoja, lo que se podría probar por testimonios o conceptos médicos. Cuando esto ocurre, es importante presentárselo al juez, debido a que sirve como orientación para aquilatar la entidad del daño. Es decir, hacerse una representación de cuán trascedente e impactante fue para esa persona el menoscabo de su derecho. 
- Aunque se ha apuntado que el daño moral por omisión del consentimiento informado es autónomo a la concreción de los riesgos del procedimiento a efectos de reconocer su existencia, no sucede lo mismo para establecer su entidad. En virtud de que, se debe tener en cuenta si los riesgos del procedimiento se materializaron o no, puesto que cuando estos se concretan la experiencia llevaría a concluir que la lesión adquiere mayor gravedad para la víctima al sentirse agraviada intensamente en su libertad.

- Teniendo en cuenta que se trata de establecer la magnitud del daño acaecido, servirá de orientación definir si se trata de una omisión total del consentimiento informado o de defectos e insuficiencia de la información, pues en el primer supuesto el daño moral aumenta más la afectación de la libertad, integridad y dignidad de la persona.

- No obstante que todos los riesgos previsibles y típicos deben ser informados, a efectos de la valoración cobra importancia examinar la frecuencia del riesgo cristalizado y la gravedad del mismo en consideración al paciente en particular, como su condición de salud que lo haga propenso a determinado riesgo, profesión, arte u oficio porque ello aproxima la frustración y el impacto de la lesión a la autodeterminación.

- El operador de justicia debe tener en cuenta para determinar la intensidad y relevancia del daño moral, si el procedimiento es invasivo, tiene como propósito mutilaciones o las consecuencias son de aquellas que generan incapacidad permanente.

- Adquiere relevancia especial aquellos casos en que la vulneración de la libertad de decidir tiene implicaciones en los derechos reproductivos, por constituir una injerencia arbitraria e intromisión abusiva en lo más íntimo de la persona con trascendencia inmensurable. En palabras de la Corte Interamericana:

...la Corte entiende que en casos de esterilizaciones femeninas es imprescindible el acceso a información sobre métodos alternativos de anticoncepción debido a que la ligadura de las trompas es sólo un método entre una diversidad de métodos que podrían haberse evaluado para lograr el mismo fin, esto es, impedir un futuro embarazo. La Corte ya ha establecido 
en otros casos que el acceso a la información integral y comprehensiva es un componente de la accesibilidad a los servicios de salud y, por ende, es imprescindible para garantizar este derecho (supra párr. 156). La señora I.V. debió haber conocido no sólo la probabilidad de éxito de otros métodos anticonceptivos, sino la conveniencia de la utilización de los mismos, en su caso en particular. Sólo [sic] así habría contado con elementos necesarios para la toma de una decisión libre e informada.

...resalta la gravedad de esta violación a los derechos de las mujeres, porque es necesario visibilizar prácticas como las verificadas en este caso que pueden esconder estereotipos de género negativos o perjudiciales asociados a los servicios de atención en salud y conllevar a legitimar, normalizar o perpetuar esterilizaciones no consentidas que afectan de forma desproporcionada a las mujeres. (Sentencia de 30/11/2016, caso I.V. vs. Bolivia) ${ }^{316}$

Como se vio en las recomendaciones, son diversas las circunstancias que debe analizar cautelosamente el juez para asignar un valor económico al daño, al devenir el daño moral de una transgresión a un derecho de la personalidad y no de lesión a la vida o a la salud.

Se ha dejado consignado que en los daños morales es el juez, quien, en ejercicio de su facultad, establece la valoración justa para cada situación. Por tanto, se requieren sentencias fundamentadas y con argumentos sólidos que justifiquen la suma otorgada al dañado, como evidente proximidad al daño sufrido.

Debe tener presente el funcionario judicial que el fin es reparar a la víctima y no sancionar la conducta del infractor. De modo que, debe buscar una justa medida en la reparación y evitar indemnizaciones desfasadas o exorbitantes que prácticamente revelarían una sanción. Además, las sumas desmedidas esconderían bajo el ropaje del daño moral una indemnización por los daños que

\footnotetext{
316 Este caso se constituye en la primera sentencia donde específicamente se trata el tema de la omisión del consentimiento informado del paciente ante un procedimiento de ligadura de trompas sin el consentimiento de la mujer o su pareja. No se toma de referencia para especificar el daño a indemnizar porque aparte de la lesión al consentimiento informado se denota una mala praxis, al no ser un procedimiento necesario ni urgente, y también, se reprocha del Estado la vulneración de las garantías judiciales, protección judicial y no discriminación en el acceso a la justicia.
} 
produjo el acto médico, que no guardarían relación causal con la específica omisión del consentimiento informado.

Asimismo, no debe perderse de vista que no puede cuantificarse igual la mala praxis derivada del procedimiento o atención médica y la omisión del consentimiento informado, pues la beneficencia y no maleficencia son principios que guían la actividad profesional médica, gobernados por el altruismo y la solidaridad en el ejercicio. De ahí que, se presuma que el acto médico tiene como norte estos lineamientos partiendo de la buena fe de la actuación.

No se trata de ser generosos o tener compasión con el ofendido en su derecho, pues esto generaría un quiebre de la institución de la responsabilidad y afectaciones económicas injustificables para el dañador o el sistema asegurador, difíciles de sostener.

También, el reconocimiento por la vulneración de la autodeterminación deviene solicitado y no sería adecuado reconocer de oficio su reparación por parte del juez, al afectar el debido proceso y el derecho de defensa del demandado y daría paso a desconocer el principio de congruencia ${ }^{317}$.

De igual forma, la propia víctima puede estimar las medidas adecuadas para su reparación, que al estar en el campo de la responsabilidad civil buscará generalmente una satisfacción económica. Pudiera el damnificado expresamente optar por medidas de reparación diferentes a las económicas, como la publicación de la sentencia o un comunicado de disculpas siempre y cuando, tengan para él un carácter reparador. En estos supuestos, el juez debe analizar si dicha medida es razonable a la entidad del daño moral.

Cabe aclarar que, no es fácil establecer un cuánto por daño moral, de ahí la diversidad de condenas. No propone esta investigación que la forma de generar seguridad jurídica sea a través de un baremo o un sistema de tarifación, ya que no sería el medio más equitativo y justo para solucionar los casos del daño moral, por la dificultad de su estimación económica y la necesidad de individualizar el daño para cada situación que se presente.

\footnotetext{
${ }^{317}$ Sobre la congruencia de las sentencias ver art. 281 del CGP.
} 
Sin embargo, desde las Altas Cortes, como órganos de cierre de la jurisdicción, se debe promover la fundamentación de las condenas por daño moral, de modo que sean verdaderos precedentes judiciales que guíen a los jueces de menor jerarquía y puedan otorgarse sumas similares para situaciones no tan divergentes. 


\section{Conclusiones}

En la presente investigación, con base en el objetivo general planteado, se identificó y analizó el perjuicio indemnizable que se genera a favor del paciente ante el incumplimiento del consentimiento informado con independencia de la corrección de la praxis médica, ya sea que se concreten o no los riesgos previsibles que no fueron informados previamente.

Para cumplir ese objetivo fue necesario un análisis pormenorizado del consentimiento informado desde sus antecedentes trascendentales, obligatoriedad legal de carácter local e internacional, finalidad, contenido, diferencia con el consentimiento contractual y tipo de obligaciones que encierra. Esta temática permitió la caracterización del daño indemnizable, pues de la misma se configuraron los parámetros para establecer cuál era el hecho, el criterio de imputación, el daño y la relación causal como presupuestos de la responsabilidad estudiados desde su función reparadora.

Las conclusiones que se derivan del trabajo de investigación enlazan la importancia del consentimiento en la praxis médica, y son las siguientes:

1. Desde la connotación del consentimiento informado como derecho y principio que integra la lex artis conforme al binomio de información completa, adecuada y suficiente para dar paso a una decisión reflexiva, libre y autónoma sobre la aceptación de un acto médico, se concluyó que el daño a reparar es un daño moral autónomo, cuya existencia deviene in re ipsa por la lesión a derechos de la personalidad.

2. El daño moral por incumplimiento del consentimiento informado no necesita la exteriorización de consecuencias para hacer valer su protección a través de la institución de la responsabilidad, dada la gravedad que constituye el menoscabo en los derechos más íntimos de la persona. Todo lo cual, resulta acorde con los principios constitucionales y tratados/convenciones internacionales de protección a la persona como un fin en sí misma, desde su dimensión espiritual y corporal.

3. El consentimiento informado es una obligación que se desprende del ejercicio de los derechos fundamentales del paciente reconocidos en virtud de la intangibilidad de la persona, supera la 
esfera de ser un deber secundario de conducta para erigirse como toda una obligación propia de la naturaleza de la relación sanitaria.

4. Por tal motivo, la discusión sobre si es precontractual, contractual o extracontractual la responsabilidad médica no genera gran utilidad desde la perspectiva de las condiciones para que haya responsabilidad -hecho, daño y nexo causal, ya que el consentimiento informado al ser un derecho es exigible legal y éticamente en todas las esferas del acto médico, al margen de si la atención es pública o privada, de si media o no un contrato, o como se encauce la relación médicopaciente o de si se está ante un tratamiento necesario/curativo o con fin satisfactivo o de embellecimiento.

5. Las obligaciones de informar y de obtener el consentimiento del paciente se enmarcan en la categoría de las obligaciones de resultado al ser de estricto cumplimiento y se verifican con su mera ejecución, siendo excusable la obligación por las causales generales de rompimiento del nexo causal y por las propias del acto médico establecidas por ley y jurisprudencia, como cuando se está ante una urgencia vital.

6. En lo que respecta a los términos de adecuación, transmisión y comprensión de la información y decisión consciente del paciente son obligaciones de medios, lo cual se deriva desde la concepción del consentimiento como un principio. En estos eventos, el galeno se compromete a desplegar sus capacidades y habilidades en procura de que el receptor de la información capte el contenido, al margen de poder asegurar el resultado específico al escapar de su control.

7. Si bien la responsabilidad médica está asentada en general en la culpa probada como criterio de atribución, no es menos cierto que, el consentimiento informado presenta cierta particularidad al sustentarse en una negación indefinida, por lo que conforme al art. 167 del Estatuto Procesal Civil colombiano, corresponde al médico la carga de demostrar su actuar diligente.

8. En el estudio de los presupuestos de la responsabilidad por incumplimiento del consentimiento informado, se constató la dificultad que encierra las conductas omisivas para la identificación del nexo causal y el correspondiente daño. Sin embargo, a través de la teoría de la causalidad adecuada 
se pudo explicar la relación causal en la omisión de una obligación y, asimismo, justificar la atribución, por cuanto en esa teoría la indagación causal se descompone en la causalidad fáctica y la jurídica.

9. La mera omisión del consentimiento informado si bien determina la selección causal por incumplir una obligación, requiere que esa causa pase por un filtro adicional que sería la causalidad jurídica-imputación normativa, luego del estudio de las circunstancias particulares del caso.

10. La propuesta del daño moral permite moderar la radicalidad en la reparación que comporta el criterio de asunción de riesgos, en donde se iguala la indemnización de incumplimiento de consentimiento informado a la práctica médica negligente, de forma tal, que el médico debe responder por absolutamente todos los perjuicios obviando el tema de la relación de causalidad. En efecto, se observó en esos casos no tanto una reparación como la punición de la conducta del profesional infractor.

11. La tesis del daño moral atempera la perplejidad de la determinación del daño y la incertidumbre causal que conlleva a la averiguación de la conducta alternativa conforme a derecho, que más que solucionar el problema, termina por asignar pruebas diabólicas al médico, al tener que demostrar que el paciente de conocer la información de todos modos hubiese aceptado el procedimiento. También, se evitan debates hipotéticos ex post facto que no revelan realmente el curso causal de los hechos, al estar impregnados de subjetividad cargada negativamente por un resultado dañoso que se ha materializado.

12. El postulado de la pérdida de la oportunidad, aunque en principio resulta atractivo como daño a reparar, genera complejidad en su aplicación para establecer el margen de posibilidades que tenía el paciente de aceptar o rechazar el acto médico propuesto, y de igual forma, medir dicho porcentaje de probabilidad. Ciertamente, conlleva a una zona de penumbra que debe descifrar el juez, en consonancia con su prudente y discrecional juicio.

13. Cuando se trata el daño por la pérdida de oportunidad de decidir como un daño moral autónomo y se cuantifica la indemnización conforme a la discrecionalidad del juez, lo que realmente se está 
indemnizando es la lesión a la autodeterminación del paciente, o sea, el derecho al consentimiento informado. Esto, porque no se resuelve la materia desde la probabilidad, sino que la justificación de la responsabilidad está cimentada sobre los derechos del paciente. En ese sentido, resulta más adecuado acudir al daño moral derivado de la lesión a un derecho y evitar confusiones terminológicas, ante un sinnúmero de diferenciaciones de daño moral que pueden derivar en dobles reparaciones.

14. A diferencia de los otros planteamientos, el daño moral autónomo resalta la importancia del derecho al consentimiento informado no solo en los casos en que se concreta un resultado adverso fruto del acto médico no consentido o consentido con defectos en la información, sino que su reparación aún puede ser viable cuando no se materializa un riesgo.

15. La investigación se sumergió en los puntos más álgidos de la determinación del daño y por eso, en su desarrollo se observó que un enunciado general de daño moral autónomo no resolvía totalmente los problemas, dados los diversos supuestos que se derivan del incumplimiento del consentimiento informado. Además, podría desencadenar la desmesurada utilización de la institución responsabilidad que desenfocaría su finalidad. Esto, implicó establecer unas fronteras del daño moral con el fin de concretar los criterios básicos para la determinación del daño, que resulten relevantes para el derecho y ameriten, por ende, su reconocimiento e indemnización.

Esos criterios fueron: actuación médica correcta, información defectuosa y materialización de un riesgo previsible: indemnizar daño moral; actuación médica correcta, defectuosa información y no se materializan riesgos: no hay lugar a indemnización; actuación médica correcta, información defectuosa de tratamientos alternativos y materialización de un riesgo previsible e informado: indemnizar daño moral; actuación médicamente correcta y ausencia total del consentimiento informado: indemnizar daño moral; mala praxis médica y ausencia total del consentimiento informado: se indemnizan todos los perjuicios ocasionados incluyendo el daño moral, se subsumen en este enunciado el desconocimiento de la voluntad expresa del paciente, los procedimientos forzosos y la información engañosa o manipulada al constituir una afrenta grave a los derechos del paciente que al mismo tiempo comporta una incorrección del acto médico. 
16. Al catalogarse el incumplimiento del consentimiento informado como un daño moral, queda en manos del juez establecer la valoración justa y estimación económica -arbitrium judicisapoyado en el caudal probatorio y las circunstancias que enmarcan cada situación.

17. Ahora bien, valorar e identificar la entidad del daño moral causa perplejidad para asignarle una compensación económica. Por ello, la investigación propendió por establecer unos parámetros que pueden servir de guía para el juez al momento de la valoración del daño moral, que permiten justipreciar la trascendencia del detrimento, tales como: las circunstancias particulares del paciente, condiciones modo/tiempo/lugar de cada caso en concreto, existencia de manifestación externa del daño, la cristalización o no de los riesgos, si el incumplimiento del consentimiento informado es total o parcial, si el procedimiento era invasivo con consecuencias de incapacidad permanente o muerte y si la vulneración de la libertad tiene implicaciones sobre los derechos reproductivos.

18. El juez no puede perder de vista que no se trata de ser generosos o tener compasión con el ofendido en su derecho, pues esto generaría un quiebre de la institución de la responsabilidad y afectaciones económicas injustificables para el dañador o el sistema asegurador, difíciles de sostener. A más de ir en contra de la finalidad reparadora de la responsabilidad y permitir enriquecimientos injustificados.

19. Como se está en materia de responsabilidad civil con una finalidad meramente reparadora, el reconocimiento por la vulneración de la autodeterminación deviene solicitado. En consecuencia, no sería adecuado reconocer de oficio su reparación por parte del juez, debido a que afecta el debido proceso y el derecho de contradicción del demandado, y también, desconocería el principio de congruencia.

20. Por otra parte, ante los defectos de la información en los eventos preliminares a la realización del acto médico encomendado, resulta jurídicamente viable la aplicación de la teoría del vicio del consentimiento para atacar el consentimiento contractual viciado de error, para que todo vuelva al estado anterior. Igual, para cuando el consentimiento contractual y para el acto médico se fusionan en un mismo momento y la actuación médica no se ha llevado a cabo. 
Pero, si los riesgos se materializan, el paciente no tiene otra alternativa que demandar la responsabilidad médica en el supuesto del incumplimiento del derecho al consentimiento informado

21. También se ofrecen reflexiones y orientaciones para los profesionales de la salud, en aras que cumplan correctamente con su obligación desde la identificación del paciente como sujeto de derechos con libertad de decisión.

De esta forma, se abordaron los temas de contenido de la información coligiendo que los riesgos a informar son los típicos y previsibles. Asimismo, se concluyó que el deber de consejo, al referirse a un criterio personal y no a una postura científica, no puede derivar vinculante.

Es recomendable que los documentos de consentimiento estén acompañados de un intercambio de información esencialmente verbal, que debe exigirse prolongado y detallado entre más complejo, delicado, invasivo y comprometido sea el procedimiento recomendado. Asimismo, debe existir correspondencia entre la información dada verbalmente y lo que se consigne en el documento y en la historia clínica.

22. La medicina requiere una mezcla de humildad, humanidad y confianza para lograr con éxito los fines de la misma. Solo con la visión de una medicina humanizada, el consentimiento informado puede ser una realidad más allá de un simple ideal. Para ello, se requiere una labor conjunta de capacitación para el médico, equipo sanitario y paciente. Igualmente, implica una labor educativa para los jueces con el fin de ilustrarse en la solución de los casos de responsabilidad médica por este concepto.

Pero asociado a ello, esa contradicción entre el humanismo y el instrumentalismo amerita intervención del Estado para que las regulaciones, políticas y recomendaciones cumplan sus cometidos, no se necesita un exceso de normas que declaren derechos de los pacientes y obligaciones en la atención médica, más bien, deben propender por la toma de conciencia, las 
condiciones y espacios para su efectividad, a través de estándares mínimos para asegurar la calidad del sistema.

Finalmente, esta investigación abre las puertas para futuras investigaciones sobre algunos problemas que no fueron abordados en el trabajo o si se trataron no fue con la suficiente profundidad, al escapar del radio de acción de la investigación. Así, se encuentran el consentimiento informado y las complicaciones con la capacidad, los hallazgos médicos en medio de una intervención quirúrgica, análisis de casos clínicos, estudios de derecho comparado, funcionabilidad de los consentimientos informados en hospitales o clínicas y perjudicados indirectos o de rebote.

De hecho, el tema del daño indemnizable no está acabado ni agotado con la presente investigación, se puede seguir estudiando y debatiendo sobre los diferentes planteamientos, pues como afirma De Ángel (2001) en cuestiones de derechos de la personalidad siempre hay algo nuevo que decir “...está eternamente inacabado. En él no hay extremo que no esté plagado de cuestiones y problemas (...)” (p. 1), y si se le agrega la complejidad del daño moral para su valoración y estimación, las puertas se abren para justificar o contradecir la postura acogida en este trabajo. 


\section{Referencias}

Abad, B. (2016). Investigación social cualitativa y dilemas éticos: de la ética vacía a la ética situada. EMPIRIA Revista de Metodología de Ciencias Sociales, (34), 101-120. DOI: https://doi.org/10.5944/empiria.34.2016.16524

Acciarri, H. y Irigoyen, M. (2015). Funciones alternativas a la compensación: prevención y punición. En Gómez, F. y Marín, I. (dir.) El daño moral y su cuantificación (189-242). Barcelona, España: Bosch.

Agón, J. (2016). Consentimiento informado y responsabilidad médica (Tesis de doctorado). Recuperado de: https://gredos.usal.es/jspui/handle/10366/135700

Alessandri, A. (1982). La nulidad y la rescisión en Derecho Civil, tomo II. Santiago, Chile: Ediar Editores.

Alexy, R. (1993). Teoría de los derechos fundamentales. Versión castellana: Ernesto Garzón Valdés. Madrid, España: Centro de Estudios Constitucionales.

Alonso, M. (2000). La relación médico-enfermo, presupuesto de responsabilidad civil (en torno a la lex artis). En Moreno, J. (coord.), Perfiles de la responsabilidad civil en el nuevo milenio (13-56). Madrid, España: Dykinson.

Andorno, L. (1993). Protección a la Persona Humana. Nuevos daños a la persona Humana. Derecho a la imagen. En Andorno, L., Barbier, E., Cifuentes, Do Cuoto e Silva, C., Goldenberg, L., Kelmelmajer, A., López, R., Mosset, J., Parellada, C., Sessarego, C., Stiglitz, G. y Stiglitz, R. Daño y protección a la persona humana (163-172). Buenos Aires, Argentina: La Roca.

Aparisi, M. (1990). La declaración de independencia americana de 1776 y los derechos del hombre. Revista de estudios políticos, (70), 209-224. Recuperado de: https://dialnet.unirioja.es/servlet/articulo?codigo $=27087$

Arbesú, V. (2015). La responsabilidad civil en el ámbito de la cirugía estética (Tesis de doctorado). Recuperado de: http://e-spacio.uned.es/fez/view/tesisuned:Derecho-Varbesu

Arcos, M. (2007). Responsabilidad Sanitaria por incumplimiento del deber de información al paciente. Cizur Menor, España: Aranzadi.

Arcos, M. (2016). Responsabilidad civil por infecciones asociadas a la asistencia sanitaria. Cizur Menor, España: Aranzadi.

Arenas, H. (2014). El régimen de responsabilidad subjetiva, primera edición. Bogotá, Colombia: Legis.

Argani, P. (2017). Responsabilidad penal del médico. Buenos Aires, Argentina: Astrea. 
Ariza, A. (2014). El criterio de imputación de la responsabilidad profesional. Análisis de la jurisprudencia civil de la Corte Suprema de Justicia 1990-2010. Bogotá, Colombia: Universidad Javeriana y Editorial Ibáñez.

Arroyave, C. (2010). El dilema del médico como paciente: Otra mirada a la experiencia de la enfermedad. Revista latinoamericana de bioética, 10 (1), 36-55. Recuperado de: http://www.scielo.org.co/scielo.php?script=sci_arttext\&pid=S1657-47022010000100004

Asúa, C. (2006). Responsabilidad civil médica. En Reglero, L. (coord.) Tratado de Responsabilidad Civil, 3a edición, (1153-1232). Cizur Menor, España: Aranzadi.

Asúa, C. (2008). Pérdida de oportunidad en la responsabilidad sanitaria. Cizur Menor, España: Aranzadi.

Asúa, C. (2013). Infracción de deberes de información y obligación de indemnizar en el ámbito sanitario. Revista CESCO de Derecho de Consumo, (8), pp. 147-161. Recuperado de https://www.revista.uclm.es/index.php/cesco/article/view/411

Ataz, J. (1985). Los médicos y la responsabilidad civil. Madrid, España: Montecorvo, S. A.

Bárcena, A. (2012). La causalidad en el derecho de daños (Tesis de doctorado). Recuperada de: https://dugi-doc.udg.edu/bitstream/handle/10256/7633/trabz.pdf?sequence=5

Bárcena, A. (2014). El derecho de daño como banco de pruebas de una disputa filosófica sobre la causalidad. En Papayanis, D. (coord.), Causalidad y atribución de responsabilidad, (181214). Madrid, España: Marcial Pons.

Barros, E. (2006). Tratado de Responsabilidad civil extracontractual. Santiago, Chile: Editorial Jurídica de Chile.

Bascuñán, M. (2005). Cambios en la relación médico-paciente y nivel de satisfacción de los médicos. Revista médica de Chile, 133(1), 11-16. DOI: https://dx.doi.org/10.4067/S003498872005000100002

Basozábal, X. (2009). En torno a las obligaciones precontractuales de información. Anuario de Derecho Civil, $62 \quad$ (2), 647-712. Recuperado de: http://www.boe.es/publicaciones/anuarios_derecho/anuario.php?id=C_2009_ANUARIO_ DE_DERECHO_CIVIL\&fasc $=2$

Bastida, F. (2012). El derecho a la autonomía del paciente como contenido de los derechos fundamentales. En Xiol, J. y Bastida, F., Autonomía del paciente, responsabilidad patrimonial y derechos fundamentales (143-322). Madrid, España: Fundación Coloquio Jurídico Europeo.

Beauchamp, T. y Childress, J. (2002). Principios de ética biomédica - cuarta edición. (Traducción de García, E; Júdez, J.y Feito, L). Barcelona, España: Masson. 
Beauchamp, T. \& Childress, J. (2013). Principles of biomedical ethics- seventh edition. New York, EEUU: Oxford University Press.

Beauchamp, T. y McCullough, L. (1984) Ética Médica - las responsabilidades morales de los médicos. (Traducción de Pareja, E). Barcelona, España: Labor.

Bercovitz, R. (1976). Derecho de la persona. Madrid, España: Montecorvo S.A.

Bedoya, G. (2018). El viaje del paciente. The Insights Co.

Bernate, F. (2006). Deber de información, consentimiento informado y responsabilidad en el ejercicio de la actividad médica. En Delgado, O. (comp.), Ideas políticas, Filosofía y Derecho: El Maestro. Liber Amicorum en Homenaje a Alirio Gómez Lobo (402 - 427). Bogotá, Colombia: ediciones Universidad del Rosario.

Berrocal, A. (2011). A propósito de la responsabilidad civil médica. La teoría de la pérdida de oportunidad y del resultado o daño desproporcionado. Revista de la Escuela de Medicina Legal, (16), 23-42. Recuperado de http://revistas.ucm.es/index.php/REML/article/view/REML1111130023A

Bobbio, N. (1991). El tiempo de los derechos. (Traducción de De Asís, R). Madrid, España: Sistema.

Boggio, A. (2013). ¿A qué nos referimos cuando hablamos de "responsabilidad extracontractual"? una aproximación sociojurídica al derecho de la responsabilidad. En Bernal, C. y Fabra, J. (ed.). La filosofía de la responsabilidad civil-estudios sobre fundamentos filosóficosjurídicos de la responsabilidad civil extracontractual (609-630). Bogotá-Colombia: Universidad Externado.

Bohórquez, F. (2004) El diálogo como mediador de la relación médico - paciente. Revista ieRed: Revista Electrónica de la Red de Investigación Educativa, 1 (1), 1-18. Recuperado de: http://revista.iered.org/v1n1/pdf/fbohorquez.pdf

Brebbia, R. (1950). El daño moral. Doctrina, legislación y jurisprudencia, precedido de una teoría jurídica del daño. Buenos Aires, Argentina: Editorial Bibliográfica Argentina.

Busto, J. (1998). La antijuridicidad del daño resarcible en la responsabilidad civil extracontractual. Madrid, España: Tecnos.

Cadena, D. (2018). El consentimiento informado y la responsabilidad médica. Madrid, España: Agencia Estatal Boletín Oficial del Estado.

Casado, M. (1998). Los derechos humanos como marco para el Bioderecho y la Bioética. En Casabona, C.M. (coord.), Derecho Biomédico y Bioética (113-135). Granada, España: Comares. 
Casals, M. (1990). Notas sobre la indemnización del daño moral en las acciones por difamación de la LO 1/198. En Asociación de Profesores de derecho civil, Centenario del Código Civil (1889-1989), Tomo II, (1231-1273). Madrid, España: Centro De Estudios Ramón Areces.

Casals, M. (2003). El daño moral. En Cámara, S. (coord.), Derecho privado europeo (857-881). Madrid, España: Colex.

Castañeda, M. (2013). Medicina y comunicación, una herramienta fundamental para la interrelación médico-paciente. Revista Cubana de Información en Ciencias de la Salud, 24 (3), 343-353. Recuperado de: http://scielo.sld.cu/scielo.php?script=sci_arttext\&pid=S2307-21132013000300010

Castaño, M. (1997). El consentimiento informado del paciente en la responsabilidad médica. Medellín, Colombia: Temis.

Chabas, F. (2013). La pérdida de una oportunidad ("chance") en el derecho francés de la responsabilidad civil. Revista IARCE, (33), 16-37.

Chinchilla, C. (2011). El deber de información contractual y sus límites. Revista De Derecho Privado, (21), 327-350. Recuperado de: http://www.scielo.org.co/pdf/rdp/n21/n21a14.pdf

Concepción, J. (2009). Derecho de daños. Tercera edición. Barcelona, España: Bosch

Corral, H. (2013). Lecciones de responsabilidad extracontractual. Segunda edición actualizada. Santiago, Chile: Thomson Reuters.

Courtis, C. (2006). El Juego de los juristas. En Courtis, C. (Ed). Observar la Ley Ensayos Sobre Metodología de la Investigación jurídica (105-156). Madrid-España: Trotta.

Dalcq, R. (1967). Traité de la responsabilité civile. Vol. I, les causes de responsabilité. Bruselas, Bélgica:Ferdinad Larcier.

De Ángel, R. (1993). Tratado de responsabilidad civil. Madrid, España: Civitas.

De Ángel, R. (2000). Responsabilidad por informar. En Moreno, J. (coord.), Perfiles de la responsabilidad civil en el nuevo milenio (171-203). Madrid, España: Dykinson.

De Ángel, R. (2001). Prólogo a la primera edición. En Galán, J. Responsabilidad médica y consentimiento informado. Primera edición (I-XXIII). Madrid, España: Civitas.

De Ángel, R. (2012). Daños punitivos. Madrid, España: Civitas.

De Ángel, R. (2013). Derecho de obligaciones en Europa. Algunos rasgos de la evolución en las dos últimas décadas. Barcelona, España: Bosh. 
De Ángel, R. (2014). Causalidad en la responsabilidad extracontractual: sobre el arbitrio judicial, la imputación objetiva y otros extremos. Cizur Menor, España: Aranzadi.

De Cupis, A. (1975). El daño. Teoría general de la responsabilidad civil. (Traducción de Martínez, A). Barcelona, España: Bosh.

De La Maza, I. (2009). Consentimiento informado y relación de causalidad. Cuadernos de Análisis Jurídico, (VI), 127-143. Recuperado de: http://app.vlex.com.ez.urosario.edu.co/\#WW/vid/651166177

De La Maza, I. (2010-a). Los límites del deber precontractual de información. Cizur Menor, España: Aranzadi.

De La Maza, I. (2010-b). Consentimiento informado una visión panorámica. Revista Ius et Praxis, 16 (2), 89 -120. Recuperado de: http://www.scielo.cl/pdf/iusetp/v16n2/art04.pdf

De La Maza, I. (2017). Consentimiento informado, un poco de realismo. Revista de Derecho, 30 (2), 111-131. Recuperado de http://revistas.uach.cl/index.php/revider/article/view/752

De La Torre, J. (2008). La recuperación del paternalismo en la relación médico-paciente. En Adroher, S y De Montalvo, F (dir), Los avances del derecho ante los avances de la medicina (85-102). Navarra, España: Aranzadi.

Díaz, E. y García, J. (2000). Oncología Clínica Básica. Madrid-España: Aran Ediciones.

Díez-Picazo, G. y Arana, I. (2009). El desbordamiento del derecho de daños. Jurisprudencia reciente. Cizur Menor, España: Aranzadi.

Díez-Picazo, L. (1979). La responsabilidad civil hoy. Anuario de Derecho Civil, (4), 727-738. Recuperado de: https://www.boe.es/publicaciones/anuarios_derecho/anuario.php?id=\&fasc=4

Díez-Picazo, L. (1999). Derecho de daños. Madrid, España: Civitas.

Díez-Picazo, L. (2004). Contrato y libertad contractual. Themis Revista de Derecho, (49), 7-14. Recuperado de: http://revistas.pucp.edu.pe/index.php/themis/article/view/8545

Díez-Picazo, L. (2007). Fundamentos del derecho civil patrimonial I - introducción teoría del contrato. Sexta edición. Cizur Menor, España: Aranzadi.

Díez-Picazo, L. (2008). Fundamentos del derecho civil patrimonial II - las relaciones obligatorias. Sexta edición. Cizur Menor, España: Aranzadi.

Díez-Picazo, L. (2008-I). El escándalo del daño moral. Cizur Menor, España: Aranzadi. 
Díez-Picazo, L. (2014). Fundamentos del derecho civil patrimonial V- responsabilidad extracontractual. Cizur Menor, España: Aranzadi.

Díez-Picazo, L. y Gullón, A. (1994). Sistema de Derecho Civil - volumen I. Octava edición. Madrid, España: Tecnos.

Díez-Picazo, L. y Gullón, A. (1992). Sistema de Derecho Civil - volumen II. Sexta edición. Madrid, España: Tecnos.

Dolgin, J. (2010). The Legal Development of the Informed Consent Doctrine: Past and Present. Cambridge Quarterly of Healthcare Ethics, 19 (1), 97-109. Recuperado de: http://heinonline.org.ez.urosario.edu.co/HOL/Page?handle=hein.journals/cqhe19\&div=15

Domínguez, A. (2007). Derecho Sanitario y responsabilidad médica (comentarios a la Ley 41/2002, de 14 de noviembre, sobre derechos del paciente, información y documentación clínica). Segunda Edición. Valladolid, España: Lex Nova.

Faden, R. \& Beauchamp T. (1986). A History and Theory of Informed Consent. New York: Oxford University Press.

Fernández, C. (1993). Protección a la persona humana. En Andorno, L., Barbier, E., Cifuentes, Do Cuoto e Silva, C., Goldenberg, L., Kelmelmajer, A., López, R., Mosset, J., Parellada, C., Sessarego, C., Stiglitz, G. y Stiglitz, R. Daño y protección a la persona humana (21-80). Buenos Aires, Argentina: La Roca.

Fernández, C. (2001). ¿Qué es ser «persona» para el Derecho?. Derecho PUCP: Revista de la Facultad de Derecho, (54), 289-333.

Fernández, C. (2007). La relación jurídica del médico con el paciente. Prolegómenos - Derechos y Valores, $\quad X \quad$ (20), 89-115. Recuperado de: http://www.umng.edu.co/documents/63968/72398/05.RelJurMedicoPaciente.pdf

Fernández, C. y Woolcoott, O. (2018-I). Derecho médico. De las nociones fundamentales y la responsabilidad médica. Tomo I. Lima, Perú: Instituto Pacífico.

Fernández, C. y Woolcoott, O. (2018-II). Derecho médico. De las nociones fundamentales y la responsabilidad médica. Tomo II. Lima, Perú: Instituto Pacífico.

Fernández, G. (2001). Las transformaciones funcionales de la responsabilidad civil: la óptica sistémica. Análisis de las funciones de incentivo o desincentivo y preventiva de la responsabilidad civil en los sistemas del civil law. Ius Et Veritas, (22), 11-33. Recuperado de: http://revistas.pucp.edu.pe/index.php/iusetveritas/issue/view/1305

Fernández, J. (1987). Responsabilidad civil médica y hospitalaria. Madrid, España: La Ley. 
Fernández, J. (2000). Sistema de responsabilidad médica. Tercera edición. Granada, España: Comares.

Fernández, M. (2015). La protección del paciente frente a los deberes de información y secreto profesional médico. Revista Prolegómenos. Derechos y Valores, 18 (35), 153-168. DOI: https://doi.org/10.18359/dere.816

Fontanes, M. (2005). Aplicación de la Ley de Defensa del Consumidor en la atención médica. Universidad Nacional del Nordeste comunicaciones científicas y tecnológicas.

Fraga, A. y Lamas, M. (1999) El Consentimiento Informado (el Consentimiento del Paciente en la Actividad Médico-Quirúrgica). Pontevedra - España: Revista Xurídica Galega.

Fuller, J. (2009). Instrumentación quirúrgica: teoría, técnicas y procedimientos. Cuarta edición. Traducción de Frydman, J; López, G.; Mezzano, G.; Rodríguez, G. y Rondinone, S. México DF, México: Editorial Médica Panamericana S.A.

Galán, J. (1997). El consentimiento informado del usuario de los servicios sanitarios. Madrid, España: COLEX

Galán, J. (1999). La responsabilidad médica y el consentimiento informado. Rev Med Uruguay 1999, (15), 5-12. Recuperado de http://www.rmu.org.uy/revista/1999v1/art2.pdf

Galán, J. (2001). La responsabilidad médica y el consentimiento informado. Madrid, España: Civitas.

Galán, J. (2003). Responsabilidad profesional en la medicina curativa y complementaria. Humanitas, humanidades médicas, 1 (2), 63-68. Recuperado de: http://www.iatros.es/wpcontent/uploads/humanitas/materiales/Revista_Humanitas_2.pdf

Galán, J. (2007). Responsabilidad civil médica, $2^{a}$ edición. Cizur Menor, España: Aranzadi.

Galán, J. (2016). Responsabilidad Civil Médica, $5^{a}$ edición. Cizur Menor, España: Aranzadi.

Garay, O. (2014). Daños por incumplimiento del consentimiento informado. En Trigo, F. y Benave, M. (dir), reparación de daños a la persona. Tomo III Lesiones, jucio de daños, supuestos especiales de responsabilidad (687-747). Buenos Aires, Argentina: La Ley.

García, C., Cózar, V. y Almenara, J. (2004). La autonomía el paciente y los derechos en materia de información y documentación clínica en el contexto de la Ley 41/2002. Revista Española de Salud Pública, 78 (4), 469-479. Recuperado de: http://www.redalyc.org/pdf/170/17078405.pdf

García, J. (2016). Responsabilidad civil médica y consentimiento informado. Derecho y Cambio Social, $13 \quad$ (44), $1-18 . \quad$ Recuperado de https://dialnet.unirioja.es/servlet/articulo?codigo $=5456243$ 
García, M. (1991). La responsabilidad precontractual en el derecho español. Madrid, España: Tecnos.

García, M. (2006). Incumplimiento del deber de información, relación de causalidad y daño en la responsabilidad civil médica. En Llamas, E. (coord), Estudios de derecho de obligaciones. Homenaje al Profesor Mariano Alonso Pérez, edición no 1, (801-827), Madrid: España: La Ley.

García, M. y Otero, M. (2010). La responsabilidad precontractual en el derecho contractual europeo. InDret Revista para el análisis del derecho, (2), 1-62. Recuperado de http://www.indret.com/pdf/731_es.pdf

Geller, M. (2002). El consentimiento informado: un proceso y no una firma. Intramed. Recuperado de: http://www.intramed.net/contenidover.asp?contenidoID=20046\#comentarios

Giddens, A. (1990). The Consequences of Modernity. Stanford, EEUU: Stanford University Press.

Giménez, T. (2006). Lex Artis y responsabilidad médico-sanitaria: una perspectiva actualizada. Revista Aranzadi de derecho patrimonial, (17), 67-77.

Giraldo, L. (2013). Los perjuicios derivados del incumplimiento del deber de solicitar el consentimiento informado al paciente. Revista Investigaciones Andina, 15 (26), pp. 700715. Recuperado de http://www.scielo.org.co/pdf/inan/v15n26/v15n26a08.pdf

Gitrama, M. (1977). En la convergencia de dos humanismos: Medicina y Derecho. Sobre el contrato de servicios médicos. Anuario de Derecho Civil, 30 (02), 273-335. Recuperado de: https://www.boe.es/publicaciones/anuarios_derecho/articulo.php?id=ANU-C-197720027300335

Godreau, M. (1992). Lealtad y buena fe contractual. Revista Crítica de Derecho Inmobiliario, (609), 291-344. Recuperado de: http://libros-revistasderecho.vlex.es.ez.urosario.edu.co/vid/lealtad-buena-contractual-326757

Goldenberg, I. (2011). La relación de causalidad en la responsabilidad civil. Buenos Aires, Argentina: Astrea.

Goldenberg, I. y López, R. (1993). Daño a la persona. De la tesis de la inviolabilidad del patrimonio a la inviolabilidad de la persona. En Andorno, L., Barbier, E., Cifuentes, Do Cuoto e Silva, C., Goldenberg, L., Kelmelmajer, A., López, R., Mosset, J., Parellada, C., Sessarego, C., Stiglitz, G. y Stiglitz, R. Daño y protección a la persona humana (173-192). Buenos Aires, Argentina: La Roca.

Gómez, C. (2015). Concepto de daño moral. En Gómez, F. y Marín, I. (dir), El daño moral y su cuantificación, pp. 27-81. Barcelona, España: Bosch. 
Gómez-Ullate, S. (2015). Derechos Humanos, Bioética y Derechos de los Pacientes (Tesis de doctorado). Recuperado de: http://e-spacio.uned.es/fez/view/tesisuned:Derecho-Sgomez

Gracia, D. (2008). Fundamentos de Bioética. Madrid: Triacastela.

Gracia, D. (1993). Ocho tesis sobre consentimiento informado. Actas del II congreso Derecho y Salud, Asociación Juristas de la Salud (115-119). Granada, España: Consejería de la Salud de la Junta de Andalucía.

Guastini, R. (2016). La sintaxis del derecho. Traducción de Núñez, A. Madrid, España: Marcial Pons.

Guérez, P. (2012). El tratamiento médico curativo y su licitud: el papel del consentimiento del paciente. Cizur Menor, España: Aranzadi.

Guerrero, J. (2004). El consentimiento informado. su valoración en la jurisprudencia. Ley básica 41/2002 y leyes autonómicas. Valladolid, España: Lex Nova.

Hanson, M. y Callahan, D. (2007). Los fines de la medicina - El establecimiento de unas prioridades nuevas un proyecto internacional del Hastings Center. Traducción de A\&G Translations. Barcelona, España: Fundación Víctor Grífols i.

Hart, H. (1958). Positivism and the Separation of Law and Morals. Harvard Law Review, 71 (4), 593-629.

Recuperado

de: https://www-jstor-org.ez.urosario.edu.co/stable/1338225

Hart. H. (1961). El concepto del derecho. Traducción de Carrio, G. Buenos Aires, Argentina: Abeledo-Perrot.

Henao, J. 2015. Las formas de reparación en la responsabilidad del Estado: hacia su unificación sustancial en todas las acciones contra el Estado. Revista de Derecho Privado, (28), 277366. DOI: https://doi.org/10.18601/01234366.n28.10.

Herrera, F. (2008). Manual de responsabilidad médica. Bogotá, Colombia: Leyer.

Herrera, J. (2008). Responsabilidad civil por incumplimiento de la obligación de información del médico. Primera y segunda parte. Revista derecho y vida, (77 y 78), 1-17. Recuperado de: https://www.uexternado.edu.co/wpcontent/uploads/2017/10/Boletin_DER_Y_VID_77_78.pdf

Highton, E. y Wierzba, S. (2003). La relación médico-paciente: el consentimiento informado. Buenos Aires, Argentina: Ad-Hoc.

Hinestrosa, F. (2015). Tratado de las obligaciones II. De las fuentes de las obligaciones: el negocio jurídico. Bogotá, Colombia: Universidad Externado de Colombia. 
Hipócrates. (1983). Tratados Hipocráticos I. Traducción por García, C.; Lara, M y López, J y Cabellos, B. Madrid, España: Gredos.

Hipócrates. (1989). Tratados hipocráticos V. Epidemias. Traducción Esteban, A., García, E., y Cabellos, B. Madrid, España: Gredos.

Jalil, J. (2013). Derecho de daños aplicado. Bogotá, Colombia: Grupo Editorial Ibañez.

Jaramillo, C. (2002). Responsabilidad civil médica - la relación médico-paciente análisis doctrinal y jurisprudencial - Colección de ensayos No. 8. Bogotá, Colombia: Universidad Javeriana.

Jaramillo, C. (2010). La Culpa y la carga de la prueba en el campo de la responsabilidad médica. Bogotá, Colombia: Universidad Javeriana e Ibáñez.

Jaramillo, C. (2016). Los deberes de evitar y mitigar el daño en el derecho Privado - Funciones de la responsabilidad civil en el siglo XXI y trascendencia de la prevención. Ciudad de México, México: Editorial Porrúa.

Katz, J. (1977). Informed Consent - A Fairy Tale? - Law 's Vision. University of Pittsburgh Law

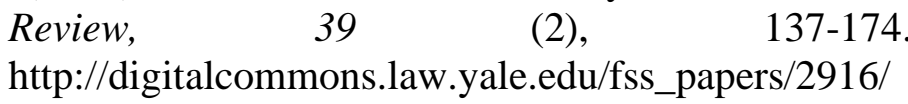

Recuperado de:

Katz, J. (2002). The silent world of doctor and patient. Baltimore, EEUU: Johns Hopkins Paperbacks edition.

Kemelmajer, A. (2001). Los dilemas de la responsabilidad civil. Revista Chilena de Derecho 28 (4), 671-679. Recuperado de: https://repositorio.uc.cl/bitstream/handle/11534/14872/000332540.pdf?sequence=1

Koteich, M. (2012). La reparación del daño como mecanismo de tutela de la persona. Del daño a la salud a los nuevos daños extrapatrimoniales. Bogotá, Colombia: Universidad Externado de Colombia.

Kvitko, L. (2009). El consentimiento informado. Ciudadela-Argentina: Dosyuna Ediciones Argentinas.

Laín, P. (1964). La relación médico-enfermo: Historia y teoría. Recuperado de: http://www.cervantesvirtual.com/obra/la-relacion-medico-enfermo-historia-y-teoria/

Lansdown, G. (2005). La evolución de las facultades del niño. Siena, Italia: Unicef.

Le Goues, M. (2015). Le consentement du patient en droit de la santé (Tesis de doctorado). Recuperado de: https://tel.archives-ouvertes.fr/tel-01267019

Leone, S. (2018). Humanization of Medicine. Historical Development. Revista Iberoamericana de Bioética, (8), 1-14. DOI: 10.14422/rib.i08.y2018.001 
Llamas, E. (1988). La responsabilidad civil del médico. Aspectos tradicionales y modernos. Madrid, España: Trivium.

Llamas, E. (2000). Responsabilidad médica, culpa y carga de la prueba. En Moreno, J. (Coord.), Perfiles de la responsabilidad civil en el nuevo milenio (297-319). Madrid, España: Dykinson.

Llamas, E. (2007). Prólogo a la primera edición. En Domínguez, A., Derecho sanitario y responsabilidad médica - comentarios a la Ley 41/2002, 14 de noviembre, sobre derechos del paciente, información y documentación clínica. 2da edición (31-40). Valladolid, España: Lex Nova.

Llamas, E. (2007-II). Prevención y reparación, las dos caras del derecho de daños. En Moreno, J. (coord.), La responsabilidad civil y su problemática actual (443-478). Madrid, España: Dykinson.

Llamas, E. (2010). Daño moral por falta de información de tratamientos médicos alternativos. Práctica de Derecho de Daños, (89), 1-3. Recuperado de: https://laleydigital-laleyes.ezproxy.usal.es

Llamas, E. (2011). La noción de daño: asignatura pendiente. Práctica de Derecho de Daños, (90), 1-3. Recuperado de: https://laleydigital-laley-es.ezproxy.usal.es

Llamas, E. (2014). Doctrina general de la culpa médica. En Llamas, E. (dir.), Estudios sobre la responsabilidad sanitaria un análisis interdisciplinar (1-24). Recuperado de: https://laleydigital-laley-es.ezproxy.usal.es

Llobet, J. (1996). El deber de información en la formación de los contratos. Madrid, España: Marcial Pons.

Loayssa, J. y Tandeter, H. (2001). Incertidumbre y la toma de decisiones clínicas. Atención Primaria 28 (8), 517-570. Recuperado de: http://www.elsevier.es/es-revista-atencionprimaria-27-articulo-incertidumbre-toma-decisiones-clinicas-13023843

López, M. (2016). Los médicos y el consentimiento informado (necesarias precisiones sobre el tema en el marco del nuevo CCC). El Derecho - Diario de doctrina y jurisprudencia, (13.892), pp. 1-8. Recuperado de: http://www.elderecho.com.ar/includes/pdf/diarios/2016/02/11022016.pdf

López y García, J. (2010). Valoración del daño por falta de consentimiento informado en la práctica médica. Revista Economist \&Jurist, 18 (146), 68-76.

Lorenzetti, R. (1998). La empresa médica. Santa Fe, Argentina: Rubinzal-Culzoni. 
Lorenzetti, R. (2016). Responsabilidad civil de los médicos -segunda edición - tomo I. Santa Fe, Argentina: Rubinzal-Culzoni.

Lovece, G. (2004). La información y publicidad del servicio médico. Buenos Aires, Argentina: Astrea.

Luna, A.; Piñeiro, J.; Ramos, S. y Rubí. A. (2002). Reparación in natura y por equivalente: opciones de la víctima en el derecho español. Revista Indret, (2), 1-9. Recuperado de: http://www.indret.com/pdf/083_es.pdf

M’Causland, M. (2008). Tipología y reparación del daño no patrimonial - situación en Iberoamérica y en la jurisprudencia de la Corte Interamericana de Derechos Humanos. Bogotá, Colombia: Universidad Externado de Colombia.

M’Causland, M. (2015). La responsabilidad extracontractual y su declaración judicial. Bogotá, D.C.: Universidad Externado de Colombia.

Mantilla, F. (2007). El principio general de responsabilidad por culpa del derecho privado colombiano. Opinión Jurídica, 6(11), pp. 129-15. Recuperado de: http://www.scielo.org.co/pdf/ojum/v6n11/v6n11a8.pdf

Marín, P. (2008). El privilegio terapéutico: punto de unión entre el paternalismo médico y la autonomía del paciente. En Adroher, S y De Montalvo, F (Dir), Los avances del derecho ante los avances de la medicina, pp. 669-682. Navarra, España: Aranzadi.

Marsh, H. (2018). Ante todo no hagas daño, $12^{a}$ edición. Traducción de Antón, P. Barcelona, España: Salamandra.

Martín, M. (2011). "La modernización” del Derecho de la responsabilidad extracontractual. En Cuestiones actuales en materia de responsabilidad civil- XV jornadas de la asociación de profesores de derecho civil, A Coruña, 8 y 9 de abril de 2011 (11-112). Murcia, España: Universidad de Murcia. Servicio de Publicaciones.

Martínez, J. (2012). Autonomía e información de los pacientes: del reconocimiento de derechos a la pérdida de confianza. Reflexiones con motivo de la aparición de nuevas normas sobre los derechos de los pacientes al final de la vida. Cuadernos Bioética, XXIII (1), 151-167. Recuperado de: http://aebioetica.org/revistas/2012/23/77/151.pdf

Martínez, N. (2014). La doctrina de la pérdida de la oportunidad en la responsabilidad sanitaria. En Llamas, E. (Ed), Estudios sobre la responsabilidad sanitaria: un análisis interdisciplinar (207-239). Las Rozas, España: La Ley

Mazeaud, H. y Mazeaud, L. (2005). Elementos de la responsabilidad civil perjuicio, culpa y relación de causalidad. Bogotá, Colombia: Leyer. 
Medina, L. (2007). La teoría de la pérdida de la oportunidad. Estudio doctrinal y jurisprudencial de derecho de daños público y privado. Cizur Menor, España: Aranzadi.

Méndez-Monasterio, P. (2016). Daños punitivos: el "patito feo" de la responsabilidad civil. Madrid, España: Fe d’ erratas.

Mendoza, J. y Herrera, L. (2017). El consentimiento informado en Colombia. Un análisis comparativo del proyecto de ley 24 de 2015 con el código vigente y otros códigos de ética. Revista CES Derecho, 8 (1), 156-171. DOI: http://dx.doi.org/10.21615/cesde

Moggia, C. (2012). Los deberes de información y de secreto en la teoría general del contrato (Tesis de doctorado). Recuperado de: http://bibliotecavirtual.unl.edu.ar:8080/tesis/bitstream/handle/11185/929/Tesis.pdf?seque nce $=1$

Monsalve, V. (2008). La buena fe como fundamento de los deberes precontractuales de conducta: una doctrina europea en construcción. Revista de Derecho, (30), 30-74. Recuperado de: http://www.scielo.org.co/scielo.php?script=sci_arttext\&pid=S0121-86972008000200003

Monsalve, V. (2010). Responsabilidad Precontractual. La ruptura injustificada de las negociaciones. Bogotá, Colombia: Grupo Editorial Ibañez.

Monsalve, V. y Navarro, D. (2014). El Consentimiento Informado en la Praxis Médica. Bogotá, Colombia: Universidad Javeriana y Temis.

Moore, P.; Gómez, G.; Kurtz, S y Vargas, A. (2010). La comunicación médico-paciente: ¿Cuáles son las habilidades efectivas? Revista Médica Chile, 138 (8), 1047-1054. DOI: https://dx.doi.org/10.4067/S0034-98872010000800016

Morales, R. (2013). Los contratos con deberes de protección: a propósito de la vinculación entre el derecho constitucional y el derecho civil. Derecho PUC, (71), pp. 53-75. Recuperado de: http://revistas.pucp.edu.pe/index.php/derechopucp/article/view/8897

Mosset, J. (1998). Responsabilidad por daños, tomo I, parte general. Santa Fe, Argentina: Rubinzal-Culzoni.

Mosset, J. (1999). Responsabilidad por daños, tomo V, el daño moral. Santa Fe, Argentina: Rubinzal-Culzoni.

Mosset, L. (2014). Parte general, relación jurídica y código de Cuba. Derecho y Cambio Social, 11 (37), 1-20. Recuperado de: https://dialnet.unirioja.es/servlet/articulo?codigo=4750436

Mosset, J. y Piedecasas, M. (2009). Responsabilidad por daños, tomo XI, actualización doctrinaria y jurisprudencial de los tomos I a X (al 31 de diciembre de 2009). Santa Fe, Argentina: Rubinzal-Culzoni. 
Namén, J. (2008) La obligación de información del médico en el derecho francés. Revista de Derecho Privado, (15), 181-198. Recuperado de http://revistas.uexternado.edu.co/index.php/derpri/article/viewFile/534/507

Narváez, A. (2009). La limitación de derechos fundamentales por razones sanitarias. Revista Aranzadi Doctrinal, (6), 79-88.

Navarro, D. (2018). La tensión de la globalización de la salud y el papel del Estado social de derecho colombiano en torno al consentimiento informado en la relación médico paciente. Vía Iuris, (24), 1-34. Recuperado de: https://revistas.libertadores.edu.co/index.php/Vialuris/article/view/834

Navia, F. (2006). Consentimiento informado y responsabilidad médica. Revista de Derecho Privado, (11), $\quad 157-170 \quad$ Recuperado de: http://revistas.uexternado.edu.co/index.php/derpri/article/view/577/545

Nelson-Marten, P., \& Rich, B. A. (1999). Perspective of informed consent in clinical practice and research. Seminars in Ontology Nursing, 15 (2), pp. 81-88. Recuperado de: https://www.sciencedirect.com/science/article/pii/S0749208199800655

Nogueira, H. (2000). El derecho a la información en el ámbito del derecho constitucional comparado en Iberoamérica y Estados Unidos. En Carpizo, J y Carbonell, M. (eds.), Derecho a la información y derechos humanos (3-144). México: Universidad Nacional Autónoma de México.

Obando, B. (2015). Bioderecho - Derecho médico y responsabilidad médica. 2da edición. Medellín, Colombia: Librería Jurídica Sánchez R Ltda.

Ordoqui, G. (2012). Buena fe contractual. Bogotá, Colombia: Pontificia Universidad Javeriana; Universidad Católica del Uruguay y Grupo Editorial Ibañez.

Ovalle, C. (2009). Práctica y significado del consentimiento informado en hospitales de Colombia y Chile. Bogotá, Colombia: Ediciones El Bosque.

Oviedo, J. (2008). Tratos preliminares y responsabilidad precontractual. Vniversitas, 57 (115), 83116. Recuperado de: http://revistas.javeriana.edu.co/index.php/vnijuri/article/view/14577

Pacheco, V. (2007). La Declaración de Ginebra: Hipócrates redivivo en la declaración de fidelidad profesional de los médicos ecuatorianos. Parte II y final. Revista Facultad Ciencias Médicas, $\quad 32 \quad$ (2), $\quad 95-100 . \quad$ Recuperado de: http://revistadigital.uce.edu.ec/index.php/CIENCIAS_MEDICAS/article/download/311/P $\underline{\mathrm{DF}}$

Pantaleón, F. (1990). Causalidad e imputación objetiva: criterios de imputación. En Asociación de Profesores de derecho civil, Centenario del Código Civil (1889-1989), Tomo II (12311273). Madrid, España: Centro De Estudios Ramón Areces. 
Pantaleón, F. (1991). Comentario al art. 1902 CC. En Paz-Ares, C; Bercovitz, R.; Diez-Picazo, L. y Salvador, P. (dir.) Comentario del Código civil tomo II (1971-2003). Madrid, España: Ministerio de Justicia y Centro de Publicaciones.

Pantaleón, F. (2000). Cómo repensar la responsabilidad civil extracontractual (También la de las Administraciones públicas). Anuario de la Facultad de Derecho de la Universidad Autónoma de Madrid, (4), 167-192.

Parra, D. (2014). La responsabilidad civil del médico en la medicina curativa (Tesis de doctorado). Recuperado de:

https://earchivo.uc3m.es/bitstream/handle/10016/19232/dario_parra_tesis.pdf

Pasquau, M. Responsabilidad civil e infracción de los deberes de información sobre los riesgos no evidentes de productos y servicios. En López y García, J. y Sánchez, I. (coord) Cuestiones actuales de responsabilidad civil (159-177). Cizur Menor, España: Aranzadi.

Peces-Barba, G. (1998). Tránsito a la modernidad y derechos fundamentales. En Fernández, E. y Peces-Barba, G. (dir.) Historia de los derechos fundamentales, tomo I: tránsito a la modernidad siglos XVI y XVII (13-263). Madrid, España: Dykinson.

Pelayo, A. (2009). El derecho a la autonomía del paciente en la relación médica. El tratamiento jurisprudencial del consentimiento informado. Granada, España: Comares.

Pérez, A. (2014). El Estatuto del Consumidor y la prestación de servicios de salud, convergencias y divergencias. Revista Prolegómenos - Derechos y Valores, XVII (2), pp. 78-95. Recuperado de: http://revistas.unimilitar.edu.co/index.php/dere/article/view/798/549

Pérez, M. (2008). la responsabilidad civil médico-sanitaria en el derecho español: significado y alcance del consentimiento informado y el deber de información. Colección de Derecho Privado, (6), 145-165.

Perlingieri, P. (2015-I). El derecho civil en la legalidad constitucional. Volumen I. (Traducción de Luna, A. y Maluquer, C). Bogotá, Colombia: Ibañez y Universidad Javeriana.

Perlingieri, P. (2015-II). El derecho civil en la legalidad constitucional. Volumen II. (Traducción de Luna, A. y Maluquer, C). Bogotá, Colombia: Ibañez y Universidad Javeriana.

Picasso, S. (2015). Las funciones del derecho de daños en el Código Civil y Comercial de la Nación. Revista de responsabilidad civil y seguros, (4), pp. 5-23. Recuperado de: http://www.nuevocodigocivil.com/wp-content/uploads/2016/04/Las-funciones-delderecho-de-da\%C3\%B1os-por-Picasso.pdf

Pizarro, C. (2014). El contrato médico. Calificación, contenido y responsabilidad. Revista Chilena de Derecho, 41 (3), 825-843. Recuperado de: https://dx.doi.org/10.4067/S0718$\underline{34372014000300003}$ 
Pizarro, C. (2017). La responsabilidad médica. Santiago, Chile: Thomson Reuters

Pizarro, C. (2018). La responsabilidad médica. Bogotá, Colombia: Ibáñez.

Pizarro, R. (1996). Daño moral. Prevención/ Reparación / Punición. El daño moral en las diversas ramas del Derecho. Buenos Aires, Argentina: Hammurabi.

Platón. (1872). Obras completas de Platón, Tomo IX - Las leyes. (Traducción por De Azcárate, P). Madrid, España: Medina y Navarro Editores.

Platón. (1986). Diálogos IV - La República. (Traducción Eggers, C). Madrid, España: Gredos.

Reglero, L. (2006). Conceptos generales y elementos de delimitación. En Reglero, L. (coord.) Tratado de Responsabilidad Civil, 3a edición (63-210). Cizur Menor, España: Aranzadi.

Reynal, E. (2017). Consentimiento informado y responsabilidad en el ámbito sanitario. Cizur Menor, España: Aranzadi.

Ribot, J. (2007). La responsabilidad civil por falta de consentimiento informado. Revista de derecho privado, (91), 29-62.

Roca, E. y Navarro, M. (2011). Derecho de daños. Textos y materiales. Valencia, España: Tirant Lo Blanch.

Rojas, S. (2014). Responsabilidad civil: la nueva tendencia y su impacto en las instituciones tradicionales. Bogotá, Colombia: Ibáñez.

Rojas, S. (2015). El daño a la persona y su reparación. Sobre la teoría general, sistemas de cuantificación y los casos difíciles. Bogotá, Colombia: Ibáñez.

Romeo, C. (1985). El médico ante el derecho - La responsabilidad penal y civil del médico. Madrid, España: Servicio de Publicaciones Ministerio de Sanidad y Consumo.

Romeo, C., Emaldi, A., Escajedo, L., Nicolás, P., Romeo, S. y Urriela, A. (2006). La ética y el derecho ante la biomedicina del futuro. Cátedra Interuniversitaria Fundación BBVA Diputación Foral de Bizkaia de Derecho y Genoma Humano. Bilbao, España: Universidad de Deusto.

Rubiera, G., Arbizu, R., Alzueta, Á., Agúndez, J., y Riera, J. (2004). La legibilidad de los documentos de consentimiento informado en los hospitales de Asturias. Gaceta Sanitaria, $18 \quad$ (2), 153-158. Recuperado de: http://scielo.isciii.es/scielo.php?script=sci_arttext\&pid=S0213$91112004000200012 \& \operatorname{lng}=$ es\&tlng=es. 
Ruiz, W. (2016). Responsabilidad del Estado y sus regímenes. Tercera edición. Bogotá, Colombia: Ecoe Ediciones.

Salinas, G. (2011). Responsabilidad civil contractual. Tomo I. Santiago, Chile: Abeledo Perrot.

Salvador, P. y Castiñeira, M. (1997). Prevenir y castigar. Libertad de información y expresión, tutela del honor y funciones del derecho de daños. Madrid, España: Marcial Pons.

Sánchez, A. (1998). Contrato de servicios médicos y contrato de servicios hospitalarios. Madrid, España: Tecnos.

Sánchez, J. (1993). El derecho a la información en la relación sanitaria: aspectos civiles. En Romeo, C. (ed.), Responsabilidad penal y responsabilidad civil de los profesionales. Presente y futuro de los conceptos de negligencia y riesgo. XXII COLOQUIO DE DERECHO EUROPEO, organizado por el Consejo de Europa y la Facultad de Derecho de la Universidad de La Laguna (193-220). La Laguna - Tenerife, España: Centro de Estudios Criminológicos, Universidad de La Laguna.

Sandoval, D. (2013). Reparación integral y responsabilidad civil: el concepto de reparación integral y su vigencia en los daños extrapatrimoniales a la persona como garantía de los derechos de las víctimas. Revista de Derecho Privado, (25), 235-272. Recuperado de http://www.scielo.org.co/pdf/rdp/n25/n25a10.pdf

Sandoya, E. (2014). La incertidumbre en medicina. Tendencias en Medicina, XXII (44), 131-138. Recuperado de: http://tendenciasenmedicina.com/Imagenes/imagenes44/art_22.pdf

Seijas, J. (2016). Cambios sustanciales durante la última década en la doctrina jurisprudencial de la responsabilidad civil. López y García, J. y López, A. (coord.). Ponencias XVI congreso nacional. Málaga noviembre 2016. Sobre responsabilidad civil y el nuevo baremos de daños (271-302). Madrid, España: Sepin.

Serrano, L. (2012). La responsabilidad médica estatal en Colombia. Bogotá, Colombia: Ediciones Doctrina y Ley LTDA.

Simón, P. (2000). El Consentimiento Informado. Historia, Teoría y Práctica. Madrid, España: Triacastela.

Skegg, P. (1984). Law, ethics and medicine: studies in medical law. Oxford, Inglaterra: Clarendon

Skegg, P. (1999). English medical law and "informed consent": an antipodean assessment and alternative. Medical Law Review, 7 (2), 135. Recuperado de: http://ez.urosario.edu.co/login?url=http://search.ebscohost.com/login.aspx?direct=true\&d $\mathrm{b}=\mathrm{a} 9 \mathrm{~h} \& \mathrm{AN}=4508716 \&$ lang $=$ es $\&$ site $=$ eds-live $\&$ scope $=$ site 
Solarte, A. (2004). La buena fe contractual y los deberes secundarios de conducta. Vniversitas, 53 (108), 282-315. Recuperado de: http://revistas.javeriana.edu.co/index.php/vnijuri/article/view/14730

Spota, A. (2015). Contratos - Instituciones de Derecho Civil. Tomo I parte general. 2da edición. Actualización de Leiva, L. Buenos Aires, Argentina: La Ley.

Stiglitz, G. y Stiglitz, R. (1999). Responsabilidad precontractual - incumplimiento del deber de información. Buenos Aires, Argentina: Abeledo Perrot.

Stiglitz, J. (2010). Regulación y fallas. Revista de Economía Institucional, 12 (23), 13-28. Recuperado de: https://www.economiainstitucional.com/pdf/No23/jstiglitz23.pdf

Szasz, T. y Marc Hollender. (1956). AMA Arch Intern Med, 97 (5), 585-592. Recuperado de: https://jamanetwork.com/journals/jamainternalmedicine/issue/97/5

Tamayo, J. (2007). Tratado de responsabilidad civil, tomo I, segunda edición. Bogotá, Colombia: Legis.

Tamayo, J. (2014). Reflexiones preliminares del profesor Javier Tamayo Jaramillo. En Rojas, S. Responsabilidad civil: la nueva tendencia y su impacto en las instituciones tradicionales (25-29). Bogotá, Colombia: Ibañez.

Tamayo, J. (2017). La pérdida de la oportunidad en la responsabilidad médica, un falso problema. Resposabilidad civil y del Estado, (40), 15-91.

Tamayo, J.; Botero, L; Polanía, N. y Rojas, S. (2017). Nuevas reflexiones sobre el daño. primera edición. Bogotá, Colombia: IARCE y Legis.

Tarodo, S. (2006). La doctrina del consentimiento informado en el ordenamiento jurídico norteamericano. Derecho y salud, 14 (1), pp. 229-249. Recuperado de: https://dialnet.unirioja.es/servlet/articulo?codigo $=2005307$

Tribunal Nacional de Ética Médica, (2012). Gaceta jurisprudencial junio de 2012, número especial: cirugía plástica y estética. Bogotá, Colombia: Giro Editores.

Valencia, D. (2016). La Globalización y sus efectos en el derecho administrativo. Revista de Direito Brasileira, 13 (6), pp. 190-212.

Vázquez, R. (2002). Daños y perjuicios en el ejercicio de la medicina. Segunda edición. Buenos Aires, Argentina: Hammurabi.

Viney, G. (2010). Tratado de derecho civil - introducción a la responsabilidad. (Traducción de Montoya, F). Bogotá-Colombia: Universidad Externado. 
Weber, M. (2002). Economía y Sociedad - Esbozo de sociología comprensiva. (Traducción de Medina, J., Roura, J., Ímaz. E., García, E. y Ferrater, J) Madrid, España: Fondo de Cultura Económica.

Wandler, M. 2001. The History of the Informed Consent Requirement in United States Federal Policy. Third Year Paper. Scholarship at Harvard. 1-40. Recuperado de: http://nrs.harvard.edu/urn-3:HUL.InstRepos:8852197

Weingarten, C. (2011). La confianza como elemento superador de la asimetría para consumidores y usuarios. En Ghersi, C. y Weingarten, C. (eds.), Manual de los derechos de usuarios y consumidores (77-97). Buenos Aires, Argentina: La Ley.

Woolcott, O. (2014). Nuevas dimensiones de la protección del paciente: en la responsabilidad médica, el derecho a la salud y el Estatuto del Consumidor. Revista Principia IURIS, (22), 237-266.

Recuperado

de: http://revistas.ustatunja.edu.co/index.php/piuris/article/view/951/920

Xiol, J. (2012). La responsabilidad patrimonial de la administración y el derecho de autodeterminación del paciente. En Xiol, J. y Bastida, F., Autonomía del paciente, responsabilidad patrimonial y derechos fundamentales pp. (15-141). Madrid, España: Fundación Coloquio Jurídico Europeo.

Yong, S. y Rodríguez, C. (2011). Pérdida de oportunidad. Revista Virtual Via Inveniendi Et $\begin{array}{lllll}\text { Iudicandi, } & 6 & (2), & 1-36 . & \text { Recuperado de }\end{array}$ https://dialnet.unirioja.es/servlet/articulo?codigo=3698482

Zavala, M. (2011). Tratado de daños a la persona. Daños a la dignidad, tomo I: identidad, honor, intimidad. Buenos Aires, Argentina: Astrea.

Zannoni, E. (2005). El daño en la responsabilidad civil. Buenos Aires, Argentina: Astrea.

\section{Páginas web:}

Adhanom, T. (2017). La salud es un derecho humano fundamental. Organización Mundial de la Salud. Recuperado de: http://www.who.int/mediacentre/news/statements/fundamentalhuman-right/es/

Asociación Médica Mundial - https://www.wma.net/es/

Comisión Interamericana de Derechos Humanos. Relatoría Especial para la Libertad de Expresión. (2009). El derecho de acceso a la información en el marco jurídico interamericano. Recuperado de:http://www.oas.org/es/cidh/expresion/docs/publicaciones/ACCESO\%20A\%20LA\%20 INFORMACION\%20FINAL\%20CON\%20PORTADA.pdf 
Comisión Interamericana de Derechos Humanos. (2011). Acceso a la información en materia reproductiva desde una perspectiva de derechos humanos. Recuperado de: https://www.cidh.oas.org/pdf\%20files/mujeresaccesoinformacionmateriareproductiva.pdf

Comisión Interamericana de Derechos Humanos. (2017). Comunicado de prensa: CIDH exhorta a todos los Estados a adoptar medidas integrales e inmediatas para respetar y garantizar los derechos sexuales y reproductivos de las mujeres. Recuperado de: http://www.oas.org/es/cidh/prensa/comunicados/2017/165.asp

Florez, C. (2016). Entrevista a la presidenta de Defensor del paciente. Asociación El Defensor del Paciente. Recuperado de: http://www.negligenciasmedicas.com/quien-somos/reflexiones/

Ministerio de la Protección Social- Dirección General de Calidad de Servicios. Garantizar la funcionabilidad de los procedimientos de consentimiento informado: Paquetes instruccionales guía técnica "buenas prácticas para la seguridad del paciente en la atención en salud". Recuperado de: https://www.minsalud.gov.co/sites/rid/Lists/BibliotecaDigital/RIDE/DE/CA/garantizarfuncionalidad-consentimiento-informado.pdf

Organización Mundial de la Salud - http://www.who.int/es

\section{Regulación Nacional:}

Decreto 1011 de 2006 - por el cual se establece el Sistema Obligatorio de Garantía de Calidad de la Atención de Salud del Sistema General de Seguridad Social en Salud.

Decreto 4107 de 2011 - Por el cual se determinan los objetivos y la estructura del Ministerio de Salud y Protección Social y se integra el Sector Administrativo de Salud y Protección Social.

Decreto 3032 de 2013 - Por el cual se reglamenta parcialmente el Estatuto Tributario.

Decreto 780 de 2016 - Por medio del cual se expide el Decreto Único Reglamentario del Sector Salud y Protección Social.

Ley 23 de 1981 (Código de Ética Médica).

Decreto 3380 de 1981 - por medio del cual se reglamenta la Ley 23 de 1981.

Constitución Política de 1991.

Ley 100 de 1993 - por la cual se crea el sistema de seguridad social integral y se dictan otras disposiciones.

Ley 1098 de 2006 - por la cual se expide el Código de la Infancia y la Adolescencia.

Ley 1328 de 2009 - por la cual se dictan normas en materia financiera, de seguros, del mercado de valores y otras disposiciones.

Ley 1306 de 2009 - por la cual se dictan normas para la Protección de Personas con Discapacidad Mental y se establece el Régimen de la Representación Legal de Incapaces Emancipados.

Ley 1412 de 2010 - por medio de la cual se autoriza la realización de forma gratuita y se promueve la ligadura de conductos deferentes o vasectomía y la ligadura de trompas de Falopio como formas para fomentar la paternidad y la maternidad responsable. 
Ley 1566 de 2012 -por la cual se dictan normas para garantizar la atención integral a personas que consumen sustancias psicoactivas y se crea el premio nacional "entidad comprometida con la prevención del consumo, abuso y adicción a sustancias psicoactivas".

Ley 1480 de 2011- por medio de la cual se expide el Estatuto del Consumidor y se dictan otras disposiciones.

Ley 1438 de 2011. Por medio de la cual se reforma el Sistema General de Seguridad Social en Salud y se dictan otras disposiciones.

Ley 1616 de 2013 - por medio de la cual se expide la ley de Salud Mental y se dictan otras disposiciones.

La Ley 1733 de 2014 -mediante la cual se regulan los servicios de cuidados paliativos para el manejo integral de pacientes con enfermedades terminales, crónicas, degenerativas e irreversibles en cualquier fase de la enfermedad de alto impacto en la calidad de vida.

Ley Estatutaria 1751 de 2015 - por medio de la cual se regula el derecho fundamental a la salud y se dictan otras disposiciones.

Ley 1799 de 2016 - por medio de la cual se prohíben los procedimientos médicos y quirúrgicos estéticos para menores de edad y se dictan otras disposiciones.

\section{Resoluciones del Ministerio de Salud y Protección Social:}

Resolución 13437 de 1991 - Por la cual se constituyen los comités de Ética Hospitalaria y se adoptan el Decálogo de los Derechos de los Pacientes.

Resolución 8430 de 1993- sobre requisitos para el desarrollo de actividades investigativas en salud.

Resolución 2927 de 1998 - Por la cual se reglamenta la práctica de terapias alternativas en la prestación de servicios de salud, se establecen normas técnicas, científicas y administrativas y se dictan otras disposiciones.

Resolución 1995 de 1999 - por la cual se establecen normas para el manejo de la Historia Clínica

Resolución 4905 de 2006 - por la cual se adopta la Norma Técnica para la atención de la Interrupción Voluntaria del Embarazo

Resolución 2263 de 2004 - por la cual se establecen los requisitos para la apertura y funcionamiento de los centros de estética y similares y se dictan otras disposiciones.

Resolución 1448 de 2006 - Por la cual se definen las Condiciones de Habilitación para las instituciones que prestan servicios de salud bajo la modalidad de Telemedicina.

Resolución 2378 de 2008 - por la cual se adopta el Manual de Buenas Prácticas Médicas para la Investigación con Medicamentos en Seres Humanos.

Resolución 001973 de 2008 - por medio de la cual se modifica la Norma Técnica para la Atención en Planificación Familiar a Hombres y Mujeres, adoptada mediante Resolución 0769 de 2008.

Resolución 4343 de 2012 se unificó la regulación respecto de los lineamientos de la Carta de Derechos y Deberes del Afiliado y del Paciente,

Resolución 1441 de 2013 - Por la cual se definen los procedimientos y condiciones que deben cumplir los Prestadores de Servicios de Salud para habilitar los servicios y se dictan otras disposiciones.

Resolución 2003 de 2014 - Por la cual se definen los procedimientos y condiciones de inscripción de los Prestadores de Servicios de Salud y de habilitación de servicios de salud. 
Resolución 1216 de 2015 - por medio de la cual se da cumplimiento a la orden cuarta de la Sentencia T-970 de 2014 de la honorable Corte Constitucional en relación con las directrices para la organización y funcionamiento de los Comités para hacer efectivo el derecho a morir con dignidad.

Resolución 001904 de 2017 - por medio de la cual se adopta el reglamento en cumplimiento de lo ordenado en la orden décima primera de la Sentencia T-573 de 2016 de la Corte Constitucional y se dictan otras disposiciones.

Resolución 825 de 2018 - Por medio de la cual se reglamenta el procedimiento para hacer efectivo el derecho a morir con dignidad de los niños, niñas y adolescentes.

Resolución 2665 de 2018- por medio de la cual se reglamenta la Ley 1733 de 2014 en cuanto al derecho de suscribir el documento de voluntad anticipada.

\section{Convenciones:}

\section{Sistema Universal}

Declaración Universal de los Derechos Humanos (1948)

Pacto Internacional de Derechos Civiles y Políticos (1966)

Carta de Otawa para la promoción de la Salud (1986).

Convención Sobre los Derechos del Niño (1989).

Declaración Universal del Genoma Humano y Derechos Humanos (1997).

Declaración Universal sobre Bioética y Derechos Humanos (2005).

Convención Internacional sobre los derechos de las personas con discapacidad (2006).

\section{Sistema Interamericano}

Declaración Americana de los Derechos y Deberes del Hombre (1948).

Convención Americana sobre Derechos Humanos "Pacto de San José de Costa Rica (1969).

Principios para la Protección de los Enfermos Mentales y el Mejoramiento de la Atención de la Salud Mental (1991).

\section{Sistema Europeo}

Convenio para la Protección de los Derechos Humanos y de las Libertades Fundamentales - 1950. Declaración de los Derechos de los Pacientes Europeos - 1994.

Tratado Sobre los Derechos del Hombre y la Biomedicina (Convenio de Oviedo) - 1997.

Carta de los Derechos Fundamentales o Tratado de Niza - 2000.

Carta Europea de los Derechos de los Pacientes - 2002.

\section{Sentencias República de Colombia:}

\section{Corte Constitucional}

Corte Constitucional. Sentencia T-059-2018 de 22/02/2018. M.P. Antonio José Lizarazo Ocampo. Corte Constitucional. Sentencia T-655-2017 de 30/10/2017. M.P. Gloria Stella Ortiz Delgado. Corte Constitucional. Sentencia C-345-2017 de 24/05/2017. M.P. Alejandro Linares Cantillo. Corte Constitucional. Sentencia C-246-2017 de 26/04/2017. M.P. Gloria Stella Ortiz Delgado. Corte Constitucional. Sentencia T-590-2016 de 28/10/2016. M.P. Luis Guillermo Guerrero Pérez. 
Corte Constitucional. Sentencia T-573-2016 de 19/10/2016. M.P. Luis Ernesto Vargas Silva. Corte Constitucional. Sentencia T-303-2016 de 15/06/2016. M.P. Jorge Ignacio Pretelt Chaljub. Corte Constitucional. Sentencia C-405-2016 de 03/08/2016. M.P. Gloria Stella Ortiz Delgado. Corte Constitucional. Sentencia C-182-2016 de 13/04/2016. M.P. Gloria Stella Ortiz Delgado. Corte Constitucional. Sentencia C-086-2016 de 24/02/2016. M.P. Jorge Iván Palacio Palacio. Corte Constitucional sentencia C-752-2015 de 10/12/2015. M.P. Luis Ernesto Vargas Silva. Corte Constitucional. Sentencia C-621-2015 de 30/09/2015. M.P. Jorge Ignacio Pretelt Chaljub. Corte Constitucional. Sentencia T-740-2014 de 03/10/2014. M.P. Luis Ernesto Vargas Silva. Corte Constitucional. Sentencia T-622-2014 de 28/08/2014. MP. Jorge Ignacio Pretelt Chaljub. Corte Constitucional. Sentencia C-313-2014 de 29/05/2014. M.P. Gabriel Eduardo Mendoza Martelo.

Corte Constitucional. Sentencia C-131-2014 de 11/03/2014. M.P. Mauricio González Cuervo. Corte Constitucional Sentencia C-606-2012 de 01/08/2012. M.P. Adriana María Guillén Arango. Corte Constitucional. Sentencia T-452-2010 de 15/06/2010. M.P. Humberto Antonio Sierra Porto. Corte Constitucional. Sentencia T-912-2008 de 18/09/2008. M.P. Jaime Córdoba Triviño.

Corte Constitucional. Sentencia T-653-2008 de 01/07/2008. M.P. Humberto Antonio Sierra Porto. Corte Constitucional. Sentencia T-216-2008 de 29/02/2008. M.P. Humberto Antonio Sierra Porto. Corte Constitucional. Sentencia T-560-2007 de 26/07/2007. M.P. Jaime Araujo Rentería. Corte Constitucional. Sentencia T-1019-2006 de 01/12/2006. M.P. Jaime Córdoba Triviño. Corte Constitucional. Sentencia T- 492-2006 de 29/06/2006. M.P. Marco Gerardo Monroy Cabra. Corte Constitucional. Sentencia T-1203-2005 de 24/11/2005. M.P. Álvaro Tafur Galvis.

Corte Constitucional. Sentencia T-1131-2004 de 10/11/2004. M.P. Humberto Antonio Sierra Porto.

Corte Constitucional. Sentencia T-762-2004 de 11/08/2004. M.P. Jaime Araujo Rentería. Corte Constitucional. Sentencia T-1021-2003 de 30/10/2003. M.P. Jaime Córdoba Triviño.

Corte Constitucional. Sentencia T-248-2003 de 10/03/2003. M.P. Eduardo Montealegre Lynett. Corte Constitucional. Sentencia T- 1025-2002 de 27/11/2002. M.P. Rodrigo Escobar Gil. Corte Constitucional. Sentencia T-850-2002 de 10/10/2002. M.P. Rodrigo Escobar Gil. Corte Constitucional. Sentencia T-925-2001 de 29/08/2001. M.P. Rodrigo Escobar Gil. Corte Constitucional. Sentencia T-1390-2000 de 12/10/2000. M.P. Alejandro Martínez Caballero. Corte Constitucional. Sentencia T-692-1999 de 16/09/1999. M.P. Carlos Gaviria Díaz. Corte Constitucional. Sentencia T-551-1999 de 02/08/1999. M.P. Alejandro Martínez Caballero. Corte Constitucional. Sentencia SU-337-1999 de 12/05/1999. M.P. Alejandro Martínez Caballero. Corte Constitucional. Sentencia T-474-1996 de 25/09/1996. M.P. Fabio Morón Díaz.

Corte Constitucional. Sentencia C-333-1996 de 01/08/1996. M.P. Alejandro Martínez Caballero. Corte Constitucional. Sentencia T-329-1996 de 25/07/1996. M.P. José Gregorio Hernández Galindo.

Corte Constitucional. Sentencia C-264-1996 de 13/06/1996. M.P. Eduardo Cifuentes Muñoz. Corte Constitucional. Sentencia T- 477-1995 de 23/10/1995. M.P. Alejandro Martínez Caballero. Corte Constitucional. Sentencia T-401-1994 de 12/09/1994. M.P. Eduardo Cifuentes Muñoz. Corte Constitucional. Sentencia T-002-1992 de 08/05/1992. MP. Alejandro Martínez Caballero.

\section{Corte Suprema de Justicia}

Corte suprema de justicia. Sala de Casación Civil. Sentencia de 19/12/2018, SC5686-2018. M.P. Margarita Cabello Blanco. 
Corte Suprema de Justicia. Sala de Casación Civil. Sentencia de 12/06/2018, SC2107-2018. M.P. Luis Armando Tolosa Villabona.

Corte suprema de justicia. Sala de Casación Civil. Sentencia de 12/06/2018, SC20448-2017. M.P. Margarita Cabello Blanco.

Corte suprema de justicia. Sala de Casación Civil. Sentencia de 12/01/2018, SC003-2018. M.P. Luis Armando Tolosa Villabona.

Corte suprema de justicia. Sala de Casación Civil. Sentencia de 24/05/2017, SC7110-2017. M.P. Luis Armando Tolosa Villabona.

Corte suprema de justicia. Sala de Casación Civil. Sentencia de 19/12/2017, SC22036-2017. M.P. Aroldo Wilson Quiroz Monsalvo.

Corte Suprema de Justicia. Sala de Casación Civil. Sentencia de 27/11/2017, SC19730-2017. M.P. Luis Armando Tolosa Villabona.

Corte suprema de justicia. Sala de Casación Civil. Sentencia de 05/04/2017, STC4819-2017. M.P. Luis Armando Tolosa Villabona.

Corte suprema de justicia. Sala de Casación Civil. Sentencia 17/11/2016, SC 16690/2016. M.P. Álvaro Fernando García Restrepo.

Corte suprema de justicia. Sala de Casación Civil. Sentencia de 16/11/2016, SC16496-2016. M.P. Margarita Cabello Blanco.

Corte suprema de justicia. Sala de Casación Civil. Sentencia 15/09/2016, SC12947-2016. M.P. Margarita Cabello Blanco.

Corte Suprema de Justicia. Sala de Casación Civil. Sentencia 20/06/2016, SC8219-2016. M.P. Fernando Giraldo Gutiérrez.

Corte suprema de justicia. Sala de Casación Civil. Sentencia 29/04/2016, SC5516-2016. M.P. Álvaro Fernando García Restrepo.

Corte suprema de justicia. Sala de Casación Civil. Sentencia 27/07/2015, SC9721-2015. M.P. Fernando Giraldo Gutiérrez.

Corte Suprema de Justicia. Sala de Casación Civil. Sentencia 04/08/2014, SC10261-2014. M.P. Margarita Cabello Blanco.

Corte Suprema de Justicia. Sala de Casación Civil. Sentencia 05/11/2013, exp. 2005-00025-01. M.P. Arturo Solarte Rodríguez.

Corte Suprema de Justicia. Sala de Casación Civil. Sentencia 13/09/2002, exp.6199. M.P. Nicolás Bechara Simancas.

Corte Suprema de Justicia. Sala de Casación Civil. Sentencia 17/11/2011, exp. 1999-00533-01. M.P. William Namén Vargas.

Corte Suprema de Justicia. Sala de Casación Civil. Sentencia 08/08/2011, exp. 20010077801. M.P. Pedro Octavio Munar Cadena.

Corte Suprema de Justicia. Sala de Casación Civil. Sentencia 24/08/2009, exp. 2001-01054-01. M.P. William Namén Vargas.

Corte Suprema de Justicia. Sala de Casación Civil. Sentencia 13/05/2008, exp. 1997-09327-01. M.P. César Julio Valencia Copete.

Corte Suprema de Justicia. Sala de Casación Civil. Sentencia 19/12/2005, exp. 1996 5497- 01. M.P. Pedro Octavio Munar Cadena.

Corte Suprema de Justicia. Sala de Casación Civil. Sentencia 05/10/2004, exp. 6975. M.P. Pedro Octavio Munar Cadena.

Corte Suprema de Justicia. Sala de Casación Civil. Sentencia 13/09/2002, exp.6199. M.P. Nicolás Bechara Simancas. 
Corte suprema de justicia. Sala de Casación Civil. Sentencia 11/09/2002, exp. 6430. M.P. José Fernando Ramírez Gómez.

Corte Suprema de Justicia. Sala de Casación Civil. Sentencia 04/04/2001, exp. 5176. M.P. Jorge Antonio Castillo Rugeles.

Corte Suprema de Justicia. Sala de Casación Civil. Sentencia 30/01/2001, exp. 5507. M.P. José Fernando Ramírez Gómez.

Corte Suprema de Justicia. Sala de Casación Civil. Sentencia de 11/04/2000, exp. 5410. M. P. Manuel Ardila Velásquez.

Corte Suprema de Justicia. Sala de Casación Civil. Sentencia de 5/03/1940. M.P. Liborio Escallón. Publicada en Gaceta Judicial: XLIX.

Corte Suprema de Justicia. Sala de Casación Civil. Sentencia de 05/10/1939. M.P. Juan Francisco Mújica. Publicada en Gaceta Judicial: Tomo XLVIII No. 1950, pp. 711 - 723

Corte Suprema de Justicia. Sentencia de 21/07/1922. M.P. Tancredo Nannetti.

Corte Suprema de Justicia. Sala de Casación Civil. Sentencia de 31/05/1938. M.P. Juan Francisco Mujica. Publicada en Gaceta Judicial: XLVI.

\section{Consejo de Estado}

Consejo de Estado, Sección Tercera. Sentencia 26/10/2018, exp. 2006-01724-01(41144). C.P. Jaime Enrique Rodríguez Navas.

Consejo de Estado, Sección Tercera. Sentencia 17/09/2018, exp. 2009-01012-01(45902)). C.P. Ramiro Pazos Guerrero.

Consejo de Estado, Sección Tercera. Sentencia 01/08/2018, exp. 2005-02541-01(35740). C.P. Stella Conto Díaz Del Castillo.

Consejo de Estado, Sección Tercera. Sentencia 24/05/2018, exp. 2005-06780-01(45925). C.P. Carlos Alberto Zambrano Barrera.

Consejo de Estado, Sección Quinta. Sentencia 31/05/2018, exp. 2017-03336-01(AC). C.P. Rocío Araújo Oñate.

Consejo de Estado, Sección Tercera. Sentencia 30/11/2017, exp. 1991-06582-02(43378). C.P. Ramiro Pazos Guerrero.

Consejo de Estado, Sección Tercera. Sentencia 22/06/2017 exp. 2004-01011-01(38874). C.P. Jaime Enrique Rodríguez Navas.

Consejo de Estado, Sección Tercera. Sentencia 08/06/2017, exp. 2007-02596-01(50352)). C.P. Danilo Rojas Betancourth.

Consejo de Estado, Sección Tercera. Sentencia 05/12/2016 exp. 2009-00051-01(41262). C.P. Ramiro Pazos Guerrero.

Consejo de Estado, Sección Tercera. Sentencia 07/08/2016, exp. 2001-01592-01(34578). C.P. Stella Conto Díaz Del Castillo.

Consejo de Estado, Sección Tercera. Sentencia 05/07/2016, exp. 2001-00874-01(36136). C.P. Danilo Rojas Betancourth.

Consejo de Estado, Sección Tercera. Sentencia 01/02/2016, exp. 2006-03158-01 (45459). C.P. Olga Mélida Valle De De La Hoz.

Consejo de Estado, Sección Tercera. Sentencia 26/06/2015, exp. 1996-00924-01(30419). C.P. Stella Conto Díaz Del Castillo.

Consejo de Estado, Sección Tercera. Sentencia 26/02/2015, exp. 2000-01368-01 (32322). C.P. Jaime Orlando Santofimio Gamboa. 
Consejo de Estado, Sección Tercera. Sentencia 12/12/2014, exp. 2002-03054-01(33756). C.P. Ramiro Pazos Guerrero.

Consejo de Estado, Sección Tercera. Sentencia 28/08/2014, exp. 2001-00278-01 (28804). C.P. Stella Conto Díaz Del Castillo.

Consejo de Estado, Sección Tercera. Sentencia 12/08/2014 exp. 1994-07946-01(29131). C.P. Olga Mélida Valle De De La Hoz.

Consejo de Estado, Sección Tercera. Sentencia 27/03/2014, exp. 2000-01924-01(26660)). C.P. Danilo Rojas Betancourth.

Consejo de Estado, Sección Tercera. Sentencia 12/12/2013 exp. 1996-12661-01(27493). C.P. Stella Conto Díaz Del Castillo.

Consejo de Estado, Sección Tercera. Sentencia 12/12/2013, exp. 1999-02962-01(26656)). C.P. Ramiro Pazos Guerrero.

Consejo de Estado, Sección Tercera. Sentencia 06/03/2013, exp. 1993-00356-01(25715). C.P. Enrique Gil Botero.

Consejo de Estado, Sección Tercera. Sentencia 13/02/2013, exp. 1999-02632-01(25870). C.P. Olga Mélida Valle De De La Hoz.

Consejo de Estado, Sección Tercera. Sentencia 29/08/2012, exp. 2001-01816-01 (26025). C.P. Danilo Rojas Betancourth.

Consejo de Estado, Sección Tercera. Sentencia 27/04/2011, exp. 08001-23-31-000-1993-0762201(19846). C.P. Ruth Stella Correa Palacio.

Consejo de Estado, Sección Tercera. Sentencia 27/04/2011 exp. 1999-00695-01(20636). C.P. Stella Conto Díaz Del Castillo.

Consejo de Estado, Sección Tercera. Sentencia 28/02/2011, exp. 1997-05218-01 (20027)). C.P. Danilo Rojas Betancourth.

Consejo de Estado, Sección Tercera. Sentencia 11/02/2009, exp. 1993-08025-01(14726). C.P. Myriam Guerrero De Escobar.

Consejo de Estado, Sección Tercera. Sentencia 15/10/2008, exp. 1994-00061-01(16350). C.P. Ramiro Saavedra Becerra.

Consejo de Estado, Sección Tercera. Sentencia 23/05/2008, exp. 1996-04798-01 (16095). C.P. Ruth Stella Correa Palacio.

Consejo de Estado, Sección Tercera. Sentencia 23/04/2008, exp. 1997-04547-01(15737). C.P. Ruth Stella Correa Palacio.

Consejo de Estado, Sección Tercera. Sentencia 03/05/2007, exp. 76001-23-31-000-1996-0555601(16098). C.P. Enrique Gil Botero.

Consejo de Estado, Sección Tercera. Sentencia 31/08/2006 exp. 2000-09610-01 (15772). C.P. Ruth Stella Correa Palacio.

Consejo de Estado, Sección Tercera. Sentencia 13/12/2004, exp. 14722. C.P. German Rodríguez Villamizar.

Consejo de Estado, Sección Tercera. Sentencia 11/04/2002, exp. 1995-2807-01(13227), C.P. Alier Eduardo Hernández Enriquez.

Consejo de Estado. Sección Tercera. Sentencia 24/01/2002, exp. 1994-9875-01(12706)), C.P. Jesús María Carrillo Ballesteros.

Consejo de Estado. Sección Tercera. Sentencia 10/02/2000 exp. 11878. C.P. Alier Eduardo Hernández Enríquez.

Consejo de Estado. Sección Tercera. Sentencia 03/05/1999, exp. 11169. Ricardo Hoyos Duque. 
Consejo de Estado, Sección Tercera. Sentencia 09/07/1993, exp. 7795. C.P. Julio César Uribe Acosta.

Consejo de Estado, Sección Tercera. Sentencia 24/10/1990 exp. 5902. C.P. Gustavo De Greiff Restrepo.

\section{Superintendencia de Industria y Comercio}

Superintendencia de Industria y Comercio. Delegatura para asuntos jurisdiccionales. Sentencia de 27/12/2018, caso Germán Ortíz v. Gas Gombel S.A. ESP.

\section{Sentencias y legislación extranjera:}

\section{EE.UU.}

Corte de Apelaciones de California. Caso Salgo vs. Leland Stanford etc., 1957. Recuperada de: https://scholar.google.ca/scholar_case?case $=1535825517909024477 \& q=317+P .2 d+170 \&$ $\underline{\mathrm{hl}=\mathrm{en} \& \mathrm{as} \_\mathrm{sdt}=2,5}$

Corte de Apelaciones de Columbia. Caso Canterbury vs. Spence de 1972. Recuperada de: https://scholar.google.ca/scholar case?case $=16106013819601769055 \& q=317+\mathrm{P} .2 \mathrm{~d}+170$ \&hl=en\&as_sdt=2006\#[129]

Corte Suprema de Pensilvania. Caso Gray vs. Grunnagle, 1966. Recuperada de: https://scholar.google.ca/scholar_case?case $=6042384157642789862 \& h l=e n \& a s \_s d t=2006$

Corte Suprema de Kansas. Caso Natanson vs. Kline, 1960. Recuperada de: https://scholar.google.ca/scholar case? case $=1590825446079418783 \& q=317+$ P. $2 \mathrm{~d}+170 \&$ hl $=$ en \&as_sdt=2006

Corte Suprema de California. Caso Cobbs vs. Grant, 1972. Recuperada de:

https://scholar.google.ca/scholar_case?case=9007336518867928085\&hl=en\&as_sdt=2006

Corte Suprema de Rhode Island. Caso Wilkinson vs. Vesey, 1972. Recuperada de: https://scholar.google.ca/scholar case?case $=374583654023246554 \& h l=e n \& a s \quad$ sdt=2006 $\#$ [r[8]

\section{Argentina}

Cámara Nacional de Apelaciones en lo Civil, Sala “C". Sentencia 9/04/2014 (CIV 098236/2008).

Dr. Luis Álvarez Juliá. https://cij.gov.ar/sentencias.html

Cámara Nacional de Apelaciones en lo Civil Sala “B”. Sentencia 18/03/2016.

Ley 26.529 de 2009.

Nuevo Código Civil y Comercial de la Nación -2014.

\section{Chile}


Ley 20.584 de 2012.

\section{Ecuador}

Acuerdo Ministerial 5316 de 2015.

\section{Panamá}

Ley 68 de 2003.

\section{Perú}

Ley 26.842 de 1997.

\section{Uruguay}

Decreto 274 de 2010.

Tribunal de Apelaciones Civil 5 turno. Sentencia 03/11/2015, DFA-0004-000579/2015.

Tribunal de Apelaciones Civil 7 turno. Sentencia 24/08/2016 (81/2016).

Tribunal de Apelaciones civil 2 turno. Sentencia 09/04/2014. DFA 0005-000062/2014.

Suprema Corte de Justicia. Sentencia 30/07/2018 (1.116/2018).

\section{España}

Audiencia provincial de Islas Baleares. Sección Quinta. Sentencia 03/02/2003, R. 753/2002. M.P. Santiago Oliver Barceló.

Tribunal Supremo Español. Sala de lo Penal. Sentencia 648-2015 de 22/10/2015. M.P. Andrés Palomo Del Arco.

Tribunal Supremo Español. Sala de lo Civil. Sentencia 24/11/2016, R.J. 5161/2016. M.P. José Antonio Seijas Quintana.

Tribunal Supremo Español. Sala de lo Civil. Sentencia 13/04/2016, R.J. 1639/2016. M.P. José Antonio Seijas Quintana.

Ley 41 de 2002.

\section{Francia}

Consejo de Estado francés, Sentencia 05/01/2000, exp. 181899. Recuperada de: https://www.legifrance.gouv.fr/affichJuriAdmin.do?idTexte=CETATEXT000008079452

Corte de Casación Francesa, Cámara de lo civil, Sentencia de 21/02/1961, Boletín No. 115.

Corte de Casación francesa, Cámara de lo civil, Sentencia de 07/10/1998, exp. 97-10267, Boletín No. 291.

Ley 303 de 2002. 


\section{Italia}

Corte de Casación Italiana. Sentencia 31/01/2018, No. 2369.

\section{Sentencias Corte Interamericana de Derechos Humanos}

Corte Interamericana de Derechos Humanos. Caso Herrera Ulloa. Sentencia de 2 de julio de 2004. Recuperada de: http://www.corteidh.or.cr/docs/casos/articulos/seriec_107_esp.pdf

Corte Interamericana de Derechos Humanos. Caso I.V. vs. Bolivia. Sentencia de 30 de noviembre de 2016.2 Recuperada de http://www.corteidh.or.cr/docs/casos/articulos/seriec_329_esp.pdf 